Universidade de São Paulo

Instituto de Astronomia, Geofísica e Ciências Atmosféricas

Departamento de Geofísica

Emerson Rodrigo Almeida

Análise da tomografia de micro-ondas em dados GPR sob condições controladas: aplicações em arqueologia e estudos forenses

São Paulo 

Emerson Rodrigo Almeida

\section{Análise da tomografia de micro-ondas em dados GPR sob condições controladas: aplicações em arqueologia e estudos forenses}

Tese apresentada ao Departamento de Geofísica do Instituto de Astronomia, Geofísica e Ciências Atmosféricas da Universidade de São Paulo como requisito parcial para obtenção do título de Doutor em Ciências.

Área de concentração: Geofísica Aplicada Orientador: Prof. Dr. Jorge Luís Porsani (IAG/USP)

Co-Orientador: Dr. Francesco Soldovieri (IREA/CNR)

Versão Corrigida. O original encontra-se disponível na Unidade.

São Paulo 
"Aqui haverá dragões."

- Referência às imagens de criaturas lendárias empregadas pelos cartógrafos medievais para indicar regiões inexploradas $e$ possivelmente perigosas. 


\section{Agradecimentos}

Agradeço primeiramente aos meus pais e avós, que desde criança me mostraram os caminhos do esforço e do trabalho justo, sempre me incentivando a fazer o meu melhor.

Agradeço e dedico esta tese à minha esposa Samantha, por ter suportado os momentos mais difíceis da nossa vida ao meu lado, e ao meu filho Joaquim, que ainda em seu primeiro ano de existência me fez enxergar a vida e o mundo de uma forma como há muito eu havia me esquecido. Nos tempos em que as tormentas foram uma constante nosso ka-tet permaneceu unido e vocês me deram armas para enfrentar os dragões das regiões desconhecidas que me pus a explorar sem saber o que me aguardava. Todos os agradecimentos que eu puder escrever aqui não serão suficientes para expressar o quanto vocês foram fundamentais para que eu pudesse completar este ciclo.

Ao meu orientador, prof. Dr. Jorge Luís Porsani, pelos conhecimentos transmitidos, pela ajuda durante a execução do experimento com o porco em Pirassununga, e principalmente pela sua paciência.

Ao meu co-orientador, Dr. Francesco Soldovieri, e à sua equipe de trabalho do IREA, Dra. Ilaria Catapano e Dr. Gianluca Gennarelli, por todo o auxílio que me prestaram tanto no desenvolvimento da pesquisa quanto pelo apoio durante os sete meses que passei em Nápoles.

Ao prof. Dr. Paulo DeBlasis, do MAE/USP, por ter cedido as antenas GPR de 270 MHz e 900 MHz para aquisição de dados em Pirassununga.

Ao corpo administrativo do campus da USP em Pirassununga, pelo apoio logístico na implantação e na escavação do experimento com o alvo orgânico.

Aos demais professores do departamento de Geofísica do IAG/USP, pelos conhecimentos transmitidos desde que ingressei no instituto.

Aos amigos Vinicius, Janine, Marco, Wanderson, Érica e Adriana e aos técnicos de campo Marcelo e Ernande, pela ajuda que prestaram nas campanhas de aquisição de 
dados do experimento em Pirassununga. Aos demais amigos do IAG, Cassiano, Bruno, Oleg, Selma e Luciana, pelas discussões durante o desenvolvimento da pesquisa.

À FAPESP pelas bolsas de doutorado (Processo 2011/21013-8) e doutorado sanduíche (Processo 2013/12606-0).

Às secretárias do departamento de Geofísica, Teca, Virgínia e Elisa, que sempre se mostraram prontas a ajudar e esclarecer dúvidas.

A todos que, de alguma forma, contribuíram para que eu pudesse chegar até aqui.

Muito obrigado. 


\section{Sumário}

Lista de abreviações e símbolos .............................................................................. ii

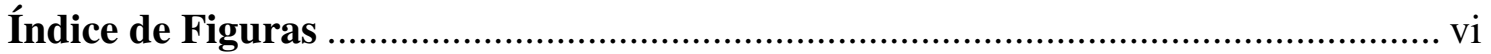

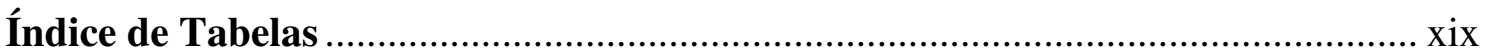

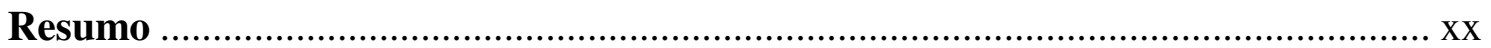

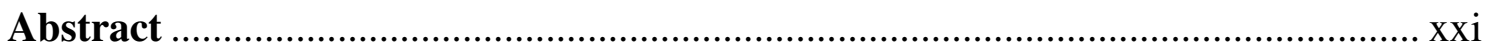

\section{CAPÍTULO 1}

INTRODUÇÃO

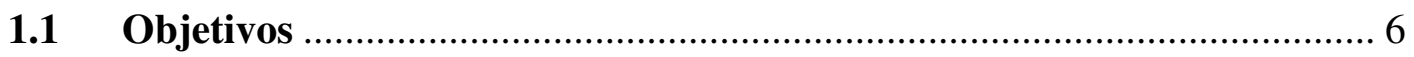

\section{CAPÍtUlO 2}

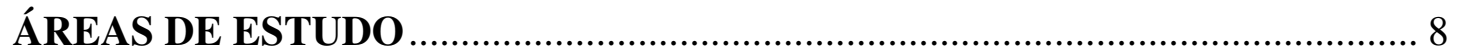

2.1 Sítio Controlado de Geofísica Rasa (SCGR) .......................................... 8

2.2 Experimento com alvo orgânico............................................................... 11

2.3 Escavação do alvo orgânico …........................................................ 15

\section{CAPÍTULO 3}

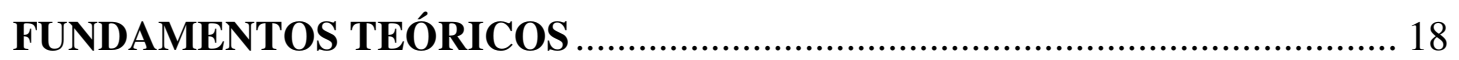

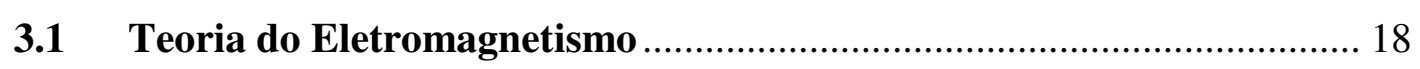

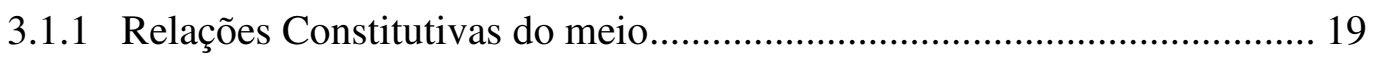

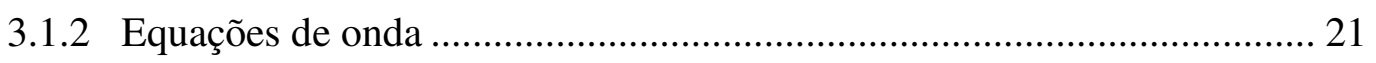

3.1.3 Propagação de ondas em um meio dielétrico ......................................... 22

3.1.4 Reflexão e transmissão do sinal em uma interface.................................. 23

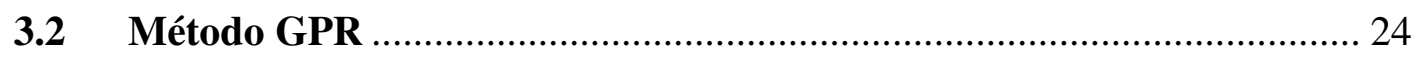

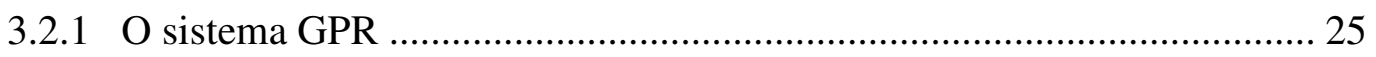

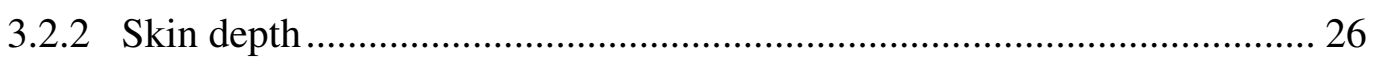

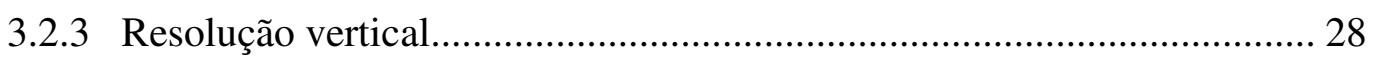

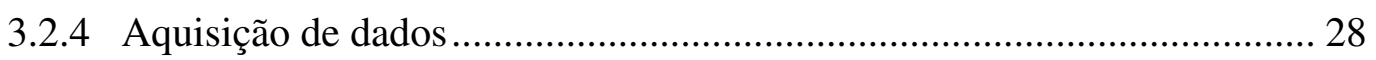

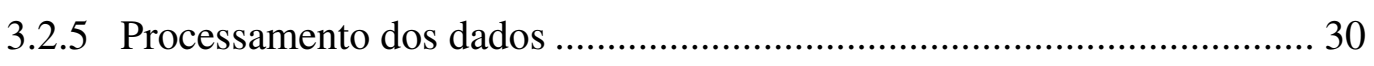

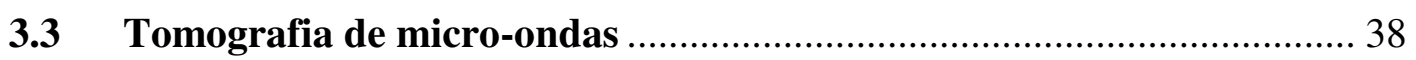

3.3.1 Princípio da equivalência de volume.................................................. 40 
3.3.2 Formulação do problema inverso ......................................................... 42

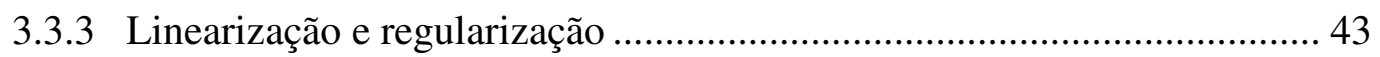

3.3.4 Implementação do código de tomografia ............................................. 46

\section{CAPÍTULO 4}

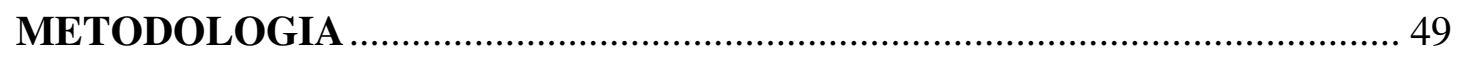

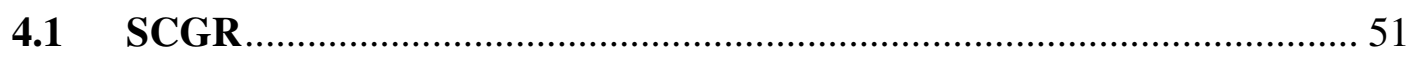

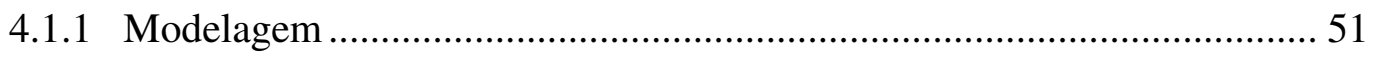

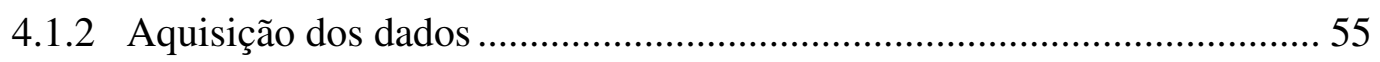

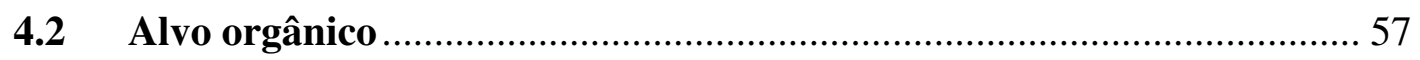

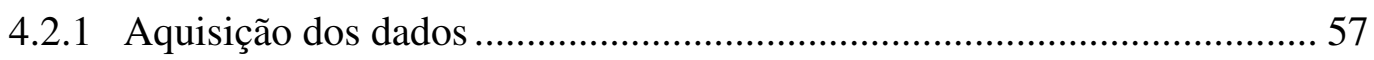

\section{CAPÍtULO 5}

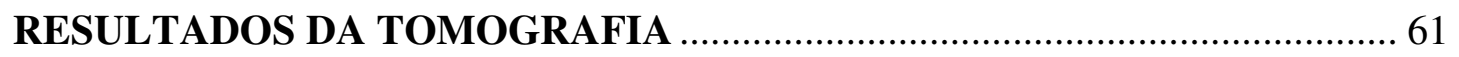

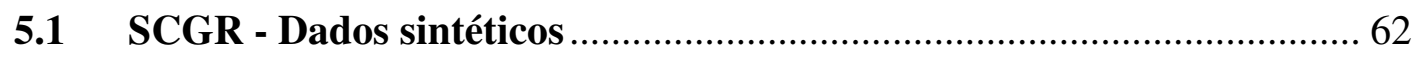

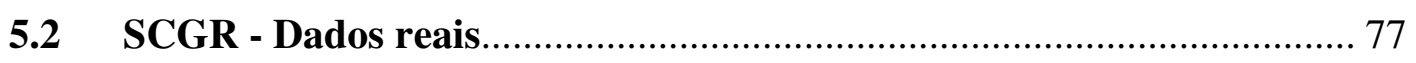

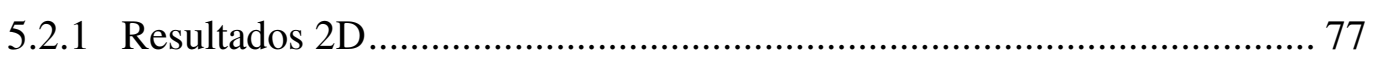

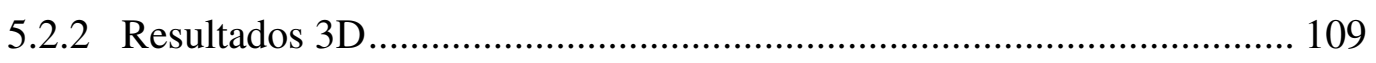

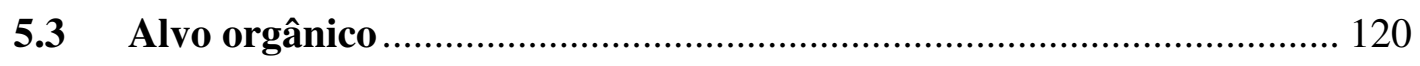

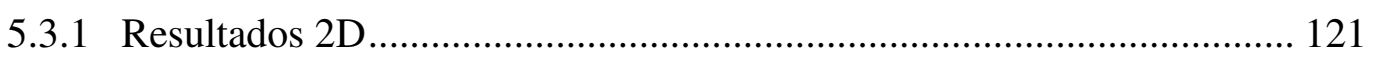

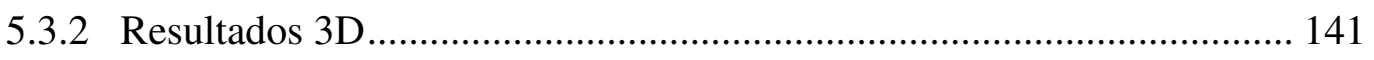

\section{CAPÍTULO 6}

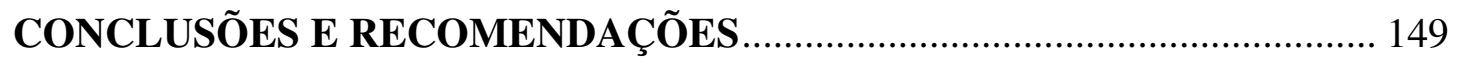

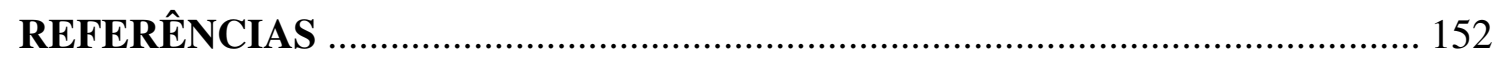

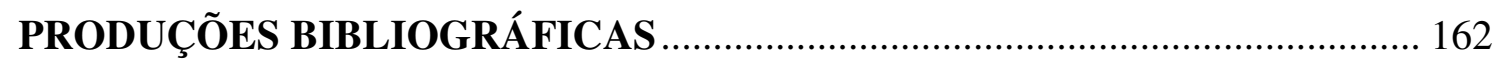




\section{Lista de abreviações e símbolos}

$\mathcal{A} \quad$ Operador linear de radiação

A Vetor de campo genérico

$\boldsymbol{B} \quad$ Vetor intensidade de fluxo magnético [T]

c Velocidade da luz $[\mathrm{m} / \mathrm{s}]$

D Vetor intensidade de fluxo elétrico $\left[\mathrm{C} / \mathrm{m}^{2}\right]$

$D_{0} \quad$ Domínio sob observação

$D_{i} \quad$ Domínio sob investigação

$d x^{\prime} \quad$ Tamanho da célula de imagem na direção $x[\mathrm{~m}]$

$d z^{\prime} \quad$ Tamanho da célula de imagem na direção $z[\mathrm{~m}]$

$\boldsymbol{E} \quad$ Vetor intensidade de campo elétrico total $[\mathrm{V} / \mathrm{m}]$

$\boldsymbol{E}_{\text {esp }} \quad$ Vetor intensidade de campo elétrico espalhado [V/m]

$\boldsymbol{E}_{\text {inc }} \quad$ Vetor intensidade de campo elétrico incidente $[\mathrm{V} / \mathrm{m}]$

$E_{x} \quad$ Intensidade de campo elétrico na direção $x[\mathrm{~V} / \mathrm{m}]$

$f \quad$ Frequência $[\mathrm{Hz}]$

$f^{*} \quad$ Frequência central da antena $[\mathrm{Hz}]$

$f_{c} \quad$ Frequência de corte do filtro [Hz]

$\boldsymbol{G}\left(\boldsymbol{r} / \boldsymbol{r}^{\prime}\right)$ Função de Green de $\boldsymbol{r}^{\prime}$ em $\boldsymbol{r}$

$\boldsymbol{H}$ Vetor intensidade de campo magnético total $[\mathrm{A} / \mathrm{m}]$

$\boldsymbol{H}_{\text {esp }} \quad$ Vetor intensidade de campo magnético espalhado $[\mathrm{A} / \mathrm{m}]$

$\boldsymbol{H}_{\text {inc }} \quad$ Vetor intensidade de campo magnético incidente $[\mathrm{A} / \mathrm{m}]$

$H_{y} \quad$ Intensidade de campo magnético na direção $y[\mathrm{~A} / \mathrm{m}]$

$H_{0}^{(2)} \quad$ Função de Henkel de grau 2 e ordem zero.

$i \quad$ Número complexo, equivalente a $\sqrt{-1}$

$I(\omega) \quad$ Espectro da fonte de sinal eletromagnético

$\boldsymbol{J} \quad$ Vetor densidade de corrente elétrica $\left[\mathrm{A} / \mathrm{m}^{2}\right]$

$\boldsymbol{J}_{c} \quad$ Vetor densidade de corrente de condução $\left[\mathrm{A} / \mathrm{m}^{2}\right]$

$\boldsymbol{J}_{d} \quad$ Vetor densidade de corrente elétrica de deslocamento $\left[\mathrm{A} / \mathrm{m}^{2}\right]$

$J_{e q} \quad$ Vetor densidade de corrente elétrica equivalente $\left[\mathrm{A} / \mathrm{m}^{2}\right]$

$J_{f} \quad$ Vetor densidade de corrente induzida pela fonte $\left[\mathrm{A} / \mathrm{m}^{2}\right]$

$k \quad$ Número de onda real do alvo [ $\mathrm{n}^{\circ}$ de ondas $/ \mathrm{m}$ ] 
$\boldsymbol{M} \quad$ Vetor densidade de corrente magnética $\left(\mathrm{V} / \mathrm{m}^{2}\right)$

$\boldsymbol{M}_{e q} \quad$ Vetor densidade de corrente magnética equivalente $\left(\mathrm{V} / \mathrm{m}^{2}\right)$

$\widehat{\boldsymbol{n}} \quad$ Vetor normal a uma interface

$N_{f} \quad$ Número de frequências

$n A \quad$ Número de amostras de um traço do radargrama

$n T, N_{x} \quad$ Número de traços de um radargrama

$N_{T}^{*} \quad$ Índice de truncamento dos valores singulares

$N_{x^{\prime}} \quad$ Número de pixels da imagem tomográfica na direção $x$

$N_{Z^{\prime}} \quad$ Número de pixels da imagem tomográfica na direção $Z$

$\boldsymbol{r} \quad$ Vetor de posição no espaço do domínio sob observação

$\boldsymbol{r}^{\prime} \quad$ Vetor de posição no espaço do domínio sob investigação

$R x \quad$ Antena receptora

$t \quad$ Tempo [s]

$t_{g} \quad$ Tempo do time-gating [ns]

$T \quad$ Coeficiente de transmissão

Tx Antena transmissora

$\left\{u^{*}\right\} \quad$ Base ortonormal do espaço para os objetos visíveis

$\left\{v^{*}\right\} \quad$ Base ortonormal para o espaço dos dados livres de ruído dentro das condições da aproximação Born

$v \quad$ Velocidade da onda eletromagnética no meio $[\mathrm{m} / \mathrm{s}]$

$(x, z) \quad$ Coordenadas espaciais de um ponto no domínio sob observação 2D [m]

$\left(x^{\prime}, z^{\prime}\right) \quad$ Coordenadas espaciais de um ponto no domínio sob investigação 2D [m]

$Y(t) \quad$ Perfil GPR em função do tempo

$Y^{*}(t) \quad$ Perfil GPR em função do tempo após a remoção do background

$y(t) \quad$ Traço do radargrama em função do tempo

$y^{*}(t) \quad$ Traço do radargrama em função do tempo após a remoção do background

$\alpha \quad$ Constante de atenuação $[\mathrm{Np} / \mathrm{m}]$

$\beta \quad$ Constante de fase $[\mathrm{rad} / \mathrm{m}]$

$\gamma \quad$ Número de onda complexo [ $\mathrm{n}^{\mathrm{o}}$ de ondas $/ \mathrm{m}$ ]

$\gamma_{b} \quad$ Número de onda complexo do background geológico [n $\mathrm{n}^{\mathrm{o}}$ de ondas/m]

$\Gamma \quad$ Coeficiente de reflexão

$\delta \quad$ Skin depth $[\mathrm{m}]$

$\Delta z \quad$ Resolução vertical teórica [m]

$\varepsilon_{0}, \epsilon_{0} \quad$ Permissividade dielétrica do vácuo $[\mathrm{F} / \mathrm{m}]$ 
$\mu_{0}$

$\mu$

$\mu_{b}$

$\sigma$

$\sigma_{b}$

$\sigma^{*}$

$\sigma_{d B}^{*}$

$\sigma_{T}^{*}$
Permissividade dielétrica complexa [F/m]

Permissividade dielétrica real [F/m]

Parte real da permissividade dielétrica complexa $[\mathrm{F} / \mathrm{m}]$

Parte imaginária da permissividade dielétrica complexa [F/m]

Permissividade dielétrica real do background geológico [F/m]

Permissividade dielétrica relativa

Permissividade dielétrica relativa do background geológico

Permissividade dielétrica para frequência tendendo a zero

Permissividade dielétrica para frequência tendendo a infinito

Impedância intrínseca do meio $[\Omega]$

Ângulo de incidência em relação à normal $\left[{ }^{\circ}\right]$

Ângulo de reflexão em relação à normal $\left[{ }^{\circ}\right]$

Ângulo de transmissão (ou de refração) em relação à normal [ [ $]$

Comprimento de onda [m]

Permeabilidade magnética do vácuo [H/m]

Permeabilidade magnética $[\mathrm{H} / \mathrm{m}]$

Permeabilidade magnética do background geológico [H/m]

Condutividade elétrica $[\mathrm{S} / \mathrm{m}]$

Condutividade elétrica do background geológico [S/m]

Valor singular

Valor singular $[\mathrm{dB}]$

Valor singular referente ao índice de truncamento

Tempo de relaxação do meio no modelo de Debye [s]

Função contraste

Frequência angular [rad/s]

Frequência angular central do pulso eletromagnético [rad/s] 


\section{Índice de Figuras}

Figura 1. Diagrama das linhas do Sítio Controlado de Geofísica Rasa (SCGR) do IAG/USP (Adaptado de Porsani et al., 2006). Os dados analisados nesta pesquisa foram adquiridos sobre a Linha 01 (em vermelho). O cano metálico guia é representado em azul, perpendicularmente à direção das linhas. 9

Figura 2. Disposição dos alvos na Linha 1 - Arqueologia (adaptado de Borges, 2007). 10

Figura 3. Localização da área onde foi conduzido o experimento com alvo orgânico. 12 Figura 4. Área de implantação de alvo controlado no campus da USP em Pirassununga. a) local de estudo. A vala está representada pelo retângulo de 2,0 $\mathrm{m} \times 1,0 \mathrm{~m}$ no centro de uma área de $6,0 \mathrm{~m} \times 5,0 \mathrm{~m}$. b) disposição do alvo no interior da vala.

Figura 5. Variação da topografia na área de estudo. A linha pontilhada indica a localização da vala.

Figura 6. Perfil lateral ao longo da direção y esquematizando a variação topográfica (linha azul) e a vala (linha preta) com o animal em seu interior (elipse cinza). A referência para a escala de profundidade em todos os perfis é a coordenada $(6,0,0,0)$, que corresponde ao ponto mais alto da área de estudo.

Figura 7. Restos orgânicos retirados da vala. a) fragmento de pele. b) parte dos ossos retirados da vala, os quais ainda apresentaram-se íntegros e resistentes à quebra. 15

Figura 8. Alteração do material geológico no interior da vala. a) não foi observada alteração significativa do material geológico ao redor do corpo. b) a única alteração significativa ocorreu no fundo da vala, onde foi observada uma camada de alteração de cerca de 10,0 cm. Esta camada apresentou um leve escurecimento na coloração do material geológico.

Figura 9. Cavidades encontradas durante a escavação. Estas cavidades são observadas nos radargramas como feições hiperbólicas não relacionadas ao alvo enterrado para execução do experimento. 17

Figura 10. Diagrama em blocos simplificado de um sistema GPR. 27 
Figura 11. Esquema de uma aquisição de um perfil de reflexão com antenas em offset constante.

Figura 12. Área abaixo da antena transmissora efetivamente abrangida pelo sinal emitido, chamada de Zona de Fresnell. Esta área tem o formato aproximado de uma elipse cujo eixo maior é dado pela função $y z, k$ e o eixo menor é dado pela função $x(z, k)$, em que $z$ é a profundidade e $k$ é o número de onda real do meio (adaptado de Annan, 2003). 30

Figura 13. Diagrama esquematizando uma anomalia hiperbólica provocada no radargrama pela presença de um alvo pontual em subsuperfície. O pulso observado no início de cada traço corresponde ao acoplamento entre as antenas e o solo.

Figura 14. Geometria para um corpo tridimensional imerso em um meio homogêneo de propriedades eletromagnéticas $\epsilon b, \sigma b$ e $\mu b$. 38

Figura 15. Interação entre o campo elétrico incidente (Einc), o campo elétrico espalhado (Eesp) e o alvo (em cinza). 39

Figura 16. Geometria do problema inverso 2D da tomografia para a aquisição de dados em perfis de afastamento constante. Cada triângulo vermelho representa uma posição diferente do conjunto transmissor-receptor. O espaço $D i$ (linha pontilhada) representa o domínio sob investigação e o espaço Do (linha tracejada) representa o domínio sob observação.

Figura 17. Diagramas esquematizando os modelos empregados para gerar os dados sintéticos. a) caixa de areia. b) caixa de brita de granito. c) muro de tijolos. d) solo revirado. e) vaso a 0,50 $\mathrm{m}$ de profundidade preenchido apenas com ar. f) vaso a 1,0 m de profundidade preenchido com ar. g) camada de seixos de quartzo.

Figura 18. Diagrama esquemático da aquisição de dados GPR sobre o alvo orgânico instalado no campus da USP em Pirassununga, com as coordenadas dos vértices da área investigada e dos vértices da vala. As setas vermelhas representam os perfis adquiridos na direção $y$ 58

Figura 19. Dados sintéticos sobre a caixa de areia. Os retângulos de linhas pontilhadas representam os limites verdadeiros do alvo. As setas vermelhas indicam a posição do topo do alvo e as setas amarelas indicam a posição da base dos mesmos. As setas 
brancas indicam reflexões múltiplas. a) radargrama sintético em $270 \mathrm{MHz}$. b) imagem tomográfica em $270 \mathrm{MHz}$. c) radargrama sintético em $400 \mathrm{MHz}$. d) imagem tomográfica em $400 \mathrm{MHz}$. e) radargrama sintético em $900 \mathrm{MHz}$. f) imagem tomográfica em $900 \mathrm{MHz}$ 64

Figura 20. Análise dos dados sintéticos sobre a caixa de brita de granito. Os retângulos de linhas pontilhadas representam os limites verdadeiros do alvo. As setas vermelhas indicam a posição do topo do alvo e as setas amarelas indicam a posição da base dos mesmos. As setas brancas indicam reflexões múltiplas. a) radargrama sintético em 270 MHz. b) imagem tomográfica em $270 \mathrm{MHz}$. c) radargrama sintético em $400 \mathrm{MHz}$. d) imagem tomográfica em $400 \mathrm{MHz}$. e) radargrama sintético em $900 \mathrm{MHz}$. f) imagem tomográfica em $900 \mathrm{MHz}$. 66

Figura 21. Análise dos dados sintéticos sobre o muro de tijolos. Os retângulos de linhas pontilhadas representam os limites verdadeiros do alvo. As setas vermelhas indicam a posição do topo do alvo e as setas amarelas indicam a posição da base dos mesmos. As setas brancas indicam reflexões múltiplas. a) radargrama sintético em $270 \mathrm{MHz}$. b) imagem tomográfica em $270 \mathrm{MHz}$. c) radargrama sintético em $400 \mathrm{MHz}$. d) imagem tomográfica em $400 \mathrm{MHz}$. e) radargrama sintético em $900 \mathrm{MHz}$. f) imagem tomográfica em $900 \mathrm{MHz}$ 68

Figura 22. Análise dos dados sintéticos sobre a caixa de solo revirado. Os retângulos de linhas pontilhadas representam os limites verdadeiros do alvo. As setas vermelhas indicam a posição do topo do alvo e as setas amarelas indicam a posição da base dos mesmos. As setas brancas indicam reflexões múltiplas. a) radargrama sintético em 270 MHz. b) imagem tomográfica em $270 \mathrm{MHz}$. c) radargrama sintético em $400 \mathrm{MHz}$. d) imagem tomográfica em $400 \mathrm{MHz}$. e) radargrama sintético em $900 \mathrm{MHz}$. f) imagem tomográfica em $900 \mathrm{MHz}$.

Figura 23. Análise dos dados sintéticos sobre o vaso à profundidade de $0,50 \mathrm{~m}$. As elipses pontilhadas representam os limites verdadeiros do alvo. As setas vermelhas indicam a posição do topo do alvo e as setas amarelas indicam a posição da base dos mesmos. As setas brancas indicam reflexões múltiplas. a) radargrama sintético em 270 MHz. b) imagem tomográfica em $270 \mathrm{MHz}$. c) radargrama sintético em $400 \mathrm{MHz}$. d) imagem tomográfica em $400 \mathrm{MHz}$. e) radargrama sintético em $900 \mathrm{MHz}$. f) imagem tomográfica em $900 \mathrm{MHz}$ 
Figura 24. Análise dos dados sintéticos sobre o vaso à profundidade de $1,0 \mathrm{~m}$. As elipses pontilhadas representam os limites verdadeiros do alvo. As setas vermelhas indicam a posição do topo do alvo e as setas amarelas indicam a posição do sinal refletido na base dos mesmos. As setas brancas indicam reflexões múltiplas. a) radargrama sintético em $270 \mathrm{MHz}$. b) imagem tomográfica em $270 \mathrm{MHz}$. c) radargrama sintético em $400 \mathrm{MHz}$. d) imagem tomográfica em $400 \mathrm{MHz}$. e) radargrama sintético em $900 \mathrm{MHz}$. f) imagem tomográfica em $900 \mathrm{MHz}$. 73

Figura 25. Análise dos dados sintéticos sobre a camada de seixos de quartzo. Os retângulos pontilhados representam os limites verdadeiros do alvo. As setas vermelhas indicam a posição do topo do alvo. As setas amarelas com pontos de interrogação indicam reflexões múltiplas que poderiam ser interpretadas equivocadamente como a base do alvo. As setas brancas indicam reflexões múltiplas. a) radargrama sintético em $270 \mathrm{MHz}$. b) imagem tomográfica em $270 \mathrm{MHz}$. c) radargrama sintético em $400 \mathrm{MHz}$. d) imagem tomográfica em $400 \mathrm{MHz}$. e) radargrama sintético em $900 \mathrm{MHz}$. f) imagem tomográfica em $900 \mathrm{MHz}$

Figura 26. Imagens tomográficas obtidas a partir dos dados adquiridos com antena de $270 \mathrm{MHz}$ sobre a caixa de areia. a) remoção de background por time-gating. b) remoção de background por subtração do traço médio. c) remoção do background por timegating seguido pela subtração do traço médio. d) remoção do background por análise de autovalores. e) remoção de background por time-gating seguido pela análise de autovalores. f) remoção de background por subtração do traço médio seguido pela análise de autovalores.

Figura 27. Imagens tomográficas obtidas a partir dos dados adquiridos com antena de $400 \mathrm{MHz}$ sobre a caixa de areia. a) remoção de background por time-gating. b) remoção de background por subtração do traço médio. c) remoção do background por timegating seguido pela subtração do traço médio. d) remoção do background por análise de autovalores. e) remoção de background por time-gating seguido pela análise de autovalores. f) remoção de background por subtração do traço médio seguido pela análise de autovalores.

Figura 28. Imagens tomográficas obtidas a partir dos dados adquiridos com antena de $270 \mathrm{MHz}$ sobre a caixa de brita de granito. a) remoção de background por time-gating. b) remoção de background por subtração do traço médio. c) remoção do background 
por time-gating seguido pela subtração do traço médio. d) remoção do background por análise de autovalores. e) remoção de background por time-gating seguido pela análise de autovalores. f) remoção de background por subtração do traço médio seguido pela análise de autovalores.

Figura 29. Imagens tomográficas obtidas a partir dos dados adquiridos com antena de $400 \mathrm{MHz}$ sobre a caixa de brita de granito. a) remoção de background por time-gating. b) remoção de background por subtração do traço médio. c) remoção do background por time-gating seguido pela subtração do traço médio. d) remoção do background por análise de autovalores. e) remoção de background por time-gating seguido pela análise de autovalores. f) remoção de background por subtração do traço médio seguido pela análise de autovalores.

Figura 30. Imagens tomográficas obtidas a partir dos dados adquiridos com antena de $270 \mathrm{MHz}$ sobre o muro de tijolos. a) remoção de background por time-gating. b) remoção de background por subtração do traço médio. c) remoção do background por time-gating seguido pela subtração do traço médio. d) remoção do background por análise de autovalores. e) remoção de background por time-gating seguido pela análise de autovalores. f) remoção de background por subtração do traço médio seguido pela análise de autovalores. 85

Figura 31. Imagens tomográficas obtidas a partir dos dados adquiridos com antena de $400 \mathrm{MHz}$ sobre o muro de tijolos. a) remoção de background por time-gating. b) remoção de background por subtração do traço médio. c) remoção do background por time-gating seguido pela subtração do traço médio. d) remoção do background por análise de autovalores. e) remoção de background por time-gating seguido pela análise de autovalores. f) remoção de background por subtração do traço médio seguido pela análise de autovalores.

Figura 32. Imagens tomográficas obtidas a partir dos dados adquiridos com antena de $270 \mathrm{MHz}$ sobre a região de solo revirado. a) remoção de background por time-gating. b) remoção de background por subtração do traço médio. c) remoção do background por time-gating seguido pela subtração do traço médio. d) remoção do background por análise de autovalores. e) remoção de background por time-gating seguido pela análise de autovalores. f) remoção de background por subtração do traço médio seguido pela análise de autovalores 
Figura 33. Imagens tomográficas obtidas a partir dos dados adquiridos com antena de $400 \mathrm{MHz}$ sobre a região de solo revirado. a) remoção de background por time-gating. b) remoção de background por subtração do traço médio. c) remoção do background por time-gating seguido pela subtração do traço médio. d) remoção do background por análise de autovalores. e) remoção de background por time-gating seguido pela análise de autovalores. f) remoção de background por subtração do traço médio seguido pela análise de autovalores. 90

Figura 34. Imagens tomográficas obtidas a partir dos dados adquiridos com antena de $270 \mathrm{MHz}$ sobre o vaso à profundidade de $0,50 \mathrm{~m}$. a) remoção de background por timegating. b) remoção de background por subtração do traço médio. c) remoção do background por time-gating seguido pela subtração do traço médio. d) remoção do background por análise de autovalores. e) remoção de background por time-gating seguido pela análise de autovalores. f) remoção de background por subtração do traço médio seguido pela análise de autovalores 92

Figura 35. Imagens tomográficas obtidas a partir dos dados adquiridos com antena de $400 \mathrm{MHz}$ sobre o vaso à profundidade de $0,50 \mathrm{~m}$. a) remoção de background por timegating. b) remoção de background por subtração do traço médio. c) remoção do background por time-gating seguido pela subtração do traço médio. d) remoção do background por análise de autovalores. e) remoção de background por time-gating seguido pela análise de autovalores. f) remoção de background por subtração do traço médio seguido pela análise de autovalores 94

Figura 36. Imagens tomográficas obtidas a partir dos dados adquiridos com antena de $270 \mathrm{MHz}$ sobre o vaso à profundidade de 1,0 m. a) remoção de background por timegating. b) remoção de background por subtração do traço médio. c) remoção do background por time-gating seguido pela subtração do traço médio. d) remoção do background por análise de autovalores. e) remoção de background por time-gating seguido pela análise de autovalores. f) remoção de background por subtração do traço médio seguido pela análise de autovalores 96

Figura 37. Imagens tomográficas obtidas a partir dos dados adquiridos com antena de $400 \mathrm{MHz}$ sobre o vaso à profundidade de $1,0 \mathrm{~m}$. a) remoção de background por timegating. b) remoção de background por subtração do traço médio. c) remoção do background por time-gating seguido pela subtração do traço médio. d) remoção do 
background por análise de autovalores. e) remoção de background por time-gating seguido pela análise de autovalores. f) remoção de background por subtração do traço médio seguido pela análise de autovalores.

Figura 38. Imagens tomográficas obtidas a partir dos dados adquiridos com antena de $270 \mathrm{MHz}$ sobre a camada de seixos de quartzo. a) remoção de background por timegating. b) remoção de background por subtração do traço médio. c) remoção do background por time-gating seguido pela subtração do traço médio. d) remoção do background por análise de autovalores. e) remoção de background por time-gating seguido pela análise de autovalores. f) remoção de background por subtração do traço médio seguido pela análise de autovalores.

Figura 39. Imagens tomográficas obtidas a partir dos dados adquiridos com antena de $400 \mathrm{MHz}$ sobre a camada de seixos de quartzo. a) remoção de background por timegating. b) remoção de background por subtração do traço médio. c) remoção do background por time-gating seguido pela subtração do traço médio. d) remoção do background por análise de autovalores. e) remoção de background por time-gating seguido pela análise de autovalores. f) remoção de background por subtração do traço médio seguido pela análise de autovalores.

Figura 40. Resultados de $270 \mathrm{MHz}$ sobre a Linha de Arqueologia a partir da concatenação das imagens tomográficas individuais. a) disposição dos alvos. b) radargrama processado no software ReflexWin. c) imagem tomográfica com remoção de background por time-gating em 7,0 ns. d) imagem tomográfica com remoção de background por time-gating em 7,0 ns seguido pela análise de autovalores. 104

Figura 41. Resultados de $400 \mathrm{MHz}$ sobre a Linha de Arqueologia a partir da concatenação das imagens tomográficas individuais. a) disposição dos alvos. b) radargrama processado no software ReflexWin. c) imagem tomográfica com remoção de background por time-gating em 6 ns. d) imagem tomográfica com remoção de background por time-gating em 6 ns seguido pela análise de autovalores. 108

Figura 42. Visualização 3D dos dados de $270 \mathrm{MHz}$ sobre a caixa de areia na forma de cortes em profundidade gerados a partir da interpolação de perfis paralelos. As linhas tracejadas vermelhas representam uma projeção dos vértices do buraco escavado para 
instalação do alvo. As cruzes vermelhas nas vistas em planta indicam as posições onde estas linhas cruzam os planos de corte em cada profundidade. a) representação de planos de corte em diferentes profundidades. b) plano de corte à profundidade de 0,63 m. c) plano de corte à profundidade de $0,88 \mathrm{~m}$. d) plano de corte à profundidade de $1,07 \mathrm{~m}$ 111

Figura 43. Visualização 3D dos dados de $400 \mathrm{MHz}$ sobre a caixa de brita na forma de cortes em profundidade gerados a partir da interpolação de perfis paralelos. As linhas tracejadas vermelhas representam uma projeção dos vértices do buraco escavado para instalação do alvo. As cruzes vermelhas nas vistas em planta indicam as posições onde estas linhas cruzam os planos de corte em cada profundidade. a) representação de planos de corte em diferentes profundidades. b) plano de corte à profundidade de $0,49 \mathrm{~m}$. c) plano de corte à profundidade de $0,66 \mathrm{~m}$. d) plano de corte à profundidade de $1,12 \mathrm{~m}$. 112

Figura 44. Visualização 3D dos dados de $400 \mathrm{MHz}$ sobre o muro de tijolos na forma de cortes em profundidade gerados a partir da interpolação de perfis paralelos. As linhas tracejadas vermelhas representam uma projeção dos vértices do buraco escavado para instalação do alvo. As cruzes vermelhas nas vistas em planta indicam as posições onde estas linhas cruzam os planos de corte em cada profundidade. a) representação de planos de corte em diferentes profundidades. b) plano de corte à profundidade de $0,38 \mathrm{~m}$. c) plano de corte à profundidade de $0,56 \mathrm{~m}$. d) plano de corte à profundidade de $0,87 \mathrm{~m}$ 113

Figura 45. Visualização 3D dos dados de $270 \mathrm{MHz}$ sobre o vaso raso na forma de cortes em profundidade gerados a partir da interpolação de perfis paralelos. As linhas tracejadas vermelhas representam uma projeção dos vértices do buraco escavado para instalação do alvo. As cruzes vermelhas nas vistas em planta indicam as posições onde estas linhas cruzam os planos de corte em cada profundidade. a) representação de planos de corte em diferentes profundidades. b) plano de corte à profundidade de $0,50 \mathrm{~m}$. c) plano de corte à profundidade de $0,63 \mathrm{~m}$. d) plano de corte à profundidade de $1,13 \mathrm{~m}$ 115

Figura 46. Visualização $3 \mathrm{D}$ dos dados de $400 \mathrm{MHz}$ sobre o vaso raso na forma de cortes em profundidade gerados a partir da interpolação de perfis paralelos. As linhas tracejadas vermelhas representam uma projeção dos vértices do buraco escavado para 
instalação do alvo. As cruzes vermelhas nas vistas em planta indicam as posições onde estas linhas cruzam os planos de corte em cada profundidade. a) representação de planos de corte em diferentes profundidades. b) plano de corte à profundidade de $0,52 \mathrm{~m}$. c) plano de corte à profundidade de $0,63 \mathrm{~m}$. d) plano de corte à profundidade de $0,77 \mathrm{~m}$. 116

Figura 47. Visualização 3D dos dados de $270 \mathrm{MHz}$ sobre o vaso profundo na forma de cortes em profundidade gerados a partir da interpolação de perfis paralelos. As linhas tracejadas vermelhas representam uma projeção dos vértices do buraco escavado para instalação do alvo. As cruzes vermelhas nas vistas em planta indicam as posições onde estas linhas cruzam os planos de corte em cada profundidade. a) representação de planos de corte em diferentes profundidades. b) plano de corte à profundidade de $0,57 \mathrm{~m}$. c) plano de corte à profundidade de $1,13 \mathrm{~m}$. d) plano de corte à profundidade de $1,64 \mathrm{~m}$ 118

Figura 48. Visualização 3D dos dados de $400 \mathrm{MHz}$ sobre o vaso profundo na forma de cortes em profundidade gerados a partir da interpolação de perfis paralelos. As linhas tracejadas vermelhas representam uma projeção dos vértices do buraco escavado para instalação do alvo. As cruzes vermelhas nas vistas em planta indicam as posições onde estas linhas cruzam os planos de corte em cada profundidade. a) representação de planos de corte em diferentes profundidades. b) plano de corte à profundidade de $0,56 \mathrm{~m}$. c) plano de corte à profundidade de $0,91 \mathrm{~m}$. d) plano de corte à profundidade de $1,15 \mathrm{~m}$ 119

Figura 49. Resultados do conjunto [01] de 17/12/2012 obtidos para o perfil em 3,4 m. a) radargrama adquirido com a antena de $270 \mathrm{MHz}$. b) imagem tomográfica obtida a partir do radargrama de $270 \mathrm{MHz}$. c) radargrama adquirido com a antena de $400 \mathrm{MHz}$. d) imagem tomográfica obtida a partir do radargrama de $400 \mathrm{MHz}$. e) radargrama adquirido com a antena de $900 \mathrm{MHz}$. f) imagem tomográfica obtida a partir do radargrama de $900 \mathrm{MHz}$. 122

Figura 50. Cavidade presente no solo e causadora da anomalia rasa observada nos perfis adquiridos em $X=3,4 \mathrm{~m}$. a) localização em profundidade. b) vista superior mostrando a extensão lateral. 123 
Figura 51. Resultados do conjunto [02] de 19/12/2012 obtidos para o perfil em 3,4 m. As linhas tracejadas brancas indicam os limites do buraco escavado para enterro do animal. a) radargrama adquirido com a antena de $270 \mathrm{MHz}$. b) imagem tomográfica obtida a partir do radargrama de $270 \mathrm{MHz}$. c) radargrama adquirido com a antena de $400 \mathrm{MHz}$. d) imagem tomográfica obtida a partir do radargrama de $400 \mathrm{MHz}$. e) radargrama adquirido com a antena de $900 \mathrm{MHz}$. f) imagem tomográfica obtida a partir do radargrama de $900 \mathrm{MHz}$

Figura 52. Resultados do conjunto [03] de 07/01/2013 obtidos para o perfil em 3,4 m. As linhas tracejadas brancas indicam os limites do buraco escavado para enterro do animal. a) radargrama adquirido com a antena de $270 \mathrm{MHz}$. b) imagem tomográfica obtida a partir do radargrama de $270 \mathrm{MHz}$. c) radargrama adquirido com a antena de $400 \mathrm{MHz}$. d) imagem tomográfica obtida a partir do radargrama de $400 \mathrm{MHz}$. e) radargrama adquirido com a antena de $900 \mathrm{MHz}$. f) imagem tomográfica obtida a partir do radargrama de $900 \mathrm{MHz}$. 126

Figura 53. Resultados do conjunto [04] de 22/01/2013 obtidos para o perfil em 3,4 m. As linhas tracejadas brancas indicam os limites do buraco escavado para enterro do animal. a) radargrama adquirido com a antena de $270 \mathrm{MHz}$. b) imagem tomográfica obtida a partir do radargrama de $270 \mathrm{MHz}$. c) radargrama adquirido com a antena de $400 \mathrm{MHz}$. d) imagem tomográfica obtida a partir do radargrama de $400 \mathrm{MHz}$. e) radargrama adquirido com a antena de $900 \mathrm{MHz}$. f) imagem tomográfica obtida a partir do radargrama de $900 \mathrm{MHz}$. 128

Figura 54. Resultados do conjunto [05] de 04/03/2013 obtidos para o perfil em 3,7 m. As linhas tracejadas brancas indicam os limites do buraco escavado para enterro do animal. a) radargrama adquirido com a antena de $270 \mathrm{MHz}$. b) imagem tomográfica obtida a partir do radargrama de $270 \mathrm{MHz}$. c) radargrama adquirido com a antena de $400 \mathrm{MHz}$. d) imagem tomográfica obtida a partir do radargrama de $400 \mathrm{MHz}$. e) radargrama adquirido com a antena de $900 \mathrm{MHz}$. f) imagem tomográfica obtida a partir do radargrama de $900 \mathrm{MHz}$. 130

Figura 55. Condições do alvo observadas nas escavações após 18 meses do início do experimento. a) parte do material extraído da vala. A quantidade de material presente não justifica o desaparecimento das hipérboles do radargrama. b) tampouco foram observadas zonas de alteração significativas no solo no entorno do animal. c) a única 
alteração perceptível foi observada abaixo do alvo. d) a alteração abaixo do alvo resume-se a uma camada de $7,0 \mathrm{~cm}$ de espessura em média.

Figura 56. Resultados do conjunto [06] de 12/04/2013 obtidos para o perfil em 3,8 m. As linhas tracejadas brancas indicam os limites do buraco escavado para enterro do animal. a) radargrama adquirido com a antena de $270 \mathrm{MHz}$. b) imagem tomográfica obtida a partir do radargrama de $270 \mathrm{MHz}$. c) radargrama adquirido com a antena de $400 \mathrm{MHz}$. d) imagem tomográfica obtida a partir do radargrama de $400 \mathrm{MHz}$. e) radargrama adquirido com a antena de $900 \mathrm{MHz}$. f) imagem tomográfica obtida a partir do radargrama de $900 \mathrm{MHz}$.

Figura 57. Comparação entre as imagens tomográficas obtidas a partir dos dados sobre o perfil em $\mathrm{X}=3,8 \mathrm{~m}$ do conjunto [06]. a) imagem em $270 \mathrm{MHz}$ com time-gating em 7,0 ns. b) imagem em $270 \mathrm{MHz}$ com time-gating em 7,0 ns seguido por análise de autovalores. c) imagem em $400 \mathrm{MHz}$ com time-gating em 6,0 ns. d) imagem em $400 \mathrm{MHz}$ com time-gating em 6,0 ns seguido por análise de autovalores. e) imagem em $900 \mathrm{MHz}$ com time-gating em 4,0 ns. f) imagem em $900 \mathrm{MHz}$ com time-gating em 4,0 ns seguido por análise de autovalores.

Figura 58. Resultados do conjunto [07] de 17/12/2013 obtidos para o perfil em 3,8 m. As linhas tracejadas brancas indicam os limites do buraco escavado para enterro do animal. a) radargrama adquirido com a antena de $270 \mathrm{MHz}$. b) imagem tomográfica obtida a partir do radargrama de $270 \mathrm{MHz}$. c) radargrama adquirido com a antena de $400 \mathrm{MHz}$. d) imagem tomográfica obtida a partir do radargrama de $400 \mathrm{MHz}$. e) radargrama adquirido com a antena de $900 \mathrm{MHz}$. f) imagem tomográfica obtida a partir do radargrama de $900 \mathrm{MHz}$. 136

Figura 59. Comparação entre as imagens tomográficas obtidas a partir dos dados sobre o perfil em $\mathrm{X}=3,8 \mathrm{~m}$ do conjunto [07]. a) imagem em $270 \mathrm{MHz}$ com time-gating em 7,0 ns. b) imagem em $270 \mathrm{MHz}$ com time-gating em 7,0 ns seguido por análise de autovalores. c) imagem em $400 \mathrm{MHz}$ com time-gating em 6,0 ns. d) imagem em $400 \mathrm{MHz}$ com time-gating em 6,0 ns seguido por análise de autovalores. e) imagem em $900 \mathrm{MHz}$ com time-gating em 4,0 ns. f) imagem em $900 \mathrm{MHz}$ com time-gating em 4,0 ns seguido por análise de autovalores. 138 
Figura 60. Resultados do conjunto [08] de 13/06/2014 obtidos para o perfil em 3,8 m. As linhas tracejadas brancas indicam os limites do buraco escavado para enterro do animal. a) radargrama adquirido com a antena de $270 \mathrm{MHz}$. b) imagem tomográfica obtida a partir do radargrama de $270 \mathrm{MHz}$. c) radargrama adquirido com a antena de $400 \mathrm{MHz}$. d) imagem tomográfica obtida a partir do radargrama de $400 \mathrm{MHz}$. e) radargrama adquirido com a antena de $900 \mathrm{MHz}$. f) imagem tomográfica obtida a partir do radargrama de $900 \mathrm{MHz}$

Figura 61. Comparação entre as imagens tomográficas obtidas a partir dos dados sobre o perfil em $X=3,8 \mathrm{~m}$ do conjunto [08]. a) imagem em $270 \mathrm{MHz}$ com time-gating em 7,0 ns. b) imagem em $270 \mathrm{MHz}$ com time-gating em 7,0 ns seguido por análise de autovalores. c) imagem em $400 \mathrm{MHz}$ com time-gating em 6,0 ns. d) imagem em $400 \mathrm{MHz}$ com time-gating em 6,0 ns seguido por análise de autovalores. e) imagem em $900 \mathrm{MHz}$ com time-gating em 4,0 ns. f) imagem em $900 \mathrm{MHz}$ com time-gating em 4,0 ns seguido por análise de autovalores.

Figura 62. Visualização 3D dos dados do conjunto [03] em 270 MHz. O retângulo tracejado representa os limites determinados para a vala que contém o alvo. a) representação de planos de corte em diferentes profundidades. b) plano de corte à profundidade de $0,56 \mathrm{~m}$. c) plano de corte à profundidade de $1,06 \mathrm{~m}$. d) plano de corte à profundidade de $1,29 \mathrm{~m}$.

Figura 63. Visualização 3D dos dados do conjunto [03] em 400 MHz. O retângulo tracejado representa os limites determinados para a vala que contém o alvo. a) representação de planos de corte em diferentes profundidades. b) plano de corte à profundidade de $0,53 \mathrm{~m}$. c) plano de corte à profundidade de $1,06 \mathrm{~m}$. d) plano de corte à profundidade de $1,29 \mathrm{~m}$.

Figura 64. Visualização $3 \mathrm{D}$ dos dados do conjunto [07] em $270 \mathrm{MHz}$. O retângulo tracejado representa os limites determinados para a vala que contém o alvo. a) representação de planos de corte em diferentes profundidades. b) plano de corte à profundidade de $0,56 \mathrm{~m}$. c) plano de corte à profundidade de $1,05 \mathrm{~m}$. d) plano de corte à profundidade de $1,30 \mathrm{~m}$. 146

Figura 65. Visualização 3D dos dados do conjunto [07] em 400 MHz. O retângulo tracejado representa os limites determinados para a vala que contém o alvo. 
xviii

a) representação de planos de corte em diferentes profundidades. b) plano de corte à profundidade de $0,71 \mathrm{~m}$. c) plano de corte à profundidade de $1,05 \mathrm{~m}$. d) plano de corte à profundidade de $1,30 \mathrm{~m}$. 


\section{Índice de Tabelas}

Tabela 1. Intervalos de frequência empregados na inversão dos dados.

Tabela 2. Dimensões e propriedades eletromagnéticas adotadas para a modelagem dos alvos do SCGR.

Tabela 3. Valores das propriedades elétricas do solo estimadas para os dados adquiridos no SCGR 55

Tabela 4. Truncamento dos valores singulares empregados na etapa de regularização do problema inverso para obtenção das imagens tomográficas obtidas a partir dos dados sintéticos 56

Tabela 5. Truncamento dos valores singulares para a etapa de regularização do problema inverso para obtenção das imagens tomográficas referentes aos dados do SCGR para cada situação de remoção de background em $270 \mathrm{MHz}$. TG = time-gating. STM = subtração do traço médio. AAV = análise de autovalores. 56

Tabela 6. Truncamento dos valores singulares para a etapa de regularização do problema inverso para obtenção das imagens tomográficas referentes aos dados do SCGR para cada situação de remoção de background em $400 \mathrm{MHz}$. TG = time-gating. $\mathrm{STM}=$ subtração do traço médio. AAV = análise de autovalores.

Tabela 7. Nomenclatura adotada para referência ao conjunto de dados adquirido em cada etapa de aquisição de dados.

Tabela 8. Valores das propriedades eletromagnéticas do solo estimadas para cada conjunto de dados.

Tabela 9. Truncamento dos valores singulares adotados na etapa de regularização do problema inverso para obtenção das imagens referentes ao experimento com o alvo orgânico. 


\section{Resumo}

Nesta pesquisa de doutorado foi desenvolvida uma metodologia de análise e interpretação de dados GPR (Ground Penetrating Radar) empregando a tomografia de micro-ondas. Esta ferramenta foi empregada com o objetivo de detectar e estimar a geometria de alvos que simulam artefatos comumente encontrados em sítios arqueológicos brasileiros e de um alvo orgânico que simula um corpo humano em decomposição visando estudos forenses sob condições controladas. Os dados de interesse arqueológico foram adquiridos sobre o Sítio Controlado de Geofísica Rasa (SCGR) do IAG/USP. Os dados de interesse forense foram adquiridos sobre um experimento controlado conduzido no campus da USP em Pirassununga (SP), onde um porco de aproximadamente $80 \mathrm{~kg}$ foi enterrado e a sua decomposição foi monitorada com o método GPR ao longo de 18 meses. Os cálculos necessários para a execução da inversão dos dados GPR através da tomografia foram implementados em linguagem Matlab, juntamente com ferramentas de remoção de background que se mostraram úteis para auxiliar a interpretação dos resultados. O programa de imageamento tomográfico foi validado a partir de dados sintéticos gerados no software GprMax a partir de modelos que simulam os alvos de interesse arqueológico instalados no SCGR. A geometria dos alvos do SCGR pôde ser bem estimada, exceto pelo alvo representado pelo muro de tijolos. Feições no solo associadas às escavações para instalação dos alvos puderam ser observadas com clareza nas imagens tomográficas. A geometria do porco, bem como o processo de decomposição foram mapeados através da tomografia mesmo em condições de baixo contraste entre as suas propriedades elétricas e as do solo. Em ambos os casos estudados as imagens tomográficas de dados GPR de $270 \mathrm{MHz}, 400$ MHz e $900 \mathrm{MHz}$ permitiram extrair mais informações acerca dos alvos do que pelo uso do processamento convencional. Os resultados mostram que a tomografia de microondas possui um grande potencial para aplicação em sítios arqueológicos brasileiros, bem como para aplicações forenses.

Palavras-chave: GPR, Ground Penetrating Radar, Inversão, Tomografia, Micro-ondas, Sítio Controlado de Geofísica Rasa, Arqueologia, Estudos forenses. 


\section{Abstract}

In this research a methodology for analysis and interpretation of GPR (Ground Penetrating Radar) data using microwave tomography was developed. This tool was used for detection and geometry evaluation of targets which simulate artifacts usually found at Brazilian archaeological sites and also of one organic target which simulates a decomposing human body for forensic studies under controlled conditions. The data of archaeological interest were acquired on the Geophysical Test Site (SCGR) at IAG/USP. The data of forensic interest were acquired on an experiment developed at the USP campus in Pirassununga (SP) city. In this experiment a pig with about $80 \mathrm{~kg}$ was buried and its decomposition was monitored through GPR profiles during 18 months. The calculations required for the GPR data inversion through microwave tomography were implemented in Matlab language, with background removal tools which were helpful for the interpretation of resulting images. The tomographic imaging program was validated using synthetic data generated by the software GprMax. The models simulate targets of archaeological interest buried at the SCGR. The geometry was well estimated for all the targets, except for the brick wall. Ground features associated to excavations done for the installation of the targets were clearly observed in the tomographic images. The pig geometry and its decomposition process were mapped through microwave tomography even under conditions of low contrast between its electric properties and those from the soil. In both studied cases the tomographic images from GPR data of $270 \mathrm{MHz}, 400 \mathrm{MHz}$ and $900 \mathrm{MHz}$ allowed to extract more information about the targets than just using the conventional processing. The results show that microwave tomography has a great potential to be applied at Brazilian archaeological sites, as well as for forensic applications.

Keywords: GPR, Ground Penetrating Radar, Inversion, Tomography, Microwave, Test Site, Archaeology, Forensic studies. 


\section{CAPÍTULO 1}

\section{INTRODUÇÃO}

A investigação geofísica rasa assume um papel importante na detecção de estruturas e objetos em subsuperfície, devido ao seu caráter não destrutivo. Por este motivo ela tem sido utilizada em estudos arqueológicos, onde o conhecimento prévio da localização de artefatos auxilia no processo de escavação por permitir a restrição a área a ser escavada e planejar o melhor método para a execução deste procedimento. Do mesmo modo, este tipo de investigação da subsuperfície vem sendo cada vez mais utilizado por arqueólogos e investigadores em casos de ocultação de cadáveres, busca por cemitérios clandestinos e localização de restos mortais.

Para tais finalidades o método GPR (Ground Penetrating Radar - Radar de Penetração no Solo) é muito usado devido à sua rapidez na aquisição de dados e à sua alta resolução. Este método detecta anomalias na permissividade dielétrica da área de estudo. Objetos como fragmentos de cerâmica, restos de fogueiras, ossos e material orgânico apresentam diferentes constantes dielétricas quando comparadas às do solo e podem ser detectados com o auxílio deste método. As anomalias podem ser observadas como hipérboles de difração no perfil de reflexão, chamado radargrama. Embora o método GPR seja capaz de detectar com facilidade as anomalias relacionadas a objetos em subsuperfície, o tamanho e geometria dos mesmos não podem ser estimados com a mesma facilidade a partir dos radargramas. Além disso, diferentes objetos podem gerar resultados visualmente similares. Esta é a principal causa de ambiguidade neste método, uma vez que diferentes interpretações podem ser elaboradas a partir de um mesmo conjunto de dados.

A inversão de dados representa um dos focos no desenvolvimento dos métodos geofísicos. No método GPR a inversão de dados busca a representação geométrica dos alvos e a estimativa das propriedades elétricas dos materiais a partir do registro do sinal eletromagnético refletido. Diversos cientistas ao redor do mundo têm se dedicado a esta linha de pesquisa buscando minimizar a ambiguidade e, por conseguinte, os erros interpretativos. Estudos têm sido desenvolvidos para estimar as propriedades elétricas 
do material geológico em subsuperfície e sua variação ao longo do perfil do radargrama empregando a inversão de forma de onda completa (Lambot et al., 2004; Ernst et al., 2007; Lambot et al., 2008; Busch et al., 2011; Kalogeropoulos et al.; 2012) e para estimar a geometria aproximada dos alvos em subsuperfície a partir da tomografia de micro-ondas, a qual é abordada nesta pesquisa.

Estudos do imageamento da subsuperfície através de tomografia vêm sendo desenvolvidos desde a década de 1980. Devaney (1984) baseou-se em uma generalização da tomografia de raios-X para desenvolver uma formulação para imageamento de heterogeneidades empregando perfilagem sísmica vertical. Chommeloux et al. (1986) apresentaram um dos trabalhos pioneiros no uso da tomografia de micro-ondas para aplicações em Geofísica utilizando métodos eletromagnéticos. Os autores apresentaram uma formulação para o imageamento tomográfico de heterogeneidades em subsuperfície, a partir de técnicas de imageamento empregadas em aplicações biomédicas. Segundo esta formulação os sinais eletromagnéticos de diferentes frequências são emitidos e registrados em diferentes ângulos de incidência em relação à interface ar-solo, permitindo extrair informações acerca da distribuição 2D de heterogeneidades no subsolo.

Posteriormente, Molyneux e Witten (1993) apresentaram um estudo relacionado ao imageamento tomográfico para aplicações GPR em arranjo monoestático (i. e., com transmissor e receptor coincidentes). Os métodos de imageamento desenvolvidos neste trabalho foram comparados empregando dados reais em estudos de caso desenvolvidos por Witten et al. (1994). Deming e Devaney (1997) apresentaram uma descrição generalizada da tomografia de difração para aplicações em GPR em arranjo multimonoestático (i. e., um arranjo monoestático em que as antenas se movem em conjunto ao longo do perfil).

O conceito de imageamento tomográfico adotado nesta pesquisa difere do conceito convencional de tomografia, em que a fonte e o receptor de sinal são colocados em posições opostas em relação ao alvo (em aplicações de tomografia entre poços, por exemplo). Nesta pesquisa empregou-se a tomografia de micro-ondas segundo uma aproximação que permite seu uso na análise de dados adquiridos através de perfis de reflexão com afastamento constante ao longo da interface ar-solo, que é uma situação comum no método GPR. Esta segunda abordagem apresenta menor quantidade de 
informação acerca dos objetos em subsuperfície, uma vez que não há a mesma redundância observada na tomografia convencional. Além disso, o próprio termo "tomografia de micro-ondas" é originado dos estudos em Engenharia Elétrica empregando sinais eletromagnéticos de frequências maiores do que 2,0 $\mathrm{GHz}$ para aplicações em biomedicina. Embora o método GPR para aplicações em Geofísica rasa utilize tipicamente sinais de frequências mais baixas, este termo tem sido empregado de forma comum por autores de ambas as áreas.

Esta aproximação tem sido aplicada com sucesso em diferentes situações. Dentre os trabalhos realizados recentemente nesta linha de pesquisa podem ser citados os trabalhos de Liu et al. (2004), Soldovieri et al. (2005), Persico e Soldovieri (2008), Crocco et al. (2009), Pettinelli et al. (2009), Soldovieri e Orlando (2009), Soldovieri et al. (2009), Leucci et al. (2011), Catapano et al. (2012), Catapano et al. (2014), Genarelli et al. (2014).

Liu et al. (2004) apresentaram a aplicabilidade do imageamento tomográfico de um alvo numa situação em que a constante dielétrica do alvo é de 8,2 e a do meio onde o alvo está inserido é de 8,0. Embora a geometria do corpo não tenha sido muito bem recuperada, a metodologia de inversão proposta permitiu estimar de maneira satisfatória a localização e a dimensão aproximada do alvo.

Soldovieri et al. (2005) desenvolveram estudos aplicando a inversão tomográfica de dados de GPR com Intervalos de Frequência (SFGPR - Stepped-Frequency Ground Penetrating Radar), empregando um sistema desenvolvido especificamente para estudos arqueológicos. Os dados foram adquiridos nas bandas de $200 \mathrm{MHz}$ a $850 \mathrm{MHz}$ com intervalos de $50 \mathrm{MHz}$ e de $300 \mathrm{MHz}$ a $600 \mathrm{MHz}$ com intervalos de $20 \mathrm{MHz}$. Os resultados obtidos foram satisfatórios, embora os autores tenham apontado diferentes causas de incertezas associadas às diferenças entre o sistema empregado e a formulação adotada para o problema.

Persico e Soldovieri (2008) fizeram uma análise dos efeitos de remoção de background no resultado final da inversão do espalhamento eletromagnético. Esta análise foi desenvolvida sobre dados sintéticos e reais, e mostrou que a remoção do background afeta a anomalia observada na imagem tomográfica final, podendo influenciar na estimativa da extensão horizontal do objeto. 
Crocco et al. (2009) apresentam um estudo de caso em que a tomografia de micro-ondas foi utilizada para detectar um vazamento em tubulações de distribuição de água (tubulações metálicas de 1,2 m de diâmetro) ainda em seu estágio inicial. Com este estudo foi possível mapear o vazamento através do imageamento da pluma, o que seria praticamente impossível de ser feito apenas através da interpretação da hipérbole no radargrama, uma vez que a influência do vazamento nesta feição do radargrama é quase imperceptível.

Pettinelli et al. (2009) apresentam um estudo específico sobre o imageamento tomográfico de alvos representados por tubulações plásticas e metálicas em um sítio de testes no Canadá, fazendo uma comparação entre a reconstrução geométrica dos alvos e os resultados do processo de migração dos radargramas. Foram analisados três perfis GPR, sendo um adquirido sobre tubulação plástica vazia, um sobre tubulação plástica preenchida com água e um sobre tubulação metálica vazia. Todas as análises mostraram que a tomografia forneceu imagens mais claras e de interpretação mais acurada do que na migração.

Soldovieri e Orlando (2009) apresentaram um estudo sobre o emprego de sistemas GPR multi-frequenciais, capazes de adquirir dados simultaneamente nas frequências de $200 \mathrm{MHz}$ e $600 \mathrm{MHz}$. Os dados adquiridos com este sistema no sítio arqueológico de Palatino, em Roma, foram analisados com a tomografia de microondas. Os resultados mostraram que as imagens tomográficas obtidas com a média aritmética dos espectros dos dados apresentaram qualidade equivalente às imagens obtidas com a média aritmética das imagens tomográficas individuais obtidas para cada frequência.

Soldovieri et al. (2009) elaboraram estratégias para a determinação das propriedades elétricas de um meio homogêneo com perdas (i. e., meios em que a condutividade é diferente de zero) através das imagens obtidas a partir da tomografia de micro-ondas. Os dados foram adquiridos sobre um tubo metálico de 0,10 $\mathrm{m}$ de diâmetro enterrado a uma profundidade de $0,55 \mathrm{~m}$ (profundidade do topo do alvo). A análise da qualidade das imagens foi feita assumindo-se diferentes valores de permissividade dielétrica e de condutividade para o meio homogêneo. Os resultados mostraram que é possível obter uma estimativa aceitável para os valores das propriedades elétricas do meio a partir da escolha da melhor imagem. Além disso, uma análise preliminar do 
problema para o caso de dados em três dimensões mostrou que modelos 2D podem fornecer bons resultados na inversão mesmo quando aplicados sobre um conjunto de dados 3D.

Leucci et al. (2011) exploraram o uso das técnicas de tomografia eletromagnética e sísmica para caracterização do grau de degradação dos pilares de uma catedral do século XII localizada na região da Basilicata, no sul da Itália. Os dados de tomografia eletromagnética foram obtidos através de perfis GPR adquiridos em modo de afastamento constante e foram posteriormente analisados com o uso da tomografia de micro-ondas. Os dados de tomografia sísmica foram obtidos da maneira convencional. A análise integrada de ambos os métodos permitiu avaliar o estado de conservação dos pilares e estimar aqueles em situação mais crítica, devido à presença de grande número de fraturas nestas estruturas.

Catapano et al. (2012) fizeram um estudo da aplicação da tomografia de microondas em levantamentos aéreos. Para isto foi desenvolvido um sistema específico para este tipo de levantamento, o qual foi acoplado em um helicóptero. Este sistema foi utilizado em levantamentos sobre uma geleira na Suíça e uma região sem cobertura vegetal na Alemanha. Os resultados permitiram obter informações acerca de heterogeneidades na camada de gelo e de feições horizontais na região com solo sem cobertura vegetal, indicando potencial para aplicações em sistemas aerotransportados.

Catapano et al. (2014) fizeram um estudo da aplicação da tomografia de microondas com dados GPR adquiridos sobre um derramamento controlado de óleo resistivo, visando o mapeamento de plumas de contaminação. Neste estudo foi feita uma análise 3D da pluma de óleo em diferentes intervalos de tempo, de modo a verificar o avanço da pluma de contaminação. Os resultados mostraram que a metodologia empregada permite uma interpretação mais acurada quando comparada à interpretação a partir dos radargramas, sendo bastante interessante na detecção de uma contaminação causada por derrame de óleo.

Genarelli et al. (2014) desenvolveram um estudo referente à tomografia de micro-ondas empregando dados 3D adquiridos em duas configurações diferentes. Um conjunto de dados foi adquirido em modo multi-monoestático e outro conjunto de dados foi adquirido em modo multiestático. Embora em ambos os casos o mesmo número de dados tenha sido empregado (121 pontos com 6 frequências de operação cada um) foi 
possível estabelecer as diferenças no imageamento entre os dois conjuntos de dados, mostrando que o alvo é melhor resolvido nos dados adquiridos em modo multimonoestático.

Estes estudos mostram que a tomografia de micro-ondas auxilia no processo interpretativo dos dados estimando a distribuição espacial do contraste entre as propriedades elétricas dos objetos enterrados e do meio geológico por onde as ondas eletromagnéticas se propagam. Embora o problema da ambiguidade seja inerente a todos os métodos geofísicos, a identificação de regiões onde há indícios de variações na constante dielétrica da área sob investigação por meio de um processo de inversão de dados pode auxiliar na análise de dados visando minimizar a ambiguidade na interpretação.

Os resultados da pesquisa são apresentados conforme segue. O Capítulo 02 apresenta uma descrição das áreas de estudo do SCGR do IAG/USP e da área onde foi desenvolvido o experimento controlado com o alvo orgânico no campus da USP em Pirassununga (SP). O Capítulo 03 apresenta os fundamentos teóricos do eletromagnetismo que servem de base para as ferramentas empregadas neste estudo, bem como a fundamentação do método GPR e do problema inverso da tomografia de

micro-ondas para perfis de afastamento constante. O Capítulo 04 apresenta a metodologia empregada na modelagem, aquisição e processamento dos dados analisados. O Capítulo 05 apresenta os resultados do imageamento tomográfico sobre os dados sintéticos e reais referentes aos alvos de interesse arqueológico presentes no SCGR do IAG/USP, bem como os resultados referentes ao imageamento tomográfico obtido a partir dos dados coletados sobre o experimento com o porco enterrado no campus da USP em Pirassununga-SP. O Capítulo 06 apresenta as conclusões da pesquisa e as recomendações para trabalhos futuros.

\subsection{Objetivos}

Esta pesquisa tem como objetivo principal empregar a tomografia de microondas para a detecção e a estimativa da geometria de alvos de interesse arqueológico e em estudos forenses. Os alvos de interesse arqueológico são representados por objetos 
enterrados no Sítio Controlado de Geofísica Rasa (SCGR) do IAG/USP (Porsani et al., 2006) e que simulam artefatos arqueológicos. O alvo de interesse forense é representado por um porco que foi enterrado em um experimento controlado realizado no campus da USP em Pirassununga (SP).

Nesta pesquisa foi estudada uma metodologia de análise e interpretação geofísica através da inversão de dados GPR por meio da tomografia de micro-ondas, visando localizar alvos no subsolo e estimar a geometria dos mesmos. Para tanto, o desenvolvimento da pesquisa deu-se nas seguintes etapas:

i) Desenvolvimento de um programa computacional dedicado à inversão de perfis GPR através da tomografia de micro-ondas para análise qualitativa de radargramas e auxílio na interpretação de dados 2D e 3D interpolados;

ii) Análise de dados GPR de $270 \mathrm{MHz}$ e $400 \mathrm{MHz}$ sobre a linha de alvos arqueológicos instalados no SCGR do IAG/USP;

iii) Análise de dados GPR de $270 \mathrm{MHz}, 400 \mathrm{MHz}$ e $900 \mathrm{MHz}$ sobre um alvo orgânico representado por um porco de aproximadamente $80 \mathrm{~kg}$, em um experimento controlado conduzido no campus da USP em Pirassununga (SP), durante oito campanhas de campo realizadas em um período total de 18 meses. 


\section{CAPÍTULO 2}

\section{ÁREAS DE ESTUDO}

Os estudos desenvolvidos nesta pesquisa ocorreram em duas áreas distintas. A primeira delas é o SCGR Do IAG/USP, localizado na Cidade Universitária Armando Salles de Oliveira e onde estão instalados alvos que representam objetos que se esperaria encontrar em sítios arqueológicos brasileiros. A segunda corresponde a uma área localizada no campus da USP na cidade de Pirassununga (SP), onde foi conduzido um experimento com um alvo orgânico com o objetivo de simular um cadáver humano. Ambas as áreas serão descritas a seguir.

\subsection{Sítio Controlado de Geofísica Rasa (SCGR)}

O SCGR corresponde a uma área de $50,0 \mathrm{~m} \times 30,0 \mathrm{~m}$ localizada entre os Institutos de Física (IF), Oceanográfico (IO), de Matemática e Estatística (IME) e de Geofísica, Astronomia e Ciências Atmosféricas (IAG). As coordenadas do seu centro são $23,5601^{\circ} \mathrm{W}$ e $46,7331^{\circ} \mathrm{S}$. Sob esta área estão enterrados diferentes tipos de objetos que visam simular as mesmas condições para aquisição de dados geofísicos que se encontram em obras de engenharia, sítios arqueológicos e áreas urbanas (Porsani et al., 2006; Borges, 2007, Porsani e Sauck, 2007; Santos, 2014; Santos et al., 2014).

A área onde está instalado o SCGR encontra-se na borda da Bacia de São Paulo. A porção mais rasa é caracterizada por uma camada de espessura máxima de 3,0 m onde predominam sedimentos argilo-siltosos e argilo-arenosos. Abaixo desta camada predominam sedimentos argilosos ricos em matéria orgânica até uma profundidade em torno de 6,0 m (Porsani et al., 2004a; Porsani et al., 2006).

Esta área possui sete linhas de alvos, que são mostradas na Figura 1. Os dados GPR foram adquiridos com um sistema SIR-3000 fabricado pela GSSI (Geophysical Survey Systems, Inc.) e antenas blindadas de $270 \mathrm{MHz}$ e $400 \mathrm{MHz}$ sobre a Linha 01, composta por alvos de interesse arqueológico que simulam a presença de paleofogueiras 
(representadas por uma camada de seixos de quartzo) e urnas funerárias (representadas por vasos cerâmicos selados preenchidos com ar), comumente encontradas nos sítios arqueológicos brasileiros. Esta linha também possui caixas de areia e de brita de granito enterradas, que simulam diferentes condições de solos, bem como um muro de tijolos que simula a fundação de igrejas históricas.

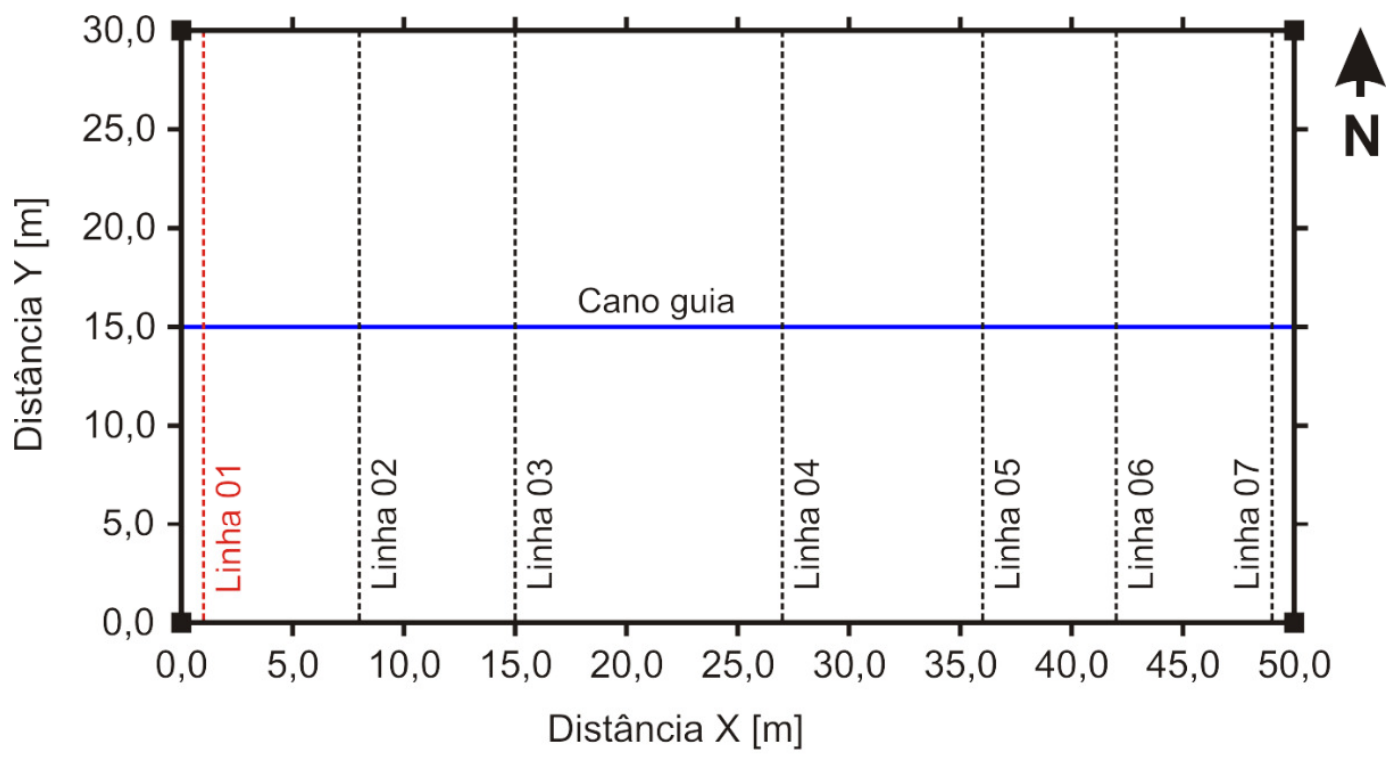

Linha 05 - Tambores de plástico

Linha 06 - Tubos de aço

Linha 07 - Tubos e cabeamento elétrico

Figura 1. Diagrama das linhas do Sítio Controlado de Geofísica Rasa (SCGR) do IAG/USP (Adaptado de Porsani et al., 2006). Os dados analisados nesta pesquisa foram adquiridos sobre a Linha 01 (em vermelho). O cano metálico guia é representado em azul, perpendicularmente à direção das linhas.

Os alvos instalados desta linha encontram-se esquematizados no diagrama da Figura 2. 


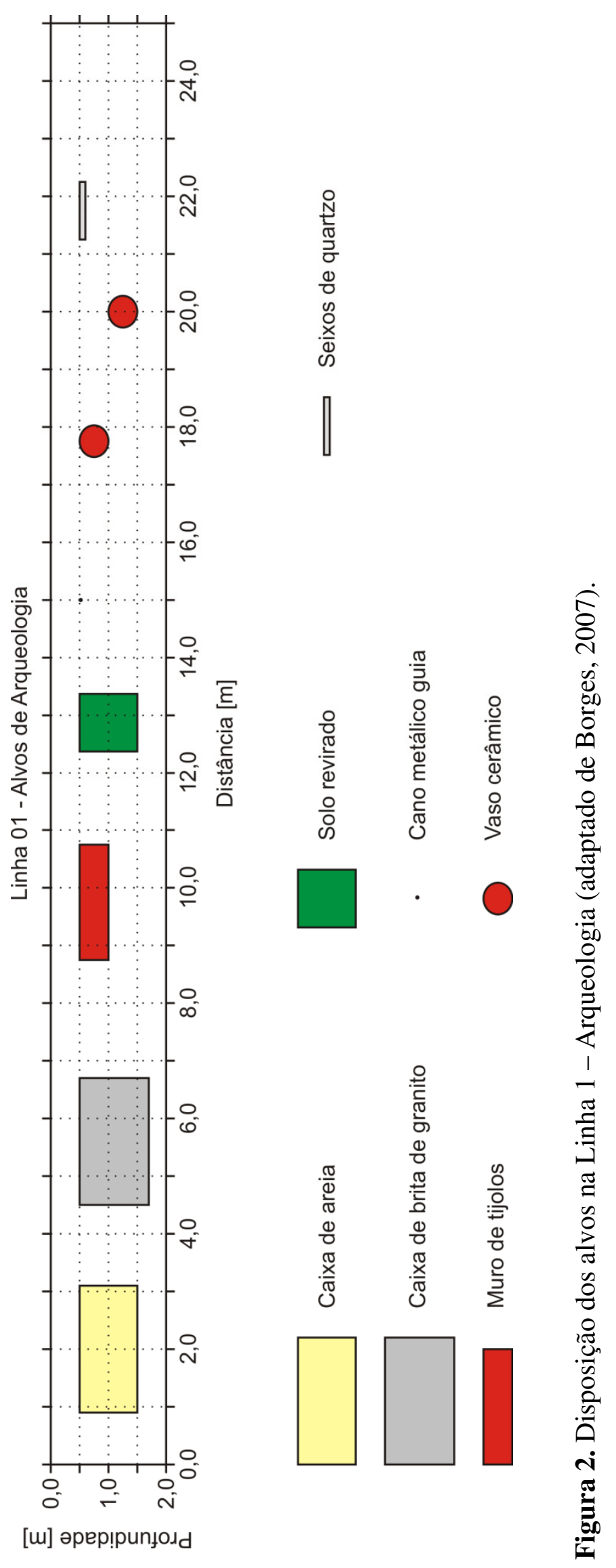




\subsection{Experimento com alvo orgânico}

Este experimento foi elaborado com o intuito de se desenvolver uma análise sobre um tipo de alvo inexistente no SCGR do IAG/USP e que é igualmente de interesse arqueológico, mais especificamente da área de pesquisa da arqueologia forense.

Uma área de 6,0 $\mathrm{m} \times 5,0 \mathrm{~m}$ foi disponibilizada no campus da USP localizado na cidade de Pirassununga (SP) para que o experimento fosse conduzido. A localização desta área é mostrada na Figura 3. As coordenadas do seu centro são $21,9523^{\circ} \mathrm{W}$ e $47,4584^{\circ} \mathrm{S}$.

Esta área localiza-se em uma região de transição entre uma vegetação mais densa, com muitas árvores de grande porte, e uma vegetação menos densa, caracterizada principalmente por vegetação rasteira (capim) e algumas árvores de médio e pequeno porte. A região denominada "Lagoa seca" na figura indica uma área que é preenchida com volume de água apenas nos meses do ano em que o volume hídrico é mais alto. $\mathrm{O}$ local é afastado das demais construções do campus, de maneira que o risco de contaminação do subsolo é mínimo. Esta mesma área foi usada no trabalho desenvolvido por Saraiva (2010), em que um total de aproximadamente $6.000 \mathrm{~kg} \mathrm{de}$ material orgânico foi enterrado com o objetivo de se estudar o avanço da pluma de necrochorume gerada pela decomposição do mesmo.

A área onde o experimento foi conduzido faz parte da Formação Pirassununga. A geologia das camadas mais rasas é composta predominantemente por material argiloso de cor avermelhada com algumas porções arenosas (Saraiva, 2010). 


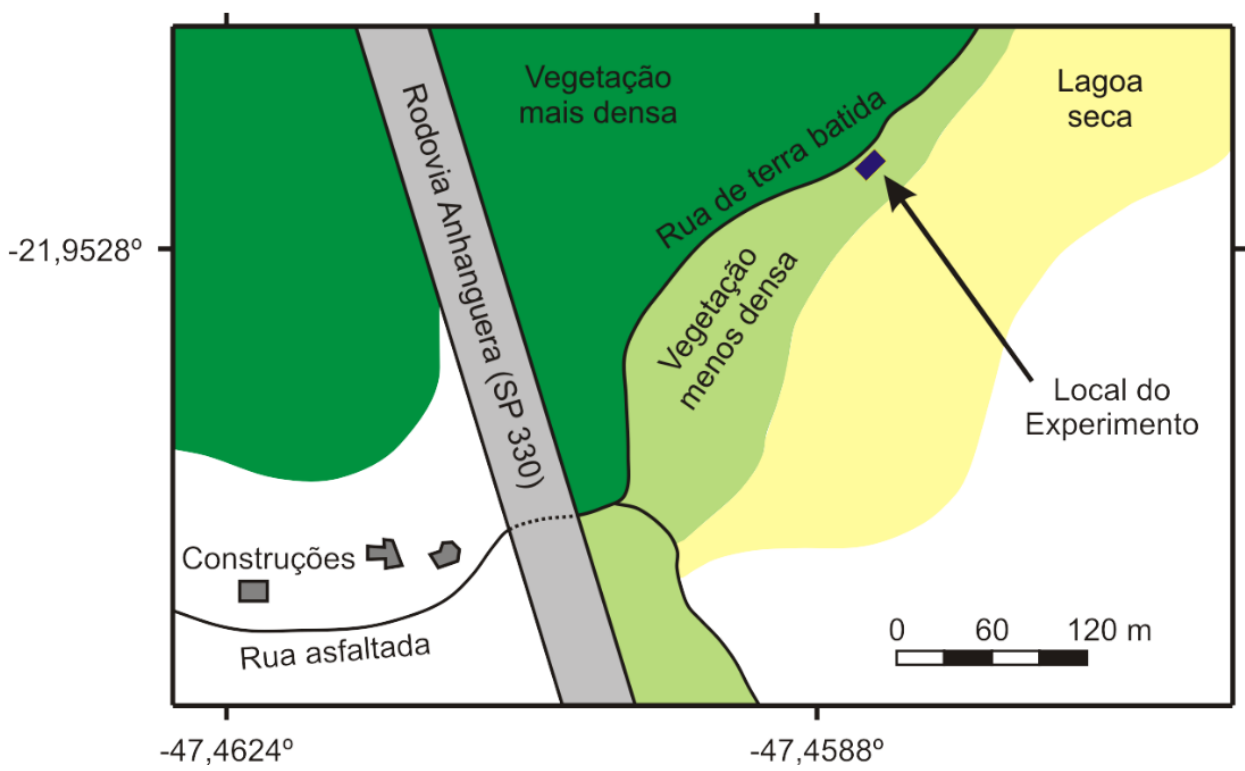

Figura 3. Localização da área onde foi conduzido o experimento com alvo orgânico.

Para este experimento foi enterrado um porco com massa corporal de aproximadamente $80 \mathrm{~kg}$ é comparável à de um ser humano adulto. O animal foi escolhido devido às similaridades do seu processo de decomposição e do processo de decomposição de um cadáver humano, conforme apontado em análises bioquímicas (Dent et al., 2004; Carter et al., 2007; Notter et al., 2009). O uso de carcaças de porcos para simulação de corpos humanos tem sido prática comum em estudos com o método GPR (France et al., 1992; Powell, 2004; Schultz et al., 2006; Schultz, 2008) e com métodos geoelétricos (Jervis et al., 2009; Pringle et al., 2010).

O animal utilizado neste experimento foi abatido momentos antes do enterro, de modo que pudesse ser enterrado ainda com a maior parte dos fluidos corporais preservada, sendo posteriormente enterrado em uma cova de 1,0 $\mathrm{m} \times 2,0 \mathrm{~m}$ dentro de uma área cercada para evitar o trânsito de outros animais sobre o local e evitar uma eventual intervenção humana. $\mathrm{O}$ animal foi disposto horizontalmente dentro da cova de $1,10 \mathrm{~m}$ de profundidade, representando um alvo cuja parte mais rasa encontra-se à profundidade de 0,85 m. A Figura 4 mostra o local da vala e a disposição do alvo em seu interior. 
a)

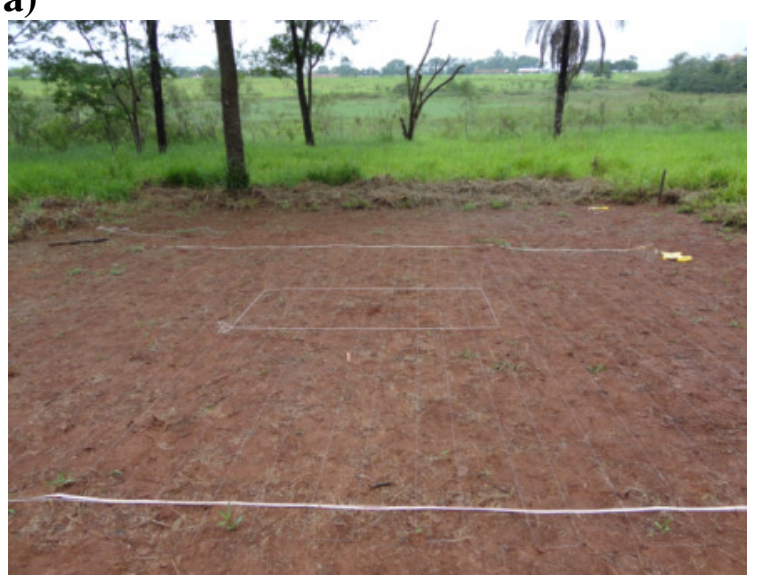

b)

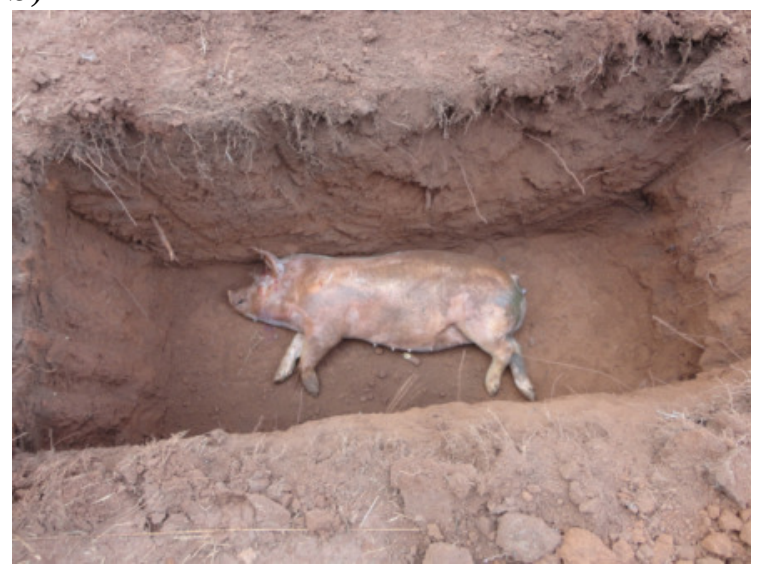

Figura 4. Área de implantação de alvo controlado no campus da USP em Pirassununga. a) local de estudo. A vala está representada pelo retângulo de $2,0 \mathrm{~m} \times 1,0 \mathrm{~m}$ no centro de uma área de $6,0 \mathrm{~m} \times 5,0 \mathrm{~m}$. b) disposição do alvo no interior da vala.

O terreno disponibilizado para os estudos apresenta uma variação topográfica de aproximadamente 0,55 m no sentido N-W (Figura 5). Para perfis de apenas 5,0 m esta variação precisa ser considerada para corrigir a distorção causada na anomalia hiperbólica e proporcionar um resultado mais acurado na imagem tomográfica final. Assim, foi feito inicialmente o levantamento topográfico do terreno através de nivelamento geométrico.

A Figura 6 mostra um perfil ao longo da direção $y$ (posição $x=3,0 \mathrm{~m}$ ) esquematizando este aspecto. Nesta figura, e em todos os perfis que serão apresentados adiante, a referência para a escala de profundidade foi sempre o ponto situado nas coordenadas $(6,0,0,0)$ da área de estudo, o qual corresponde ao ponto mais alto. 


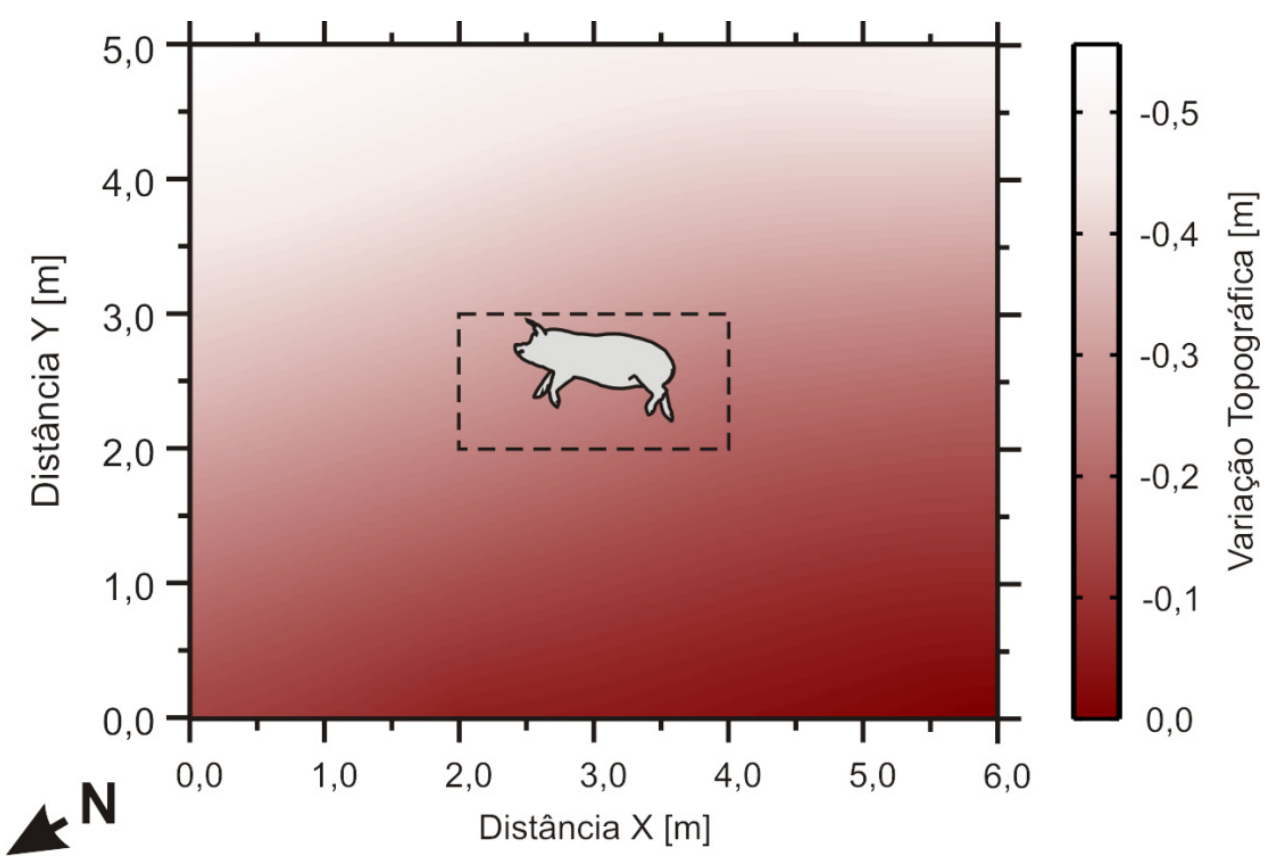

Figura 5. Variação da topografia na área de estudo. A linha pontilhada indica a localização da vala.

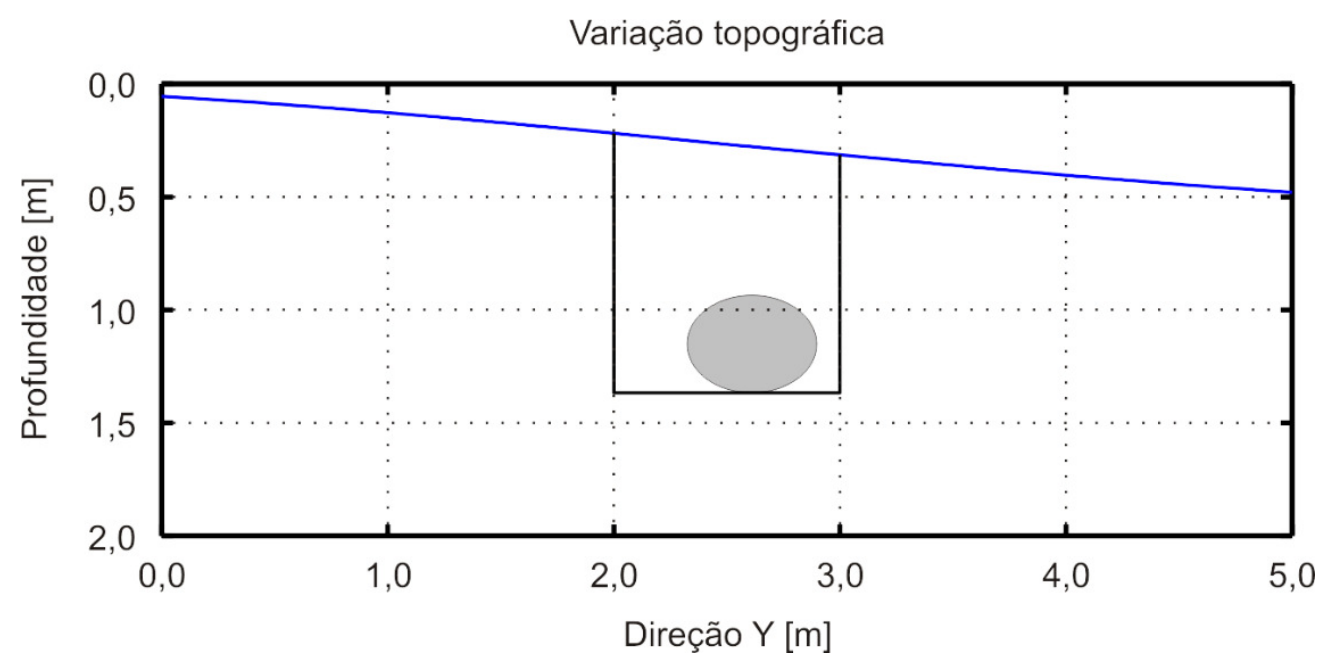

Figura 6. Perfil lateral ao longo da direção $y$ esquematizando a variação topográfica (linha azul) e a vala (linha preta) com o animal em seu interior (elipse cinza). A referência para a escala de profundidade em todos os perfis é a coordenada $(6,0,0,0)$, que corresponde ao ponto mais alto da área de estudo. 


\subsection{Escavação do alvo orgânico}

A decomposição do animal foi monitorada durante um período de 18 meses, com a última aquisição de dados sendo realizada em junho 2014. Após esta aquisição foi feita a escavação da vala com o objetivo de verificar a quantidade de material orgânico restante em seu interior e poder fazer a correlação entre este material e as características das anomalias observadas nos dados GPR antes e após a tomografia.

Observou-se no local a presença dos ossos expostos, ainda íntegros. Em torno destes havia uma quantidade considerável de material orgânico, originária principalmente da gordura e da pele do animal. Pedaços de carne eram observáveis, aderidos à pele (Figura 7a). Os ossos do crânio apresentavam indícios da ação de insetos, possivelmente presentes desde o momento do enterro. De modo geral, os ossos ainda mostravam-se pouco deteriorados e com alguma resistência à quebra. Parte dos restos retirados da vala é mostrada na Figura $7 \mathrm{~b}$.

a)

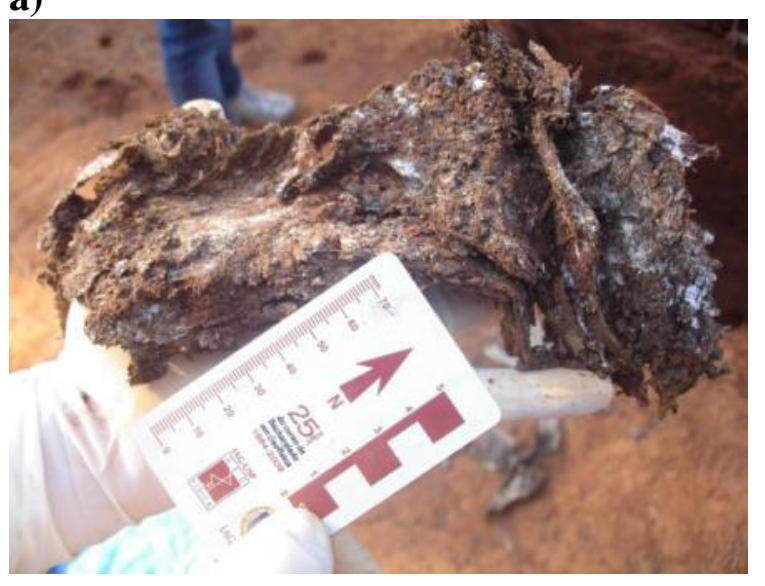

b)

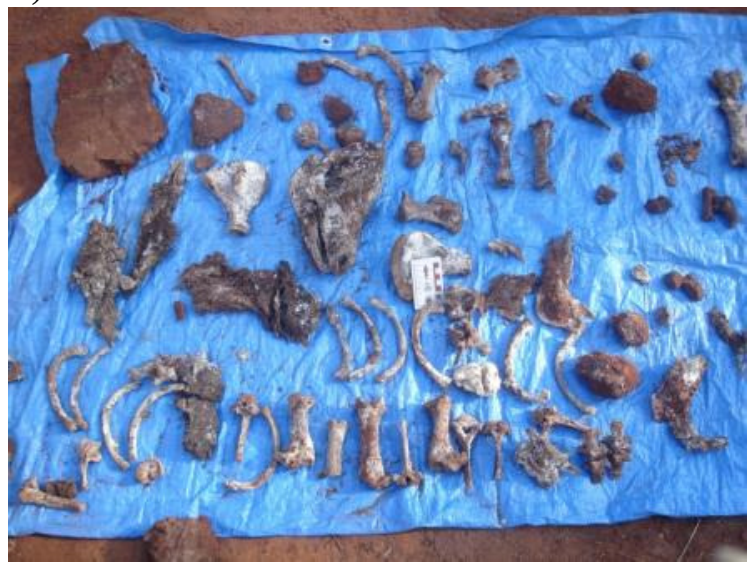

Figura 7. Restos orgânicos retirados da vala. a) fragmento de pele. b) parte dos ossos retirados da vala, os quais ainda apresentaram-se íntegros e resistentes à quebra.

Apesar da grande quantidade de matéria orgânica em decomposição, não foi observada alteração significativa no material geológico em torno do corpo, como pode ser observado na Figura 8a. Entretanto, uma pequena camada de alteração de aproximadamente $10,0 \mathrm{~cm}$ foi observada abaixo deste. Nesta camada, o material 
geológico apresentou-se um pouco mais consolidado do que o material não alterado. Houve também uma leve alteração na coloração, que passou de predominantemente avermelhada a marrom conforme pode ser observado na Figura $8 b$.

a)

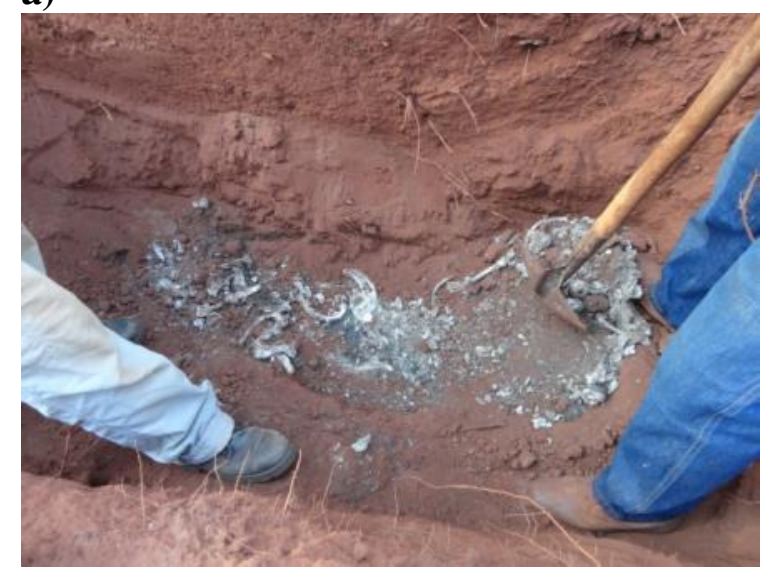

b)

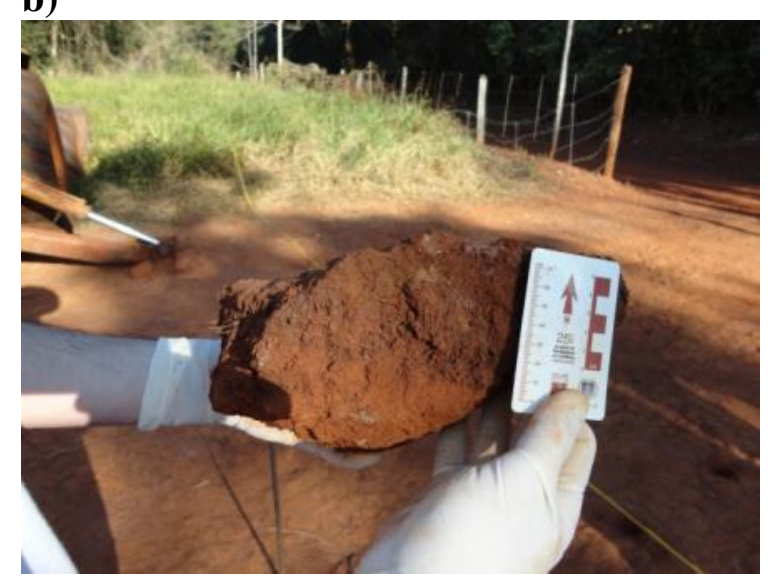

Figura 8. Alteração do material geológico no interior da vala. a) não foi observada alteração significativa do material geológico ao redor do corpo. b) a única alteração significativa ocorreu no fundo da vala, onde foi observada uma camada de alteração de cerca de 10,0 cm. Esta camada apresentou um leve escurecimento na coloração do material geológico.

Algumas anomalias pontuais identificadas como hipérboles nos radargramas mostraram-se provenientes de alterações geológicas localizadas ou de cavidades no solo possivelmente relacionadas a variações na compactação do solo ou a buracos de formigas, visto que havia uma grande quantidade destes insetos na área. A Figura 9 mostra um exemplo destas cavidades, localizadas ao longo do perfil na direção $y$ localizado na posição $x=0,0 \mathrm{~m}$. Nesta figura é possível observar duas cavidades, uma à profundidade de $0,55 \mathrm{~m}$ e outra à profundidade de $1,10 \mathrm{~m}$. A anomalia mais profunda aparentemente apresentava uma continuidade estendendo-se para além da área do experimento, porém não foi possível verificar isto de forma conclusiva uma vez que a cavidade se estendia até regiões de difícil visualização. É possível que uma conexão tenha existido entre estas cavidades, uma vez que ambas estão muito próximas entre si. A conexão entre ambas poderia ter sido feita por animais de habitat subterrâneo, e poderia estar na parte removida durante a escavação. A presença de grande quantidade de formigas e tatus no local, juntamente com evidências de túneis observados nas 
proximidades do experimento, sugere que estas cavidades possam estar relacionadas a uma rede subterrânea criada por estes animais. Uma análise mais detalhada acerca da formação destas estruturas está além do objetivo desta pesquisa.

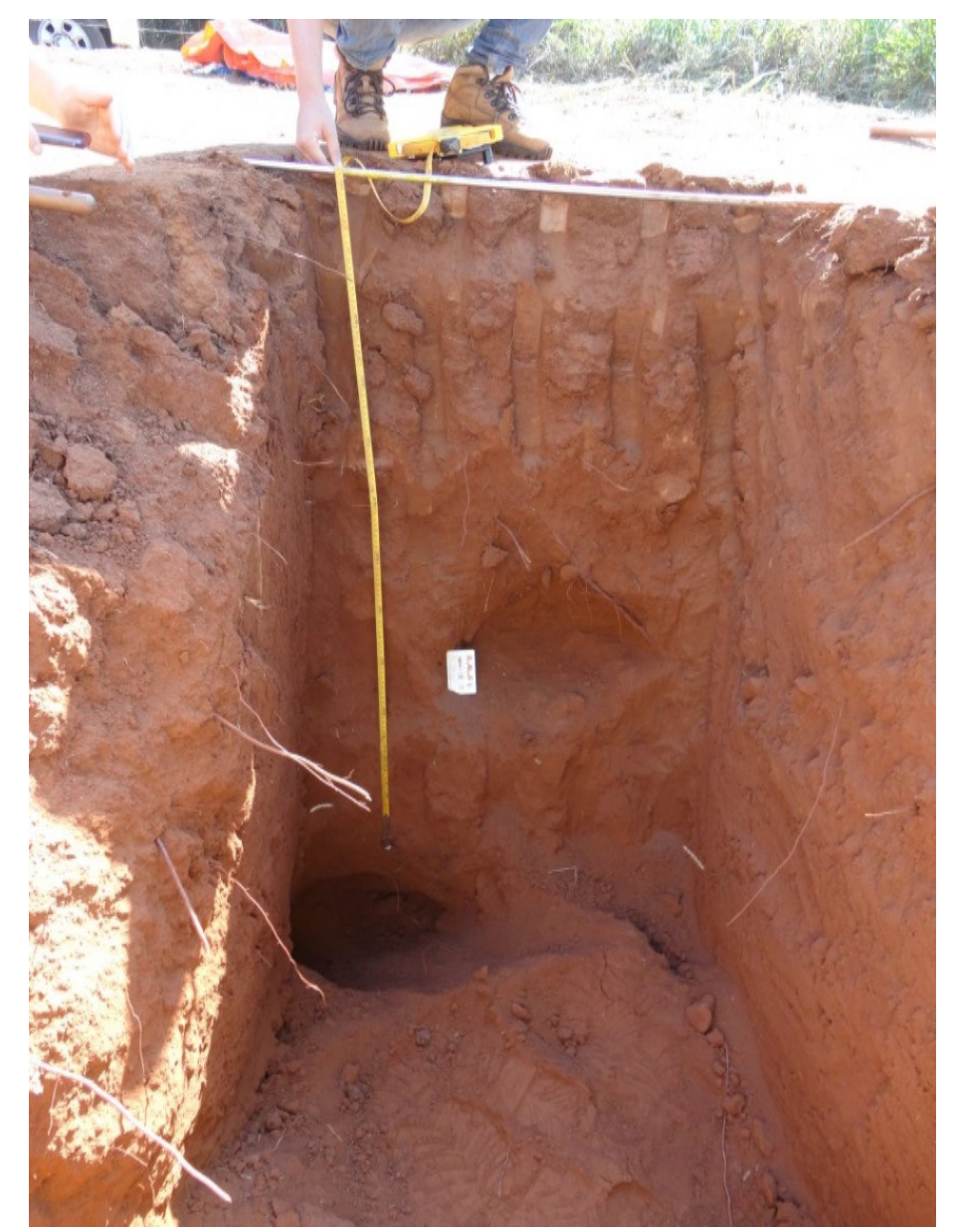

Figura 9. Cavidades encontradas durante a escavação. Estas cavidades são observadas nos radargramas como feições hiperbólicas não relacionadas ao alvo enterrado para execução do experimento. 


\section{CAPÍTULO 3}

\section{FUNDAMENTOS TEÓRICOS}

Neste capítulo serão apresentados os conceitos teóricos envolvidos no desenvolvimento da pesquisa. Inicialmente será apresentada uma introdução à teoria do eletromagnetismo, na qual se baseia o método GPR. Em seguida será feita uma abordagem da formulação do problema inverso da tomografia para aplicação em perfis de afastamento constante, bem como os métodos empregados para linearização e regularização do mesmo. Por fim, os aspectos teóricos que constituem o método GPR são apresentados e discutidos.

\subsection{Teoria do Eletromagnetismo}

A propagação das ondas eletromagnéticas é regida pelas equações de Maxwell, as quais são definidas em termos dos vetores de intensidade de campo elétrico $(\boldsymbol{E})$ e magnético $(\boldsymbol{H})$ e dos vetores de intensidade de fluxo elétrico $(\boldsymbol{D})$ e magnético $(\boldsymbol{B})$. Em uma situação onde não existem cargas livres no meio as equações são dadas em sua forma diferencial no domínio do tempo pelo conjunto de equações (Balanis, 1989; Griffiths, 1999):

\section{Domínio do Tempo Domínio da Frequência}

$$
\begin{array}{ccc}
\begin{array}{c}
\text { Lei da Indução } \\
\text { de Faraday }
\end{array} & \nabla \times \boldsymbol{E}(\boldsymbol{r})=-\frac{\partial \boldsymbol{B}(\boldsymbol{r})}{\partial t} & \nabla \times \boldsymbol{E}(\boldsymbol{r})=-i \omega \boldsymbol{B}(\boldsymbol{r}) \\
\begin{array}{c}
\text { Lei de Ampère- } \\
\text { Maxwell }
\end{array} & \nabla \times \boldsymbol{H}(\boldsymbol{r})=\boldsymbol{J}(\boldsymbol{r})+\frac{\partial \boldsymbol{D}(\boldsymbol{r})}{\partial t} & \nabla \times \boldsymbol{H}(\boldsymbol{r})=\boldsymbol{J}(\boldsymbol{r})+i \omega \boldsymbol{D}(\boldsymbol{r})
\end{array}
$$

Lei de Gauss da eletrostática

$$
\nabla \cdot \boldsymbol{D}(\boldsymbol{r})=0 \quad \nabla \cdot \boldsymbol{D}(\boldsymbol{r})=0
$$

Lei de Gauss da magnetostática

$$
\begin{array}{ll}
\nabla \cdot \boldsymbol{B}(\boldsymbol{r})=0 & \nabla \cdot \boldsymbol{B}(\boldsymbol{r})=0
\end{array}
$$


em que $\boldsymbol{r}$ é o vetor espacial de coordenadas $(x, y, z), \boldsymbol{E}$ é o vetor intensidade de campo elétrico $(\mathrm{V} / \mathrm{m}), \boldsymbol{B}$ é o vetor densidade de fluxo magnético $\left(\mathrm{Wb} / \mathrm{m}^{2}\right.$, ou $\left.\mathrm{T}\right), \boldsymbol{H}$ é o vetor intensidade de campo magnético $(\mathrm{A} / \mathrm{m}), \boldsymbol{J}$ é o vetor densidade de corrente elétrica $\left(\mathrm{A} / \mathrm{m}^{2}\right), \boldsymbol{D}$ é o vetor densidade de fluxo elétrico $\left(\mathrm{C} / \mathrm{m}^{2}\right)$ e $\omega$ é a frequência angular $(\mathrm{rad} / \mathrm{s})$.

A densidade de corrente elétrica $(\boldsymbol{J})$ é composta pela soma de dois outros termos, que são a densidade de corrente induzida pela fonte $\left(\boldsymbol{J}_{f}\right)$ e a densidade de corrente de condução $\left(\boldsymbol{J}_{c}\right)$, que será abordada adiante. O termo diferencial na lei de AmpèreMaxwell pode ser denominado também como densidade de corrente de deslocamento elétrica $\left(\boldsymbol{J}_{d}\right)$. Similarmente, o termo diferencial na lei da indução de Faraday pode ser denominado como densidade de corrente de deslocamento magnética. Estes termos diferenciais representam as correntes resultantes da presença de campos variáveis no tempo, e não das fontes.

Para os estudos com o método GPR é mais conveniente utilizar as equações no domínio da frequência, uma vez que as derivadas parciais são substituídas por produtos, simplificando assim as etapas de cálculos.

\subsubsection{Relações Constitutivas do meio}

As relações constitutivas do meio são grandezas tensoriais que permitem relacionar as componentes elétrica $(\boldsymbol{E})$ e magnética $(\boldsymbol{H})$ do campo eletromagnético às densidades de fluxo elétrico $(\boldsymbol{D})$, de fluxo magnético $(\boldsymbol{B})$ e de corrente de condução $\left(\boldsymbol{J}_{c}\right)$. Estas grandezas representam as características físicas do meio, permitindo quantificar o comportamento deste diante da aplicação de um campo eletromagnético. As relações constitutivas são dadas pelas equações (3.5) a (3.7) (Ward e Hohmann, 1988):

$$
\begin{gathered}
\boldsymbol{D}=\varepsilon \boldsymbol{E} \\
\boldsymbol{B}=\mu \boldsymbol{H} \\
\boldsymbol{J}_{c}=\sigma \boldsymbol{E} \quad(\text { Lei de Ohm })
\end{gathered}
$$


em que $\varepsilon$ é a permissividade dielétrica $(\mathrm{F} / \mathrm{m}), \mu$ é a permeabilidade magnética $(\mathrm{H} / \mathrm{m})$ e $\sigma$ é a condutividade elétrica $(\mathrm{S} / \mathrm{m})$.

A permissividade dielétrica quantifica a capacidade de polarização de um material mediante a aplicação de um campo elétrico. No vácuo, esta grandeza assume o valor constante $\varepsilon_{0}=8,85 \times 10^{-12} \mathrm{~F} / \mathrm{m}$ (Griffiths, 1999). Dependendo das considerações adotadas acerca do meio em que o sinal eletromagnético propaga, a permissividade dielétrica pode assumir valores reais ou complexos. Adotar um valor complexo para a permissividade dielétrica implica em estabelecer que tal valor possui uma parte real e uma imaginária, sendo que esta segunda apresenta uma variação em função da componente de frequência do espectro do sinal eletromagnético. Os mecanismos que regem esta característica podem ser descritos por diferentes modelos, sendo que o mais comum é aquele descrito pelo modelo de Debye (Debye, 1945):

$$
\varepsilon(\omega)=\varepsilon^{\prime}-i \varepsilon^{\prime \prime}=\epsilon_{\infty}+\frac{\epsilon_{s}-\epsilon_{\infty}}{1+i \omega \tau(s)}
$$

em que $\epsilon_{s}$ é a permissividade real para $\omega=0, \epsilon_{\infty}$ é a permissividade para $\omega \rightarrow \infty$ e $\tau(s)$ é um parâmetro do meio denominado tempo de relaxação. Deste ponto em diante será adotada a notação $\epsilon$ para representar a permissividade dielétrica real e $\varepsilon$ para representar a permissividade dielétrica complexa, evitando assim um possível conflito na interpretação das equações devido à notação matemática.

A permeabilidade magnética quantifica a predisposição de um meio em ser magnetizado quando submetido a um campo magnético, assumindo o valor constante $\mu_{0}=4 \pi \times 10^{-7} \mathrm{H} / \mathrm{m}$ no vácuo (Griffiths, 1999). A condutividade elétrica quantifica as cargas elétricas em movimento na presença de um campo elétrico, que nada mais é do que a capacidade que um material tem de conduzir corrente elétrica.

No método GPR é comum referir-se a um material geológico por meio de sua permissividade dielétrica relativa ou constante dielétrica. Esta constante é a razão entre a permissividade dielétrica real do material e a permissividade dielétrica do vácuo e é normalmente representada apenas pelos valores reais, ou seja:

$$
\epsilon_{r}=\frac{\epsilon}{\epsilon_{0}}=\frac{\varepsilon^{\prime}}{\epsilon_{0}}
$$


em que $\epsilon_{r}$ é a constante dielétrica do meio.

\subsubsection{Equações de onda}

As equações de Maxwell podem ser reescritas de modo que cada uma delas fique dependente apenas do campo elétrico ou do campo magnético. Isto é feito aplicando-se o rotacional nas equações (3.1) e (3.2) e fazendo-se as devidas substituições. Assim, tem-se para o campo elétrico:

$\nabla \times \nabla \times \boldsymbol{E}=-i \omega \mu_{0} \nabla \times \boldsymbol{H} \quad \Rightarrow \quad \nabla \times \nabla \times \boldsymbol{E}=-i \omega \mu_{0}(\sigma+i \omega \epsilon) \boldsymbol{E}$

De maneira similar, para o campo magnético tem-se:

$$
\nabla \times \nabla \times \boldsymbol{H}=\sigma \nabla \times \boldsymbol{E}+i \omega \epsilon \nabla \times \boldsymbol{E} \Rightarrow \nabla \times \nabla \times \boldsymbol{H}=-i \omega \mu_{0}(\sigma+i \omega \epsilon) \boldsymbol{H}
$$

Reagrupando os termos, aplicando a identidade vetorial $\nabla \times \nabla \times \boldsymbol{A}=\nabla(\nabla \cdot \boldsymbol{A})-\nabla^{2} \boldsymbol{A}$ e considerando-se que não há a presença de cargas livres tem-se as equações de Helmholtz homogêneas, dadas por:

$$
\begin{aligned}
& \nabla^{2} \boldsymbol{E}(\boldsymbol{r})+\gamma^{2} \boldsymbol{E}(\boldsymbol{r})=0 \\
& \nabla^{2} \boldsymbol{H}(\boldsymbol{r})+\gamma^{2} \boldsymbol{H}(\boldsymbol{r})=0
\end{aligned}
$$

em que $\gamma=\sqrt{\omega^{2} \mu_{0} \epsilon-i \omega \mu_{0} \sigma}$ é chamado de número de onda complexo e é interpretado fisicamente como o número de ondas existentes em uma unidade de espaço. O número de onda complexo pode ser reescrito como

$$
\gamma^{2}=\omega^{2} \mu_{0} \epsilon-i \omega \mu_{0} \sigma=\omega^{2} \mu_{0}\left(\epsilon-i \frac{\sigma}{\omega}\right)=\omega^{2} \mu_{0}\left(\varepsilon^{\prime}-i \varepsilon^{\prime \prime}\right)=\omega^{2} \mu_{0} \varepsilon
$$

em que $\epsilon$ é a permissividade dielétrica real e $\varepsilon=(\epsilon-i \sigma / \omega)$ equivale à permissividade dielétrica complexa, a qual também pode ser modelada através da equação (3.8). 


\subsubsection{Propagação de ondas em um meio dielétrico}

A velocidade de uma onda propagando-se em um meio dielétrico homogêneo sem perdas (i. e., onde $\sigma=0 \mathrm{~S} / \mathrm{m}$ ) de permissividade dielétrica real $\epsilon$ e constante dielétrica $\epsilon_{r}$ é dada em m/s pela equação (Porsani, 1999; Daniels, 2004)

$$
v=\frac{\omega}{k}=\frac{\omega}{\omega \sqrt{\mu_{0} \epsilon}}=\frac{\omega}{\omega \sqrt{\mu_{0} \epsilon_{0} \epsilon_{r}}}=\frac{1}{\sqrt{\mu_{0} \epsilon_{0}}} \frac{1}{\sqrt{\epsilon_{r}}}=\frac{c}{\sqrt{\epsilon_{r}}}
$$

em que $c$ é a velocidade da luz em $\mathrm{m} / \mathrm{s}$ e $k$ corresponde ao número de onda quando $\sigma=0 \mathrm{~S} / \mathrm{m}$.

Quando a condutividade do meio é diferente de zero há a atenuação do sinal em função do tempo de propagação deste através do meio. Desta forma adota-se o número de onda complexo $\gamma$ dado por (3.14) para caracterizar a propagação no meio, uma vez que a condutividade é um fator a ser considerado.

Stratton (1941) descreve o número de onda complexo como sendo composto por um termo real denominado constante de atenuação $(\alpha)$ e um termo imaginário denominado constante de propagação $(\beta)$.

$$
\gamma=\sqrt{\omega^{2} \mu_{0} \epsilon-i \omega \mu_{0} \sigma}=\alpha+i \beta
$$

Igualando-se as partes real e imaginária da equação (3.16) pode-se obter as constantes de atenuação e de propagação ( $\alpha$ e $\beta$ respectivamente) dadas por Stratton (1941) como

$$
\begin{aligned}
& \alpha=\omega \sqrt{\mu \epsilon}\left\{\frac{1}{2}\left[\sqrt{1+\left(\frac{\sigma}{\omega \epsilon}\right)^{2}}+1\right]\right\}^{1 / 2}=\omega \sqrt{\mu \varepsilon^{\prime}}\left\{\frac{1}{2}\left[\sqrt{1+\left(\frac{\varepsilon^{\prime \prime}}{\varepsilon^{\prime}}\right)^{2}}+1\right]\right\}^{1 / 2} \\
& \beta=\omega \sqrt{\mu \epsilon}\left\{\frac{1}{2}\left[\sqrt{1+\left(\frac{\sigma}{\omega \epsilon}\right)^{2}}-1\right]\right\}^{1 / 2}=\omega \sqrt{\mu \varepsilon^{\prime}}\left\{\frac{1}{2}\left[\sqrt{1+\left(\frac{\varepsilon^{\prime \prime}}{\varepsilon^{\prime}}\right)^{2}}-1\right]\right\}^{1 / 2}
\end{aligned}
$$

com $\alpha$ dado em $\mathrm{Np} / \mathrm{m}$ e $\beta$ dado em $\mathrm{rad} / \mathrm{m}$. 


\subsubsection{Reflexão e transmissão do sinal em uma interface}

Desenvolvendo-se o rotacional do campo elétrico na equação (3.1) referente à lei de indução de Faraday, e considerando uma onda unidimensional propagando-se ao longo do eixo $z$ positivo em um meio com perdas, obtém-se a relação entre as componentes ortogonais dos campos elétrico e magnético expressa por

$$
\frac{E_{x}}{H_{y}}=\sqrt{\frac{i \omega \mu_{0}}{\sigma+i \omega \epsilon}} \equiv \eta
$$

em que $\eta$ é denominado impedância intrínseca do meio.

A fração de sinal refletida em uma interface e a fração transmitida através desta podem ser quantificadas através dos coeficientes de reflexão $(\Gamma)$ e transmissão $(T)$, respectivamente. Estes parâmetros são definidos por Balanis (1989) para uma incidência normal à interface em função das impedâncias dos meios separados pela mesma como

$$
\begin{gathered}
\Gamma=\frac{\eta_{2}-\eta_{1}}{\eta_{2}+\eta_{1}} \\
T=\frac{2 \eta_{2}}{\eta_{2}+\eta_{1}}
\end{gathered}
$$

No caso de uma onda incidindo obliquamente na interface com um ângulo de incidência $\theta_{i}$ em relação à normal, parte da mesma será refletida de volta ao meio de origem com um ângulo $\theta_{r}$ igual ao ângulo de incidência. A outra parte da onda será transmitida para o meio após a interface com um ângulo $\theta_{t}$ dependente da relação entre as velocidades de propagação em ambos os meios $\left(v_{1}\right.$ e $\left.v_{2}\right)$ e do ângulo de incidência $\left(\theta_{i}\right)$. Tal relação é expressa pela lei de Snell-Descartes (Griffiths, 1999; Daniels, 2004):

$$
\frac{\operatorname{sen} \theta_{i}}{\operatorname{sen} \theta_{t}}=\frac{v_{1}}{v_{2}}=\frac{\sqrt{\varepsilon_{2}}}{\sqrt{\varepsilon_{1}}}
$$

Maiores informações a respeito dos procedimentos matemáticos envolvidos no desenvolvimento das equações apresentadas podem ser encontradas em Ward e Hohmann (1988), Balanis (1989), Chew (1995), Griffiths (1999), Porsani (1999), Daniels (2004), entre outros. 


\subsection{Método GPR}

O método GPR consiste em obter uma imagem de alta resolução da subsuperfície através da emissão e reflexão de ondas eletromagnéticas de alta frequência (da ordem de 10,0 MHz a 2,6 GHz) por uma antena transmissora colocada na superfície, permitindo a localização tanto de objetos enterrados pelo homem quanto de estruturas e feições geológicas rasas. Os sinais são enviados ao solo e, ao encontrarem diferenças de propriedades elétricas nos materiais, uma parte da energia enviada é refletida de volta à superfície. Os sinais refletidos são captados por uma antena receptora e registrados em um radargrama através de um computador portátil. Neste radargrama é representada a amplitude do sinal em função do tempo de reflexão (tempo de ida e volta do sinal). A frequência de operação das antenas varia de um equipamento para outro e de acordo com o objetivo da investigação.

Segundo Daniels (2004), a primeira utilização de ondas eletromagnéticas para localização de objetos em profundidade foi na Alemanha, em 1910, por Gotthelf Leimbach e Heinrich Löwy utilizando antenas verticais em furos de sondagem, técnica conhecida como borehole radar. Ainda segundo este autor, a primeira utilização de técnicas de pulso eletromagnético para localizar estruturas em subsuperfície foi feita em 1926 por Hülsenbeck, quando este percebeu que qualquer variação na constante dielétrica poderia produzir reflexões do sinal eletromagnético, sem necessariamente envolver a condutividade dos materiais.

A aplicação da técnica de sinais pulsados para sondagens no interior da Terra iniciou-se na década de 1950, com a determinação da profundidade do nível freático em desertos egípcios por El Said (1956). Nas décadas de 1960 e 1970 os sinais eletromagnéticos pulsados começaram a ser amplamente utilizados para investigação de ambientes sob camadas de gelo (Evans, 1967; Weber e Andrieux, 1970; Paren e Robin, 1975, Annan e Davis, 1976).

O uso do radar deixou de ser direcionado apenas para o estudo de camadas de gelo quando Holser et al. (1972) mostraram que este método poderia ser aplicado também no estudo de domos salinos em um trabalho experimental utilizando um sistema de $230 \mathrm{MHz}$ para perfilagem de poço. Na década de 1970 a tecnologia do radar também passou a ser direcionada para fins de estudo de geologia de engenharia (Cook, 
1975; Rubin e Fowler, 1978) e na década de 1980 o método começou a ser empregado em estudos de mineração (Coon et al., 1981; Annan et al.; 1988). Estudos acerca da teoria do método (Annan, 1973; Rossiter et al., 1973) foram impulsionados em parte pela pesquisa aero-espacial, a qual estava em andamento na década de 1970, permitindo o desenvolvimento do Sistema de Radar de Sondagem Lunar, enviado à Lua na missão Apollo 17 (Phillips et al., 1973; Porcello et al., 1974).

O uso do GPR em arqueologia teve início ainda na década de 1970 com os estudos de Bevan e Kenyon (1975 apud Jol, 2009), Bevan (1977 apud Jol, 2009) e Kenyon (1977) e tiveram interesse crescente nas décadas de 1980 e 1990 devido aos avanços na metodologia para esta finalidade (Vaughan, 1986; Stove e Addyman, 1989; Goodman et al., 1995). Nestas décadas também surgiram os primeiros estudos empregando o método GPR na localização de corpos humanos (Bevan, 1991; Strongman, 1992), por vezes utilizando carcaças de porcos para simular os alvos humanos (France et al., 1992). Análises referentes ao processo de decomposição do material orgânico seriam feitas apenas na década seguinte (Miller et al., 2002, Powell, 2004).

No Brasil o método GPR tem sido empregado em estudos de engenharia civil (localização de túneis (Porsani et al., 2012), tubulações (Santos et al., 2014), cabeamento, tambores metálicos (Porsani e Sauck, 2007)), estudos estruturais e ambientais (Porsani et al., 2004b; Bertolla et al., 2014), estudos de arqueologia (Rodrigues et al., 2009; Porsani et al., 2010) e, mais recentemente, de arqueologia forense (Nascimento, 2009; Borges et al., 2010, Almeida et al., 2016), dentre outros.

\subsubsection{O sistema GPR}

O sistema GPR pode ser descrito de maneira simplificada como sendo composto por três blocos principais:

i) uma unidade de controle, responsável pela visualização e armazenamento dos dados;

ii) um par de antenas, que podem ser blindadas ou não; 
iii) um hodômetro e/ou um receptor GPS, responsável por obter a informação de posicionamento do conjunto durante a aquisição do perfil.

Estes três blocos são representados no diagrama da Figura 10. A unidade de controle é composta por um computador portátil, o qual permite a visualização e o armazenamento dos dados adquiridos. A unidade de controle também é responsável por enviar a informação referente à emissão do sinal pulsado por parte da antena transmissora (Tx). Este sinal é gerado por um impulso elétrico, que é convertido em energia eletromagnética através de um sinal cuja frequência corresponde à frequência de ressonância da antena. Este pulso se propaga em subsuperfície na forma de uma onda e, após ser refletido devido a um contraste de propriedades eletromagnéticas em subsuperfície, é captado pela antena receptora $(\mathrm{Rx})$. Esta informação é então enviada à unidade de controle onde passará por um conversor analógico/digital e será registrada em um dispositivo de armazenamento.

As antenas dos sistemas GPR comerciais são projetadas de forma a emitir um sinal cujo espectro possui uma largura de banda limitada. A largura de banda total do espectro é aproximadamente igual ao valor numérico da frequência central $\left(f^{*}\right)$ da antena, ou seja, as frequências mínima e máxima do espectro vão de $f^{*} / 2$ a $3 f^{*} / 2$. Assim, uma antena de $200 \mathrm{MHz}$ emitirá um pulso com espectro compreendido entre as frequências de $100 \mathrm{MHz}$ e $300 \mathrm{MHz}$, o que corresponde a uma largura de banda de 200 MHz. A antena receptora por sua vez é dimensionada a registrar sinais em um espectro amplo, idealmente de largura de banda infinita.

\subsubsection{Skin depth}

No capítulo anterior foi discutido como a condutividade elétrica do meio em que a onda eletromagnética se propaga influencia a atenuação do sinal eletromagnético. Em meios com perdas significativas, quando a relação $\sigma / \omega \epsilon \gg 1$, pode-se aproximar o coeficiente de atenuação $\alpha$ descrito pela equação (3.17) conforme (Balanis, 1989)

$$
\alpha \approx \sqrt{\frac{\omega \mu \sigma}{2}}
$$




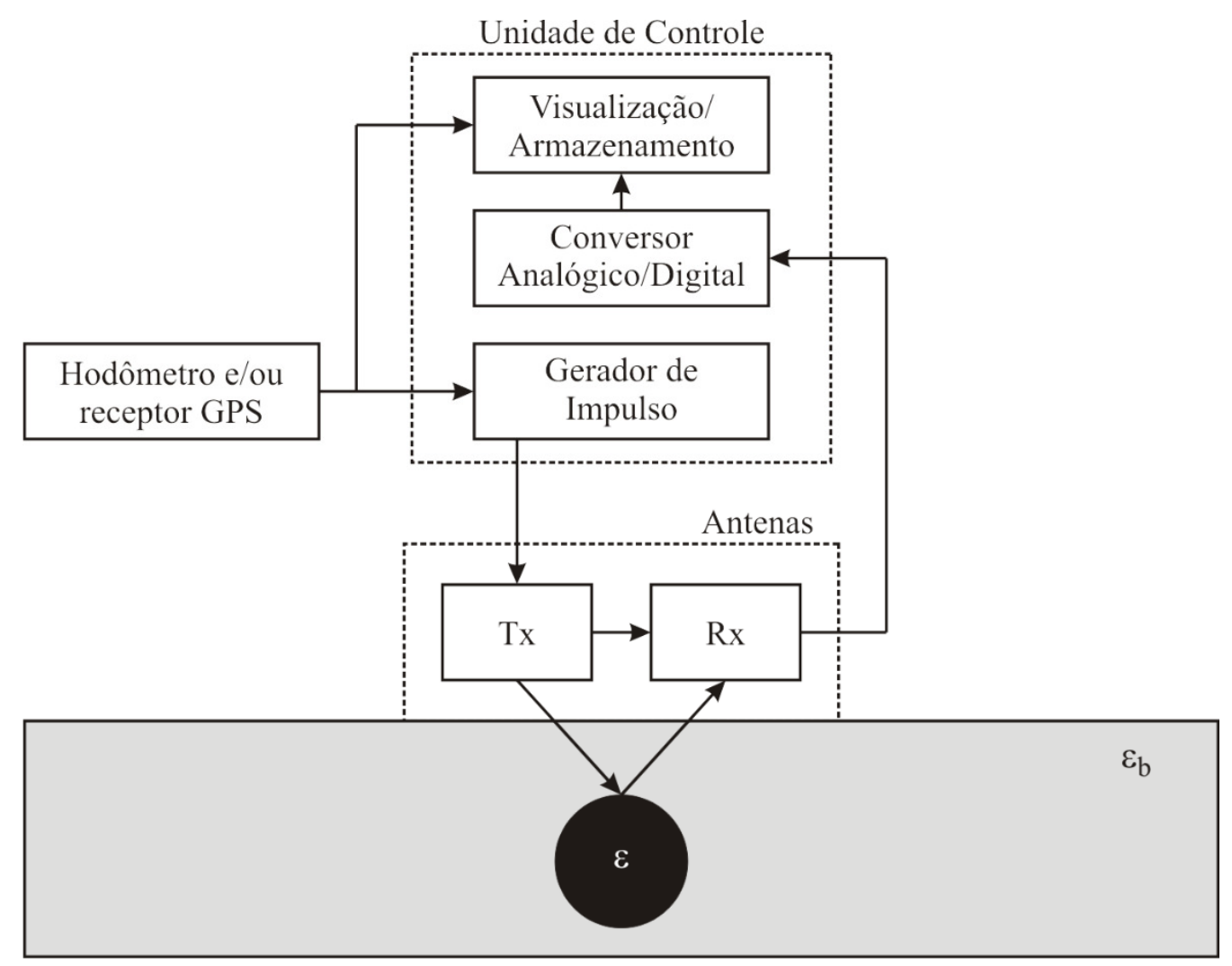

Figura 10. Diagrama em blocos simplificado de um sistema GPR.

O skin depth é um parâmetro definido como sendo o inverso deste coeficiente de atenuação aproximado (Balanis, 1989). O skin depth corresponde à profundidade em que a amplitude do sinal é reduzida por um fator de $1 / e$, ou a $37 \%$ do seu valor na superfície (Telford et al., 1990). Considerando a aproximação $\mu=\mu_{0}$ para a permeabilidade magnética do meio geológico, obtém-se uma equação para o cálculo da máxima profundidade teórica em função da frequência do sinal e da condutividade do meio:

$$
\delta \cong \frac{1}{\alpha}=\sqrt{\frac{2}{\omega \mu \sigma}}=\sqrt{\frac{2}{2 \pi f \mu \sigma}}=503.3 \frac{1}{\sqrt{f \sigma}}
$$

em que $\delta$ é o skin depth (m), $f$ é a frequência do sinal eletromagnético (Hz) e $\sigma$ é a condutividade elétrica $(\mathrm{S} / \mathrm{m})$.

Este parâmetro é utilizado para estimar de forma aproximada a profundidade de penetração do sinal eletromagnético durante uma aquisição ou mesmo durante a fase de planejamento da mesma. Quanto mais condutivo for o material em que a onda se 
propaga, maior será a atenuação do sinal e menor será a profundidade teórica de investigação. Desta forma, materiais muito condutivos como solos argilosos saturados representam situações pouco favoráveis para investigações com o método GPR, enquanto materiais resistivos como solos arenosos secos representam condições ideais para estas investigações.

\subsubsection{Resolução vertical}

Entende-se por resolução vertical a capacidade de separar visualmente duas estruturas ou interfaces dispostas em profundidades diferentes em um registro. A resolução está associada ao espectro do sinal emitido pela antena e depende da frequência central da antena utilizada na aquisição dos dados.

A separação espacial mínima para resolução vertical é dada pelo critério de Rayleigh, que estabelece esta distância mínima deve ser equivalente a 1/4 do comprimento de onda (Daniels, 2004; Jol, 2009). Desta forma pode-se calcular a resolução vertical como

$$
\Delta z \geq \frac{\lambda}{4} \quad \Rightarrow \quad \Delta z \geq \frac{v}{4 f^{*}} \quad \Rightarrow \quad \Delta z \geq \frac{1}{4 f^{*}} \frac{c}{\sqrt{\epsilon_{r}}}
$$

em que $\Delta z$ é a diferença entre a profundidade das interfaces (m), $\lambda$ é o comprimento de onda $(\mathrm{m}), c$ é a velocidade da luz $(\mathrm{m} / \mathrm{s}), \epsilon_{r}$ é a constante dielétrica do meio e $f^{*}$ é a frequência central da antena $(\mathrm{Hz})$.

\subsubsection{Aquisição de dados}

Nesta pesquisa adotou-se a metodologia de aquisição dos dados GPR na forma de perfis de reflexão com afastamento (offset) constante. Esta metodologia é empregada quando se deseja obter informações a respeito de refletores em subsuperfície (nível d'água, contato entre materiais geológicos distintos, etc.) ou de estruturas ou objetos enterrados (tubulação, cabeamento elétrico, etc.). A Figura 11 esquematiza este arranjo. As antenas transmissora e receptora são separadas por uma distância $d$ e se movem 
simultaneamente sobre o local de investigação, sempre mantendo fixa a distância de separação. As antenas podem não estar envoltas por uma blindagem dependendo do equipamento utilizado. A blindagem das antenas consiste em uma caixa metálica retangular que recobre as antenas (Warren e Giannopoulos, 2011) e que tem a finalidade de impedir que sinais eletromagnéticos provenientes de fontes externas ou de reflexões em objetos acima da superfície interfiram no sinal proveniente da reflexão em subsuperfície registrado pela antena receptora.

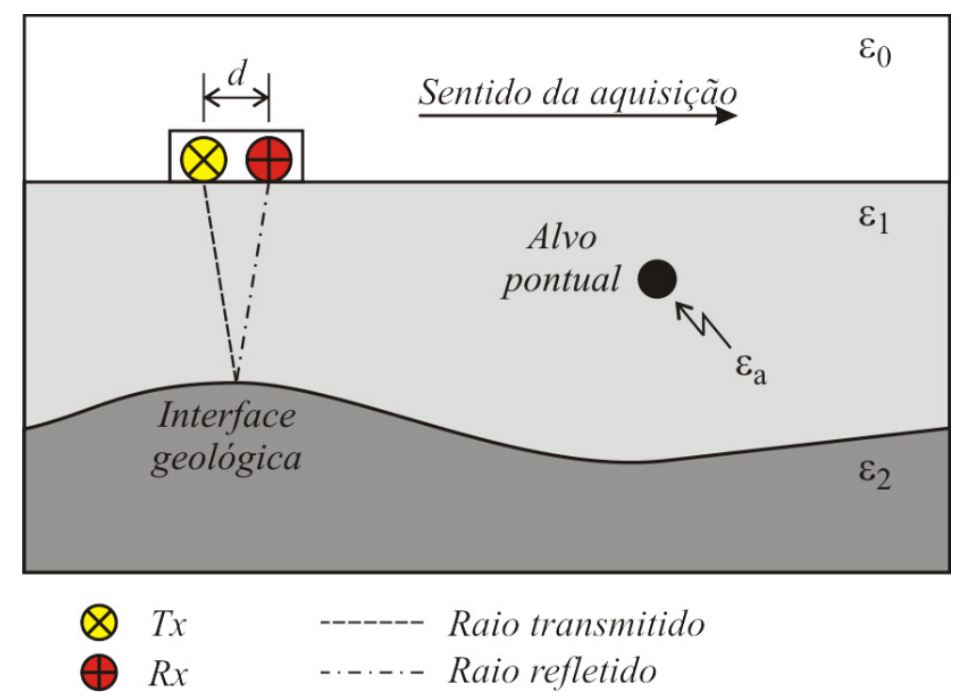

Figura 11. Esquema de uma aquisição de um perfil de reflexão com antenas em offset constante.

Entende-se por alvo pontual a estrutura, heterogeneidade ou artefato presente em subsuperfície cuja seção cruzada possui dimensão comparável à do comprimento de onda do sinal. Nos radargramas adquiridos como perfis de afastamento constante os alvos pontuais aparecem como feições anômalas de formato hiperbólico. Isto acontece porque o sinal do GPR não é emitido totalmente na direção vertical abaixo da antena, mas sim numa região denominada zona de Fresnell e que é definida uma área em subsuperfície que corresponde a uma região em torno da região da antena. Esta área é definida por Annan (2003) em função da profundidade (z), do comprimento de onda do sinal $(\lambda)$ e do número de onda real $(k)$ conforme mostrado na Figura 12. 


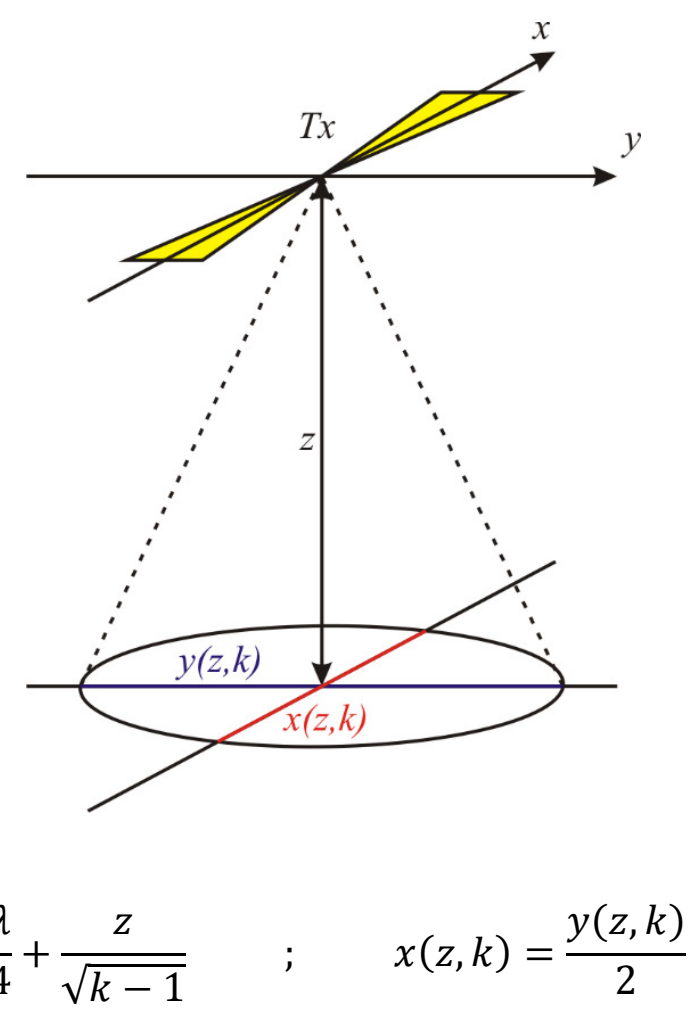

Figura 12. Área abaixo da antena transmissora efetivamente abrangida pelo sinal emitido, chamada de Zona de Fresnell. Esta área tem o formato aproximado de uma elipse cujo eixo maior é dado pela função $y(z, k)$ e o eixo menor é dado pela função $x(z, k)$, em que $z$ é a profundidade e $k$ é o número de onda real do meio (adaptado de Annan, 2003).

Deste modo, a antena pode registrar uma reflexão do sinal mesmo antes de estar posicionada diretamente sobre o alvo, e também depois de ter passado sobre este, acarretando em uma anomalia de formato hiperbólico conforme exemplificado na Figura 13. Nesta figura é apresentado um radargrama com 251 traços, dos quais 11 foram isolados para representação individual no domínio do tempo (em azul) e cujas posições em relação ao alvo também estão indicadas.

\subsubsection{Processamento dos dados}

O processamento de dados GPR consiste em aplicar diferentes ferramentas matemáticas de forma a melhorar a qualidade visual dos mesmos, tornando sua interpretação mais fácil e menos ambígua da melhor forma possível. Existe um grande número de ferramentas desenvolvidas para esta finalidade (Yilmaz, 2001; Kearey et al., 

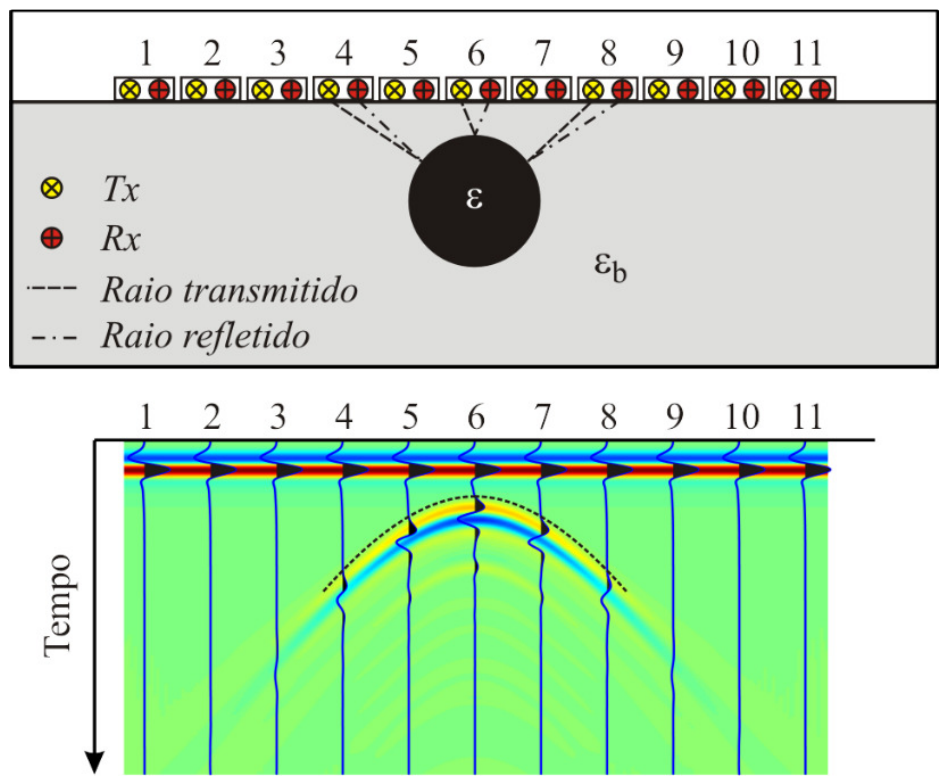

Figura 13. Diagrama esquematizando uma anomalia hiperbólica provocada no radargrama pela presença de um alvo pontual em subsuperfície. $\mathrm{O}$ pulso observado no início de cada traço corresponde ao acoplamento entre as antenas e o solo.

2009; Rosa, 2010), de modo que serão abordadas apenas as ferramentas mais comuns e aquelas que foram necessárias para a análise dos dados apresentados nos capítulos subsequentes.

Todos os dados adquiridos na presente pesquisa foram processados utilizando o software ReflexWin v7.2.4 (Sandmeier, 2012). Este software é bastante difundido entre os pesquisadores do método GPR, possuindo diversas ferramentas já implementadas. Entretanto, para algumas etapas desenvolvidas nesta pesquisa foi necessário o uso de ferramentas além daquelas disponíveis no software. Para estas situações foram desenvolvidas rotinas próprias utilizando a linguagem de programação Matlab®. As ferramentas utilizadas no processamento dos dados adquiridos nesta pesquisa são descritas a seguir.

\section{Remoção do ganho de cabeçalho}

É comum, durante a aquisição dos dados, que o operador do sistema aplique aos dados uma função de ganho que lhe proporcione a melhor visualização dos dados em tempo real. Entretanto, é incorreto proceder à análise e interpretação dos dados desta forma, pois as amplitudes observadas não correspondem às amplitudes reais das 
anomalias. A remoção do ganho do cabeçalho é então a primeira etapa a ser executada após o download dos dados armazenados na unidade de controle.

\section{Filtragem dewow}

Algumas vezes é possível que o dado adquirido venha a estar contaminado com uma componente espectral de baixa frequência, ou mesmo com uma componente contínua (i. e., de frequência igual a zero) causada pela presença de um campo externo próximo ao equipamento de aquisição. O deslocamento causado por esta última é também chamado de deslocamento DC. A filtragem dewow é uma ferramenta que permite remover estas componentes de frequência muito baixa.

Um efeito secundário desta ferramenta é que, ao minimizar as componentes de frequências mais baixas do espectro, é possível compensar o efeito de filtro passa-baixa causado pelos materiais geológicos. Desta forma, o espectro de um sinal que apresenta uma frequência central menor do que a esperada de acordo com a frequência central da antena pode ser compensado de forma a apresentar uma frequência central mais alta, aproximando-se da frequência central original.

\section{Correção do tempo zero}

A correção do tempo zero permite ajustar o início do registro do dado GPR de forma que ele corresponda ao instante de tempo zero. Durante a aquisição é possível que o sistema inicie o registro do dado uma fração de segundo após de o sinal pulsado ser emitido. Mesmo que este atraso seja pequeno, ele pode representar uma fonte de erro adicional na estimativa das profundidades das anomalias observadas, pois as primeiras amostras dos traços do radargrama podem não ser registradas. Para evitar esta situação é prática comum ajustar o sistema de aquisição para iniciar o registro com algum tempo de atraso. Em geral este atraso é de 5,0 a 10,0 ns, porém pode ser maior ou menor a critério de quem opera o equipamento. Isto faz com que o registro seja iniciado antes da emissão do sinal, garantindo que todas as amostras sejam devidamente registradas. Este tempo de atraso deve ser removido durante o processamento, através da ferramenta de correção de tempo zero. 


\section{Ganho temporal}

A ferramenta de ganho temporal visa proporcionar um aumento na amplitude do sinal de forma a compensar a atenuação sofrida por este durante a propagação em um meio com perdas. Isto permite que feições mais profundas possam ser evidenciadas, facilitando sua visualização e posterior interpretação. O ganho temporal é aplicado a cada traço do radargrama no domínio do tempo, daí sua denominação. Os dados apresentados nos capítulos subsequentes foram tratados com uma função de ganho exponencial (Sandmeier, 2012).

\section{Filtragem em frequência}

A filtragem em frequência é empregada para remover componentes de frequências indesejadas do espectro do radargrama. A filtragem em frequência é aplicada a cada traço do dado. Os filtros podem ser representados por funções no domínio da frequência cujo valor associado a uma determinada componente pode variar no intervalo $[0,1]$, que são então multiplicados pelo espectro do dado de forma a alterar a amplitude das componentes de frequências indesejadas. Os filtros podem ser classificados em: i) passa-baixa, que atenua as componentes acima de uma frequência de corte $f_{c 1}$; ii) passa-alta, que atenua as componentes abaixo de uma frequência de corte $f_{c 1}$; iii) passa banda, que atenua as componentes abaixo de uma frequência de corte $f_{c 1}$ e acima de uma frequência de corte $f_{c 2}$; iv) rejeita-banda, que atenua as componentes entre as frequências de corte $f_{c 1}$ e $f_{c 2}$.

\section{Remoção de background}

A remoção de background tem como objetivo reduzir ou mesmo eliminar efeitos causados por heterogeneidades presentes no meio geológico que não sejam de interesse para a investigação. Esta ferramenta também é empregada para remover efeitos de reverberação do sinal eletromagnético causados pelo acoplamento entre a antena e o solo, tanto em profundidade quanto na porção inicial do radargrama onde se observa sempre uma forte reflexão referente ao próprio acoplamento. $\mathrm{Na}$ literatura estes efeitos indesejados são chamados de clutter, algo como "confusão" ou "bagunça" numa 
tradução para a língua portuguesa. $\mathrm{Na}$ ausência de um termo mais apropriado, o presente texto irá referir-se ao clutter como ruído geológico.

As ferramentas mais comuns para remoção do background são o corte no tempo (time-gating) e a subtração do traço médio (mean trace removal), ambos presentes na maioria dos softwares de processamento de dados.

O corte no tempo é uma ferramenta simples que consiste em estabelecer um instante de tempo $t_{g}$ na escala temporal do radargrama e substituir todas as amostras dos sinais anteriores a este instante por amostras de amplitude igual a zero. $\mathrm{O}$ uso mais comum desta ferramenta é para eliminar do sinal de acoplamento entre a antena e o solo no início do radargrama, bem como para eliminar feições rasas que não sejam de interesse para os objetivos do levantamento. Matematicamente esta ferramenta pode ser descrita como

$$
Y(t)=0 \quad \text { para } \quad 0 \leq t \leq t_{g}
$$

em que $Y(t)$ representa o radargrama em função do tempo $t$.

A subtração do traço médio consiste em calcular uma média aritmética entre todos os traços que compõem o radargrama sob análise e, em seguida, subtrair este traço médio de cada um dos traços do radargrama. O objetivo desta ferramenta é eliminar feições horizontais presentes em qualquer profundidade no registro, sem afetar significativamente as feições hiperbólicas. O resultado deste processo é tão melhor quanto maior for o número de traços presentes no radargrama, visto que as feições horizontais irão prevalecer no traço médio em relação a quaisquer outras feições presentes no registro. Esta ferramenta pode ser representada matematicamente como

$$
y_{n}^{*}(t)=y_{n}(t)-\frac{\sum_{m=1}^{n T} y_{m}(t)}{n T} \quad ; \quad n=1,2, \ldots, n T
$$

onde $y_{n}^{*}(t)$ é o $n$-ésimo traço do radargrama após a remoção de background, $y_{n}(t)$ é o $n$-ésimo traço do radargrama antes da remoção de background e $n T$ é o número de traços do radargrama.

Uma terceira ferramenta foi empregada na análise de dados desta pesquisa. Esta ferramenta foi desenvolvida por Khan e Al-Nuaimy (2010). Esta ferramenta consiste em remover feições associadas a ruídos no radargrama através da decomposição em valores 
singulares do mesmo, explorando a relação entre características dos dados e os valores singulares provenientes da sua decomposição descrito por Cagnoli e Ulrych (2001). Para tal, o procedimento é descrito segundo Khan e Al-Nuaimy (2010) conforme segue. É feita uma busca pelas posições em que se encontram os autovalores máximo e mínimo $\left(n_{\max }\right.$ e $n_{\min }$ respectivamente) dentro da matriz diagonal $M$ dada por $M=$ $L^{T} Y L$, onde $Y$ é a matriz equivalente ao radargrama dado por $Y(t)$ e $L$ é a matriz de autovetores da matriz de covariância dada por $Y Y^{T}$. Calcula-se então as matrizes $P^{\prime}$ e $P^{\prime \prime}$ segundo as equações (3.29) e (3.30):

$$
\begin{aligned}
& P^{\prime}=\sigma_{n_{\text {max }}}^{*} \cdot \operatorname{Aim}_{n_{\text {max }}}^{\prime} \cdot \operatorname{Aim}_{n_{\text {max }}}^{\prime \prime}{ }^{T} \\
& P^{\prime \prime}=\sigma_{n_{\text {min }}}^{*} \cdot \operatorname{Aim}_{n_{\text {min }}}^{\prime} \cdot \operatorname{Aim}_{n_{\text {min }}}^{\prime \prime} T
\end{aligned}
$$

em que $\sigma^{*}$ é o vetor de valores singulares decorrente da decomposição da matriz $Y$, $A i m^{\prime}$ é a autoimagem de $Y^{T} Y, A i m^{\prime \prime}$ é a autoimagem de $Y Y^{T}$ e os índices $n_{\text {max }}$ e $n_{\text {min }}$ referem-se aos índices das colunas destas matrizes. Fazendo a normalização das matrizes $Y, P^{\prime}, P^{\prime \prime}$ obtém-se as matrizes $Y_{N}, P_{N}^{\prime}, P_{N}^{\prime \prime}$, respectivamente. A partir destas matrizes calcula-se então as matrizes $X^{\prime}$ e $X^{\prime \prime}$ como:

$$
\begin{gathered}
X^{\prime}=Y_{N}-P_{N}^{\prime} \\
X^{\prime \prime}=Y_{N}-P_{N}^{\prime \prime}
\end{gathered}
$$

Por fim, a partir das normalizações destas matrizes $\left(X_{N}^{\prime}\right.$ e $\left.X_{N}^{\prime \prime}\right)$ é possível calcular o radargrama com a remoção de background como

$$
\begin{gathered}
Y_{i, j}^{*}=X_{N_{i, j}}^{\prime} * X_{N_{i, j}}^{\prime \prime} \\
i=1,2, \ldots, n A \quad ; \quad j=1,2, \ldots, n T
\end{gathered}
$$

Como esta ferramenta não faz parte do conjunto disponível no software ReflexWin foi necessário fazer a sua implementação utilizando a linguagem Matlab. 


\section{Correção topográfica}

A correção topográfica visa deslocar o traço no domínio do tempo positiva ou negativamente, de acordo com a topografia do local onde os dados foram adquiridos. $\mathrm{O}$ levantamento topográfico pode ser feito separadamente, através de ferramentas apropriadas, ou em conjunto com a aquisição dos dados, através da coleta de informações do receptor GPS conectado à unidade de controle caso este apresente um erro aceitável na medição da variação topográfica. Esta etapa foi necessária apenas para o processamento dos dados adquiridos no experimento com o alvo orgânico, e foi executada diretamente no programa de imageamento tomográfico.

\section{Conversão tempo-profundidade}

As feições observadas no radargrama podem ser atribuídas a artefatos ou interfaces presentes em subsuperfície após se realizar a conversão da escala de tempo observada nos dados para a escala de profundidade. Esta conversão é feita simplesmente atribuindo uma velocidade constante a todo o radargrama e calculando-se as profundidades das feições através do tempo duplo de reflexão do sinal. Existem diferentes maneiras de se estimar a velocidade das ondas eletromagnéticas no meio (Porsani, 1999; Daniels, 2004; Kearey et al., 2009, Sandmeier, 2012):

i) Através de levantamentos CMP (common midpoint, ou ponto médio comum): este tipo de aquisição de dados, também chamado de sondagem de velocidade, consiste em estabelecer um ponto fixo em superfície e posicionar a antena transmissora e a antena receptora de modo que o ponto fixo seja localizado à meia distância entre as duas. Adquire-se então o primeiro traço do levantamento. Posteriormente cada antena é posicionada de maneira que a distância entre ambas seja incrementada sucessivamente em intervalos regulares, onde um novo traço é adquirido em cada nova localização do par de antenas;

ii) Ajuste de hipérboles: este método é bastante empregado em dados adquiridos na forma de perfis de reflexão de afastamento constante. Um valor de velocidade é fornecido ao programa, e a partir deste valor o mesmo gera uma hipérbole teórica. Quando o valor fornecido ao programa produz uma hipérbole teórica que se ajusta 
da melhor forma possível às feições hiperbólicas observadas no radargrama, este valor é adotado como a velocidade de propagação das ondas no meio geológico;

iii) Através de um objeto conhecido: é possível determinar a velocidade das ondas no meio com o auxílio de um objeto que conhecidamente irá produzir uma reflexão evidente no radargrama (um cano metálico, por exemplo). Este objeto é enterrado a uma profundidade conhecida e um perfil GPR é adquirido sobre o mesmo. A partir do tempo duplo de reflexão do sinal é possível então determinar a velocidade de propagação do sinal;

iv) Através de migração: A migração dos dados consiste em um tratamento matemático cujo objetivo é alterar a posição dos eventos observados nos traços de forma que estes reproduzam com maior a fidelidade possível a sua disposição real em subsuperfície através de um modelo de velocidades. A velocidade de propagação das ondas eletromagnéticas no meio pode ser determinada através da migração quando há a presença de anomalias hiperbólicas no radargrama. Neste procedimento diferentes valores de velocidade são testados e para cada um deles é executada a migração. $\mathrm{O}$ valor correto é considerado como sendo aquele em que as feições hiperbólicas são convertidas em feições pontuais cujas dimensões podem se aproximar das dimensões da secção do objeto ou estrutura que provocou a anomalia. Nesta pesquisa foi utilizada a migração Kirchhoff, já implementada no software ReflexWin.

A análise de velocidades foi feita em duas etapas nesta pesquisa. Primeiramente foi estimado um valor através do ajuste de hipérboles. Em seguida o valor de velocidade obtido foi empregado como valor inicial no processo de migração dos dados. A velocidade foi considerada constante em cada radargrama, de maneira que o valor adotado para velocidade de propagação das ondas no meio foi aquele em que todas as feições hiperbólicas foram convertidas da melhor maneira possível em feições pontuais. Uma descrição mais detalhada acerca desta etapa será apresentada no Capítulo 04. 


\subsection{Tomografia de micro-ondas}

A tomografia de micro-ondas é uma técnica de imageamento de subsuperfície que visa obter de forma aproximada a geometria dos alvos causadores das anomalias hiperbólicas observadas em um radargrama. Um alvo qualquer pode ser representado por um volume $V_{0}$ de propriedades $\epsilon, \sigma$ e $\mu$, as quais são funções da distância $\boldsymbol{r}(x, y, z)$ conforme a Figura 14, imerso em um meio homogêneo (background geológico) de propriedades $\epsilon_{b}, \sigma_{b}$ e $\mu_{b}$.

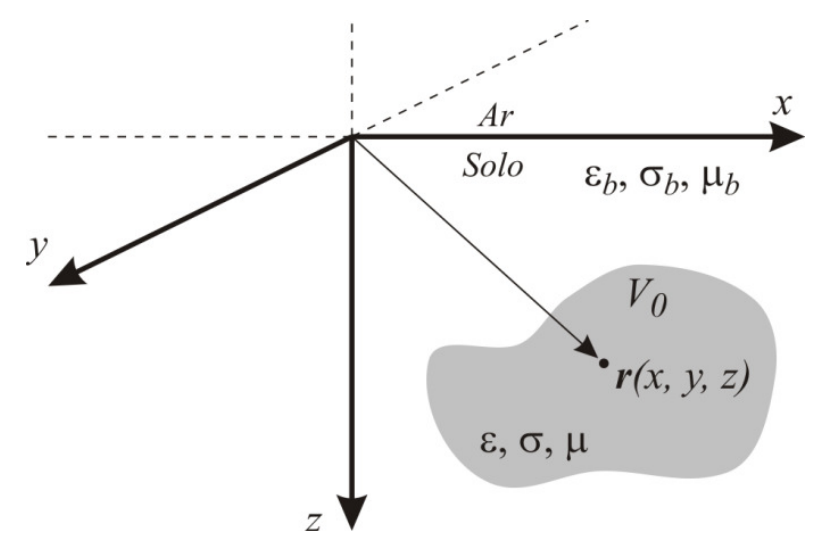

Figura 14. Geometria para um corpo tridimensional imerso em um meio homogêneo de propriedades eletromagnéticas $\epsilon_{b}, \sigma_{b}$ e $\mu_{b}$.

Um campo eletromagnético propagando-se neste meio irá interagir com o alvo desde que haja contraste de propriedades eletromagnéticas suficiente para tal. O campo eletromagnético total, que é aquele captado pela antena receptora e registrado pelo sistema GPR, é composto pela soma de outros dois campos: o campo incidente, que é emitido pela antena transmissora e que se propaga pelo meio na ausência de heterogeneidades, e o campo espalhado, que é refletido de volta à superfície na presença de heterogeneidades. Desta forma:

$$
\begin{gathered}
\boldsymbol{E}(\boldsymbol{r})=\boldsymbol{E}_{i n c}(\boldsymbol{r})+\boldsymbol{E}_{e s p}(\boldsymbol{r}) \\
\boldsymbol{H}(\boldsymbol{r})=\boldsymbol{H}_{i n c}(\boldsymbol{r})+\boldsymbol{H}_{e s p}(\boldsymbol{r})
\end{gathered}
$$

em que os subscritos inc e esp indicam respectivamente os campos incidente e espalhado. 
A interação entre os campos é exemplificada para o caso do campo elétrico no diagrama da Figura 15. O campo incidente $\boldsymbol{E}_{\text {inc }}$ (em vermelho) irradiado pela antena transmissora $(T x)$ interage com as propriedades eletromagnéticas do alvo gerando o campo espalhado $\boldsymbol{E}_{\text {esp }}$ (em azul). O campo espalhado só existe na presença de um corpo anômalo que apresente contraste de propriedades eletromagnéticas em relação ao meio geológico. $\mathrm{Na}$ ausência deste corpo o campo total equivale ao campo incidente. Simultaneamente, o sinal é irradiado em direção à antena receptora $(R x)$ onde, juntamente com o campo espalhado $\boldsymbol{E}_{\text {esp }}$ irá compor o campo total $\boldsymbol{E}$ registrado pelo sistema GPR.

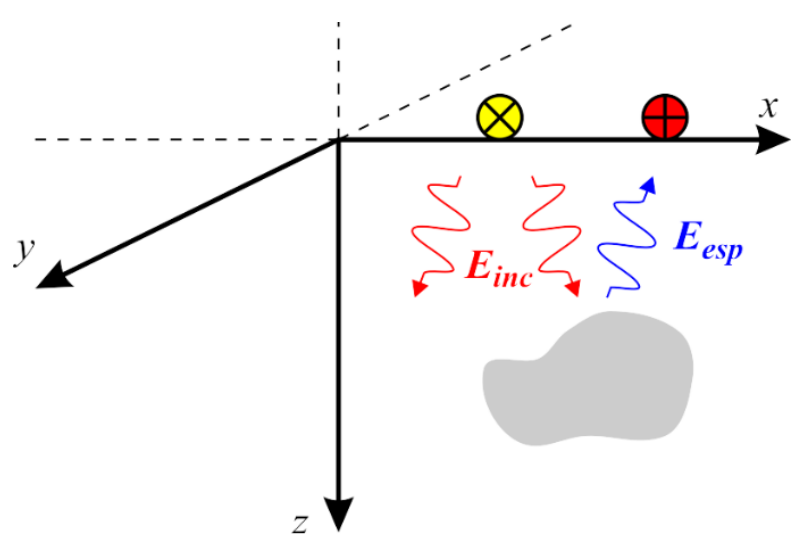

Figura 15. Interação entre o campo elétrico incidente $\left(\boldsymbol{E}_{\text {inc }}\right)$, o campo elétrico espalhado $\left(\boldsymbol{E}_{\text {esp }}\right)$ e o alvo (em cinza).

Quando o campo eletromagnético incidente, a geometria do alvo e a distribuição das propriedades eletromagnéticas do mesmo são conhecidos pode-se calcular o campo espalhado e, a partir deste, calcular o campo eletromagnético total. Isto caracteriza o problema direto. O problema inverso consiste na estimativa de informações acerca do alvo a partir do campo eletromagnético espalhado, assumindo-se que o campo eletromagnético incidente seja conhecido na solução do problema direto.

$\mathrm{Na}$ formulação do problema o alvo é tratado como uma descontinuidade no meio homogêneo, de maneira que faz-se interessante o uso das equações de Maxwell na sua forma integral dadas por 


$$
\begin{gathered}
\oint_{C} \boldsymbol{E}(\boldsymbol{r}) \cdot d \boldsymbol{l}=-i \omega \mu \int_{S} \boldsymbol{H}(\boldsymbol{r}) \cdot \widehat{\boldsymbol{n}} d s \\
\oint_{C} \boldsymbol{H}(\boldsymbol{r}) \cdot d \boldsymbol{l}=i \omega \varepsilon \int_{S} \boldsymbol{E}(\boldsymbol{r}) \cdot \widehat{\boldsymbol{n}} d s+\int_{S} \boldsymbol{J}(\boldsymbol{r}) \cdot \widehat{\boldsymbol{n}} d s
\end{gathered}
$$

\subsubsection{Princípio da equivalência de volume}

O princípio de equivalência de volume estabelece que o espalhamento do campo eletromagnético após sua incidência em um alvo real equivale ao campo eletromagnético gerado por uma fonte de corrente equivalente localizada nas coordenadas do alvo (Pastorino, 2010). A partir do conjunto de equações integrais referentes ao campo elétrico dadas por

$$
\begin{gathered}
\oint_{C} \boldsymbol{E}(\boldsymbol{r}) \cdot d \boldsymbol{l}=-i \omega \mu \int_{S} \boldsymbol{H}(\boldsymbol{r}) \cdot \widehat{\boldsymbol{n}} d s \\
\oint_{C} \boldsymbol{E}_{i n c}(\boldsymbol{r}) \cdot d \boldsymbol{l}=-i \omega \mu_{b} \int_{S} \boldsymbol{H}_{i n c}(\boldsymbol{r}) \cdot \widehat{\boldsymbol{n}} d s
\end{gathered}
$$

e subtraindo-se o campo incidente do campo total perturbado dado pela equação (3.34) tem-se que

$$
\oint_{C}\left[\boldsymbol{E}(\boldsymbol{r})-\boldsymbol{E}_{i n c}(\boldsymbol{r})\right] \cdot d \boldsymbol{l}=-i \omega \int_{S}\left[\mu(\boldsymbol{r}) \boldsymbol{H}(\boldsymbol{r})-\mu_{b}(\boldsymbol{r}) \boldsymbol{H}_{i n c}(\boldsymbol{r})\right] \cdot \widehat{\boldsymbol{n}} d s
$$

e, após algum desenvolvimento algébrico, chega-se a:

$$
\begin{gathered}
\oint_{C} \boldsymbol{E}_{e s p}(\boldsymbol{r}) \cdot d \boldsymbol{l}=-i \omega \int_{S}\left[\mu(\boldsymbol{r})-\mu_{b}(\boldsymbol{r})\right] \boldsymbol{H}(\boldsymbol{r}) \cdot \widehat{\boldsymbol{n}} d s- \\
-i \omega \int_{S} \mu_{b}(\boldsymbol{r}) \boldsymbol{H}_{e s p}(\boldsymbol{r}) \cdot \widehat{\boldsymbol{n}} d s
\end{gathered}
$$


A fonte de corrente equivalente, associada ao alvo, pode então ser inserida na equação através do termo $i \omega\left[\mu(\boldsymbol{r})-\mu_{b}(\boldsymbol{r})\right] \boldsymbol{H}(\boldsymbol{r})$, de forma que obtém-se

$$
\oint_{C} \boldsymbol{E}_{e s p}(\boldsymbol{r}) \cdot d \boldsymbol{l}=-\int_{S} \boldsymbol{M}_{e q}(\boldsymbol{r}) \cdot \widehat{\boldsymbol{n}} d s-i \omega \int_{S} \mu_{b}(\boldsymbol{r}) \boldsymbol{H}_{e s p}(\boldsymbol{r}) \cdot \widehat{\boldsymbol{n}} d s
$$

em que $\boldsymbol{M}_{e q}$ é a densidade de corrente magnética equivalente $\left(\boldsymbol{M}_{e q}(\boldsymbol{r})=0, \boldsymbol{r} \notin V_{0}\right)$. Através do mesmo raciocínio tem-se, para o campo magnético:

$$
\oint_{C} \boldsymbol{H}_{e s p}(\boldsymbol{r}) \cdot d \boldsymbol{l}=\int_{S} \boldsymbol{J}_{e q}(\boldsymbol{r}) \cdot \widehat{\boldsymbol{n}} d s+i \omega \int_{S} \varepsilon_{b}(\boldsymbol{r}) \boldsymbol{E}_{e s p}(\boldsymbol{r}) \cdot \widehat{\boldsymbol{n}} d s
$$

em que $\boldsymbol{J}_{e q}$ é a densidade de corrente elétrica equivalente $\left(\boldsymbol{J}_{e q}(\boldsymbol{r})=0\right.$ para $\left.\boldsymbol{r} \notin V_{0}\right)$ dada por $\boldsymbol{J}_{e q}(\boldsymbol{r})=i \omega\left[\varepsilon(\boldsymbol{r})-\varepsilon_{b}(\boldsymbol{r})\right] \boldsymbol{E}(\boldsymbol{r})$.

Utilizando-se as equações (3.42) e (3.43) e resolvendo-se para o campo elétrico, obtém-se a equação que descreve continuamente o campo espalhado gerado pela fonte equivalente ao alvo de volume $V_{0}$, dado por (Pastorino, 2010):

$$
\boldsymbol{E}_{e s p}(\boldsymbol{r})=i \omega \mu_{b} \int_{V_{0}} \boldsymbol{J}_{e q}\left(\boldsymbol{r}^{\prime}\right) \boldsymbol{G}\left(\boldsymbol{r} / \boldsymbol{r}^{\prime}\right) d \boldsymbol{r}^{\prime}+\int_{V_{0}} \nabla \times \boldsymbol{M}_{e q}\left(\boldsymbol{r}^{\prime}\right) \boldsymbol{G}\left(\boldsymbol{r} / \boldsymbol{r}^{\prime}\right) d \boldsymbol{r}^{\prime}
$$

em que $\boldsymbol{G}\left(\boldsymbol{r} / \boldsymbol{r}^{\prime}\right)$ é a função de Green que representa o campo eletromagnético irradiado em um ponto $\boldsymbol{r}$ por uma fonte localizada em um ponto $\boldsymbol{r}^{\prime}$. Para o caso 2D esta função é dada por (Tai, 1994):

$$
\boldsymbol{G}\left(\boldsymbol{r} / \boldsymbol{r}^{\prime}\right)=-\frac{i}{4} H_{0}^{(2)}\left(\gamma_{b}\left|\boldsymbol{r}-\boldsymbol{r}^{\prime}\right|\right)
$$

em que $H_{0}^{(2)}$ é a função de Hankel de grau 2 e ordem zero e $\gamma_{b}$ é o número de onda complexo do meio.

Finalmente, para materiais não-magnéticos, a densidade de corrente magnética é igual a zero $\left(\boldsymbol{M}_{e q}=0\right)$. Desta forma, simplificando-se a equação (3.44) e substituindose o termo referente à densidade de corrente elétrica equivalente chega-se a: 


$$
\boldsymbol{E}_{e s p}(\boldsymbol{r})=\gamma_{b}^{2} \int_{V_{0}}\left[\frac{\varepsilon(\boldsymbol{r})}{\varepsilon_{b}}-1\right] \boldsymbol{E}(\boldsymbol{r}) \boldsymbol{G}\left(\boldsymbol{r} / \boldsymbol{r}^{\prime}\right) d \boldsymbol{r}^{\prime}
$$

em que o termo entre colchetes é denominado função contraste $\chi(\boldsymbol{r})$, a qual é uma função que descreve o contraste entre a permissividade do alvo e a do meio.

O campo elétrico espalhado e o campo elétrico total perturbado podem então ser escritos utilizando-se as equações (3.34) e (3.46) como (Turk et al., 2011):

$$
\begin{gathered}
\boldsymbol{E}_{e s p}(\boldsymbol{r})=\gamma_{b}^{2} \int_{V_{0}} \chi(\boldsymbol{r}) \boldsymbol{E}(\boldsymbol{r}) \boldsymbol{G}\left(\boldsymbol{r} / \boldsymbol{r}^{\prime}\right) d \boldsymbol{r}^{\prime} \\
\boldsymbol{E}(\boldsymbol{r})=\boldsymbol{E}_{\text {inc }}+\gamma_{b}^{2} \int_{V_{0}} \chi(\boldsymbol{r}) \boldsymbol{E}(\boldsymbol{r}) \boldsymbol{G}\left(\boldsymbol{r} / \boldsymbol{r}^{\prime}\right) d \boldsymbol{r}^{\prime}
\end{gathered}
$$

configurando assim o problema direto da tomografia de micro-ondas.

\subsubsection{Formulação do problema inverso}

A abordagem adotada nesta pesquisa considera o problema inverso como um problema 2D, uma vez que visa a análise dos radargramas individualmente. Um diagrama com a geometria para um problema 2D é mostrada na Figura 16. A linha ao longo da qual os dados GPR são adquiridos e que coincide com a interface ar-solo (cujas posições são indicadas pelos triângulos vermelhos) corresponde ao domínio sob observação, definido por $D_{o}=\left[x_{\min }, x_{\max }\right] \times\left[z_{\min }, z_{\max }\right]$. O alvo está localizado dentro do domínio $D_{i}=\left[x_{\text {min }}^{\prime}, x_{\text {max }}^{\prime}\right] \times\left[z_{\text {min }}^{\prime}, z_{\text {max }}^{\prime}\right]$, denominado domínio sob investigação. O domínio sob investigação pode corresponder a todo o radargrama ou apenas a uma parte dele. O tamanho da região compreendida pelo domínio sob investigação influencia diretamente no custo computacional da tomografia, conforme será abordado nos capítulos subsequentes. As coordenadas dos pontos pertencentes ao domínio sob observação são indicadas por $r(x, z)$, e correspondem às posições onde os traços foram adquiridos no perfil. As coordenadas dos pontos pertencentes ao domínio sob investigação são indicados por $r^{\prime}\left(x^{\prime}, z^{\prime}\right)$ e correspondem à discretização da imagem resultante da tomografia, onde cada coordenada é associada a um pixel da imagem. 
O problema inverso da tomografia de micro-ondas empregado nesta pesquisa visa estimar a geometria aproximada dos alvos existentes dentro do domínio sob investigação, estimando-se a função contraste neste domínio a partir da informação do campo elétrico espalhado. A partir de uma variação da equação (3.47) pode-se formular o problema inverso como

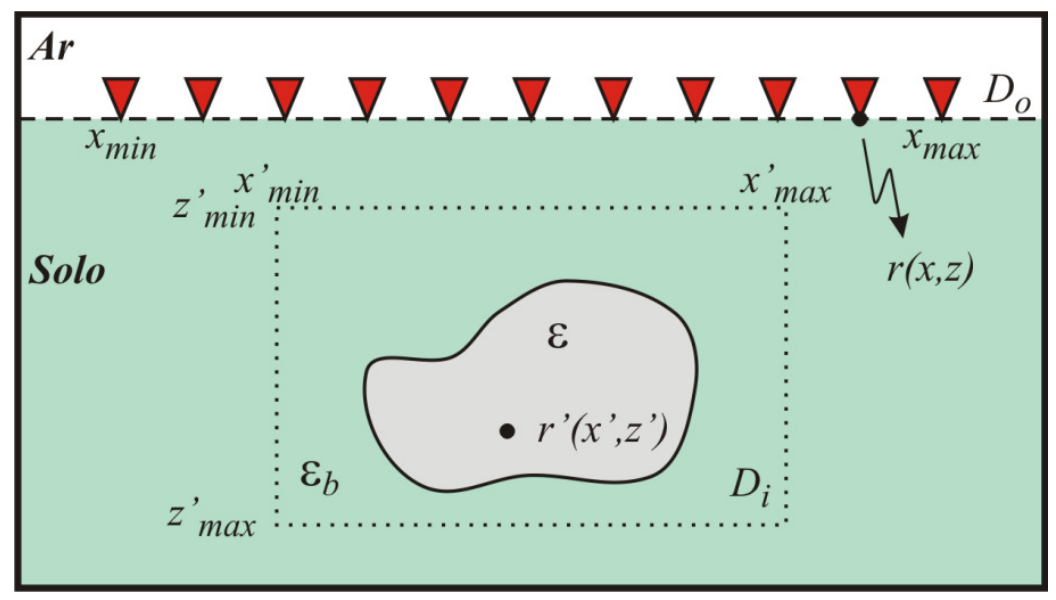

Figura 16. Geometria do problema inverso 2D da tomografia para a aquisição de dados em perfis de afastamento constante. Cada triângulo vermelho representa uma posição diferente do conjunto transmissor-receptor. O espaço $D_{i}$ (linha pontilhada) representa o domínio sob investigação e o espaço $D_{o}$ (linha tracejada) representa o domínio sob observação.

$$
\boldsymbol{E}_{e s p}(\boldsymbol{r})=\gamma_{b}^{2} \int_{D_{i}} \chi\left(\boldsymbol{r}^{\prime}\right) \boldsymbol{E}\left(\boldsymbol{r}^{\prime}\right) \boldsymbol{G}\left(\boldsymbol{r} / \boldsymbol{r}^{\prime}\right) d \boldsymbol{r}^{\prime}, \quad \boldsymbol{r} \in D_{o}
$$

Para a geometria apresentada na Figura 16 a função contraste é dada por

$$
\chi\left(\boldsymbol{r}^{\prime}\right)=\frac{\varepsilon\left(\boldsymbol{r}^{\prime}\right)-\varepsilon_{b}}{\varepsilon_{b}}=\frac{\left[\varepsilon^{\prime}\left(\boldsymbol{r}^{\prime}\right)-i \sigma\left(\boldsymbol{r}^{\prime}\right) / \omega\right]-\left[\varepsilon_{b}^{\prime}-i \sigma_{b} / \omega\right]}{\varepsilon_{b}^{\prime}-i \sigma_{b} / \omega}
$$

\subsubsection{Linearização e regularização}

O problema da tomografia é caracterizado como um problema não linear devido às interações mútuas entre diferentes alvos em subsuperfície ou entre diferentes partes 
do mesmo alvo (Turk et al., 2011). A linearização do problema permite contornar esta situação.

Uma forma simples de se fazer esta linearização é através da aproximação Born (Chew, 1995). Nesta aproximação a dimensão da seção cruzada do alvo é considerada pequena em termos do comprimento de onda do sinal emitido, e o contraste entre suas propriedades eletromagnéticas e as do meio onde ele está inserido é considerado baixo. Deste modo a contribuição do campo espalhado é relativamente pequena e o campo total pode ser aproximado pelo campo incidente, ou seja:

$$
\boldsymbol{E} \approx \boldsymbol{E}_{\text {inc }}
$$

Além disso, por meio desta aproximação assume-se que não exista interação entre os campos espalhados provenientes de diferentes alvos, de modo que na presença de mais de um objeto o campo espalhado é tido como a soma do campo espalhado gerado por cada alvo separadamente (Turk et al., 2011). Assim, tem-se que a equação linearizada do campo elétrico espalhado é dada por

$$
\boldsymbol{E}_{\text {esp }}(\boldsymbol{r})=\gamma_{b}^{2} \int_{D_{i}} \chi\left(\boldsymbol{r}^{\prime}\right) \boldsymbol{E}_{\text {inc }}\left(\boldsymbol{r}^{\prime}\right) \boldsymbol{G}\left(\boldsymbol{r} / \boldsymbol{r}^{\prime}\right) d \boldsymbol{r}^{\prime}, \quad \boldsymbol{r} \in D_{o}
$$

Naturalmente esta forma de linearização causa alguma perda de informação. Entretanto, a aproximação Born oferece resultados de acurácia considerável no problema da tomografia de micro-ondas (Pastorino, 2010). Além disso, esta aproximação permite obter bons resultados mesmo em casos de alvos de alto contraste como condutores elétricos perfeitos (PEC - Perfect Electric Conductor), conforme descrito por Polat e Meincke (2004).

Além da não linearidade o problema proposto é caracterizado também como um problema mal posto, uma vez que não satisfaz a definição de Hadamard (Hadamard, 1923 apud Pastorino, 2010). Esta definição coloca como um problema bem posto aquele cuja solução existe, é única e depende continuamente dos dados. Em um problema bem posto uma pequena perturbação nos dados reflete-se como uma pequena perturbação na solução do problema inverso, enquanto que em um problema mal posto uma pequena perturbação nos dados pode levar a uma grande perturbação na sua solução. Para o problema da tomografia a condição de problema mal posto deve-se 
principalmente ao ruído presente nos dados, o qual pode induzir a soluções com artefatos que não correspondem a objetos reais.

Um problema mal posto pode ser tratado como um problema bem posto mediante a sua regularização. Como a questão principal dos dados GPR é a presença de ruído, um meio comum de se fazer a regularização é minimizando a influência destes através da Decomposição em Valores Singulares Truncada (TSVD - Truncated Singular Value Decomposition), também chamada de Filtragem Numérica (Pastorino, 2010; Soldovieri e Solimene, 2010; Turk et al., 2011).

A função contraste e o campo espalhado da equação linear (3.52) relacionam-se através de um operador linear de radiação $\mathcal{A}$ (Turk et al., 2011):

$$
\boldsymbol{E}_{e s p}(\boldsymbol{r})=\gamma_{b}^{2} \int_{D_{i}} \chi\left(\boldsymbol{r}^{\prime}\right) \boldsymbol{E}_{\text {inc }}\left(\boldsymbol{r}^{\prime}\right) \boldsymbol{G}\left(\boldsymbol{r} / \boldsymbol{r}^{\prime}\right) d \boldsymbol{r}^{\prime}=\mathcal{A}(\chi), \quad \boldsymbol{r} \in D_{o}
$$

A decomposição em valores singulares deste operador linear fornece o sistema singular $\left\{\sigma_{n}^{*}, u_{n}^{*}, v_{n}^{*}\right\}_{n=0}^{\infty}$. O conjunto $\left\{\sigma_{n}^{*}\right\}_{n=0}^{\infty}$ consiste em uma seqüência de valores singulares ordenados de forma decrescente e que converge para zero. O conjunto $\left\{u_{n}^{*}\right\}_{n=0}^{\infty}$ constitui a base ortonormal do espaço para os objetos visíveis, e representa os objetos que podem ser recuperados por dados livres de erro. O conjunto $\left\{v_{n}^{*}\right\}_{n=0}^{\infty}$ constitui a base ortonormal para o espaço dos dados livres de ruído dentro das condições da aproximação Born (Turk et al., 2011). O campo espalhado pode ser escrito então como

$$
\boldsymbol{E}_{\text {esp }}=\sum_{n=0}^{\infty} \sigma_{n}^{*}\left\langle\chi, u_{n}^{*}\right\rangle v_{n}^{*}
$$

Os valores singulares decrescem conforme o índice $n$ cresce, de modo que os valores singulares de índice mais alto contribuem pouco para o campo espalhado e podem ser facilmente mascarados pela presença de ruído nos dados coletados. Deste modo, estipulando-se um índice de truncamento $N_{T}^{*}$ sobre os valores singulares de $\mathcal{A}$ elimina-se a possível influência do ruído. A solução formal do problema inverso pode então ser expressa como (Turk et al., 2011) 


$$
\chi=\sum_{n=0}^{N_{T}^{*}} \frac{\left\langle\boldsymbol{E}_{e s p}, v_{n}^{*}\right\rangle}{\sigma_{n}^{*}} u_{n}^{*}
$$

O índice $N_{T}^{*}$ é escolhido manualmente através de uma análise sobre a relação sinal-ruído nos dados, pois um valor alto deste índice pode induzir a uma solução instável, enquanto que um valor baixo pode induzir à redução da acurácia da solução (Soldovieri e Solimene, 2010).

\subsubsection{Implementação do código de tomografia}

Todo o processo de inversão se dá no domínio da frequência, de forma que o primeiro passo é calcular a transformada de Fourier de cada traço, obtendo-se uma matriz de dados no domínio distância $(x)$ por frequência $(f)$. Calcula-se então o espectro médio do radargrama, que permitirá definir a banda de frequência em que as informações mais significativas se concentram.

Em seguida define-se os parâmetros conhecidos que serão empregados para se realizar a inversão. Primeiramente define-se a constante dielétrica do background geológico $\left(\epsilon_{r_{b}}\right)$, o qual pode ser obtido no software de processamento de dados radargrama partir do ajuste de velocidades. Em seguida define-se o valor da condutividade elétrica do background geológico $\left(\sigma_{b}\right)$. A estimativa deste valor deve ser feita cautelosamente em função do tipo de solo existente no local onde os dados foram adquiridos, visto que o processamento convencional de dados GPR não fornece ferramentas para se estimar este parâmetro. A condutividade elétrica do solo pode ser estimada através de um processo que envolve a obtenção de sucessivas imagens tomográficas a partir do mesmo conjunto de dados, considerando-se como estimativa ideal aquela em que for obtida a imagem com melhor definição (Soldovieri et al., 2009).

A partir dos valores da constante dielétrica e da condutividade elétrica do meio geológico é possível obter a permissividade dielétrica complexa $\left(\varepsilon_{b}\right)$ e, a partir dela, obtém-se o número de onda complexo $\gamma_{b}(\omega)$ do meio, conforme a equação (3.14).

Os limites $\mathrm{x}^{\prime}$ e $\mathrm{z}^{\prime}$ do domínio sob investigação $\mathrm{D}_{\mathrm{i}}$ são escolhidos de forma que compreendam toda a área em torno da anomalia associada ao alvo de interesse. Este 
espaço é discretizado em função do comprimento de onda $(\lambda)$ do sinal no meio, considerando-se a condição do limite mínimo de resolução igual a $\lambda / 4$ (Telford et al., 1990) de acordo com a equação (3.25). O domínio $\mathrm{D}_{\mathrm{i}}$ é então discretizado em $\mathrm{Nx}^{\prime} \times \mathrm{Nz}^{\prime}$ elementos, onde $\mathrm{Nx}^{\prime}$ é o número de elementos do eixo $\mathrm{x}^{\prime}$ e $\mathrm{Nz}^{\prime}$ é o número de elementos do eixo $z^{\prime}$.

Define-se também o espectro do campo incidente $\left(\boldsymbol{E}_{\text {inc }}\right)$ a ser empregado. Este espectro pode ser definido na mesma banda de frequência observada no espectro médio dos dados. Os resultados apresentados nos próximos capítulos foram obtidos considerando-se um espectro de wavelet Ricker (Ricker, 1943; 1944), a qual fornece uma boa aproximação do pulso emitido pelas antenas dos sistemas GPR comerciais (Bradford, 2007). O espectro desta wavelet é calculado através da equação (Daniels, 2004).

$$
I(\omega)=\frac{2}{\sqrt{\pi}} \frac{\omega^{2}}{\omega^{* 3}} e^{-\left(\frac{\omega}{\omega^{*}}\right)^{2}}
$$

em que $\omega$ é a frequência angular $(\mathrm{rad} / \mathrm{s})$ e $\omega^{*}$ é a frequência angular correspondente à frequência central do pulso, que neste trabalho equivale à frequência nominal da antena empregada na aquisição dos dados a serem invertidos.

O operador $\mathcal{A}$, definido na equação (3.53), é discretizado utilizando o método dos momentos (Harrington, 1968), o qual permite que uma equação linear do tipo $E=\mathcal{A}(\chi)$, em que $E$ é uma função conhecida, $\mathcal{A}$ é um operador linear e $\chi$ é a função a ser determinada, seja convertida em um sistema linear para posterior resolução (Harrington, 1968; Gibson, 2008). Este operador contém as informações de todos os pontos do domínio sob observação $\left(D_{o}\right)$, do domínio sob investigação $\left(D_{i}\right)$ e de todas as frequências do espectro dos dados, podendo ser expresso por

$$
\mathcal{A}=i \omega \varepsilon_{b} I(\omega)\left[\frac{\omega \mu_{0}}{4} H_{0}^{(2)}\left(\gamma_{b} \sqrt{\left(x^{\prime}-x\right)^{2}+\left(z^{\prime}-z\right)^{2}}\right)\right]^{2}
$$

em que $I(\omega)$ é o espectro da fonte, $H_{0}^{(2)}$ é a função de Henkel de ordem zero e grau 2, $\gamma_{b}$ é o número de onda complexo do meio homogêneo, $x^{\prime}$ e $z^{\prime}$ são as coordenadas de um ponto qualquer dentro do domínio sob investigação $D_{i}$ e $x$ e $z$ são as coordenadas de um ponto de aquisição de dados no domínio sob observação $D_{o}$. 
A matriz referente ao operador linear $\mathcal{A}$ é construída no código implementado conforme segue. Primeiramente, para uma frequência $\omega_{1}$, calcula-se o resultado do termo entre colchetes na equação (3.57) para todos os pontos $z^{\prime}$ associados a um ponto $x_{1}^{\prime}$, e a uma coordenada $\left(x_{1}, z_{1}\right)$. Em seguida calcula-se o resultado para todos os pontos $z^{\prime}$ associados a um ponto $x_{2}^{\prime}$, e assim sucessivamente até que o cálculo tenha sido feito para todos os pontos associados às coordenadas do eixo $x^{\prime}$. Estes resultados são então concatenados e armazenados em um vetor linha, associado a um único ponto $x_{1}$. Este processo se repete para todas as coordenadas do domínio sob observação $\left(D_{o}\right)$. Cada vetor do conjunto contendo os resultados obtidos para estas coordenadas é por sua vez armazenado em uma linha de uma matriz. Desta maneira uma matriz é gerada para cada valor de frequência a ser analisada. Cada uma destas matrizes é então multiplicada pelo termo $i \omega_{i} \varepsilon_{b_{i}} I\left(\omega_{i}\right)$, com $i=1,2, \ldots, N f$, onde $N f$ corresponde ao número de frequências.

O cálculo inverso é então executado através da equação (3.55), após a decomposição em valores singulares da matriz referente ao operador $\mathcal{A}$. Esta etapa pode requerer um elevado custo computacional dependendo de como o domínio sob investigação é definido e discretizado. $\mathrm{O}$ índice de truncamento dos valores singulares é escolhido posteriormente pelo usuário, visando obter a melhor qualidade possível da imagem com relação à definição dos contornos das anomalias. 


\section{CAPÍTULO 4}

\section{METODOLOGIA}

Este capítulo aborda a metodologia empregada na aquisição de dados, no processamento dos mesmos e os parâmetros empregados na inversão dos dados a fim de se obter as imagens tomográficas referentes aos perfis GPR adquiridos.

A aquisição de dados foi feita em ambas as áreas utilizando o sistema SIR-3000 fabricado pela GSSI. O processamento destes dados foi feito no software ReflexWin utilizando as ferramentas descritas no Capítulo 3. As ferramentas de processamento foram aplicadas aos dados adquiridos em ambas as áreas na seguinte sequência: remoção de ganho de cabeçalho, filtragem dewow, correção do tempo zero, ganho temporal e filtragem em frequência. A remoção de background e a correção topográfica requerida para análise dos dados do experimento sobre o alvo orgânico foram executadas diretamente no programa de imageamento tomográfico. Alguns perfis apresentaram um forte ruído horizontal que precisou ser removido durante $\mathrm{o}$ processamento para tornar viável as análises posteriores, porém estes perfis foram exceções. Deste ponto em diante todo o processamento executado no ReflexWin será denominado pré-processamento.

A mesma sequência de pré-processamento foi aplicada para todos os conjuntos de dados adquiridos em uma determinada frequência, i. e., foi aplicada uma sequência de processamento para todos os dados de $270 \mathrm{MHz}$, uma sequência diferente para todos os dados de $400 \mathrm{MHz}$ e uma terceira sequência para todos os dados de $900 \mathrm{MHz}$ (no experimento com o alvo orgânico). Este procedimento foi adotado para manter a amplitude relativa do sinal entre diferentes perfis paralelos de uma mesma aquisição. No caso do experimento com alvo orgânico este procedimento previne que ocorram alterações na amplitude do sinal que não sejam causadas unicamente pela variação do contraste entre as propriedades elétricas do solo e as do alvo orgânico em decomposição.

A frequência mínima e a frequência máxima que delimitam o intervalo foram definidas de forma a corresponderem à região onde o espectro do radargrama possui 
amplitude maior do que $20 \%$ da amplitude máxima. O número de frequências é definido de forma que se possa amostrar o espectro com boa representatividade dentro desta faixa. Persico et al., 2006 definem como intervalo de frequências $(\Delta f)$ teórico ótimo para esta representatividade em um solo sem perdas a relação

$$
\Delta f=\frac{c}{2 z_{\max } \sqrt{\epsilon_{r b}}}
$$

onde $c$ é a velocidade da luz, $z_{\max }$ é a profundidade máxima investigada e $\epsilon_{r b}$ é a constante dielétrica do meio geológico. Nesta pesquisa a relação dada por (4.1) foi considerada como o $\Delta f$ máximo aceitável, e a partir deste valor obtém-se o número de frequências a serem amostradas no intervalo. Por outro lado, o número máximo de frequências é limitado pela configuração de hardware disponível para execução das rotinas de inversão. Os valores apresentados na Tabela 1 foram adotados para os dados adquiridos em ambas as áreas de estudo.

\begin{tabular}{cccc}
\hline $\begin{array}{c}\text { Frequência da } \\
\text { antena (MHz) }\end{array}$ & $\begin{array}{c}\text { Frequência } \\
\text { mínima (MHz) }\end{array}$ & $\begin{array}{c}\text { Frequência } \\
\text { máxima (MHz) }\end{array}$ & $\begin{array}{c}\mathbf{N}^{\mathbf{0}} \text { de } \\
\text { frequências }\end{array}$ \\
\hline 270 & 100 & 450 & 25 \\
400 & 200 & 600 & 29 \\
900 & 400 & 950 & 25 \\
\hline
\end{tabular}

Tabela 1. Intervalos de frequência empregados na inversão dos dados.

A discretização do espaço sob investigação foi de $1 / 5$ do comprimento de onda no meio geológico para os dados em $270 \mathrm{MHz}$ e $400 \mathrm{MHz}$, e de 1/4 do comprimento de onda para os dados em $900 \mathrm{MHz}$. A discretização mais grosseira no caso dos dados em $900 \mathrm{MHz}$ se deve à limitação de hardware disponível para execução da inversão.

As velocidades de propagação das ondas eletromagnéticas foram obtidas no software ReflexWin através do ajuste de hipérboles seguido pela migração. Posteriormente foram definidos valores para a condutividade elétrica do solo através da qualidade da imagem obtida através da tomografia num processo baseado no trabalho de Soldovieri et al. (2009). Entretanto, diferentemente do que os autores apresentam no 
referido trabalho, foi feita uma avaliação visual buscando simultaneamente o melhor foco e o maior valor possível da função contraste durante a etapa de regularização de uma determinada imagem, sem estabelecer valores fixos para o truncamento dos valores singulares.

O truncamento dos valores singulares foi feito de maneira a se obter a melhor imagem sobre cada tipo de alvo. O mesmo valor de truncamento foi utilizado para os perfis paralelos correspondentes a cada alvo, do mesmo modo que o pré-processamento foi feito adotando-se os mesmos parâmetros para os perfis paralelos. $\mathrm{O}$ truncamento na matriz de valores singulares é comumente representado segundo a amplitude do valor singular em um determinado índice, utilizando-se uma escala logarítimica para representar a relação de amplitude entre o primeiro valor singular (que é o de maior valor) e o valor singular do índice em que foi feito o truncamento. Isto é feito através da conversão dos valores para decibel $(\mathrm{dB})$ em uma escala normalizada, calculados conforme a equação (4.2):

$$
\sigma_{d B}^{*}=20 \log _{10} \frac{\left|\sigma_{T}^{*}\right|}{\left|\sigma_{1}^{*}\right|}
$$

em que $\sigma_{T}^{*}$ é a amplitude do valor singular correspondente ao índice de truncamento adotado.

\subsection{SCGR}

\subsubsection{Modelagem}

Os dados sintéticos foram gerados com o software GprMax (Gianopoulos, 2005), onde a resolução das equações para obtenção dos dados se dá através do método das Diferenças Finitas no Domínio do Tempo (Finite Differences in Time Domain FDTD) desenvolvido por Yee (1966). As modelagens foram feitas considerando-se as dimensões reais dos alvos instalados no SCGR. Um modelo foi criado para cada alvo para evitar eventuais interferências entre anomalias geradas por diferentes alvos e para 
evitar interações do sinal eletromagnético entre alvos próximos, permitindo assim uma análise mais precisa da geometria de cada tipo de alvo.

Os dados foram modelados de maneira a simular o comportamento de dados adquiridos com antenas de $270 \mathrm{MHz}, 400 \mathrm{MHz}$ e $900 \mathrm{MHz}$. Uma wavelet Ricker (Ricker, 1943; 1944) foi adotada como forma de onda da fonte por suas similaridades com o sinal real observado em dados GPR (Bradford, 2007). Adotou-se uma separação entre antenas transmissora e receptora igual a 10 células do espaço do modelo. Entre as antenas e a interface ar-solo adotou-se uma distância igual a cinco células. A recomendação é que se use células de tamanho máximo equivalente a 1/10 do menor comprimento de onda a ser observado nos dados (Giannopoulos, 2005), de modo que o tamanho das células depende da frequência do sinal a ser modelado. Para a modelagem em $270 \mathrm{MHz}$ empregou-se modelos discretizados em células de 0,02 m × 0,02 m. Na modelagem de $400 \mathrm{MHz}$ os modelos foram discretizados em células de 0,01 $\mathrm{m} \times 0,01$ m. Os modelos empregados para gerar os dados de $900 \mathrm{MHz}$ foram discretizados em células de $0,005 \mathrm{~m} \times 0,005 \mathrm{~m}$. O sinal de acoplamento com a interface ar-solo foi suprimido através de time-gating de $10,0 \mathrm{~ns}, 6,0 \mathrm{~ns}$ e 5,0 ns nos dados de $270 \mathrm{MHz}, 400$ $\mathrm{MHz}$ e $900 \mathrm{MHz}$ respectivamente.

As propriedades elétricas dos materiais foram retiradas de Reynolds (1997), Jol (1999), Porsani (1999), Daniels (2004). Estes parâmetros são apresentados na Tabela 2. Para o muro de tijolos foram adotados valores referentes à argila seca.

A Figura 17 apresenta um diagrama de todos os modelos analisados. Para a análise dos dados sintéticos os limites do domínio sob investigação $\left(D_{i}\right)$ da tomografia foram considerados iguais aos limites do radargrama. A profundidade máxima deste domínio foi estimada com base na conversão tempo-profundidade do radargrama. Os resultados são apresentados agrupados de acordo com o alvo, visando uma melhor comparação entre as três frequências empregadas. As escalas dos radargramas referemse à amplitude do sinal refletido e foram normalizadas em relação à máxima amplitude de reflexão dentre todos os radargramas sintéticos para uma dada frequência, após a supressão do sinal de acoplamento na superfície através do time-gating adequado. $\mathrm{O}$ time-gating foi o único processamento empregado nos dados sintéticos, visando eliminar o sinal de acoplamento com a superfície por este mostrar-se predominante após o processo de tomografia. Isto permite que se possa estabelecer uma relação entre as 


\begin{tabular}{ccccc}
\hline Alvo & Dimensões [m] & $\begin{array}{c}\text { Profundidade } \\
\text { do topo }[\mathbf{m}]\end{array}$ & $\boldsymbol{\epsilon}_{\boldsymbol{r}}$ & $\boldsymbol{\sigma}[\mathbf{S} / \mathbf{m}]$ \\
\hline $\begin{array}{c}\text { Background geológico } \\
\text { (solo argiloso) } \\
\text { Caixa de areia }\end{array}$ & - & - & 18,0 & $10^{-2}$ \\
$\begin{array}{c}\text { Caixa de brita de } \\
\text { granito }\end{array}$ & $2,2 \times 1,0$ & 0,50 & 6,0 & $10^{-3}$ \\
$\begin{array}{c}\text { Solo revirado } \\
\text { Muro de tijolos }\end{array}$ & $1,0 \times 1,0$ & 0,50 & 5,0 & $10^{-4}$ \\
$\begin{array}{c}\text { Vasos cerâmicos } \\
\text { preenchidos com ar }\end{array}$ & $\begin{array}{c}\emptyset_{\text {externo }}=0,55 \\
\emptyset_{\text {interno }}=0,51\end{array}$ & $0,0,50$ & 15,0 & $10^{-2}$ \\
Seixos de quartzo & $1,0 \times 0,10$ & 0,50 & 4,0 & $10^{-2}$ \\
\hline
\end{tabular}

Tabela 2. Dimensões e propriedades eletromagnéticas adotadas para a modelagem dos alvos do SCGR.

amplitudes de reflexão do sinal eletromagnético em diferentes alvos inseridos em um mesmo meio geológico. As tomografias são apresentadas juntamente com os dados modelados para favorecer a comparação entre ambos. As dimensões verdadeiras dos alvos modelados são representadas nas figuras por formas geométricas de linha pontilhada. 
a)

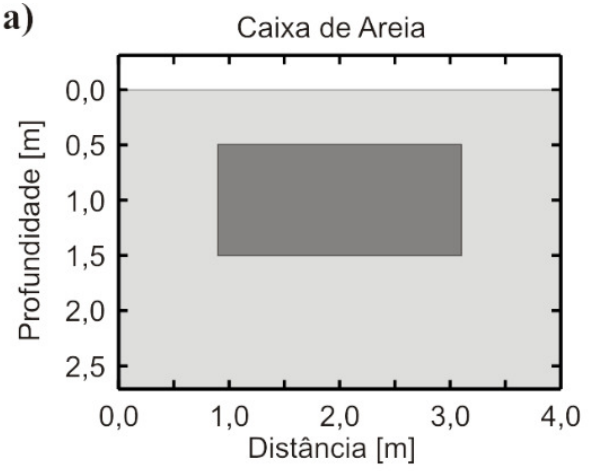

c)

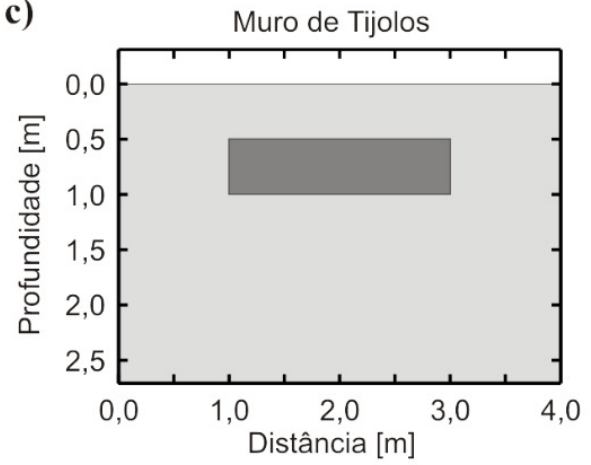

e)

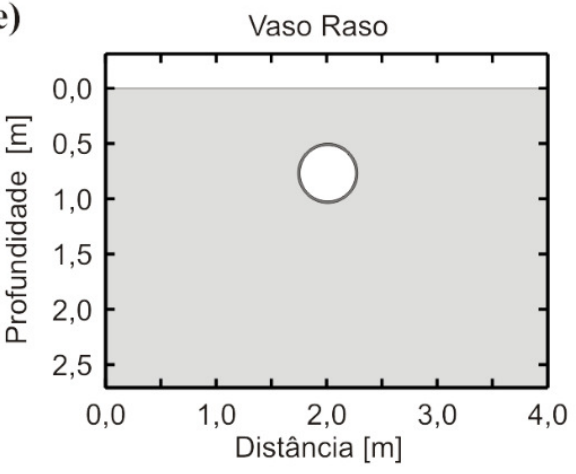

g)

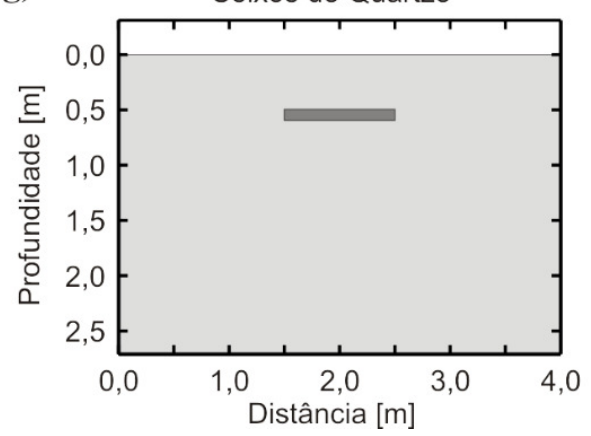

b)

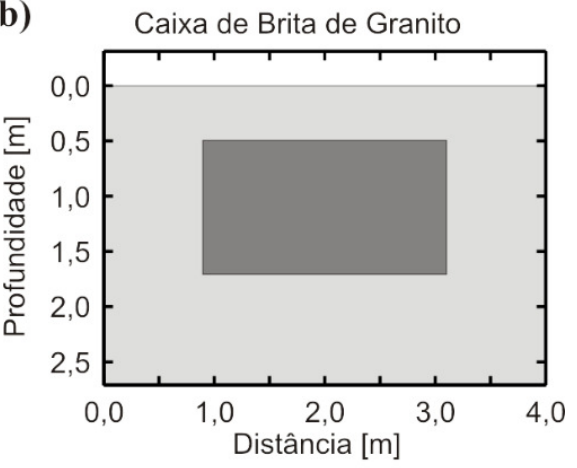

d)

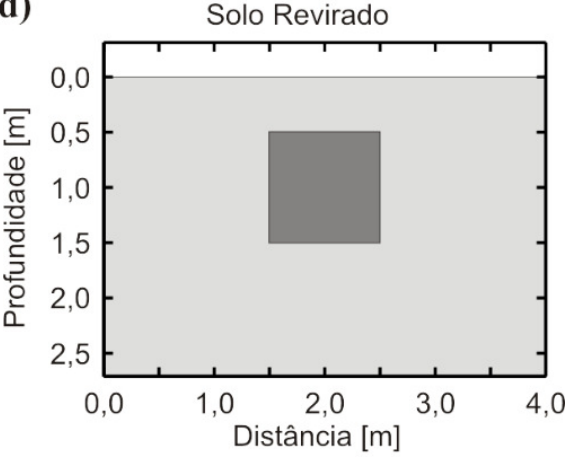

f)

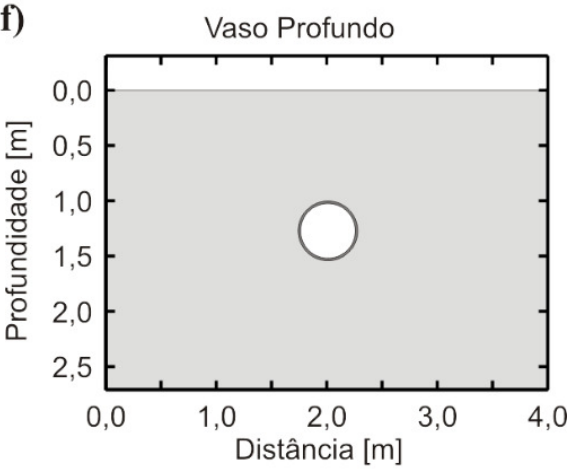

Figura 17. Diagramas esquematizando os modelos empregados para gerar os dados sintéticos. a) caixa de areia. b) caixa de brita de granito. c) muro de tijolos. d) solo revirado. e) vaso a $0,50 \mathrm{~m}$ de profundidade preenchido apenas com ar. f) vaso a 1,0 m de profundidade preenchido com ar. g) camada de seixos de quartzo. 


\subsubsection{Aquisição dos dados}

Os dados GPR foram adquiridos no SCGR utilizando antenas blindadas de 270 MHz e $400 \mathrm{MHz}$. Foram adquiridos 21 perfis paralelos orientados na direção Y, de forma a cobrir toda a extensão desta linha. Os perfis foram espaçados de 0,20 m entre si, cobrindo assim uma faixa de 4,0 $\mathrm{m}$ de largura sobre esta linha. $\mathrm{O}$ espaçamento entre traços de cada perfil foi de $0,02 \mathrm{~m}$.

As propriedades elétricas adotadas para o background geológico no SCGR são mostradas na Tabela 3. A diferença entre os valores adotados para cada frequência se deve ao fato de os conjuntos de dados terem sido adquiridos em épocas diferentes do ano, com os dados de $270 \mathrm{MHz}$ sendo adquiridos em uma época menos chuvosa e os dados de $400 \mathrm{MHz}$ sendo adquiridos em uma época mais chuvosa.

\begin{tabular}{cccc}
\hline Conjunto de dados & Velocidade $(\mathbf{m} / \mathbf{n s})$ & $\begin{array}{c}\text { Constante } \\
\text { dielétrica }\left(\boldsymbol{\epsilon}_{\boldsymbol{r}}\right)\end{array}$ & $\begin{array}{c}\text { Condutividade } \\
\text { elétrica }(\boldsymbol{\sigma})(\mathbf{S} / \mathbf{m})\end{array}$ \\
\hline $270 \mathrm{MHz}$ & 0,0849 & 12,5 & 0,005 \\
$400 \mathrm{MHz}$ & 0,0707 & 18,0 & 0,010 \\
\hline
\end{tabular}

Tabela 3. Valores das propriedades elétricas do solo estimadas para os dados adquiridos no SCGR.

A remoção de background nestes dados foi feita aplicando-se as ferramentas de time-gating, subtração do traço médio, análise de autovalores e combinações de pares destas ferramentas. Esta análise foi feita com o objetivo de se observar possíveis melhorias nas qualidades das imagens tomográficas.

A regularização através do truncamento dos valores singulares do operador linear foi feita para os dados sintéticos de acordo com os valores apresentados na Tabela 4. O truncamento dos valores singulares empregados na regularização do problema inverso no caso dos dados reais adquiridos sobre cada alvo do SCGR foram feitos de acordo com os valores apresentados na Tabela 5 (dados de $270 \mathrm{MHz}$ ) e na Tabela 6 (dados de $400 \mathrm{MHz}$ ). Esta tabela apresenta os valores empregados em cada caso de remoção de background. 


\begin{tabular}{cccc}
\hline Alvo & $\mathbf{2 7 0} \mathbf{~ M H z}$ & $\mathbf{4 0 0} \mathbf{~ M H z}$ & $\mathbf{9 0 0} \mathbf{~ M H z}$ \\
\hline Caixa de areia & $-42,8 \mathrm{~dB}$ & $-37,6 \mathrm{~dB}$ & $-38,1 \mathrm{~dB}$ \\
Caixa de brita & $-42,4 \mathrm{~dB}$ & $-37,6 \mathrm{~dB}$ & $-38,3 \mathrm{~dB}$ \\
Muro de tijolos & $-43,7 \mathrm{~dB}$ & $-41,9 \mathrm{~dB}$ & $-38,8 \mathrm{~dB}$ \\
Solo revirado & $-40,5 \mathrm{~dB}$ & $-35,9 \mathrm{~dB}$ & $-40,7 \mathrm{~dB}$ \\
Vaso raso & $-42,5 \mathrm{~dB}$ & $-43,7 \mathrm{~dB}$ & $-41,0 \mathrm{~dB}$ \\
Vaso profundo & $-41,0 \mathrm{~dB}$ & $-46,1 \mathrm{~dB}$ & $-41,0 \mathrm{~dB}$ \\
Camada de seixos & $-40,3 \mathrm{~dB}$ & $-39,8 \mathrm{~dB}$ & $-37,7 \mathrm{~dB}$ \\
\hline
\end{tabular}

Tabela 4. Truncamento dos valores singulares empregados na etapa de regularização do problema inverso para obtenção das imagens tomográficas obtidas a partir dos dados sintéticos

\begin{tabular}{|c|c|c|c|c|c|c|}
\hline Alvo & TG & STM & $\begin{array}{l}\text { TG e } \\
\text { STM }\end{array}$ & $\mathbf{A A V}$ & $\begin{array}{l}\text { TG e } \\
\text { AAV }\end{array}$ & $\begin{array}{c}\text { STM e } \\
\text { AAV }\end{array}$ \\
\hline $\begin{array}{c}\text { Caixa de } \\
\text { areia }\end{array}$ & $-34,7 \mathrm{~dB}$ & $-35,0 \mathrm{~dB}$ & $-35,8 \mathrm{~dB}$ & $-35,7 \mathrm{~dB}$ & $-43,8 \mathrm{~dB}$ & $-40,7 \mathrm{~dB}$ \\
\hline $\begin{array}{l}\text { Caixa de } \\
\text { brita }\end{array}$ & $-31,8 \mathrm{~dB}$ & $-31,7 \mathrm{~dB}$ & $-31,3 \mathrm{~dB}$ & $-33,6 \mathrm{~dB}$ & $-33,2 \mathrm{~dB}$ & $-31,8 \mathrm{~dB}$ \\
\hline $\begin{array}{l}\text { Muro de } \\
\text { tijolos }\end{array}$ & $-29,9 \mathrm{~dB}$ & $-27,5 \mathrm{~dB}$ & $-28,7 \mathrm{~dB}$ & $-33,3 \mathrm{~dB}$ & $-30,2 \mathrm{~dB}$ & $-28,4 \mathrm{~dB}$ \\
\hline $\begin{array}{l}\text { Solo } \\
\text { revirado }\end{array}$ & $-32,5 \mathrm{~dB}$ & $-30,6 \mathrm{~dB}$ & $-32,3 \mathrm{~dB}$ & $-33,5 \mathrm{~dB}$ & $-37,5 \mathrm{~dB}$ & $-38,0 \mathrm{~dB}$ \\
\hline Vaso raso & $-30,7 \mathrm{~dB}$ & $-31,6 \mathrm{~dB}$ & $-31,7 \mathrm{~dB}$ & $-32,0 \mathrm{~dB}$ & $-30,8 \mathrm{~dB}$ & $-29,9 \mathrm{~dB}$ \\
\hline $\begin{array}{l}\text { Vaso } \\
\text { profundo }\end{array}$ & $-37,9 \mathrm{~dB}$ & $-38,4 \mathrm{~dB}$ & $-36,5 \mathrm{~dB}$ & $-34,2 \mathrm{~dB}$ & $-37,5 \mathrm{~dB}$ & $-39,0 \mathrm{~dB}$ \\
\hline $\begin{array}{l}\text { Camada de } \\
\text { seixos }\end{array}$ & $-32,9 \mathrm{~dB}$ & $-33,6 \mathrm{~dB}$ & $-32,9 \mathrm{~dB}$ & $30,6 \mathrm{~dB}$ & $-30,2 \mathrm{~dB}$ & $-31,8 \mathrm{~dB}$ \\
\hline
\end{tabular}

Tabela 5. Truncamento dos valores singulares para a etapa de regularização do problema inverso para obtenção das imagens tomográficas referentes aos dados do SCGR para cada situação de remoção de background em $270 \mathrm{MHz}$. TG = time-gating. $\mathrm{STM}=$ subtração do traço médio. AAV = análise de autovalores. 


\begin{tabular}{ccccccc}
\hline Alvo & TG & STM & $\begin{array}{c}\text { TG } \\
\text { STM }\end{array}$ & AAV & $\begin{array}{c}\text { TG e } \\
\text { AAV }\end{array}$ & $\begin{array}{c}\text { STM } \\
\text { AAV }\end{array}$ \\
\hline $\begin{array}{c}\text { Caixa de } \\
\text { areia }\end{array}$ & $-32,5 \mathrm{~dB}$ & $-33,2 \mathrm{~dB}$ & $-32,8 \mathrm{~dB}$ & $-37,6 \mathrm{~dB}$ & $-38,0 \mathrm{~dB}$ & $-38,0 \mathrm{~dB}$ \\
$\begin{array}{c}\text { Caixa de } \\
\text { brita }\end{array}$ & $-32,7 \mathrm{~dB}$ & $-32,8 \mathrm{~dB}$ & $-32,8 \mathrm{~dB}$ & $-38,7 \mathrm{~dB}$ & $-37,2 \mathrm{~dB}$ & $-36,5 \mathrm{~dB}$ \\
$\begin{array}{c}\text { Muro de } \\
\text { tijolos }\end{array}$ & $-32,4 \mathrm{~dB}$ & $32,1 \mathrm{~dB}$ & $-30,3 \mathrm{~dB}$ & $-35,0 \mathrm{~dB}$ & $-34,7 \mathrm{~dB}$ & $-34,3 \mathrm{~dB}$ \\
$\begin{array}{c}\text { Solo } \\
\text { revirado }\end{array}$ & $-35,3 \mathrm{~dB}$ & $-32,1 \mathrm{~dB}$ & $-33,6 \mathrm{~dB}$ & $-34,3 \mathrm{~dB}$ & $-33,2 \mathrm{~dB}$ & $-34,7 \mathrm{~dB}$ \\
$\begin{array}{c}\text { Vaso raso } \\
\text { Vaso }\end{array}$ & $-32,5 \mathrm{~dB}$ & $-31,7 \mathrm{~dB}$ & $-32,1 \mathrm{~dB}$ & $-27,0 \mathrm{~dB}$ & $-27,0 \mathrm{~dB}$ & $-26,6 \mathrm{~dB}$ \\
$\begin{array}{c}\text { profundo } \\
\text { Camada de } \\
\text { seixos }\end{array}$ & $-35,1 \mathrm{~dB}$ & $-35,2 \mathrm{~dB}$ & $-33,2 \mathrm{~dB}$ & $-31,7 \mathrm{~dB}$ & $-35,1 \mathrm{~dB}$ & $-32,2 \mathrm{~dB}$ \\
\hline
\end{tabular}

Tabela 6. Truncamento dos valores singulares para a etapa de regularização do problema inverso para obtenção das imagens tomográficas referentes aos dados do SCGR para cada situação de remoção de background em $400 \mathrm{MHz}$. TG = time-gating. $\mathrm{STM}=$ subtração do traço médio. AAV = análise de autovalores.

\subsection{Alvo orgânico}

\subsubsection{Aquisição dos dados}

Os dados GPR foram adquiridos sobre o porco enterrado utilizando antenas blindadas de $270 \mathrm{MHz}, 400 \mathrm{MHz}$ e $900 \mathrm{MHz}$. Os perfis paralelos foram adquiridos com espaçamento de $0,10 \mathrm{~m}$ entre si possibilitando a aquisição de 61 perfis orientados perpendicularmente à orientação do alvo. Este espaçamento foi adotado visando melhorar a interpolação para a visualização 3D e assim identificar eventuais alterações no solo provocadas pelo material orgânico em decomposição. O espaçamento entre traços de cada perfil foi de 0,02 m. A Figura 18 mostra um diagrama da aquisição dos dados. 


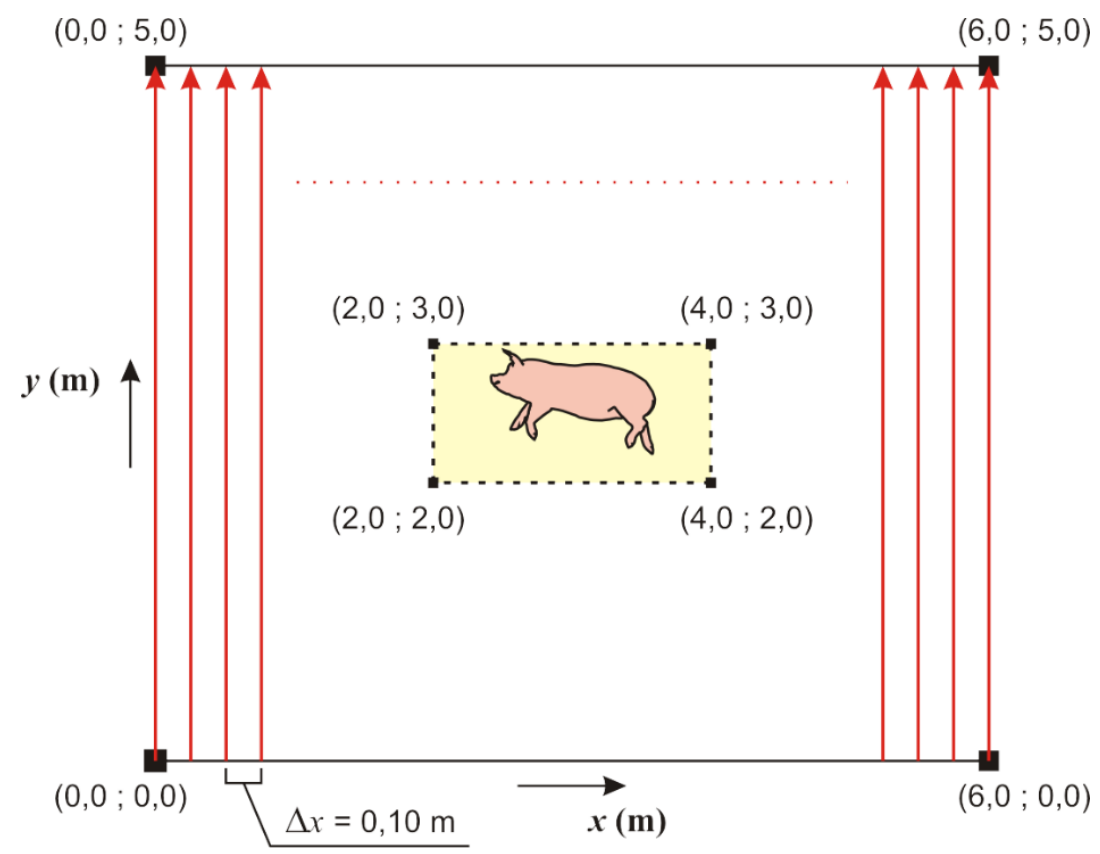

Figura 18. Diagrama esquemático da aquisição de dados GPR sobre o alvo orgânico instalado no campus da USP em Pirassununga, com as coordenadas dos vértices da área investigada e dos vértices da vala. As setas vermelhas representam os perfis adquiridos na direção $y$

Durante o experimento os dados foram adquiridos em sete etapas: uma no final de 2012 (17 a 21 de dezembro), cinco em 2013 (07 a 10 de janeiro, 21 a 24 de janeiro, 04 a 07 de março, 12 a 14 de abril, 17 a 19 de dezembro) e uma em 2014 (13 a 16 de junho).

$\mathrm{Na}$ primeira etapa os dados GPR foram adquiridos antes do enterro do animal para que se pudesse ter uma análise do background geológico da área de estudo. Uma nova aquisição foi feita imediatamente após o enterro, de modo a proporcionar uma análise das feições produzidas apenas pelo animal ainda intacto e fornecer um padrão para comparação em etapas posteriores, visando proporcionar uma análise sobre as anomalias decorrentes da decomposição do material orgânico.

O grupo de perfis paralelos de uma mesma frequência adquiridos durante uma mesma etapa será denominado um "conjunto de dados" a fim de diferenciar os dados correspondentes a cada etapa de aquisição. Para melhor referência a cada conjunto de dados ao longo do texto, será adotada neste capítulo a nomenclatura especificada na Tabela 7. 


\begin{tabular}{cc}
\hline $\begin{array}{c}\text { Data da etapa de } \\
\text { aquisição }\end{array}$ & $\begin{array}{c}\text { Nomenclatura do } \\
\text { conjunto de dados }\end{array}$ \\
\hline 17 / Dez / 2012 & {$[01]$} \\
19 / Dez / 2012 & {$[02]$} \\
07 / Jan / 2013 & {$[03]$} \\
22 / Jan / 2013 & {$[04]$} \\
04 / Mar / 2013 & {$[05]$} \\
12 / Abr / 2013 & {$[06]$} \\
17 / Dez / 2013 & {$[07]$} \\
13 / Jun / 2014 & {$[08]$} \\
\hline
\end{tabular}

Tabela 7. Nomenclatura adotada para referência ao conjunto de dados adquirido em cada etapa de aquisição de dados.

As propriedades elétricas estimadas para os dados adquiridos sobre o porco enterrado são apresentadas na Tabela 8 .

\begin{tabular}{cccc}
\hline Conjunto de dados & Velocidade $(\mathbf{m} / \mathbf{n s})$ & $\begin{array}{c}\text { Constante } \\
\text { dielétrica }\left(\boldsymbol{\epsilon}_{\boldsymbol{r}}\right)\end{array}$ & $\begin{array}{c}\text { Condutividade } \\
\text { elétrica }(\boldsymbol{\sigma})(\mathbf{S} / \mathbf{m})\end{array}$ \\
\hline$[01]$ & 0,0707 & 18,0 & 0,010 \\
{$[02]$} & 0,0707 & 18,0 & 0,010 \\
{$[03]$} & 0,0750 & 16,0 & 0,007 \\
{$[04]$} & 0,0750 & 16,0 & 0,007 \\
{$[05]$} & 0,0750 & 16,0 & 0,007 \\
{$[06]$} & 0,0721 & 17,3 & 0,085 \\
{$[07]$} & 0,0832 & 13,0 & 0,001 \\
{$[08]$} & 0,0889 & 11,4 & 0,001 \\
\hline
\end{tabular}

Tabela 8. Valores das propriedades eletromagnéticas do solo estimadas para cada conjunto de dados. 
Nos dados adquiridos sobre o experimento com alvo orgânico foi aplicada apenas a remoção de background por time-gating e pela combinação desta ferramenta com a análise de autovalores, pois foram as análises que apresentaram melhor resultado sobre os alvos estudados no SCGR. A remoção do background nos dados foi executada antes da correção topográfica.

A regularização através do truncamento dos valores singulares para o caso dos dados adquiridos no experimento com o alvo orgânico foi feita de acordo com os valores apresentados na Tabela 9. Os valores de truncamento para as imagens tomográficas em que o background foi removido através da combinação das duas ferramentas são apresentados apenas para os conjuntos [06], [07] e [08], pois foram os casos em que esta análise mostrou-se mais relevante para a interpretação das imagens.

\begin{tabular}{|c|c|c|c|c|c|c|}
\hline \multirow[b]{2}{*}{$\begin{array}{l}\text { Conjunto } \\
\text { de dados }\end{array}$} & \multicolumn{3}{|c|}{ Time-gating } & \multicolumn{3}{|c|}{$\begin{array}{c}\text { Time-gating e análise de } \\
\text { autovalores }\end{array}$} \\
\hline & $270 \mathrm{MHz}$ & $400 \mathrm{MHz}$ & $900 \mathrm{MHz}$ & $270 \mathrm{MHz}$ & $400 \mathrm{MHz}$ & $900 \mathrm{MHz}$ \\
\hline [01] & $-41,7 \mathrm{~dB}$ & $-44,9 \mathrm{~dB}$ & $-42,1 \mathrm{~dB}$ & - & - & - \\
\hline [02] & $-41,6 \mathrm{~dB}$ & $-52,8 \mathrm{~dB}$ & $-42,2 \mathrm{~dB}$ & - & - & - \\
\hline [03] & $-42,5 \mathrm{~dB}$ & $-51,7 \mathrm{~dB}$ & $-49,3 \mathrm{~dB}$ & - & - & - \\
\hline [04] & $-44,5 \mathrm{~dB}$ & $-49,8 \mathrm{~dB}$ & $-46,5 \mathrm{~dB}$ & - & - & - \\
\hline$[05]$ & $-41,8 \mathrm{~dB}$ & $-47,5 \mathrm{~dB}$ & $-41,4 \mathrm{~dB}$ & - & - & - \\
\hline [06] & $-39,7 \mathrm{~dB}$ & $-44,9 \mathrm{~dB}$ & $-46,6 \mathrm{~dB}$ & $-38,4 \mathrm{~dB}$ & $-47,5 \mathrm{~dB}$ & $-48,2 \mathrm{~dB}$ \\
\hline [07] & $-37,2 \mathrm{~dB}$ & $-46,1 \mathrm{~dB}$ & $-43,8 \mathrm{~dB}$ & $-37,6 \mathrm{~dB}$ & $-51,3 \mathrm{~dB}$ & $-43,8 \mathrm{~dB}$ \\
\hline [08] & $-42,3 \mathrm{~dB}$ & $-43,1 \mathrm{~dB}$ & $-42,5 \mathrm{~dB}$ & $-36,1 \mathrm{~dB}$ & $-39,4 \mathrm{~dB}$ & $-35,2 \mathrm{~dB}$ \\
\hline
\end{tabular}

Tabela 9. Truncamento dos valores singulares adotados na etapa de regularização do problema inverso para obtenção das imagens referentes ao experimento com o alvo orgânico. 


\section{CAPÍTULO 5}

\section{RESULTADOS DA TOMOGRAFIA}

Neste capítulo serão apresentados os resultados da inversão de dados GPR através da tomografia de micro-ondas. Primeiramente foram feitas análises sobre dados sintéticos gerados sobre modelos que simulam os alvos de interesse arqueológico instalados na Linha 01 do SCGR do IAG de forma a validar o programa de imageamento tomográfico. As imagens tomográficas obtidas a partir dos dados sintéticos também permitem analisar as feições observadas para cada alvo em uma situação ideal, uma vez que estes dados não apresentam influência de ruído. Além disso, a ausência de ruído simplifica o processo de regularização da inversão, uma vez que o índice de truncamento ideal é identificado mais facilmente.

Os dados reais adquiridos sobre o SCGR foram então comparados com os resultados sintéticos com o objetivo de se avaliar a qualidade das imagens obtidas e estabelecer uma geometria aproximada para as feições observadas em subsuperfície. Nestes dados há a presença de ruído geológico, diferentemente dos dados sintéticos. Isto possibilitou a análise de diferentes ferramentas de remoção de background visando melhorar a interpretação das imagens tomográficas. Cada alvo foi analisado separadamente para evitar a influência do sinal proveniente de alvos adjacentes. Posteriormente os resultados obtidos foram concatenados para uma análise da Linha 01 como um todo.

Os resultados são apresentados a seguir. A seção 5.1 apresenta os resultados obtidos sobre dados sintéticos. A seção 5.2 apresenta os resultados obtidos sobre dados reais no SCGR e a análise das ferramentas de remoção de background. A seção 5.3 apresenta os resultados obtidos sobre os dados adquiridos durante a execução do experimento com o alvo orgânico no campus da USP em Pirassununga. 


\subsection{SCGR - Dados sintéticos}

A Figura 19 mostra os resultados obtidos a partir dos dados sintéticos correspondentes à caixa de areia do SCGR. A Figura 19a apresenta o radargrama sintético para o sinal de $200 \mathrm{MHz}$. Observa-se claramente duas anomalias fortes, a primeira em 14,0 ns (indicada pela seta vermelha) e outra em 30,0 ns (indicada pela seta amarela). Estas reflexões estão associadas ao topo e à base da caixa, respectivamente. Notam-se feições hiperbólicas nas extremidades da caixa, pois estas se comportam como pontos de difração do sinal eletromagnético. Nas interfaces da caixa com o solo as reflexões aparecem planas tanto no topo como na base da mesma, pois reflete o comportamento plano-horizontal destas interfaces. A Figura 19b mostra a imagem tomográfica obtida a partir destes dados. As reflexões de topo e base da caixa aparecem bastante claras na imagem, respectivamente às profundidades de $0,50 \mathrm{~m}$ (seta vermelha) e de 1,07 m (seta amarela). Note-se que a anomalia relacionada ao fundo da caixa aparece em uma profundidade menor do que a profundidade verdadeira desta interface devido ao fato de a onda eletromagnética se propagar em um meio cuja constante dielétrica é menor do que aquela do meio geológico, implicando em uma velocidade de propagação maior dentro da caixa. A extensão da anomalia relacionada ao topo da caixa é exatamente igual à sua extensão verdadeira, enquanto anomalia relacionada ao fundo da caixa apresenta uma extensão ligeiramente menor, porém ainda comparável com a extensão da caixa. Nota-se ainda que a tomografia não apresenta anomalias associadas às múltiplas reflexões observadas no radargrama.

A Figura 19c mostra os dados modelados com sinal de $400 \mathrm{MHz}$. Novamente observam-se com clareza as reflexões de topo e base da caixa em 14,0 ns e 30,0 ns respectivamente, bem como reflexões múltiplas em tempos posteriores a estas. A imagem tomográfica correspondente (Figura 19d) mostra claramente as anomalias referentes ao topo (à profundidade de $0,50 \mathrm{~m}$ ) e à base (à profundidade de 1,07 m) do alvo. A extensão da anomalia do topo mostra uma boa correspondência com a extensão verdadeira desta interface no modelo. A anomalia relacionada à base, por outro lado, apresenta uma extensão ligeiramente menor do que a verdadeira. Além disso é possível observar que a partir desta frequência as anomalias hiperbólicas causadas pela difração do sinal nas arestas da base do alvo são resolvidas pela inversão como dois alvos pontuais. A interface plano-horizontal da base do alvo aparece como uma anomalia 
horizontal que conecta as duas anomalias pontuais, indicando que este conjunto referese a uma mesma interface.

A Figura 19e apresenta o radargrama sintético em $900 \mathrm{MHz}$ sobre este alvo. As mesmas reflexões de topo e base são observadas nos tempos de $14,0 \mathrm{~ns}$ e $30,0 \mathrm{~ns}$, e apenas uma reflexão múltipla pode ser identificada. A Figura 19f apresenta a imagem tomográfica correspondente. Aqui observa-se que a anomalia referente ao topo do alvo apresenta uma extensão de 2,10 m, sendo ligeiramente menor do que a verdadeira $(2,20$ m). Na anomalia associada à base da caixa nota-se o mesmo efeito observado na imagem tomográfica dos dados de $400 \mathrm{MHz}$, em que as arestas são resolvidas como anomalias pontuais. $\mathrm{Na}$ imagem tomográfica de $900 \mathrm{MHz}$ estas anomalias também aparecem interligadas por uma anomalia plano horizontal, que corresponde à interface da base da caixa.

A Figura 20 apresenta os resultados para a caixa de brita de granito, os quais são bastante parecidos com os resultados apresentados para a caixa de areia. A Figura 20a mostra o radargrama sintético obtido com o sinal de $270 \mathrm{MHz}$. Duas anomalias fortes podem ser observadas, as quais são associadas às reflexões no topo (14,0 ns) e na base $(32,0 \mathrm{~ns})$ da caixa de brita de granito, bem como uma fraca anomalia observada em 50,0 ns (indicada pela seta branca) associada a uma reflexão múltipla na base da caixa. A Figura 20b apresenta a imagem tomográfica obtida a partir destes dados. A anomalia mais rasa, associada ao topo da caixa, apresenta extensão e profundidade compatíveis com o modelo (seta vermelha). Tal como observado nos dados sintéticos sobre a caixa de areia, a anomalia associada ao fundo da caixa encontra-se em uma profundidade menor do que a profundidade verdadeira do modelo, além de apresentar também uma extensão ligeiramente menor. Nota-se neste caso que a imagem tomográfica apresenta feições de amplitude baixa (da ordem de 0,24 ) entre as anomalias associadas ao topo e à base da caixa. Estas feições devem-se à diferença entre as constantes dielétricas adotadas para a brita de granito $\left(\epsilon_{r}=5,0\right)$ e para o meio geológico $\left(\epsilon_{r}=18,0\right)$ e que pôde ser identificada através da função contraste. Isto permite sugerir que as anomalias indicadas pelas setas vermelha e amarela estejam relacionadas ao mesmo alvo. A reflexão múltipla observada nos dados sintéticos também aparece na imagem tomográfica como duas anomalias de amplitude 0,3 com uma anomalia de amplitude 0,25 entre elas (indicadas pela seta branca). Entretanto, para efeitos de interpretação da 

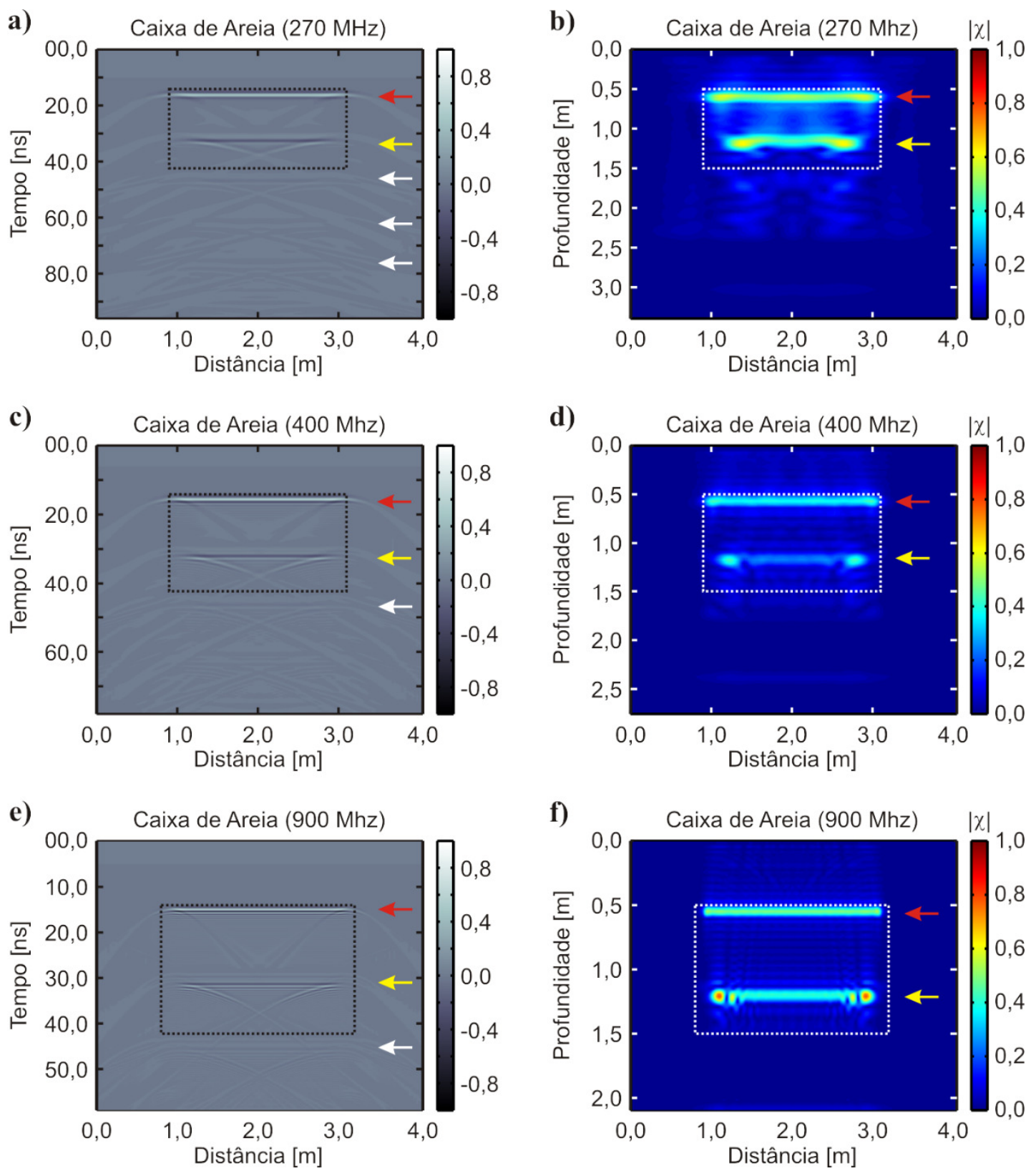

Figura 19. Dados sintéticos sobre a caixa de areia. Os retângulos de linhas pontilhadas representam os limites verdadeiros do alvo. As setas vermelhas indicam a posição do topo do alvo e as setas amarelas indicam a posição da base dos mesmos. As setas brancas indicam reflexões múltiplas. a) radargrama sintético em $270 \mathrm{MHz}$. b) imagem tomográfica em $270 \mathrm{MHz}$. c) radargrama sintético em $400 \mathrm{MHz}$. d) imagem tomográfica em $400 \mathrm{MHz}$. e) radargrama sintético em $900 \mathrm{MHz}$. f) imagem tomográfica em $900 \mathrm{MHz}$.

imagem esta anomalia pode facilmente ser classificada como um artefato decorrente da inversão dos dados, uma vez que se observa que sua amplitude é muito menor do que as duas anomalias indicadas pelas setas vermelha e amarela, que não há a mesma continuidade observada nestas anomalias ao longo do eixo de distância e que a feição 
observada entre as duas anomalias mais forte não aparece nas proximidades destas anomalias.

A Figura 20c apresenta os dados modelados com sinal de $400 \mathrm{MHz}$, onde observam-se as mesmas feições observadas no radargrama sintético de $270 \mathrm{MHz}$. Sua respectiva imagem tomográfica (Figura 20d) apresenta a anomalia do topo da caixa em 0,50 m de profundidade e com extensão equivalente à extensão desta interface no modelo $(2,2 \mathrm{~m})$. A interface referente à base da caixa apresenta a mesma separação observada na caixa de areia, com duas anomalias pontuais representando as arestas do alvo e uma anomalia plano-horizontal representando a interface entre este e o meio geológico. Nesta imagem já não se observa efeito da reflexão múltipla observada no radargrama.

A Figura 20e apresenta o radargrama sintético em $900 \mathrm{MHz}$, onde se observam as reflexões referentes ao topo (seta vermelha) e à base (seta amarela) do alvo, bem como uma reflexão múltipla (seta branca). A Figura 20f apresenta a respectiva imagem tomográfica. Observa-se aqui a anomalia referente ao topo do alvo muito bem definida à profundidade de $0,50 \mathrm{~m}$. A anomalia associada à base do alvo apresenta de forma mais evidente o efeito observado nos dados de $400 \mathrm{MHz}$, com as arestas representadas por anomalias pontuais. Nesta imagem a reflexão múltipla presente no radargrama não é observada.

A Figura 21 mostra a análise para um alvo representado pelo muro de tijolos. No radargrama (Figura 21a) observa-se uma reflexão forte em 14,0 ns, associada ao topo do alvo (seta vermelha), e uma reflexão mais fraca próxima a esta, em 20,8 ns e associada à base do alvo (seta amarela). Notam-se ainda várias reflexões fracas associadas a múltiplas reflexões do sinal entre a base e o topo do alvo, todas indicadas pelas setas brancas. A Figura $21 \mathrm{~b}$ apresenta a imagem tomográfica correspondente a estes dados. A anomalia relacionada ao topo do alvo localiza-se à profundidade de $0,50 \mathrm{~m}$ e seu comprimento corresponde exatamente ao comprimento do alvo verdadeiro. A anomalia relacionada à base do muro não aparece tão claramente quanto nas imagens tomográficas das caixas de areia e brita. Neste caso a base está relacionada à anomalia de amplitude 0,36 à profundidade de $0,83 \mathrm{~m}$, indicada pela seta amarela. Como nos casos anteriores, a interface entre o muro e o solo encontra-se a uma profundidade 

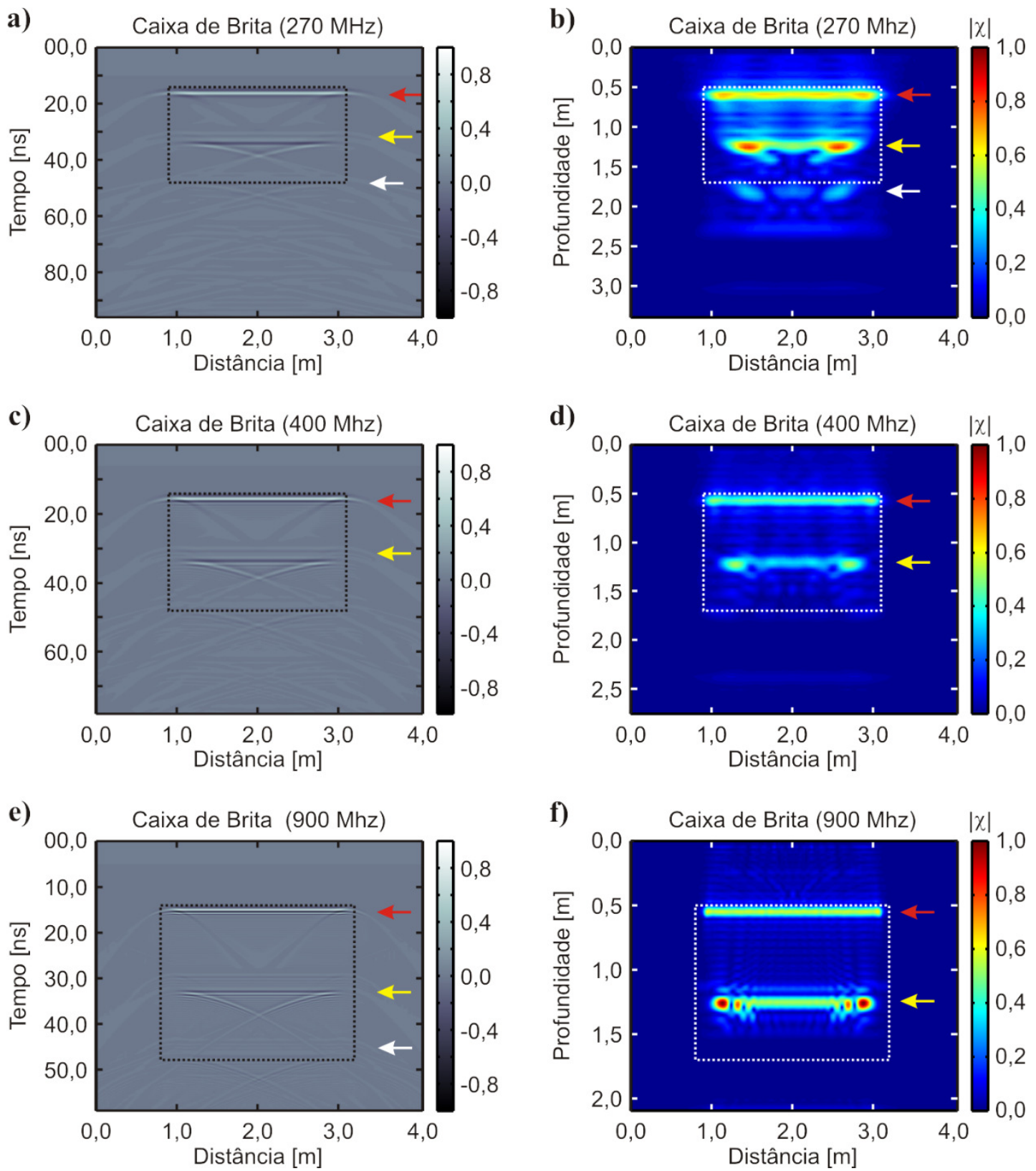

Figura 20. Análise dos dados sintéticos sobre a caixa de brita de granito. Os retângulos de linhas pontilhadas representam os limites verdadeiros do alvo. As setas vermelhas indicam a posição do topo do alvo e as setas amarelas indicam a posição da base dos mesmos. As setas brancas indicam reflexões múltiplas. a) radargrama sintético em 270 MHz. b) imagem tomográfica em $270 \mathrm{MHz}$. c) radargrama sintético em $400 \mathrm{MHz}$. d) imagem tomográfica em $400 \mathrm{MHz}$. e) radargrama sintético em $900 \mathrm{MHz}$. f) imagem tomográfica em $900 \mathrm{MHz}$.

menor do que a verdadeira devido à maior velocidade das ondas eletromagnéticas no interior do alvo. Ainda assim, considerando-se ambas as anomalias é possível estimar uma espessura de $0,33 \mathrm{~m}$ para o alvo, o que é comparável à sua espessura verdadeira. 
As múltiplas reflexões observadas no radargrama são suprimidas na imagem tomográfica, havendo apenas anomalias de baixíssima amplitude (da ordem de 0,14) que correspondem a efeitos numéricos observados na modelagem e que se mantém após a tomografia.

Na Figura 21c é mostrado o radargrama sintético de $400 \mathrm{MHz}$, onde é possível identificar as reflexões de topo e base do muro de tijolos, representadas pelas setas vermelha e amarela respectivamente. Além destas, quatro reflexões múltiplas podem ser observadas, as quais são indicadas pelas setas brancas. Analisando-se a imagem tomográfica correspondente (Figura 21d) observa-se que também nesta frequência o topo do alvo é bem resolvido. A anomalia referente à base do muro aparece à profundidade de $0,83 \mathrm{~m}$ (seta amarela), e é possível observar anomalias de amplitude similar $(|\chi|=0,28)$ entre esta e a anomalia referente ao topo. Estas anomalias sugerem aquelas indicadas pelas setas vermelha e amarela possam estar relacionadas a um mesmo objeto, já que em seu interior a função contraste sugere que exista uma constante dielétrica diferente daquela do meio geológico. Nesta imagem observa-se ainda que as reflexões múltiplas observadas no radargrama também são resolvidas; no entanto, observa-se que estas múltiplas foram resolvidas com as mesmas características dimensionais das anomalias já identificadas como topo e base do muro, porém com amplitude menor. Estas anomalias estão indicadas com setas vermelha e amarela tracejadas, uma vez que este par aparece como um "fantasma" do par de anomalias relacionado ao alvo verdadeiro. Na Figura 21e é apresentado o radargrama de $900 \mathrm{MHz}$ e a indicação das reflexões de topo, base e múltiplas. A imagem tomográfica obtida a partir destes dados (Figura 21f) mostra as anomalias relacionadas ao topo e à base do muro, indicadas pelas setas vermelha e amarela contínuas, respectivamente. Nesta figura é possível observar mais claramente o efeito observado nos dados de $400 \mathrm{MHz}$, onde as reflexões múltiplas do radargrama são resolvidas como réplicas do topo e da base reais do muro (indicadas pelas setas vermelha e amarela tracejadas, respectivamente).

A Figura 22 apresenta o resultado da tomografia aplicada à reflexão gerada por uma caixa de 1,0 $\mathrm{m} \times 1,0 \mathrm{~m}$ de solo revirado, sem alvos em seu interior. Nota-se que as amplitudes das reflexões nos radargramas (Figura 22a, c, e) são muito baixas em comparação aos alvos observados anteriormente, visto que o solo revirado não apresenta 

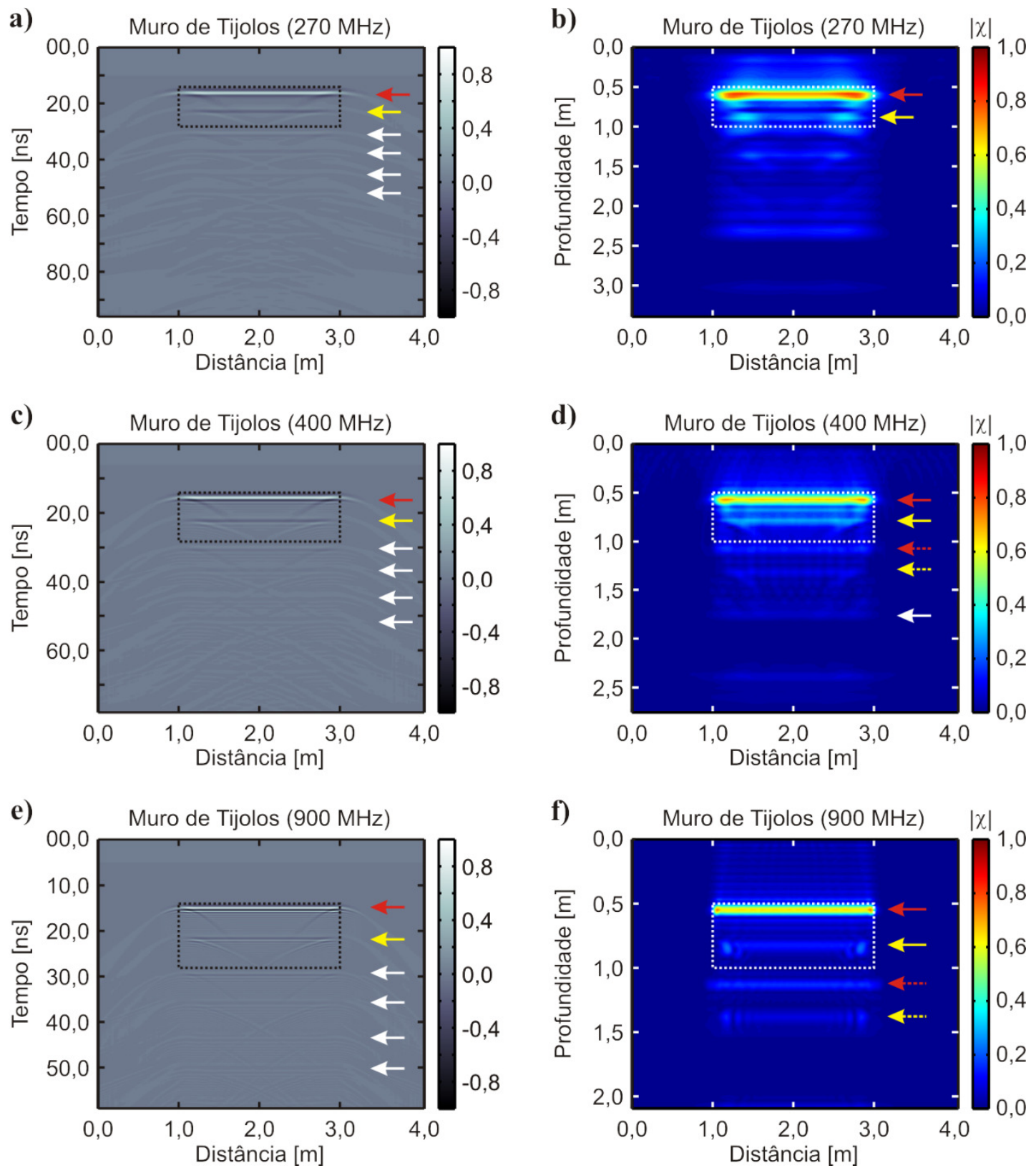

Figura 21. Análise dos dados sintéticos sobre o muro de tijolos. Os retângulos de linhas pontilhadas representam os limites verdadeiros do alvo. As setas vermelhas indicam a posição do topo do alvo e as setas amarelas indicam a posição da base dos mesmos. As setas brancas indicam reflexões múltiplas. a) radargrama sintético em $270 \mathrm{MHz}$. b) imagem tomográfica em $270 \mathrm{MHz}$. c) radargrama sintético em 400 MHz. d) imagem tomográfica em $400 \mathrm{MHz}$. e) radargrama sintético em $900 \mathrm{MHz}$. f) imagem tomográfica em $900 \mathrm{MHz}$.

um grande contraste com o material geológico não perturbado ao seu redor. Nos dados sintéticos é possível observar as reflexões de topo e base da caixa, porém deve-se atentar para o fato de que estas reflexões poderiam facilmente ser mascaradas por ruído 

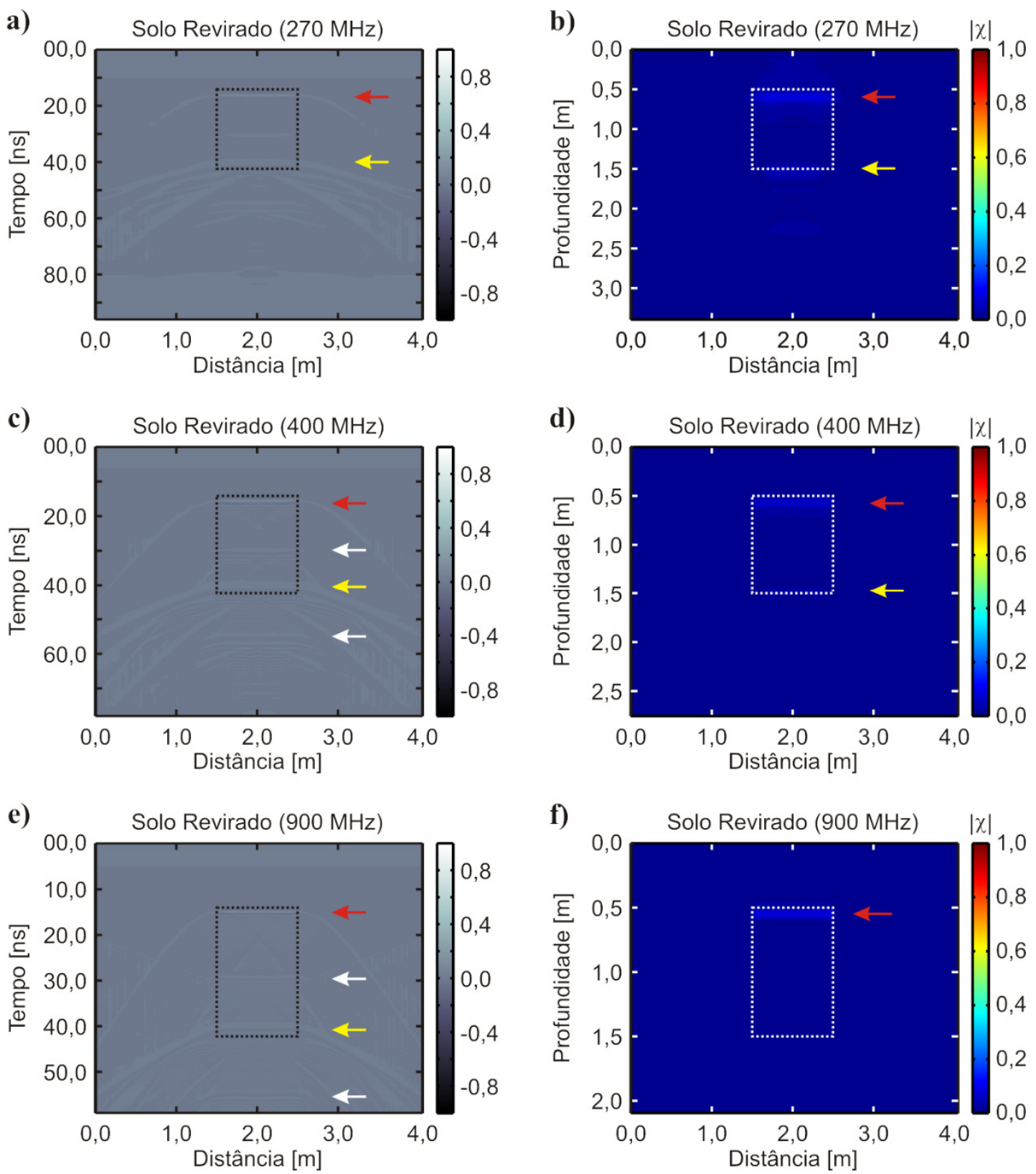

Figura 22. Análise dos dados sintéticos sobre a caixa de solo revirado. Os retângulos de linhas pontilhadas representam os limites verdadeiros do alvo. As setas vermelhas indicam a posição do topo do alvo e as setas amarelas indicam a posição da base dos mesmos. As setas brancas indicam reflexões múltiplas. a) radargrama sintético em 270 MHz. b) imagem tomográfica em $270 \mathrm{MHz}$. c) radargrama sintético em $400 \mathrm{MHz}$. d) imagem tomográfica em $400 \mathrm{MHz}$. e) radargrama sintético em $900 \mathrm{MHz}$. f) imagem tomográfica em $900 \mathrm{MHz}$.

geológico em uma situação real. A mesma condição pode ser observada nas imagens tomográficas correspondentes (Figura 22b, d, f), onde as anomalias relacionadas ao topo e base do alvo (setas vermelha e amarela respectivamente) aparecem com amplitudes menores do que 0,1 . Note-se que neste caso a anomalia referente à base do alvo 
coincide com a posição verdadeira no modelo, visto que o contraste entre as constantes dielétricas no alvo e no meio geológico é pequeno.

A Figura 23 mostra os resultados obtidos para o vaso cerâmico mais raso, à profundidade de $0,50 \mathrm{~m}$. Nesta figura as elipses pontilhadas que indicam o tamanho verdadeiro do alvo referem-se ao diâmetro externo do mesmo. A Figura 23a mostra o radargrama gerado para o vaso mais raso, a $0,50 \mathrm{~m}$ de profundidade. Uma anomalia hiperbólica que corresponde ao topo do alvo pode ser observada em 14,0 ns. A reflexão associada à base do alvo não pode ser identificada, uma vez que a velocidade da onda eletromagnética maior no seu interior $\left(\operatorname{ar}, \epsilon_{r}=1,0\right)$ faz com que esta reflexão seja registrada em 17,8 ns, misturando-se com a reflexão do topo. A hipérbole gerada por este tipo de alvo não permite estimar sua dimensão aproximada, diferentemente das anomalias observadas nos alvos cujas interfaces são planas. Em contrapartida, a anomalia obtida na tomografia (Figura 23b) apresenta uma correspondência boa com a largura da porção superior do alvo, bem como com a profundidade do topo do mesmo (seta vermelha). Note-se que a porção superior da anomalia se encaixa muito bem no contorno da elipse que indica a dimensão verdadeira do alvo. A anomalia fraca observada à profundidade de 1,04 m (seta branca) parece corresponder à localização da base do alvo, porém trata-se na verdade de uma reflexão múltipla entre o topo do alvo e a superfície. A Figura 23c mostra o radargrama sintético obtido com o sinal de 400 MHz. Aqui é possível observar a reflexão no topo do alvo em 14,0 ns (seta vermelha) e, graças ao menor comprimento de onda, é possível também observar a reflexão da base do alvo em 17,8 ns (seta amarela). Observam-se ainda duas reflexões múltiplas em 28,0 ns e 42,0 ns, indicadas pelas setas brancas. Na imagem tomográfica (Figura 23d) observam-se apenas as anomalias relacionadas ao topo e à base do alvo em 0,50 m e 0,64 m respectivamente. A reflexão da base do alvo aparece a esta profundidade por ter sido registrada no dado em um tempo que corresponde à velocidade de propagação da onda eletromagnética no ar contido no interior do vaso. Para esta frequência a anomalia relacionada ao topo do alvo se encaixa dentro do contorno da dimensão verdadeira deste, porém ocupa uma área menor do que a observada nos dados de $270 \mathrm{MHz}$. A Figura 23e mostra os dados modelados para o sinal de $900 \mathrm{MHz}$, onde também é possível identificar as reflexões de topo e base do alvo. As anomalias relacionadas ao topo e base também podem ser identificadas na imagem tomográfica (Figura 23f). 

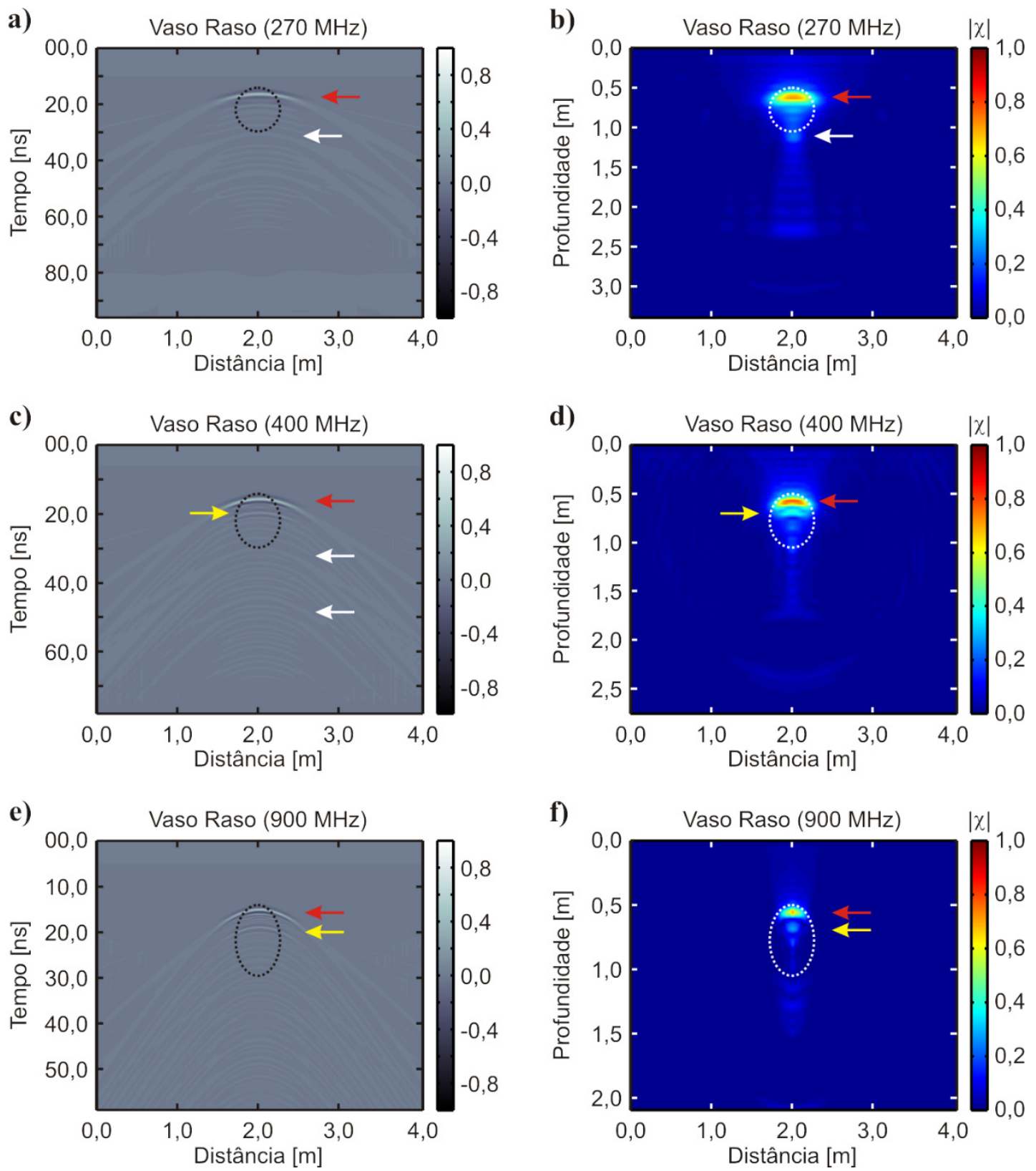

Figura 23. Análise dos dados sintéticos sobre o vaso à profundidade de $0,50 \mathrm{~m}$. As elipses pontilhadas representam os limites verdadeiros do alvo. As setas vermelhas indicam a posição do topo do alvo e as setas amarelas indicam a posição da base dos mesmos. As setas brancas indicam reflexões múltiplas. a) radargrama sintético em 270 MHz. b) imagem tomográfica em $270 \mathrm{MHz}$. c) radargrama sintético em $400 \mathrm{MHz}$. d) imagem tomográfica em $400 \mathrm{MHz}$. e) radargrama sintético em $900 \mathrm{MHz}$. f) imagem tomográfica em $900 \mathrm{MHz}$.

Embora pequena, a anomalia referente ao topo do vaso ainda se encaixa no contorno do diâmetro real do alvo. 
Os resultados observados para o vaso profundo, apresentados na Figura 24, são bastante similares. Os radargrama sintéticos modelados com sinais de $270 \mathrm{MHz}$ (Figura 24a) apresentam apenas a reflexão do topo do alvo, em 28,3 ns. A reflexão da base não é vista devido ao comprimento de onda do sinal, que impede que se possa separar estas duas reflexões. Em 56,6 ns é possível observar ainda uma reflexão múltipla. A imagem tomográfica (Figura 24b) mostra apenas a reflexão do topo do alvo, que coincide com sua profundidade em 1,0 m. A porção superior desta anomalia corresponde exatamente ao contorno da elipse que representa a dimensão verdadeira do alvo. Nos dados modelados para o sinal de $400 \mathrm{MHz}$ (Figura 24c) é possível observar a reflexão relacionada ao topo do alvo em 28,3 ns, porém a reflexão do sinal na base do alvo se confunde com as reverberações e efeitos numéricos decorrentes do processo de modelagem, podendo ser corretamente localizado em 32,0 ns através do cálculo do tempo esperado para seu registro. Por outro lado, a imagem tomográfica destes dados (Figura 24d) permite identificar com maior clareza a anomalia relacionada à base do alvo à profundidade de 1,16 m (seta amarela), logo abaixo da anomalia relacionada ao topo do mesmo em 1,0 m (seta vermelha). Embora esta anomalia esteja relacionada à base do alvo, ela se localiza em uma profundidade menor do que a real devido à maior velocidade de propagação do sinal eletromagnético no ar que preenche os vasos cerâmicos. A reflexão múltipla observada no radargrama sintético não aparece na imagem tomográfica. A Figura 24e apresenta os dados modelados para o sinal de 900 MHz. Nestes dados é possível identificar com clareza a reflexão do topo do alvo em 28,3 ns. A reflexão do fundo do alvo ainda se confunde com as reverberações e efeitos numéricos decorrentes da modelagem, porém ainda são identificáveis à profundidade de 32,0 ns. A imagem tomográfica (Figura 24f) mostra as anomalias relacionadas ao topo e base do alvo de forma bastante clara, porém o posicionamento destas em profundidade é levemente superestimado, com a anomalia do topo aparecendo em 1,07 $\mathrm{m}$ de profundidade e a anomalia da base aparecendo em 1,20 $\mathrm{m}$ de profundidade.

Por fim, a Figura 25 apresenta o resultado para os dados sintéticos referentes à camada de seixos de quartzo de 0,10 m de espessura. Este alvo apresenta uma situação singular, pois sua espessura é inferior ao comprimento de onda do sinal $(\lambda=0,59 \mathrm{~m}$ para a frequência de $270 \mathrm{MHz}, \lambda=0,40 \mathrm{~m}$ para a frequência de $400 \mathrm{MHz}$ e $\lambda=0,18 \mathrm{~m}$ para a frequência de $900 \mathrm{MHz}$ ), de forma que se espera que os sinais empregados não tenham resolução suficiente para separar as interfaces referentes ao topo e à base do 

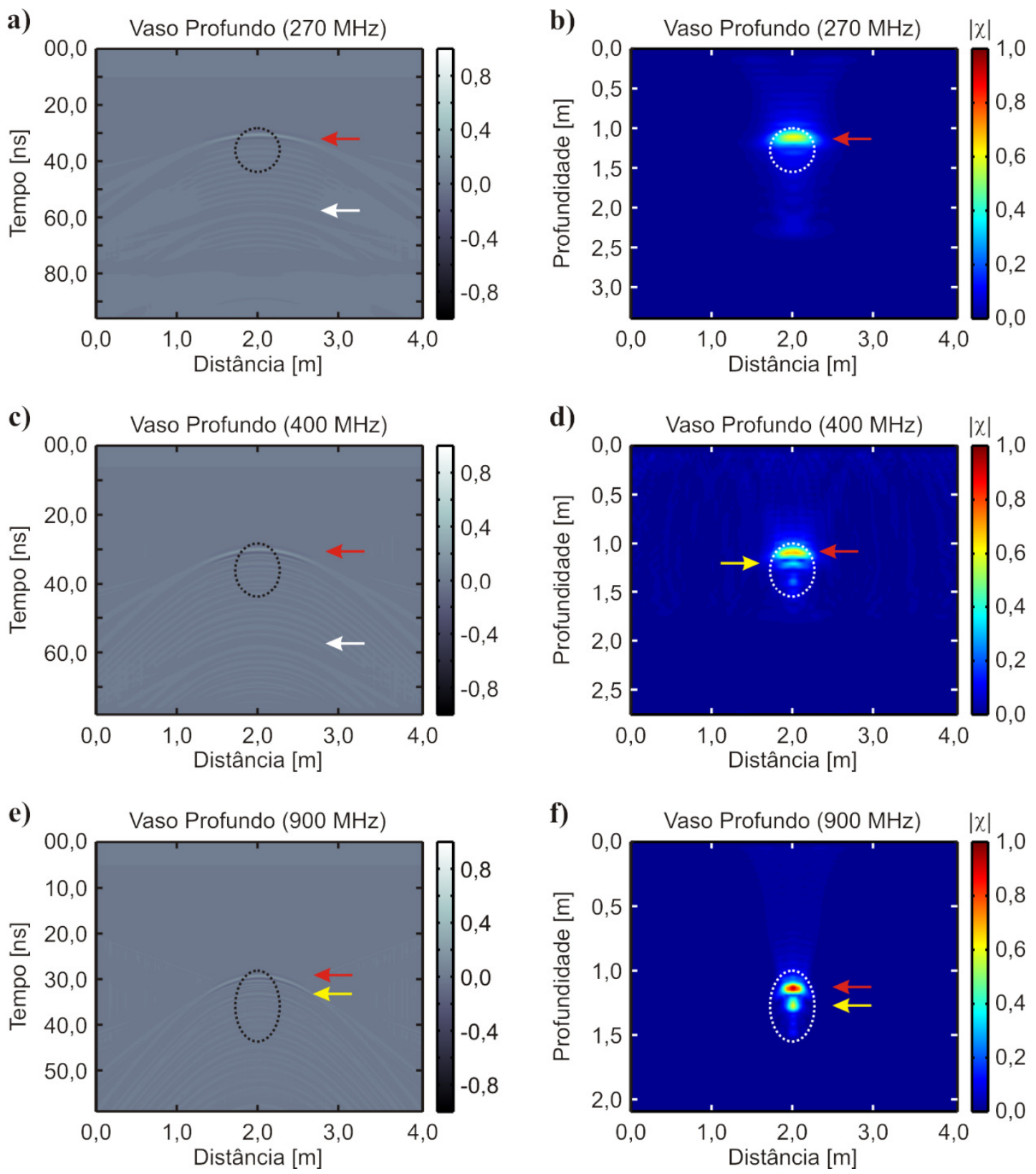

Figura 24. Análise dos dados sintéticos sobre o vaso à profundidade de $1,0 \mathrm{~m}$. As elipses pontilhadas representam os limites verdadeiros do alvo. As setas vermelhas indicam a posição do topo do alvo e as setas amarelas indicam a posição do sinal refletido na base dos mesmos. As setas brancas indicam reflexões múltiplas. a) radargrama sintético em $270 \mathrm{MHz}$. b) imagem tomográfica em $270 \mathrm{MHz}$. c) radargrama sintético em $400 \mathrm{MHz}$. d) imagem tomográfica em $400 \mathrm{MHz}$. e) radargrama sintético em $900 \mathrm{MHz}$. f) imagem tomográfica em $900 \mathrm{MHz}$.

alvo com clareza. Isto faz com que as reflexões em ambas as interfaces nos dados sintéticos de $270 \mathrm{MHz}$ (Figura 25a), de $400 \mathrm{MHz}$ (Figura 25c) e de $900 \mathrm{MHz}$ (Figura 25e) apareçam como uma única anomalia em 14,0 ns. Nos radargramas de $270 \mathrm{MHz}$ e $400 \mathrm{MHz}$ (Figura 25a, c) é possível identificar uma reflexão em 29,0 ns (seta amarela 
com um ponto de interrogação), a qual poderia facilmente ser interpretada como uma interface. Na verdade esta anomalia se refere a uma reflexão múltipla entre os seixos e a superfície. Outras reflexões múltiplas podem ser observadas em tempos posteriores (setas brancas).

A mesma interpretação se aplica à imagem tomográfica destes dados (Figura 25b). A anomalia associada ao topo da camada de seixos de quartzo é facilmente identificada em 0,50 $\mathrm{m}$ de profundidade, apresentando um comprimento equivalente ao comprimento real do alvo no modelo (seta vermelha). A anomalia real associada à base não pode ser separada da anomalia relacionada ao topo. Em lugar disto, uma anomalia relacionada à reflexão múltipla observada em 29,0 ns no radargrama é identificável aqui à profundidade de 1,0 m. Comparando-se esta imagem com as imagens tomográficas das caixas de areia e de brita, pode-se facilmente tomar esta anomalia como sendo a interface inferior de um alvo mais espesso do que o verdadeiro. Além disso, observa-se que duas das reflexões múltiplas ainda permanecem na imagem tomográfica, sendo uma à profundidade de $1,56 \mathrm{~m}$ e outra à profundidade de $2,1 \mathrm{~m}$.

A Figura 25c apresenta o radargrama sintético em $400 \mathrm{MHz}$. Observa-se novamente as mesmas feições observadas nos dados de $270 \mathrm{MHz}$, porém com uma reflexão múltipla a menos. O mesmo ocorre com a imagem tomográfica correspondente (Figura 25d). A primeira múltipla aparece nesta imagem com amplitude de 0,38 , o que é maior do que a amplitude da múltipla observada à profundidade de 1,56 m $(|\chi|=0,13)$. Desta forma, esta múltipla pode ser facilmente confundida com uma interface também nos dados de $400 \mathrm{MHz}$. No radargrama sintético de $900 \mathrm{MHz}$ (Figura 25e) observam-se apenas duas reflexões, a primeira em 14,0 ns e a segunda em 29,0 ns. Neste caso, porém, é possível identificar prontamente que a segunda reflexão é uma múltipla, visto que segue o mesmo padrão de reflexão da primeira anomalia. No radargrama ainda não é possível identificar a base da camada. Sua imagem tomográfica (Figura 25f) mostra que a anomalia localizada em $0,50 \mathrm{~m}$ apresenta o padrão esperado para a anomalia do topo da camada (seta vermelha), que parece ser sobreposta por uma segunda anomalia (seta amarela). Esta anomalia que sobrepõe a anomalia relacionada ao topo da camada refere-se à base da mesma. Nota-se que ambas as anomalias se encaixam no contorno verdadeiro do alvo no modelo. A reflexão múltipla mais profunda, por sua vez, apresenta novamente a característica de uma réplica do conjunto de anomalias referente 

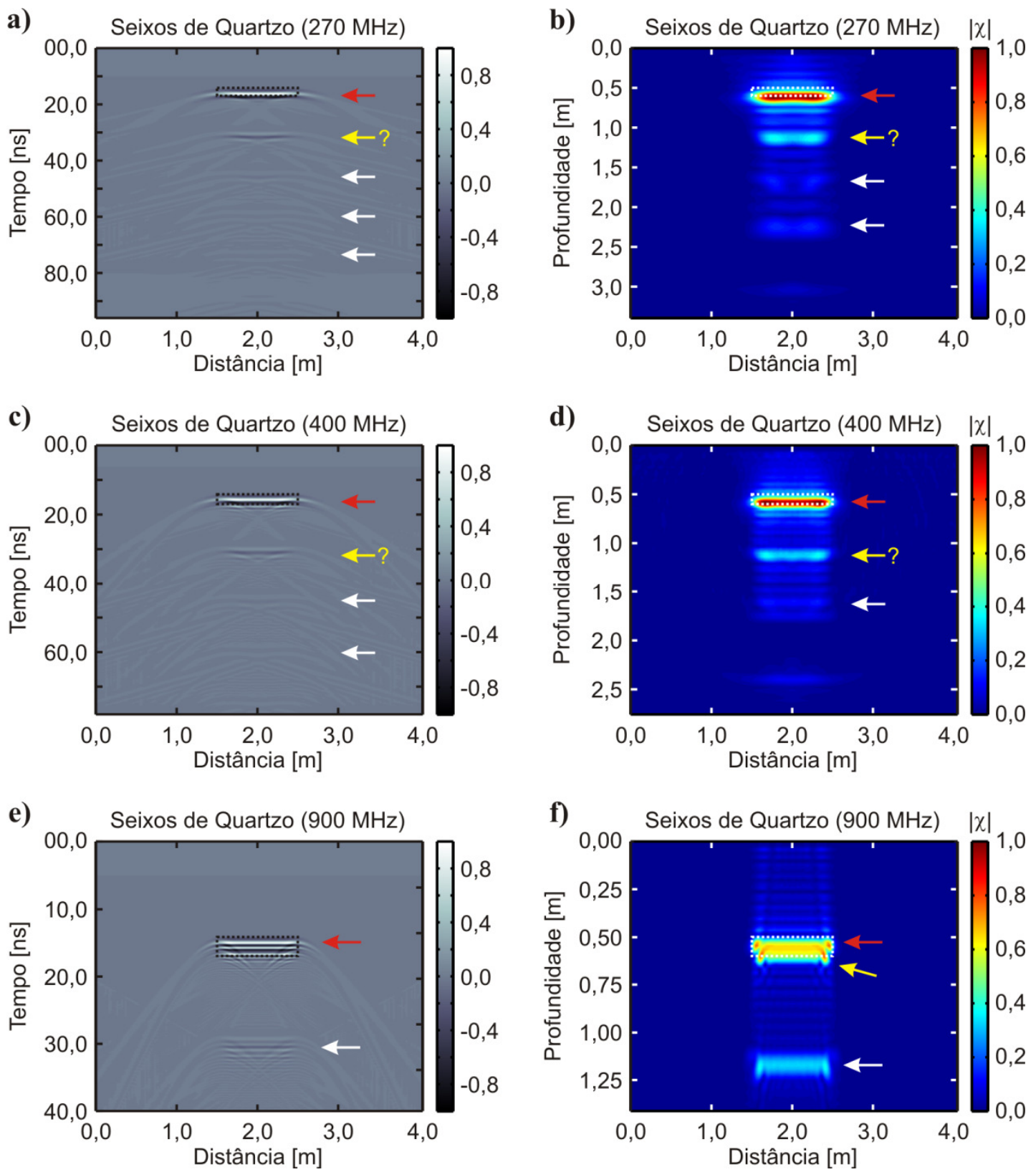

Figura 25. Análise dos dados sintéticos sobre a camada de seixos de quartzo. Os retângulos pontilhados representam os limites verdadeiros do alvo. As setas vermelhas indicam a posição do topo do alvo. As setas amarelas com pontos de interrogação indicam reflexões múltiplas que poderiam ser interpretadas equivocadamente como a base do alvo. As setas brancas indicam reflexões múltiplas. a) radargrama sintético em $270 \mathrm{MHz}$. b) imagem tomográfica em $270 \mathrm{MHz}$. c) radargrama sintético em $400 \mathrm{MHz}$. d) imagem tomográfica em $400 \mathrm{MHz}$. e) radargrama sintético em $900 \mathrm{MHz}$. f) imagem tomográfica em $900 \mathrm{MHz}$.

ao alvo verdadeiro já observada na análise dos dados do muro de tijolos, podendo facilmente ser descartada. 
A análise dos dados sintéticos mostra que o processo a que os dados são submetidos para obtenção das imagens tomográficas é muito bom para estimar a extensão de interfaces plano-horizontais em alvos de geometria retangular, bem como a profundidade do topo dos mesmos. A profundidade da base destes alvos também é identificável, porém apresenta extensão inferior à extensão verdadeira dos alvos. Sua profundidade também não pode ser estimada com precisão, uma vez que o tempo duplo de trânsito em que a reflexão é registrada depende da constante dielétrica do material existente entre estas interfaces (areia, brita ou ar, no caso dos alvos considerados). Em alvos circulares, representados pelos vasos preenchidos com ar, a tomografia pôde identificar com precisão a profundidade do topo. A profundidade da base dos alvos pôde ser identificada apenas nos dados de $400 \mathrm{MHz}$ e $900 \mathrm{MHz}$, tendo sido estimada a uma profundidade menor do que a verdadeira de acordo com o tempo duplo de trânsito da onda eletromagnética registrado e não com relação à sua profundidade verdadeira no modelo. A imagem tomográfica permitiu ainda reduzir o número de reflexões múltiplas observadas nos dados modelados, ou ao menos identificar com mais clareza as reflexões múltiplas através da análise das características das anomalias geradas por estas, sem a necessidade do cálculo do tempo de trânsito para cada reflexão.

A ferramenta de imageamento tomográfico mostrou-se bastante útil em alvos como a caixa de areia, a caixa de brita de granito e dos vasos cerâmicos. No caso do solo revirado a tomografia não foi capaz de fornecer muitas informações, visto que o contraste entre as propriedades elétricas é muito pequeno por se tratar do mesmo material dentro e fora do alvo. No caso dos seixos de quartzo a extensão lateral e a profundidade do topo do alvo foram bem estimadas. Entretanto, por se tratar de um alvo de espessura menor do que o comprimento de onda do sinal a presença de reflexões múltiplas pode induzir a uma interpretação errada nos dados de $270 \mathrm{MHz}$ e $400 \mathrm{MHz}$. Há alguma indicação de separação entre as interfaces superior e inferior do alvo apenas nos dados de $900 \mathrm{MHz}$ e, embora mesmo neste caso as interfaces ainda não possam ser diferenciadas com exatidão, é possível obter esta indicação de forma mais clara do que no radargrama correspondente. 


\subsection{SCGR - Dados reais}

Neste tópico serão apresentadas as análises sobre dados reais adquiridos no SCGR. Os dados foram adquiridos com antenas de $270 \mathrm{MHz}$ e $400 \mathrm{MHz}$. Os alvos foram separados em seções individuais para facilitar a comparação com a análise dos dados sintéticos e para evitar a influência lateral entre alvos diferentes presentes na linha de Arqueologia. Além disso o processo de imageamento requer um elevado uso de memória do computador, de modo que gerar uma única imagem para toda a linha tornase inviável.

Os dados reais estão sujeitos a efeitos que não são observáveis em dados sintéticos, como por exemplo o ruído geológico. Nesta pesquisa considera-se como ruído geológico as anomalias de baixa amplitude observadas no radargrama decorrentes das heterogeneidades naturais do solo. Para minimizar estes efeitos foi feita uma comparação entre seis diferentes combinações de remoção de background: i) timegating, ii) subtração do traço médio, iii) time-gating seguido pela subtração do traço médio, iv) análise de autovalores, v) time-gating seguido pela análise de autovalores e vi) subtração do traço médio seguido pela análise de autovalores. Estas ferramentas foram implementadas no programa de imageamento tomográfico de forma a possibilitar uma análise mais clara sobre cada alvo. As escalas de amplitude foram normalizadas em relação ao valor máximo observado para cada alvo em cada frequência. Ao se aplicar a análise de autovalores sobre os dados a amplitude das anomalias resultantes sofrem uma redução drástica, da ordem de cinco ordens de grandeza. No entanto, esta redução não prejudica a interpretação das imagens; em realidade a interpretação torna-se mais clara como será discutido nos tópicos subsequentes.

\subsubsection{Resultados $2 D$}

A Figura 26 apresenta os resultados 2D obtidos com a antena de $270 \mathrm{MHz}$ sobre a caixa de areia. As Figura 26a, b, c mostram as imagens tomográficas obtidas sobre este alvo aplicando-se as ferramentas de time-gating, subtração do traço médio e uma combinação destas, respectivamente. Nestas três imagens observam-se dois padrões claros de anomalia de amplitude maior do que 0,6 entre as posições de 1,0 m e 3,0 m. 
Estes padrões são assinalados pelas linhas pontilhadas preta e branca, as quais correspondem respectivamente ao topo e à base da caixa de areia. A anomalia associada à base aparece em uma profundidade menor que a esperada $(1,5 \mathrm{~m})$, tal como observado nos dados sintéticos. A anomalia associada ao topo, por outro lado, aparece à profundidade de $0,50 \mathrm{~m}$. Há anomalias similares à profundidade de $0,50 \mathrm{~m}$ no início e no final desta seção. Estas anomalias correspondem à interface entre o material argiloarenoso de cor rósea e o material argilo-arenoso de cor avermelhada descritos por Borges (2007). O conjunto de anomalias associado ao topo da caixa diferencia-se das anomalias associadas à interface geológica devido à proximidade dos picos de amplitude e pelo seu alinhamento quase horizontal. Abaixo da base da caixa podem ser observadas anomalias fracas de amplitude menor do que 0,4. Estas anomalias representam o clutter, ou o ruído geológico decorrente das heterogeneidades ou distúrbios no solo, e são feições bastante comuns em uma imagem tomográfica. As Figura 26d, e, f introduzem a remoção de background por análise de autovalores desenvolvida por Khan e Al-Nuaimy (2010). A primeira característica a ser observada neste caso é que o ruído geológico é fortemente reduzido, e as anomalias já apontadas como sendo referentes à caixa de areia ficam mais bem definidas. Ao se combinar esta ferramenta com uma etapa prévia de time-gating (Figura 26e) ou de subtração do traço médio (Figura 26f) duas novas feições passam a ser observadas com amplitude muito baixa. Estas feições são indicadas nas figuras por linhas amarelas pontilhadas, e podem ser causadas pelas laterais da caixa de areia. Estas feições aparecem muito fracas nas imagens devido à pequena quantidade de energia decorrente destas reflexões registrada pelo equipamento.

A Figura 27 apresenta os resultados obtidos neste mesmo alvo com a antena de $400 \mathrm{MHz}$. As Figura 27a, b, c apresentam as imagens tomográficas com a aplicação do time-gating em 06 ns, com a subtração do traço médio e com a análise de autovalores, respectivamente, todas com interpretações bastante similares. Em todas as figuras a anomalia do topo da caixa de areia aparece claramente em $0,55 \mathrm{~m}$ de profundidade. É possível observar também a anomalia relacionada à base da caixa em 1,20 $\mathrm{m}$ de profundidade. Entre as anomalias do topo e da base existe uma grande quantidade de anomalias de menor amplitude, as quais fornecem fortes indícios de que estas duas anomalias possam estar relacionadas a um mesmo alvo de propriedades elétricas diferentes daquelas do meio geológico. Isto mostra que nem sempre o as anomalias 
a)
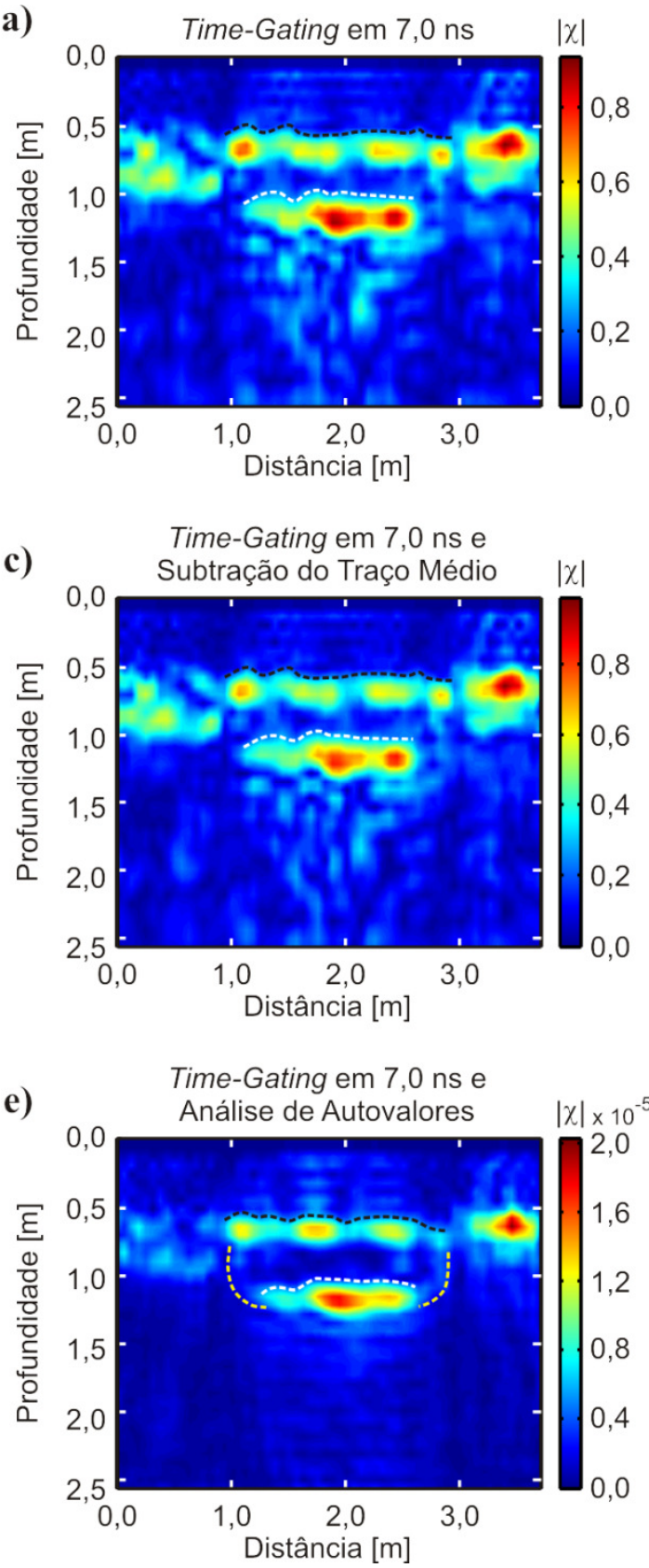
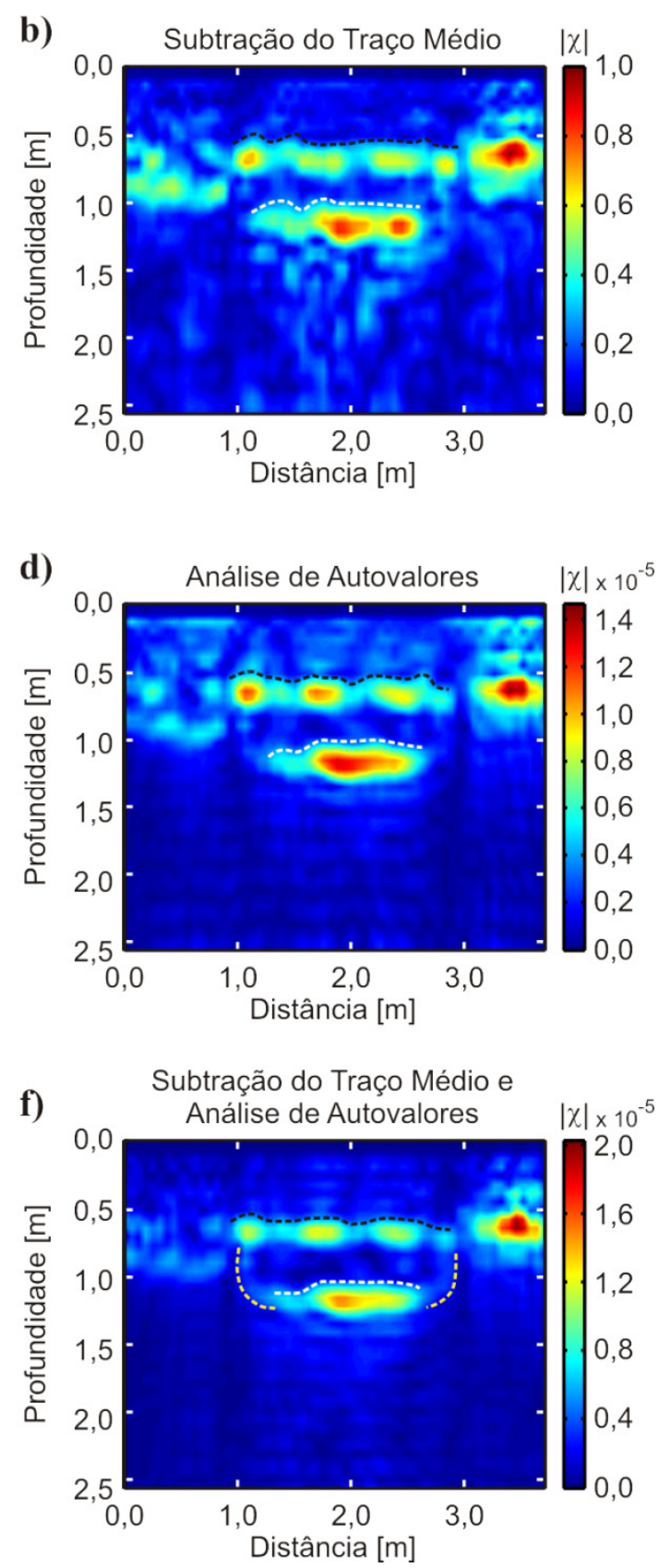

Figura 26. Imagens tomográficas obtidas a partir dos dados adquiridos com antena de $270 \mathrm{MHz}$ sobre a caixa de areia. a) remoção de background por time-gating. b) remoção de background por subtração do traço médio. c) remoção do background por timegating seguido pela subtração do traço médio. d) remoção do background por análise de autovalores. e) remoção de background por time-gating seguido pela análise de autovalores. f) remoção de background por subtração do traço médio seguido pela análise de autovalores.

geradas por heterogeneidades naturais são necessariamente prejudiciais à interpretação da imagem. Assim, é possível traçar um contorno para o que seria o alvo, o qual é representado pela linha tracejada branca. Este contorno apresenta formato aproximadamente retangular, estendendo-se da posição de $1,60 \mathrm{~m}$ à posição de $3,20 \mathrm{~m}$, 
correspondendo a um comprimento de 1,60 m (0,60 m menor do que o comprimento real do alvo). Quando se inclui a análise de autovalores na remoção de background (Figura 27d, e, f) o ruído g eológico é fortemente reduzido. Isto permite identificar com clareza a interrupção na série de anomalias próximas a $0,50 \mathrm{~m}$ de profundidade, a qual é indicada pelas linhas tracejadas amarelas. Suas posições, de 0,90 m e 3,20 m, correspondem à extensão do alvo. A variação na amplitude da anomalia entre estas posições pode ser provocada por variações na amplitude do sinal registrado no radargrama, o que é resolvido como anomalias de diferentes amplitudes durante o processo de imageamento tomográfico.
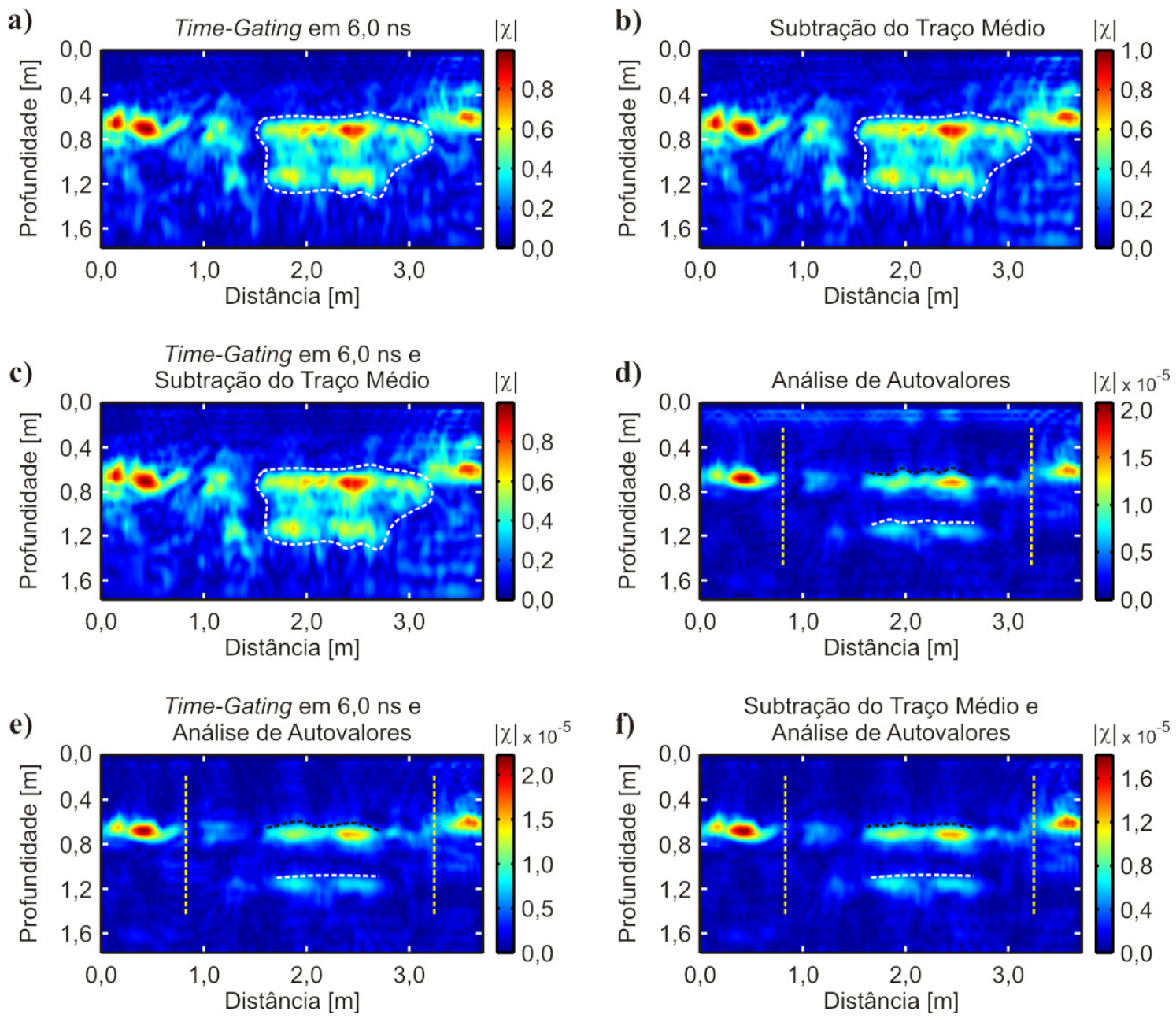

Figura 27. Imagens tomográficas obtidas a partir dos dados adquiridos com antena de $400 \mathrm{MHz}$ sobre a caixa de areia. a) remoção de background por time-gating. b) remoção de background por subtração do traço médio. c) remoção do background por time-gating seguido pela subtração do traço médio. d) remoção do background por análise de autovalores. e) remoção de background por time-gating seguido pela análise de autovalores. f) remoção de background por subtração do traço médio seguido pela análise de autovalores. 
A Figura 28 mostra a análise das imagens obtidas com dados adquiridos com antena de $270 \mathrm{MHz}$ sobre a caixa de brita de granito. As Figura 28a, b, c mostram as imagens obtidas com aplicação de time-gating em 7,0 ns, com subtração de traço médio e com uma combinação de ambos. Exceto por uma diferença sutil na amplitude das anomalias não se observa melhoria significativa em alguma situação específica. Nas três figuras é possível identificar a anomalia do topo (linha tracejada preta) e da base (linha tracejada branca) do alvo. A anomalia indicada pela seta vermelha poderia ser interpretada como parte do alvo, porém nota-se que ela não apresenta o mesmo padrão de amplitude e de dimensões daquelas indicadas sob a linha tracejada preta. É possível identificar também uma anomalia bastante sutil, indicada pela linha tracejada amarela, que sugere uma conexão entre a anomalia da base e a do topo. As Figura 28d, e, f mostram de forma mais evidente a diferença entre a anomalia do topo (linha tracejada preta) e a anomalia indicada pela seta vermelha. Não há uma alteração significativa na dimensão das anomalias relacionadas ao alvo real, porém o ruído geológico é fortemente atenuado. A feição indicada pela linha tracejada amarela nas três primeiras imagens desta figura também é suprimida.

A Figura 29 mostra as imagens para a caixa de brita de granito obtidas com a antena de $400 \mathrm{MHz}$. As imagens obtidas com aplicação de time-gating, subtração de traço médio e com ambos (Figura 29a, b, c) apresentam resultados bastante similares. Em todas estas imagens é possível identificar uma anomalia de formato aproximadamente retangular à profundidade de $0,55 \mathrm{~m}$ entre as posições de 4,70 $\mathrm{m} \mathrm{e}$ $6,80 \mathrm{~m}$, representada pelo contorno branco tracejado. Esta anomalia possui um comprimento de $2,10 \mathrm{~m}$, o que é bastante próximo do comprimento real do alvo $(2,20$ $\mathrm{m})$. O conjunto compreendido pelo contorno estende-se em profundidade de $0,55 \mathrm{~m}$ até $1,20 \mathrm{~m}$, correspondendo a uma espessura de $0,65 \mathrm{~m}$. Conforme foi observado nos dados sintéticos, é esperado que a anomalia relacionada ao fundo da caixa de brita se localize a uma profundidade menor do que a real devido à diferença na velocidade de propagação do sinal eletromagnético em relação ao meio geológico. Após aplicar a análise de autovalores para obter os resultados apresentados nas Figura 29d, e, f o ruído geológico é removido de tal modo que as anomalias relacionadas ao interior da caixa de brita são suprimidas, sobrando apenas as anomalias do topo e da base. A análise conjunta de todas estas ferramentas permite observar que as anomalias às profundidades de $0,55 \mathrm{~m} \mathrm{e}$ 

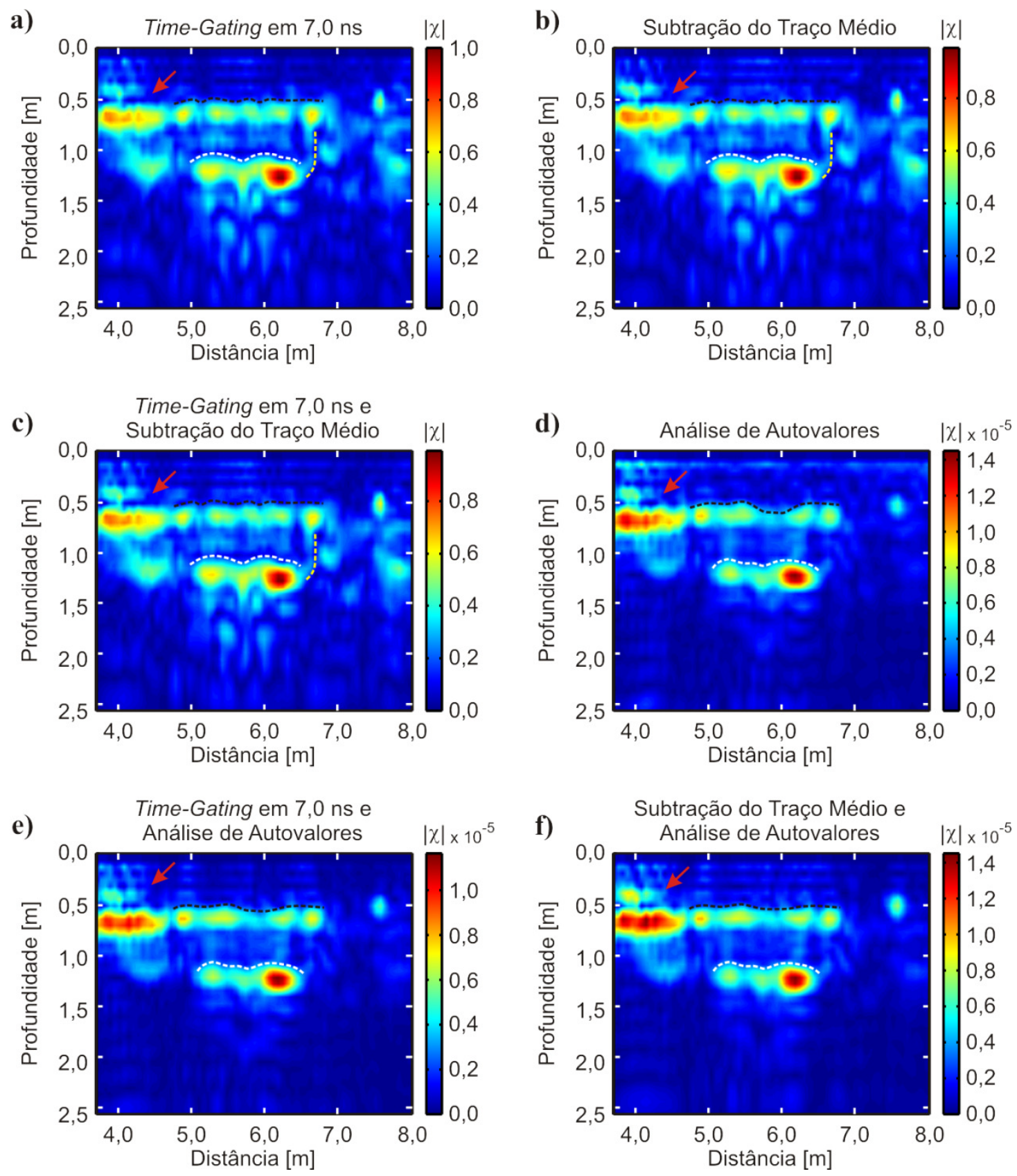

Figura 28. Imagens tomográficas obtidas a partir dos dados adquiridos com antena de $270 \mathrm{MHz}$ sobre a caixa de brita de granito. a) remoção de background por time-gating. b) remoção de background por subtração do traço médio. c) remoção do background por time-gating seguido pela subtração do traço médio. d) remoção do background por análise de autovalores. e) remoção de background por time-gating seguido pela análise de autovalores. f) remoção de background por subtração do traço médio seguido pela análise de autovalores.

de 1,20 m devem-se a variações significativas no contraste entre propriedades elétricas e não a efeitos do ruído geológico, e que além disso estão relacionadas a um mesmo alvo. 
a)
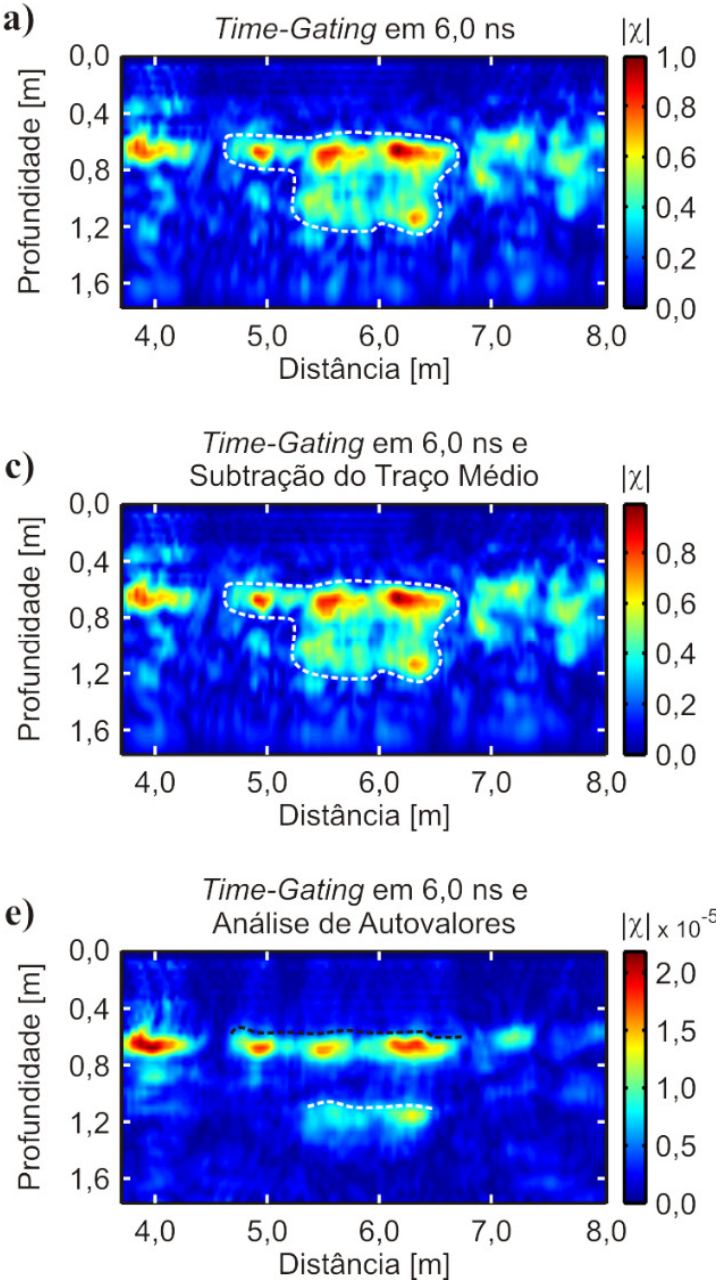
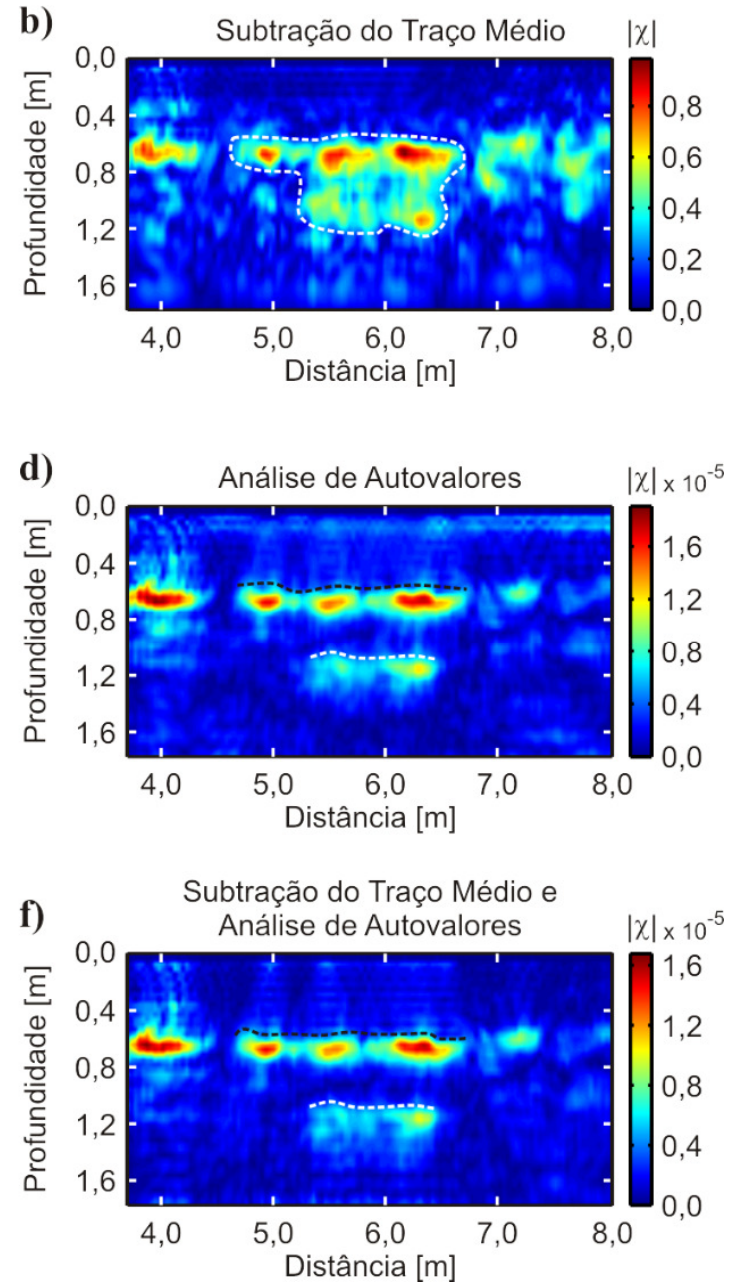

Figura 29. Imagens tomográficas obtidas a partir dos dados adquiridos com antena de $400 \mathrm{MHz}$ sobre a caixa de brita de granito. a) remoção de background por time-gating. b) remoção de background por subtração do traço médio. c) remoção do background por time-gating seguido pela subtração do traço médio. d) remoção do background por análise de autovalores. e) remoção de background por time-gating seguido pela análise de autovalores. f) remoção de background por subtração do traço médio seguido pela análise de autovalores.

A Figura 30 apresenta as imagens tomográficas obtidas sobre o muro de tijolos com a antena de $270 \mathrm{MHz}$. Este alvo apresenta certa dificuldade em ser identificado por ser disposto paralelamente à direção do perfil. Na Figura 30a é possível identificar uma feição que parece ser o topo do alvo, posicionado à profundidade de $0,45 \mathrm{~m}$ (linha tracejada preta) que vai da posição 9,20 m até 11,0 m. Estes valores correspondem à extensão real do alvo e à sua profundidade real. Abaixo desta anomalia observa-se uma outra, à profundidade de $0,80 \mathrm{~m}$ e indicada pela linha tracejada branca. Esta anomalia 
pode estar relacionada ao fundo do buraco que foi escavado para instalação do alvo durante a construção do SCGR.

A Figura 30b mostra várias anomalias isoladas e é de difícil interpretação. Duas anomalias destacam-se à profundidade de $0,50 \mathrm{~m}$, as quais são indicadas pelas setas vermelhas. Estas anomalias destacam-se por apresentarem uma certa inclinação que não é observada em nenhuma outra anomalia da imagem. Elas podem estar relacionadas à influência das arestas do muro de tijolos, uma vez que a distância entre elas (1,80 m, de 9,20 m a 11,0 m) é comparável à extensão real do alvo (2,0 m). As anomalias indicadas pelas setas amarelas podem estar relacionadas ao fundo do buraco onde foi instalado o muro de tijolos, porém a profundidade destas anomalias varia de $0,80 \mathrm{~m}$ a $1,0 \mathrm{~m}$, o que difere do fundo real do buraco, que é plano-horizontal em 1,0 m. Uma interpretação bastante semelhante pode ser feita sobre a imagem mostrada na Figura 30c, onde novamente são observadas anomalias possivelmente associadas às arestas do muro (setas vermelhas) e ao fundo do buraco (setas amarelas).

A imagem da Figura 30d não permite identificar muitas anomalias porque o sinal refletido na superfície é predominante, já que esta reflexão no radargrama é mais significativa do que a reflexão do muro. As únicas anomalias identificáveis localizam-se entre 9,0 m e 10,4 m à profundidade de 1,0 m (setas amarelas). Desta vez as anomalias podem ser associadas ao fundo do buraco com maior confiabilidade, uma vez que apresentam uma disposição conjunta de aspecto plano-horizontal. As Figura 30e, f possuem interpretações similares, uma vez que são bastante semelhantes. As anomalias possivelmente associadas às arestas do muro são observadas novamente (setas vermelhas), bem como o provável fundo do buraco (linhas tracejadas brancas). Nestas imagens observa-se ainda que existe algum ruído geológico antes de 8,90 m e após 11,10 m, o que não acontece entre estas posições à exceção das anomalias indicadas pelas setas vermelhas. Isto sugere que as posições de $8,90 \mathrm{~m}$ e $11,10 \mathrm{~m}$ possam representar os limites do buraco escavado para instalação do muro, onde o padrão geológico natural teria sido perturbado.

A Figura 31 mostra as imagens obtidas com os dados de $400 \mathrm{MHz}$ sobre o muro de tijolos. As Figura 31a, b, c assemelham-se bastante e portanto sua interpretação é praticamente a mesma. A interpretação destas imagens requer bastante atenção em virtude da grande quantidade de anomalias que são observadas, provavelmente pelo 

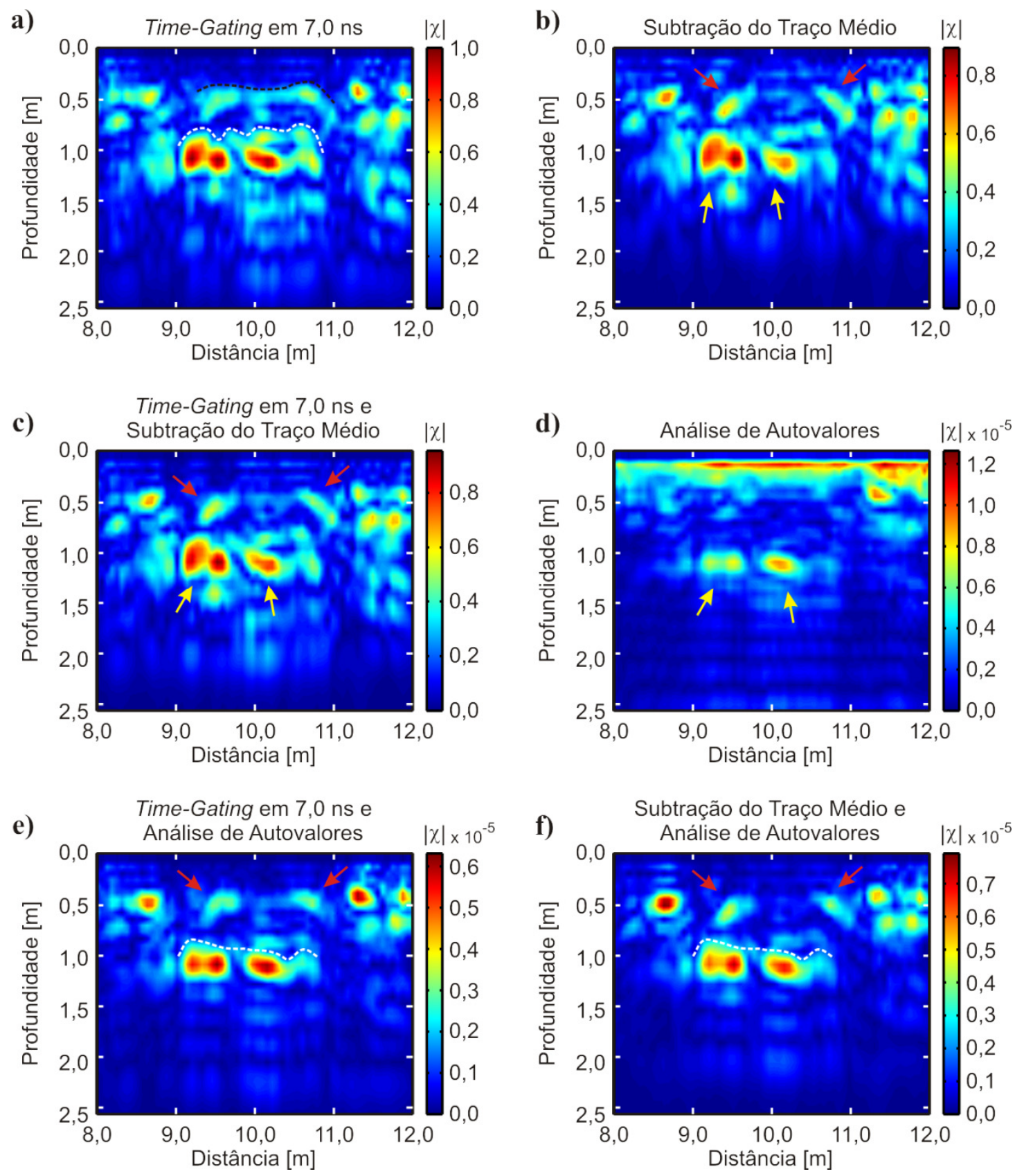

Figura 30. Imagens tomográficas obtidas a partir dos dados adquiridos com antena de $270 \mathrm{MHz}$ sobre o muro de tijolos. a) remoção de background por time-gating. b) remoção de background por subtração do traço médio. c) remoção do background por time-gating seguido pela subtração do traço médio. d) remoção do background por análise de autovalores. e) remoção de background por time-gating seguido pela análise de autovalores. f) remoção de background por subtração do traço médio seguido pela análise de autovalores.

baixo contraste entre as propriedades elétricas deste alvo e as do solo. Considerando-se a proximidade entre anomalias de amplitude semelhante é possível delimitar uma região 
(linha tracejada branca) que engloba estas anomalias e as separa do restante do meio geológico. Esta região estende-se da posição de 9,0 m à posição de 11,80 m e de 0,40 m a 1,20 $\mathrm{m}$ de profundidade. Estas dimensões de 2,80 $\mathrm{m}$ de comprimento e 0,80 $\mathrm{m}$ de espessura assemelham-se às dimensões do muro de tijolos $(2,0 \mathrm{~m} \times 0,50 \mathrm{~m})$, sugerindo que este conjunto de anomalias possa estar relacionado ao alvo. Estas imagens mostram que o alvo não precisa necessariamente estar associado ao formato de uma anomalia específica, podendo também ser associado a todo um conjunto. Neste caso as várias anomalias podem estar sendo provocadas por interações do sinal eletromagnético no interior do muro. A Figura 31d, obtida a partir da remoção por análise de autovalores não fornece quaisquer informações acerca do alvo, pois a anomalia causada pela reflexão do sinal na superfície do solo é predominante. Entretanto, quando se remove esta influência através do time-gating (Figura 31e) ou da subtração do traço médio (Figura 31f) seguidas pela análise de autovalores as anomalias passam a ser identificadas com resultados semelhantes em ambas as situações. Em ambos os casos é possível novamente delimitar uma região com base na proximidade de anomalias de amplitudes semelhantes. Neste caso a região delimitada é menor, possuindo extensão de 2,50 $\mathrm{m}$ (de 9,10 $\mathrm{m}$ a 11,60 m) e espessura de 0,55 m (de 0,45 a 1,0 m de profundidade), o que já se aproxima melhor da dimensão real do alvo.

Na pesquisa desenvolvida durante a instalação dos alvos do SCGR, Borges (2007) relata que o muro de tijolos só pôde ser identificado com uso de antenas de frequência superior a $500 \mathrm{MHz}$. As imagens obtidas através da tomografia de microondas sugerem que é possível extrair alguma informação acerca da presença de alvos no subsolo com baixo contraste de propriedades elétricas e que possam deixar de ser observados no radargrama devido à baixa influência que exercem sobre o sinal eletromagnético ante outras feições observadas com mais clareza, ainda que estes alvos não sejam delimitados com exatidão.

A Figura 32 apresenta as imagens obtidas com a antena de $270 \mathrm{MHz}$ sobre a região de solo revirado. Conforme observado nos dados sintéticos possíveis anomalias geradas por este alvo são de difícil identificação devido ao baixo contraste entre a constante dielétrica dentro e fora do alvo. Além disso, os dados apresentados aqui foram coletados no ano de 2012, dez anos após a instalação dos alvos no SCGR. Após todo este tempo, é esperado que o material tenha se assentado e que o ruído geológico 

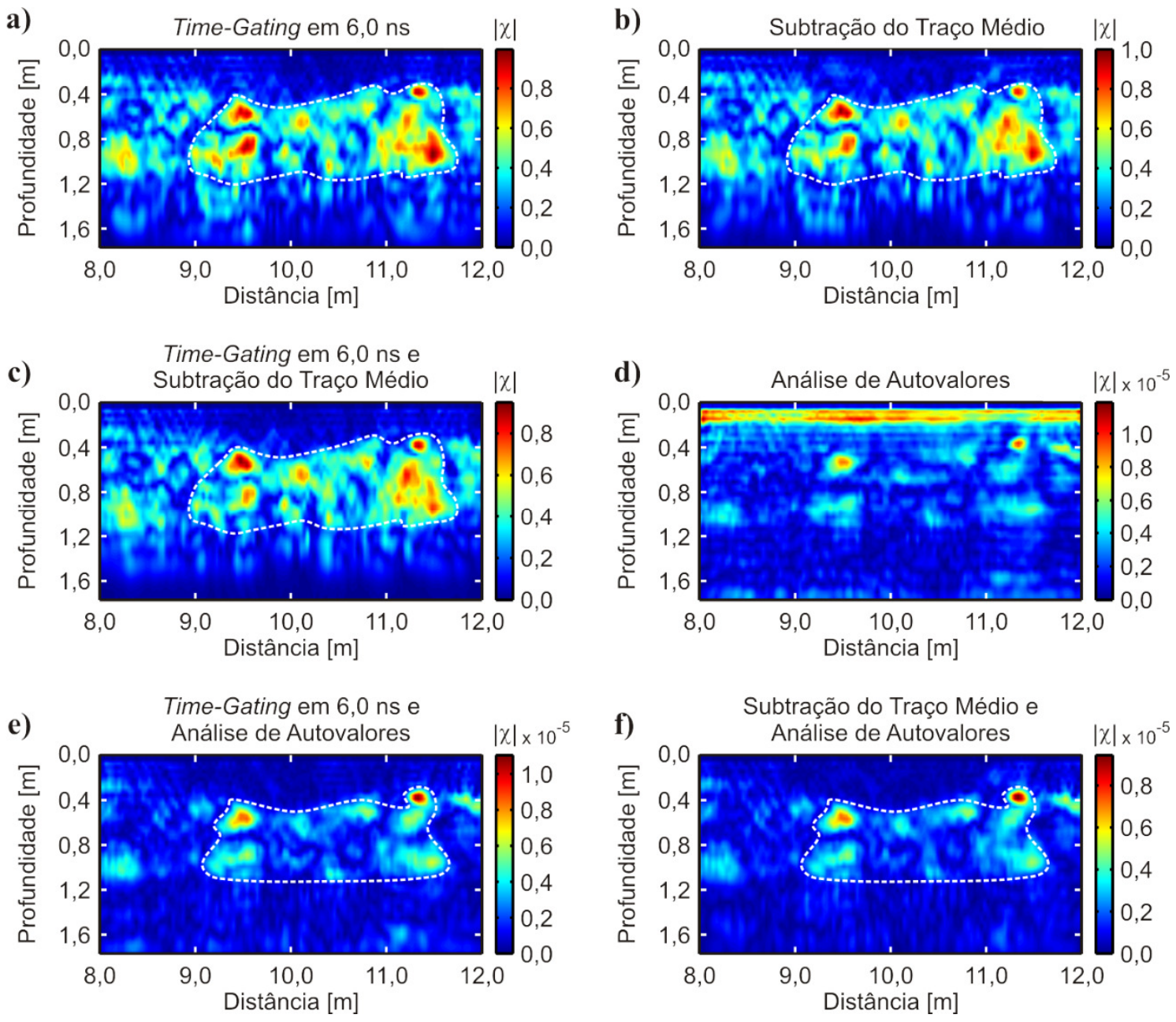

Figura 31. Imagens tomográficas obtidas a partir dos dados adquiridos com antena de $400 \mathrm{MHz}$ sobre o muro de tijolos. a) remoção de background por time-gating. b) remoção de background por subtração do traço médio. c) remoção do background por time-gating seguido pela subtração do traço médio. d) remoção do background por análise de autovalores. e) remoção de background por time-gating seguido pela análise de autovalores. f) remoção de background por subtração do traço médio seguido pela análise de autovalores.

observado no interior deste alvo se assemelhe ao ruído geológico observado fora dele, visto que trata-se do mesmo material, salvo por eventuais camadas interrompidas durante o processo de escavação.

Nas Figura 32a, b, c é possível fazer uma interpretação semelhante àquela feita sobre o muro de tijolos nos dados de $400 \mathrm{MHz}$. As linhas tracejadas brancas nestas imagens separam uma região em que existe alta concentração de ruído geológico de uma região em que esta concentração é menor. Esta diferença pode ser um indicativo de que o material geológico foi perturbado, alterando-se a distribuição natural das 
heterogeneidades. Apenas algumas poucas anomalias isoladas (setas vermelhas) são observadas acima da linha que separa as regiões. Como é sabido não haver alvos neste local, estas anomalias são causadas apenas por heterogeneidades naturais do solo. Isto tanto é verdade que, após a remoção de background através da análise de autovalores (Figura 32d) e da sua combinação com as outras duas ferramentas empregadas (Figura 32e, f), estas anomalias são suprimidas juntamente com várias outras. Nestas três imagens não é mais possível traçar a linha que delimitaria a região do solo perturbado, porém ainda é possível observar que existe uma interrupção nas feições observadas antes de 12,5 m e após 13,4 m. Note-se como não há padrão algum entre estas posições (indicadas pelas linhas tracejadas amarelas) quando em comparação com as regiões antes e após as mesmas. Esta região sem a presença de anomalias compreende uma extensão de 0,90 m, o que é comparável à extensão da área perturbada do solo, que é de $1,0 \mathrm{~m}$.

As imagens obtidas com a antena de $400 \mathrm{MHz}$ sobre esta região mostram resultados similares (Figura 33). Nas Figura 33a, b, c é possível novamente traçar uma linha que separa regiões com maior concentração de anomalias daquelas com menor concentração de anomalias (linha tracejada branca). O contorno apresentado na interpretação destas figuras mostra claramente uma interrupção entre as posições de 12,50 m e 13,50 m, o que corresponde à extensão do buraco escavado. Enquanto nos dados de $270 \mathrm{MHz}$ foi possível traçar este limite até uma profundidade de 1,50 m, nos dados de $400 \mathrm{MHz}$ este limite pode ser traçado apenas até a profundidade de 0,90 m. É possível que as anomalias identificadas aqui se misturem àquelas causadas pelas mesmas heterogeneidades indicadas por setas vermelhas na Figura 32. O menor comprimento de onda do sinal faz com que aquelas anomalias se confundam com anomalias menores observáveis apenas nos dados de $400 \mathrm{MHz}$ e induzindo a erros de interpretação. A remoção de background por análise de autovalores (Figura 33d) e as combinações desta com o time-gating e com a subtração do traço médio (Figura 33e, f) apresenta novamente a interrupção do padrão de anomalias entre 12,50 e 13,40 m, sugerindo novamente que estes sejam os limites da região com solo perturbado. 

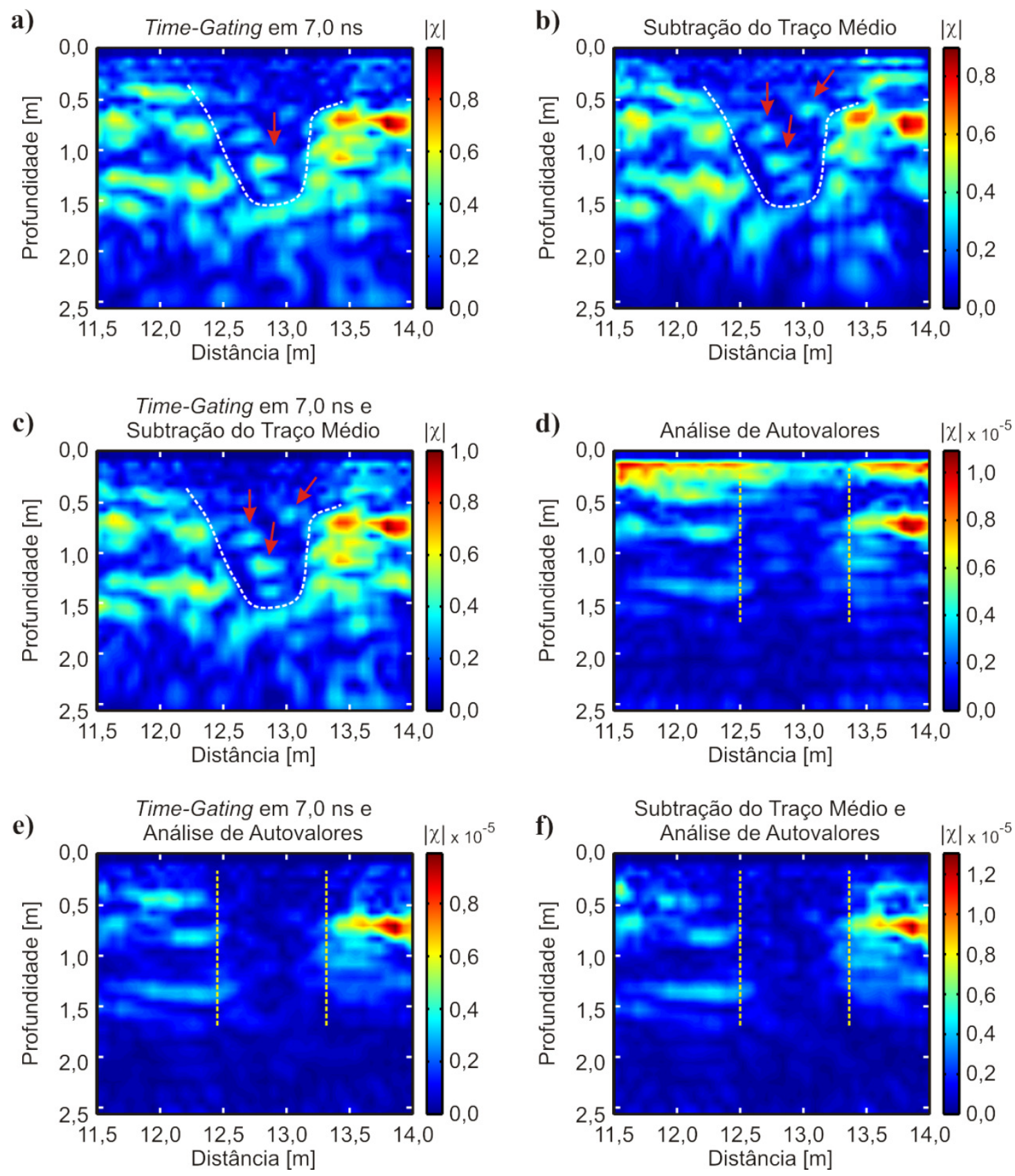

Figura 32. Imagens tomográficas obtidas a partir dos dados adquiridos com antena de $270 \mathrm{MHz}$ sobre a região de solo revirado. a) remoção de background por time-gating. b) remoção de background por subtração do traço médio. c) remoção do background por time-gating seguido pela subtração do traço médio. d) remoção do background por análise de autovalores. e) remoção de background por time-gating seguido pela análise de autovalores. f) remoção de background por subtração do traço médio seguido pela análise de autovalores. 

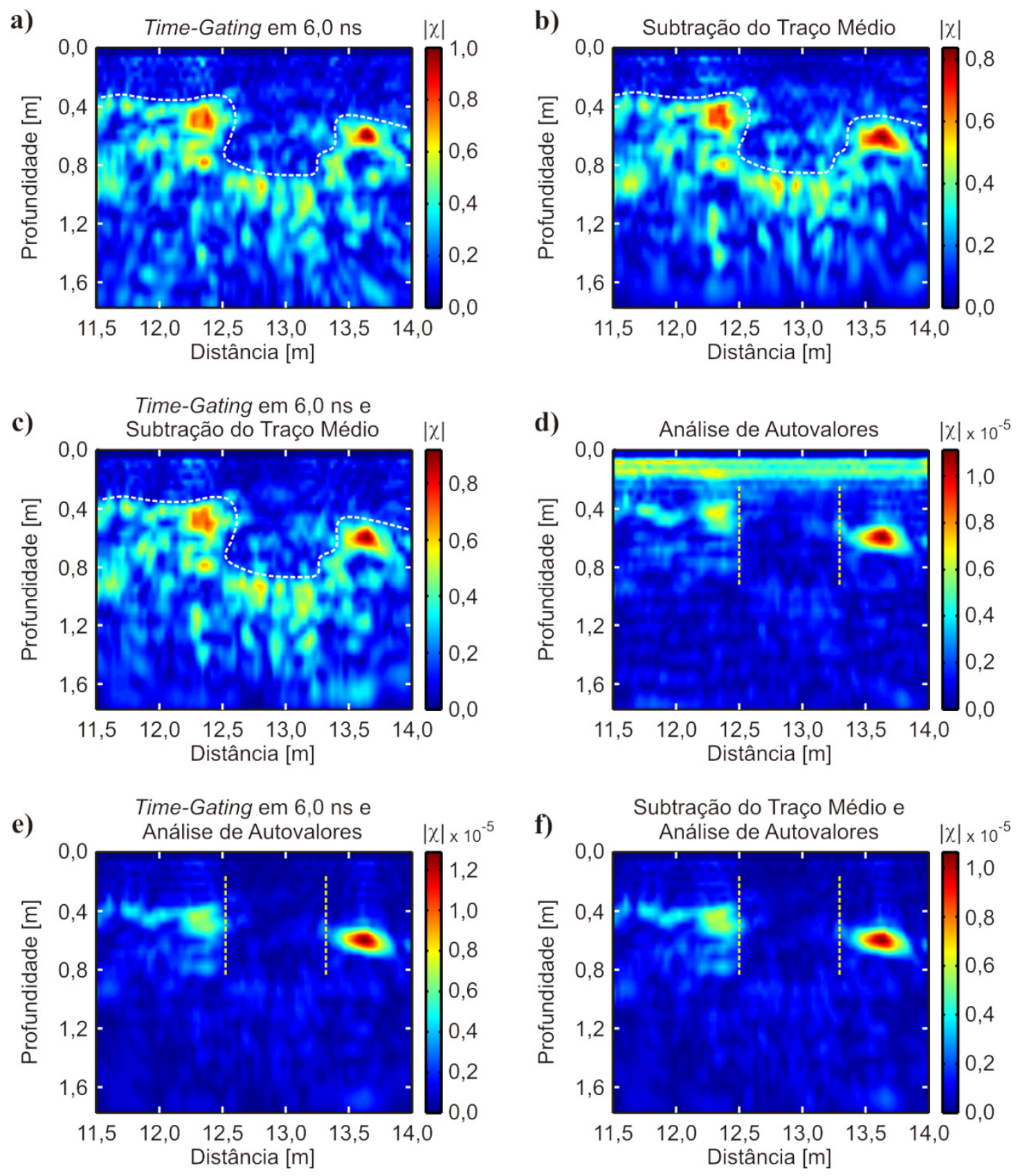

Figura 33. Imagens tomográficas obtidas a partir dos dados adquiridos com antena de $400 \mathrm{MHz}$ sobre a região de solo revirado. a) remoção de background por time-gating. b) remoção de background por subtração do traço médio. c) remoção do background por time-gating seguido pela subtração do traço médio. d) remoção do background por análise de autovalores. e) remoção de background por time-gating seguido pela análise de autovalores. f) remoção de background por subtração do traço médio seguido pela análise de autovalores.

A Figura 34 mostra as imagens tomográficas obtidas para os dados de $270 \mathrm{MHz}$ sobre o vaso mais raso, a 0,50 $\mathrm{m}$ de profundidade. As imagens obtidas após a remoção de background com time-gating em 7,0 ns (Figura 34a), com a subtração do traço médio 
(Figura 34b) e com a combinação de ambos (Figura 34c) apresentam resultados similares. Uma anomalia é observada com clareza à profundidade de 0,50 m e na posição de 17,40 m, indicada pela seta vermelha em cada uma destas imagens. Esta anomalia aparece com um contorno mais bem definido do que as demais. Pela sua posição e definição esta anomalia pode ser associada ao vaso mais raso. Conforme observado nos dados sintéticos, não é possível estabelecer a localização da base deste alvo. Entre as posições de 17,55 m e $18,80 \mathrm{~m}$, à profundidade de 1,0 m pode ser observada uma anomalia (indicada pela linha tracejada preta) que, em uma situação não controlada, poderia ser interpretada como uma anomalia de interesse. Quando se aplica a remoção de background por análise de autovalores (Figura 34d, e, f) esta anomalia é fortemente atenuada. Nestas imagens que as anomalias correspondentes ao vaso cerâmico, apontada pelas setas vermelhas, aparecem com maior destaque. Além disso, em todas as imagens a anomalia causada pelo alvo aparece em uma região em que parece haver uma interrupção na anomalia horizontal presente à profundidade de 0,50 m. Esta interrupção é indicada pelas linhas tracejadas amarelas e se estende de 16,50 m a 18,0 m e corresponde à extensão do buraco escavado para instalação do alvo durante a construção do SCGR de acordo com o mapa apresentado por Borges (2007).

A Figura 35 apresenta os resultados obtidos com os dados de $400 \mathrm{MHz}$ sobre o vaso mais raso. Neste caso não se observam muitas anomalias além daquela provocada pelo alvo real, indicada pelas setas vermelhas em todas as imagens. Nas imagens onde o background foi removido através do time-gating (Figura 35a), subtração do traço médio (Figura 35b) e com a combinação de ambos (Figura 35c) é possível observar que a anomalia associada ao vaso cerâmico aparece em uma região onde há a interrupção das anomalias fracas $(|\chi|<0,4)$ ao longo do eixo da distância. Esta interrupção se inicia em $16,95 \mathrm{~m}$ e varia com a profundidade entre as posições de $17,90 \mathrm{~m}$ e $18,10 \mathrm{~m}$, sendo indicada pelas linhas tracejadas amarelas. Assim como observado nos dados de 270 $\mathrm{MHz}$, esta região sugere a escavação do solo para colocação do objeto em seu interior. A anomalia associada ao alvo, por sua vez, apresenta uma extensão vertical entre 0,55 m e 0,95 m, sugerindo que o alvo tenha uma circunferência da ordem de 0,40 m. Embora esta estimativa possa dar uma ideia aproximada da dimensão real do alvo $(0,55$ m), neste caso não se pode afirmar se a anomalia inferior é causada por alguma feição relacionada ao alvo ou a algum outro tipo de heterogeneidade. De fato, ao se aplicar a remoção de background por análise de autovalores (Figura 35d) a anomalia associada 

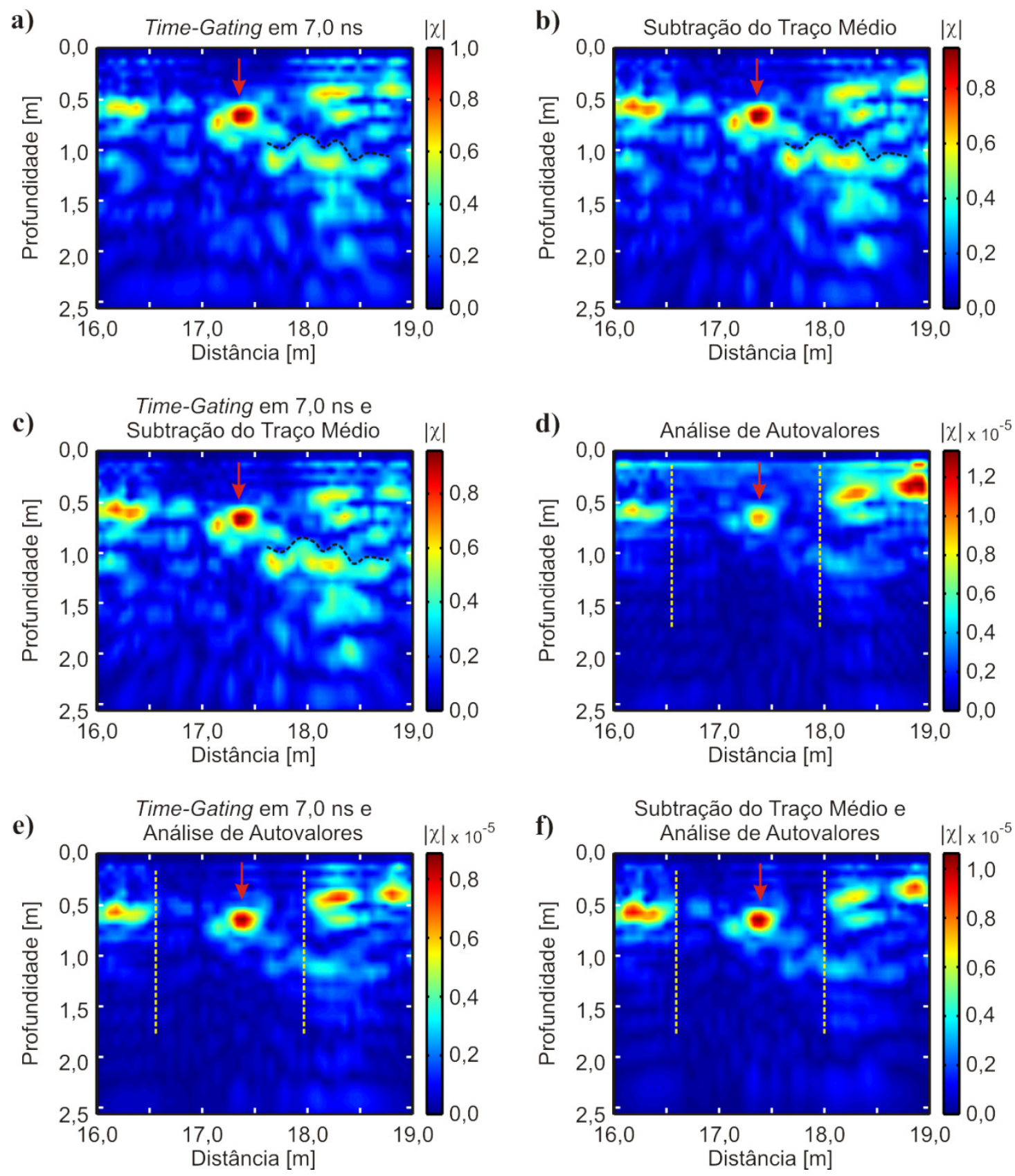

Figura 34. Imagens tomográficas obtidas a partir dos dados adquiridos com antena de $270 \mathrm{MHz}$ sobre o vaso à profundidade de $0,50 \mathrm{~m}$. a) remoção de background por timegating. b) remoção de background por subtração do traço médio. c) remoção do background por time-gating seguido pela subtração do traço médio. d) remoção do background por análise de autovalores. e) remoção de background por time-gating seguido pela análise de autovalores. f) remoção de background por subtração do traço médio seguido pela análise de autovalores.

ao vaso cerâmico perde o seu aspecto prolongado em profundidade, ficando quase circular e mais próxima daquela observada na análise dos dados sintéticos. Além disso não é mais possível identificar a interrupção no padrão de heterogeneidades do solo, 
uma vez que as anomalias de baixa amplitude utilizadas como referência para isto são quase que completamente suprimidas pela remoção de background. Isto se repete também ao se fazer a combinação da remoção de background por análise de autovalores combinada com a remoção por time-gating (Figura 35e) e com a remoção por subtração do traço médio (Figura 35f).

Na Figura 36 são mostradas as imagens tomográficas obtidas com os dados de $270 \mathrm{MHz}$ sobre o vaso instalado à profundidade de 1,0 m. Aplicando-se apenas a remoção de background por time-gating em 7,0 ns (Figura 36a) é possível identificar uma anomalia bastante evidente à profundidade de $1,0 \mathrm{~m}$ na posição de $20,0 \mathrm{~m}$. No entanto, esta anomalia parece apresentar uma extensão lateral entre 19,60 m e 20,40 m (indicada pela linha tracejada preta). Abaixo desta, uma segunda anomalia extensa pode ser identificada à profundidade de 1,50 m entre as posições de 19,50 m e 20,50 m (indicada pela linha tracejada branca). Fazendo uma comparação com as anomalias observadas sobre as caixas de areia e brita é possível interpretar estas duas anomalias como sendo relativas ao topo e a base de algum alvo com interfaces aproximadamente paralelas. Esta observação se repete ao se aplicar a remoção de background por remoção de traço médio (Figura 36b) e pela combinação do time-gating em 7,0 ns e da remoção do traço médio (Figura 36c).

Quando se aplica apenas a remoção por análise de autovalores (Figura 36d) é possível identificar uma anomalia pontual à profundidade de $1,0 \mathrm{~m}$ e na posição de 20,0 m (indicada pela seta vermelha), a qual corresponde ao alvo real. Entretanto, não é possível obter muitas informações acerca desta anomalia pois há a predominância de uma anomalia forte nos primeiros 0,50 $\mathrm{m}$ de profundidade, entre as posições de 18,90 m e 19,50 m. Ao se aplicar esta ferramenta de remoção de background em combinação com o time-gating em 7,0 ns (Figura 36e) é possível analisar a imagem resultante com muito mais detalhes. Nesta imagem a anomalia associada ao alvo ainda aparecem à profundidade de 1,0 m (indicada pela seta vermelha), porém já não apresenta a extensão lateral observada anteriormente. Em vez disso, esta anomalia aparece muito mais como algo causado por um alvo pontual.

Entre as posições de $19,50 \mathrm{~m}$ e $20,50 \mathrm{~m}$ (região entre as linhas tracejadas amarelas) ocorre uma redução significativa do número de anomalias causadas pelas heterogeneidades naturais do solo, sugerindo que estes sejam os limites do buraco 

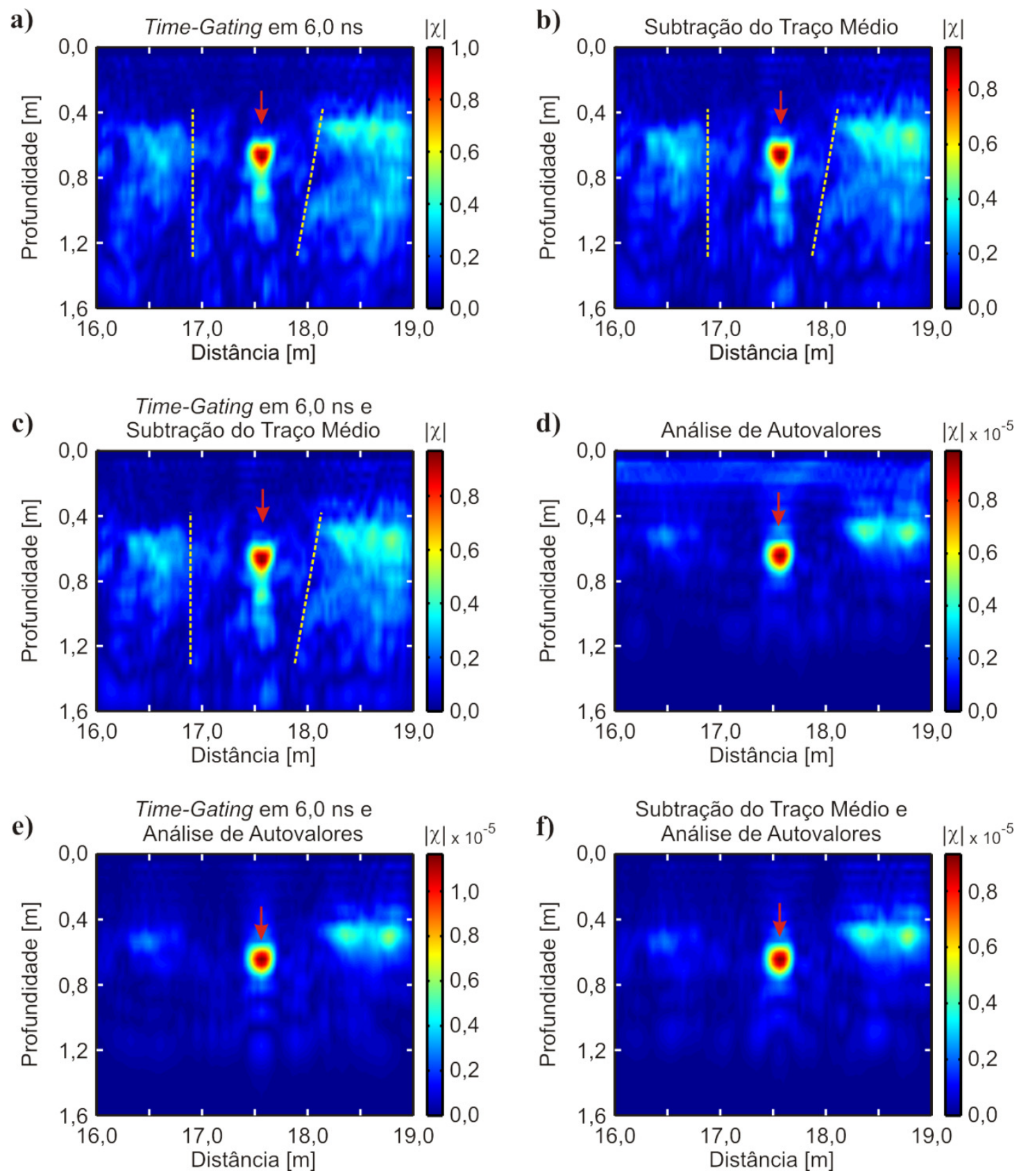

Figura 35. Imagens tomográficas obtidas a partir dos dados adquiridos com antena de $400 \mathrm{MHz}$ sobre o vaso à profundidade de $0,50 \mathrm{~m}$. a) remoção de background por timegating. b) remoção de background por subtração do traço médio. c) remoção do background por time-gating seguido pela subtração do traço médio. d) remoção do background por análise de autovalores. e) remoção de background por time-gating seguido pela análise de autovalores. f) remoção de background por subtração do traço médio seguido pela análise de autovalores.

escavado para colocação do vaso cerâmico. Ainda entre estas posições e à profundidade de 1,50 m é possível identificar uma anomalia horizontal, indicada pela linha tracejada branca. Como o alvo possui $0,55 \mathrm{~m}$ de diâmetro pode-se estabelecer esta profundidade 
como correspondente ao fundo do buraco onde se localiza o alvo. Além disso observase que a anomalia associada ao alvo se encontra sobre o centro desta anomalia horizontal, fortalecendo esta interpretação. A combinação da análise de autovalores com a subtração do traço médio (Figura 36f) mostra uma anomalia mais bem definida referente ao alvo (seta vermelha), entretanto outras feições como a anomalia associada ao fundo do buraco aparecem bastante atenuadas.

A Figura 37 apresenta os resultados obtidos com a antena de $400 \mathrm{MHz}$ sobre o vaso mais profundo. Nas Figura 37a, b, c três anomalias destacam-se em meio ao ruído geológico, sendo duas à profundidade de $0,45 \mathrm{~m}$ (indicadas pelas setas amarelas) e uma à profundidade de 1,0 m (indicada pela seta vermelha). A anomalia mais profunda é referente ao alvo, enquanto que as anomalias mais rasas estão relacionadas a uma interrupção na interface geológica rasa presente na região do SCGR, sendo assim associadas às bordas do buraco escavado para instalação do alvo, nas posições de 19,10 m e 20,60 m. Logo acima da anomalia referente ao alvo é possível ver uma anomalia de menor amplitude que, assim como no caso do vaso mais raso, não é possível identificar se é pertencente ao alvo ou se é causada por alguma outra feição do solo. Esta ambiguidade é reduzida ao se analisar as imagens obtidas com a remoção de background com a análise de autovalores (Figura 37d) e com as combinações desta com as outras duas ferramentas (Figura 37e, f). Nestas imagens a anomalia associada ao alvo permanece após o processo e aparece mais bem definida do que nas imagens anteriores, embora com amplitude menor em relação às anomalias mais rasas. De qualquer maneira, a análise de autovalores permite definir esta anomalia como sendo provocada por um alvo real enquanto que a anomalia que anteriormente era observada acima dela seria de fato provocada por heterogeneidades do solo. Observa-se ainda que as anomalias mais rasas também aparecem mais bem definidas, de forma que se assemelham mais uma feição horizontal que sofre uma interrupção entre as posições de $19,10 \mathrm{~m}$ e $20,60 \mathrm{~m}$. 

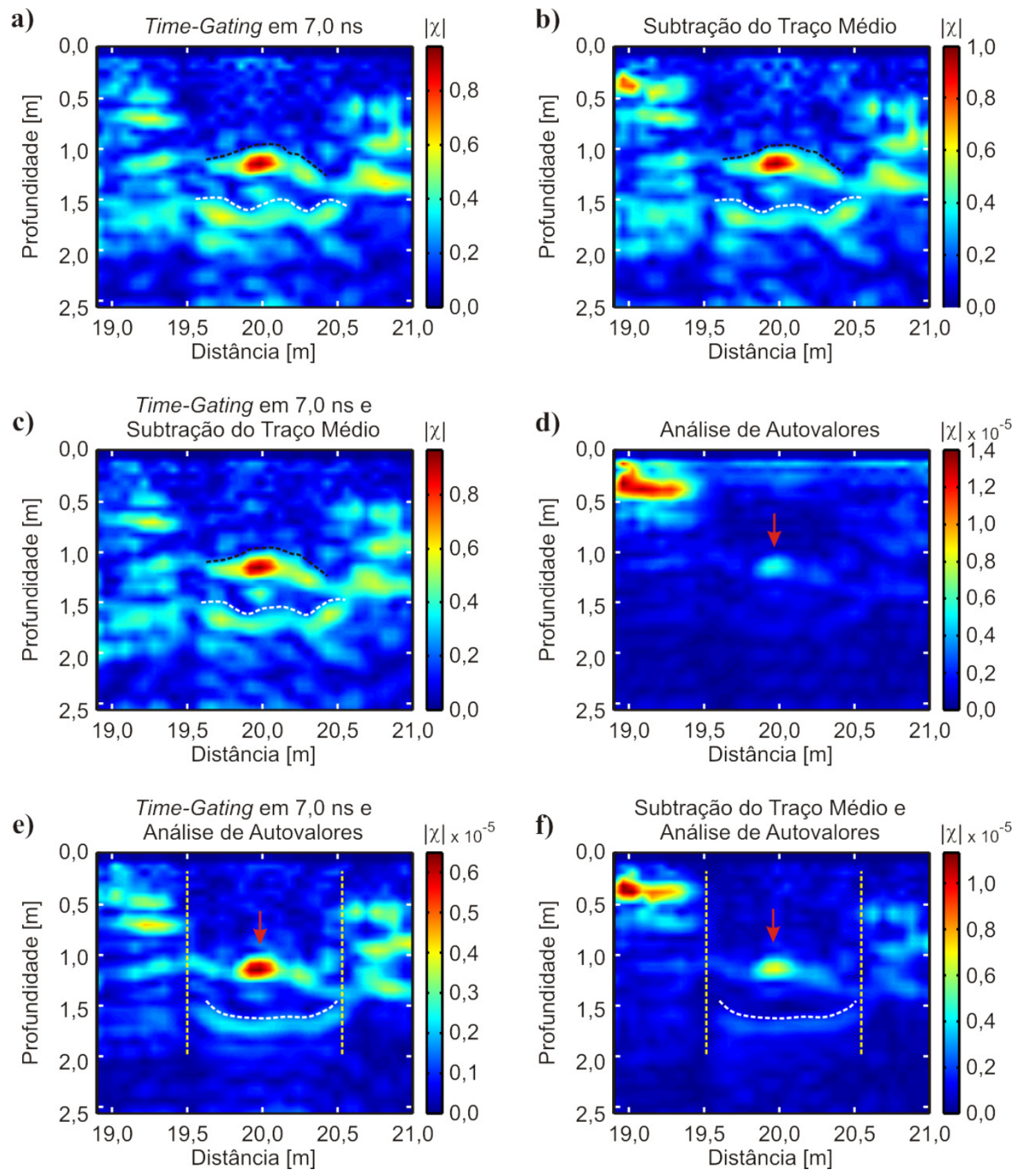

Figura 36. Imagens tomográficas obtidas a partir dos dados adquiridos com antena de $270 \mathrm{MHz}$ sobre o vaso à profundidade de $1,0 \mathrm{~m}$. a) remoção de background por timegating. b) remoção de background por subtração do traço médio. c) remoção do background por time-gating seguido pela subtração do traço médio. d) remoção do background por análise de autovalores. e) remoção de background por time-gating seguido pela análise de autovalores. f) remoção de background por subtração do traço médio seguido pela análise de autovalores. 

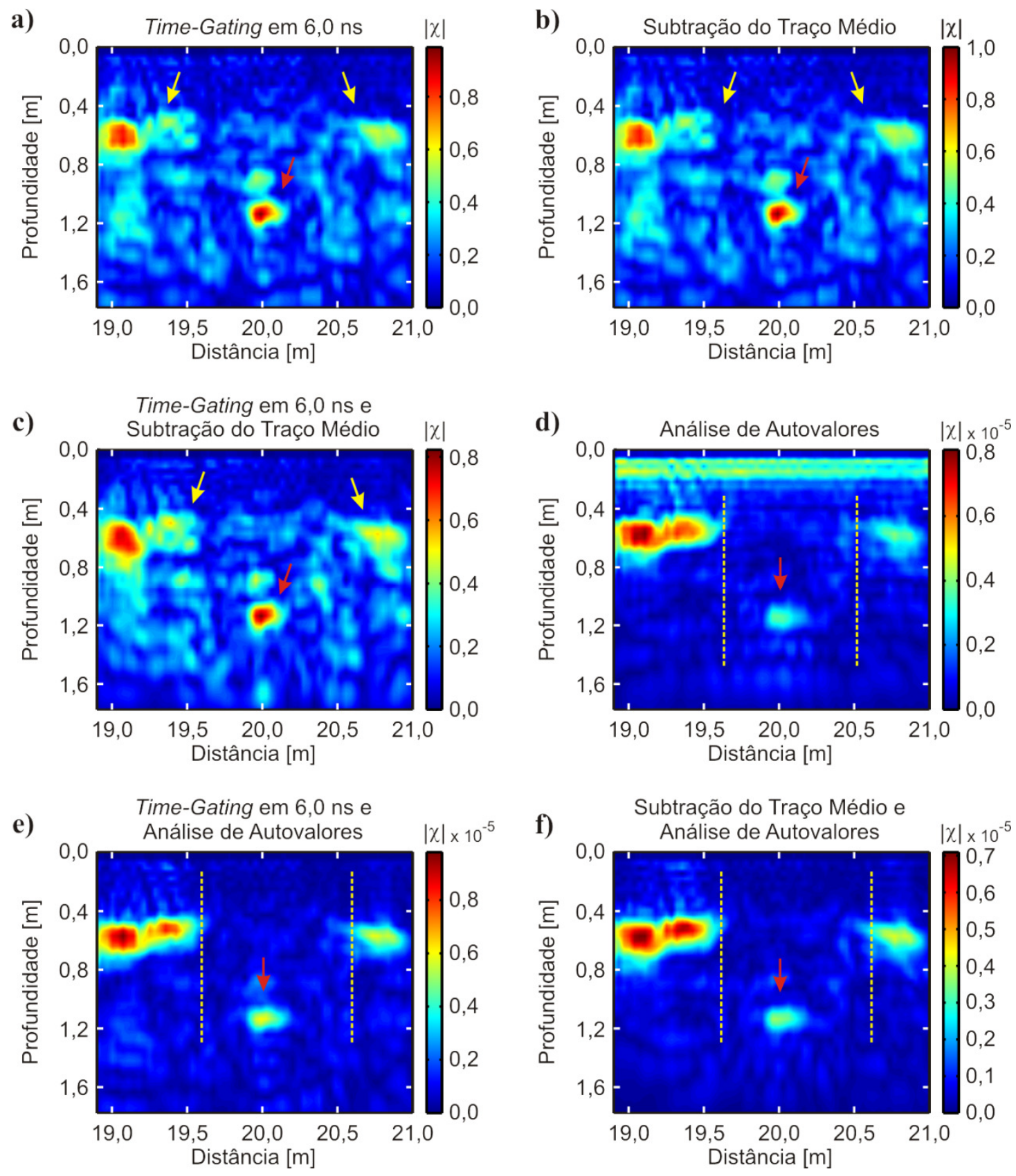

Figura 37. Imagens tomográficas obtidas a partir dos dados adquiridos com antena de $400 \mathrm{MHz}$ sobre o vaso à profundidade de $1,0 \mathrm{~m}$. a) remoção de background por timegating. b) remoção de background por subtração do traço médio. c) remoção do background por time-gating seguido pela subtração do traço médio. d) remoção do background por análise de autovalores. e) remoção de background por time-gating seguido pela análise de autovalores. f) remoção de background por subtração do traço médio seguido pela análise de autovalores.

A Figura 38 mostra as imagens obtidas com os dados de $270 \mathrm{MHz}$ sobre a camada de seixos de quartzo. De maneira geral observam-se as mesmas feições em todas as seis imagens, sem muitas alterações entre elas. As Figura 38a, b, c mostram a 
anomalia correspondente à camada de seixos como duas anomalias de amplitude similar e que podem ser interpretadas como algo contínuo (linha tracejada preta) que se entende de 21,50 $\mathrm{m}$ até $22,30 \mathrm{~m}$. À profundidade de 1,0 $\mathrm{m}$ há uma anomalia que predomina nas imagens, indicada nas três imagens pelas setas amarelas. Esta anomalia não está relacionada a um alvo específico instalado no SCGR, devendo ser causada por uma feição natural do solo. A anomalia indicada pelas setas vermelhas está associada à feição estratigráfica do solo (Borges, 2007) que é interrompida na mesma posição em que começa a anomalia associada ao alvo, embora esta anomalia não apresente uma amplitude muito alta. Nas Figura 38d, e, f a anomalia associada à camada de seixos aparece de maneira mais uniforme, evidenciando melhor a sua continuidade.

A Figura 39 apresenta as imagens obtidas a partir dos dados da antena de 400 $\mathrm{MHz}$ sobre a camada de seixos de quartzo. Assim como nas imagens obtidas com a antena de $270 \mathrm{MHz}$, todas as seis imagens mostram basicamente as mesmas feições e, portanto, a mesma interpretação. Nas Figura 39a, b, c há uma feição horizontal rasa à profundidade de $0,42 \mathrm{~m}$, indicada pelas linhas tracejadas pretas, que sofre uma interrupção entre as posições de 21,55 m e 22,50 m (linhas tracejadas amarelas). No interior desta região ocorre uma anomalia um pouco mais profunda, em 0,60 cm (indicada pela linha tracejada branca), e que é associada à camada de seixos de quartzo. A única alteração observada após se remover o background com a análise de autovalores (Figura 39d, e, f) é que a anomalia associada ao alvo aparece mais bem definida.

Estas imagens mostram que os resultados obtidos com a remoção de background por time-gating, subtração de traço médio e com a combinação de ambos apresenta resultados bastante similares entre si. Do mesmo modo, foram obtidos resultados similares entre as imagens obtidas com a remoção do background por time-gating combinado com a análise de autovalores e com a subtração do traço médio combinada com a análise de autovalores. A remoção apenas por análise de autovalores não apresentou resultados em que se pudesse extrair tantas informações quanto nas demais imagens tomográficas. Desta maneira, nas análises subsequentes serão apresentados somente os resultados da aplicação do time-gating e da combinação deste com a análise de autovalores. No primeiro caso foi identificado um número maior de anomalias, possibilitando uma análise sobre a continuidade de feições geológicas presentes no solo. 

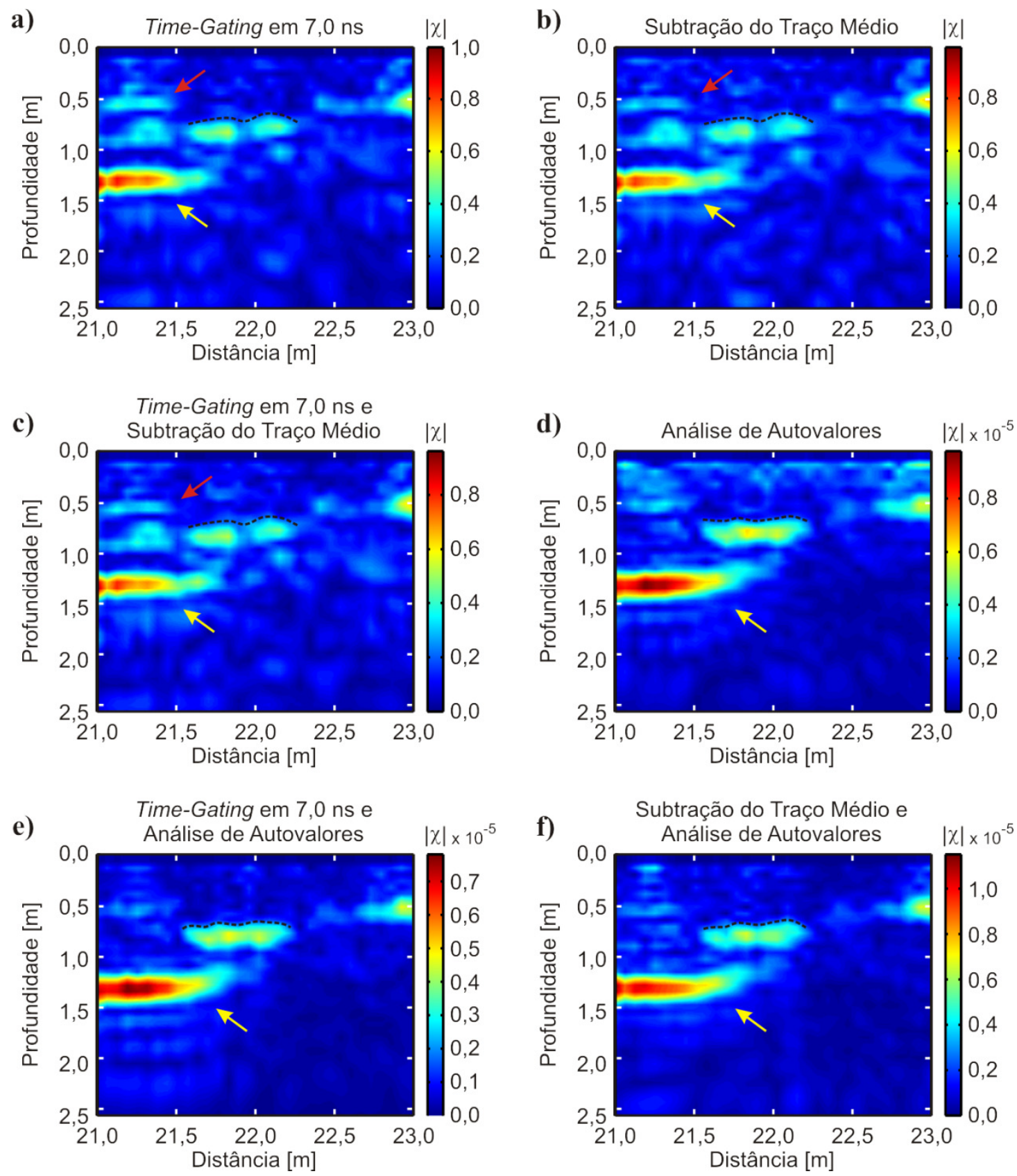

Figura 38. Imagens tomográficas obtidas a partir dos dados adquiridos com antena de $270 \mathrm{MHz}$ sobre a camada de seixos de quartzo. a) remoção de background por timegating. b) remoção de background por subtração do traço médio. c) remoção do background por time-gating seguido pela subtração do traço médio. d) remoção do background por análise de autovalores. e) remoção de background por time-gating seguido pela análise de autovalores. f) remoção de background por subtração do traço médio seguido pela análise de autovalores.

No segundo caso o número de anomalias foi fortemente reduzido. Entretanto, observou-se que esta redução afetou principalmente as feições causadas por heterogeneidades do solo, sendo que as anomalias causadas pelos alvos reais 
a)
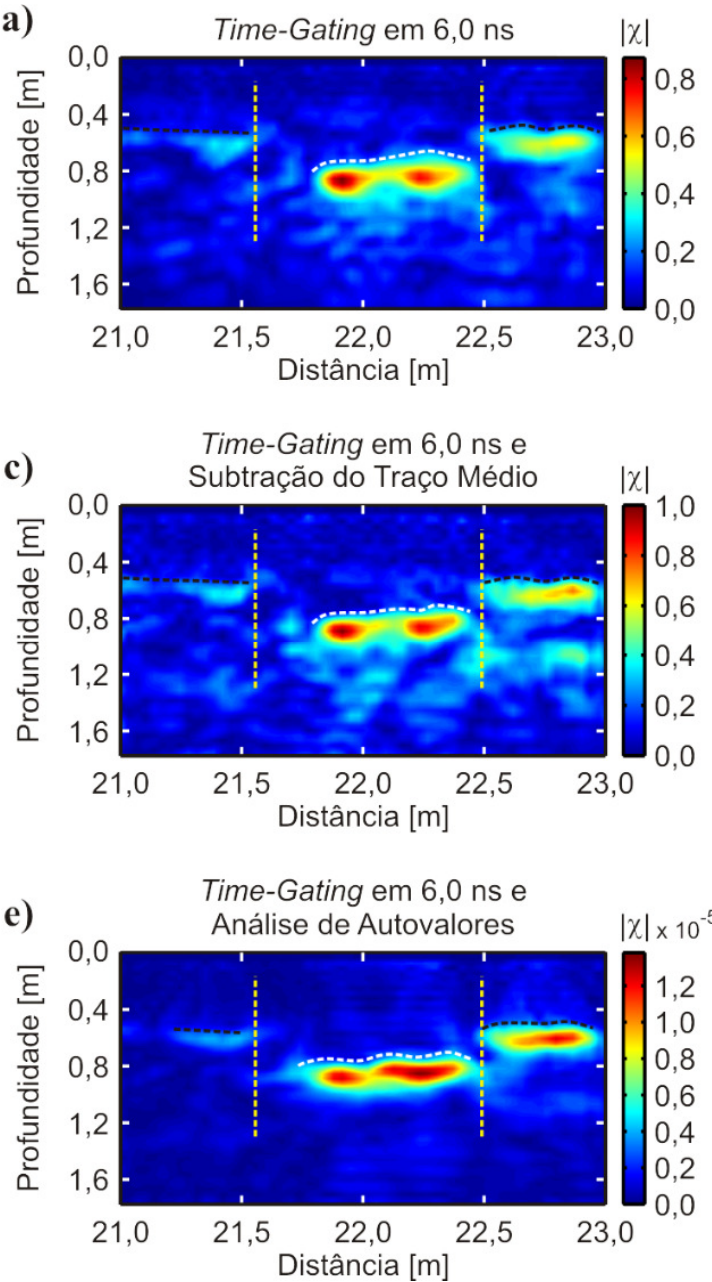

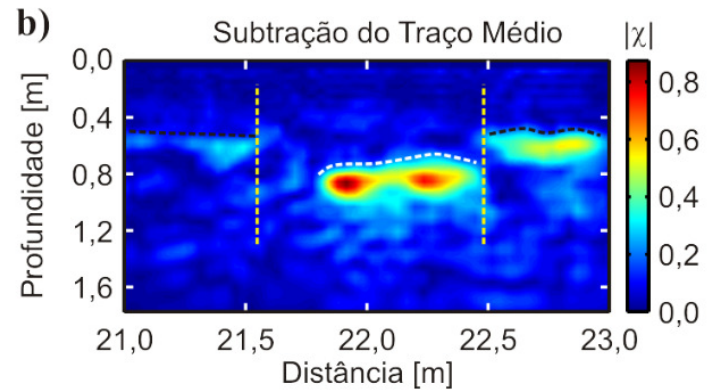

d)
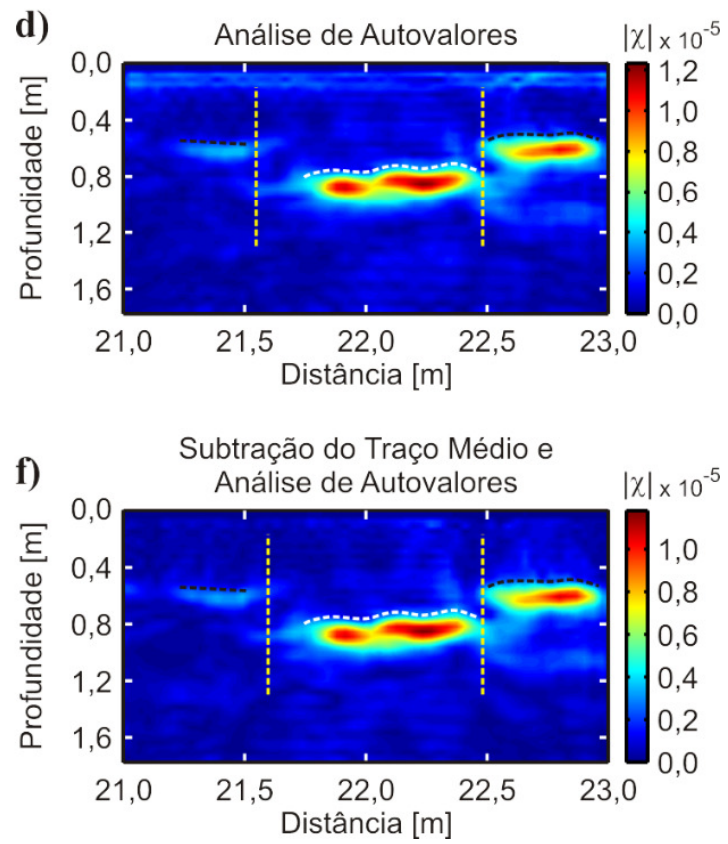

Figura 39. Imagens tomográficas obtidas a partir dos dados adquiridos com antena de $400 \mathrm{MHz}$ sobre a camada de seixos de quartzo. a) remoção de background por timegating. b) remoção de background por subtração do traço médio. c) remoção do background por time-gating seguido pela subtração do traço médio. d) remoção do background por análise de autovalores. e) remoção de background por time-gating seguido pela análise de autovalores. f) remoção de background por subtração do traço médio seguido pela análise de autovalores.

permaneceram preservadas nas imagens. Isto mostrou-se bastante útil na interpretação dos resultados pois permite evidenciar melhor as anomalias causadas pelos alvos e reduzir a ambiguidade tanto na identificação destas quanto na determinação dos seus contornos.

Assim, foram montados perfis representando a linha de arqueologia completa para comparação das características entre as anomalias geradas por cada tipo de alvo. Na Figura 40 são apresentados os perfis obtidos com a antena de $270 \mathrm{MHz}$. As escalas de cores das imagens tomográficas apresentadas nesta figura foram limitadas entre $|\chi|=$ 
0,05, para suprimir anomalias de amplitude muito baixa que pudessem prejudicar a interpretação, e $|\chi|=0,70$ para evitar que anomalias de amplitudes intermediárias fossem mascaradas por anomalias de alta amplitude. A Figura 40a reproduz novamente o diagrama da disposição dos alvos instalados na linha.

A Figura 40b apresenta o radargrama completo processado no software ReflexWin. As linhas tracejadas pretas representam uma interpretação dos refletores contínuos, os quais são provocados por feições geológicas. Especificamente na caixa de brita as linhas tracejadas pretas indicam um possível contorno para o alvo. Esta interpretação é possível uma vez que nas suas extremidades podem ser observadas feições aparentemente hiperbólicas, tipicamente causadas por pontos de difração. Notese que não é possível observar efeitos similares no alvo representado pela caixa de areia. As setas azuis indicam anomalias associadas a alvos pontuais. Na posição de 7,50 m há uma anomalia bastante clara que não está associada a nenhum alvo. Pela sua localização em relação às árvores existentes no SCGR, é provável que esta anomalia seja provocada por uma raiz. Na posição referente à localização do muro de tijolos, é possível observar apenas um refletor horizontal à profundidade de $0,95 \mathrm{~m}$, que poderia estar associado ao fundo do buraco onde foi instalado este alvo. A porção de solo revirado é muito difícil de ser observada no radargrama uma vez que não há feições claras que indiquem tal perturbação no meio geológico. Na posição de $15,0 \mathrm{~m}$ pode-se observar a anomalia provocada pelo cano metálico guia, que aparece no radargrama juntamente com um refletor horizontal à profundidade de $0,50 \mathrm{~m}$. Este refletor horizontal é interrompido na posição de 16,5 m e reaparece na posição de 18,0 m. Entre estas posições é possível identificar de forma bastante clara a anomalia gerada pelo vaso cerâmico mais raso. $\mathrm{O}$ refletor horizontal é interrompido novamente na posição de $19,50 \mathrm{~m}$ e reaparece na posição de 20,50 m. A anomalia gerada pelo vaso mais profundo é observada entre estas posições à profundidade de $1,0 \mathrm{~m}$, porém a identificação desta hipérbole não é tão clara quanto a do vaso mais raso visto que sua amplitude e sua abertura podem se confundir com outras feições observadas nesta mesma profundidade em todo o radargrama. Por fim, o alvo representado pela camada de seixos de quartzo dificilmente é identificado, pois a amplitude da sua reflexão se confunde com feições similares próximas como anomalia indicada pela seta em 21,20 m, em 1,10 m de profundidade, induzindo a uma interpretação de que ambas sejam causadas por feições naturais do meio geológico. 
A Figura 40c mostra o perfil resultante da concatenação das imagens obtidas através da remoção de background por time-gating em 7,0 ns, e nela é possível extrair mais informação do que no radargrama. Aqui a continuidade das feições e o contorno dos alvos são indicados pelas linhas tracejadas brancas. Logo no início do perfil identificam-se as caixas de areia e de brita. Em cada uma delas é possível observar que as anomalias relacionadas ao topo apresentam um padrão característico e diferente das outras anomalias próximas, tais como aquelas existentes na região entre as caixas. A caixa de areia pode ser delimitada entre as posições de $1,0 \mathrm{~m}$ e $3,0 \mathrm{~m}$, enquanto que a caixa de brita possui uma ambiguidade na sua delimitação. Considerando-se as características das anomalias do topo a delimitação pode ser feita entre as posições de 4,70 m e 6,90 m (linha tracejada). Porém, ao se analisar as anomalias relacionadas a base, a delimitação da base pode ser feita entre as posições de 3,60 m e 6,90 m (linha traço e ponto), o que representa uma extensão maior do que a real. Há uma feição horizontal que se inicia na posição de 7,40 m, é interrompida na posição de 8,90 m e reaparece na imagem na posição de $11,20 \mathrm{~m}$, sempre a $0,40 \mathrm{~m}$ de profundidade. Entre as posições em que esta feição é interrompida observa-se a anomalia em 1,0 m de profundidade que pode ser relacionada ao fundo do buraco onde o alvo está instalado e, sobre esta e com amplitude muito baixa, observa-se uma feição que poderia corresponder à influência do sinal eletromagnético nas arestas do muro de tijolos, entre as posições de $9,0 \mathrm{~m}$ e $11,0 \mathrm{~m}$. A feição horizontal que reaparece na imagem à profundidade de $0,45 \mathrm{~m}$ e na posição de $11,20 \mathrm{~m}$ sofre uma variação abrupta para a profundidade de $1,0 \mathrm{~m}$ na posição de $12,40 \mathrm{~m}$ e varia repentinamente para a profundidade de $0,55 \mathrm{~m}$ na posição de $13,40 \mathrm{~m}$. Este padrão não é observado em nenhuma outra parte da linha de arqueologia, sugerindo que este seja o local da região de solo revirado embora a profundidade de 1,0 seja menor do que a esperada para a profundidade real da base do alvo. $\mathrm{Na}$ posição de $15,0 \mathrm{~m}$ a feição horizontal é interrompida pela anomalia gerada pelo cano metálico guia. Uma nova interrupção entre as posições de 16,50 m e 17,50 m, entre as quais é possível identificar com a anomalia associada ao vaso mais raso à profundidade de $0,50 \mathrm{~m}$ (posição $17,30 \mathrm{~m}$ ). A feição que se reinicia na posição de 17,50 m encontra-se à profundidade de 1,0m, o que coincide a localização do fundo do buraco onde foi instalado este vaso. Pelo padrão de amplitude das anomalias mais próximas, pode-se interpretar esta feição com um contorno que se inicia neste ponto, sobe para $0,40 \mathrm{~m}$ na posição de $18,0 \mathrm{~m}$, cai repentinamente para 1,50 
m de profundidade em 19,50 m e apresenta comportamento ascendente novamente em $20,50 \mathrm{~m}$. A anomalia associada ao vaso em $1,0 \mathrm{~m}$ de profundidade é facilmente identificada entre as posições de $19,50 \mathrm{~m}$ e 20,50 m. Esta porção da linha que envolve os dois vasos cerâmicos é um exemplo bastante interessante de como a imagem tomográfica pode melhorar a interpretação de uma seção de dados GPR. No radargrama processado a anomalia gerada pelo vaso mais raso era identificada com maior clareza do que a anomalia gerada pelo vaso mais profundo, enquanto que na imagem tomográfica não só ambas as anomalias puderam ser facilmente identificadas como foi possível também traçar o contorno das regiões escavadas para a instalação de ambos, o que permite estimar indiretamente a distância entre a base e o topo de ambos, igual a 0,50 $\mathrm{m}$. Finalmente, na posição de $22,0 \mathrm{~m}$ observa-se a anomalia gerada pela camada de seixos de quartzo. Embora sua identificação seja relativamente mais fácil nesta imagem do que no radargrama, esta ainda é uma anomalia de difícil interpretação visto que suas características de dimensão e amplitude se confundem facilmente com as anomalias mais próximas. Um indício para a presença do alvo é a interrupção na feição à profundidade de $0,40 \mathrm{~m}$ na posição de $21,50 \mathrm{~m}$, porém aqui não é possível fazer uma afirmação mais conclusiva.

A Figura 40d, gerada a partir da concatenação das imagens obtidas com remoção de background por time-gating em 7,0 ns seguido pela análise de autovalores, apresenta uma imagem com muito menos anomalias associadas a pequenas heterogeneidades geológicas. Nota-se como há uma predominância das anomalias provocadas por alvos reais, tais como os vasos cerâmicos, o cano metálico guia e mesmo a raiz de árvore localizada na posição de 7,50 m, ainda que estas anomalias apareçam com amplitude reduzida. Nesta imagem também é possível observar com maior clareza o padrão de anomalias nas regiões associadas ao topo das caixas de areia e de brita. $\mathrm{Na}$ parte superior das regiões internas dos respectivos contornos destas caixas as anomalias apresentam padrões bastante definidos quanto às suas amplitudes, tamanhos e posições. Isto permite eliminar a ambiguidade referente à delimitação do contorno da caixa de brita de granito, que aqui pode ser feito com segurança entre as posições de 4,80 m e $6,90 \mathrm{~m}$. 


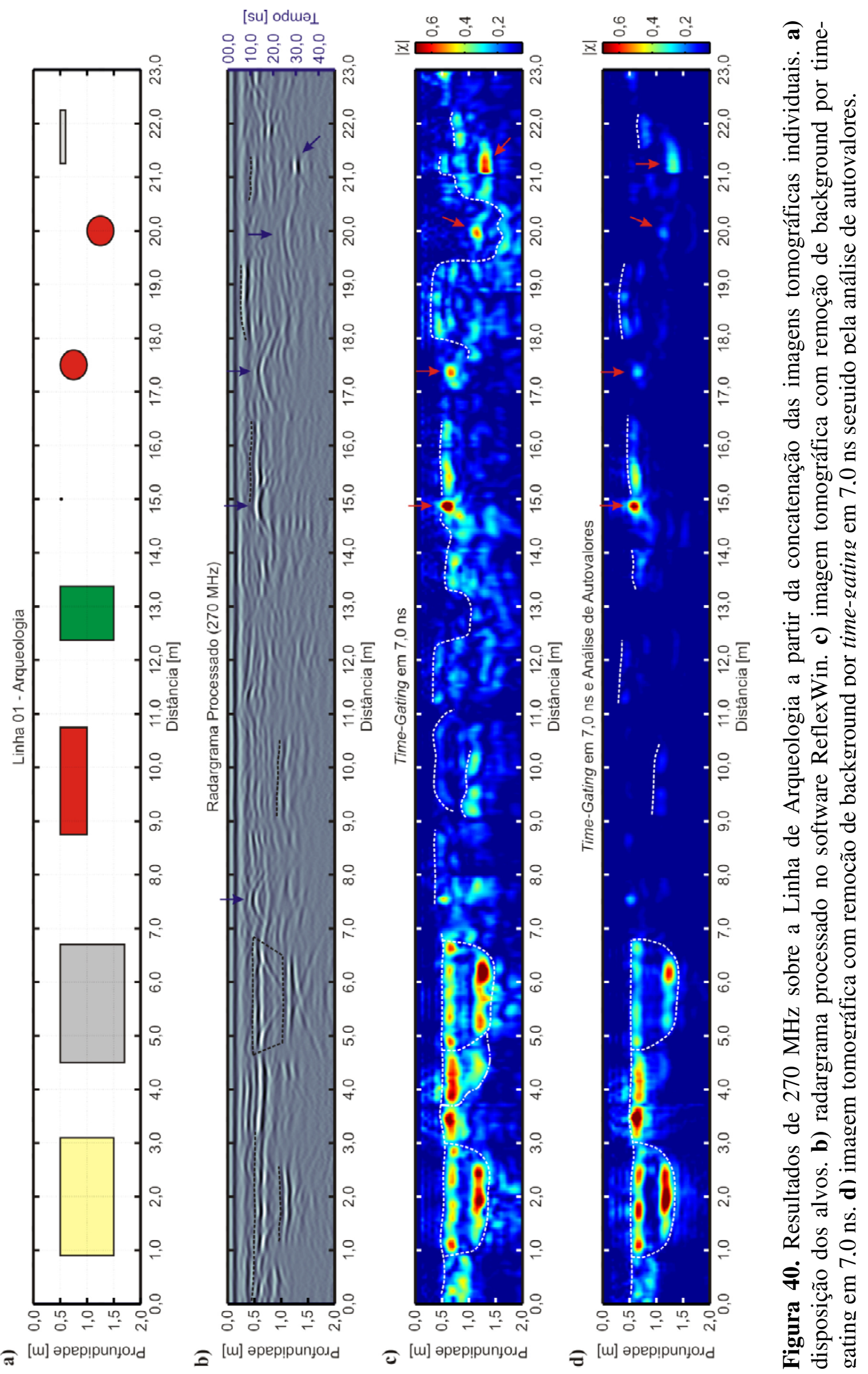


Uma análise similar pode ser feita a partir da Figura 41, que mostra os perfis de anomalias construídos com as imagens obtidas a partir dos dados de $400 \mathrm{MHz}$. A Figura 41a mostra novamente o diagrama com a disposição dos alvos para auxiliar na comparação dos resultados. A Figura $41 \mathrm{~b}$ apresenta o radargrama completo processado no software ReflexWin. As linhas tracejadas mostram os refletores contínuos, os quais permitem evidenciar de forma satisfatória a interrupção provocada no solo para a escavação dos buracos que acomodaram os vasos cerâmicos (indicados por setas azuis nas posições de 17,50 m e 20,0 m). O cano metálico guia localizado na posição de 15,0 m não fica tão evidente nesta seção, por gerar uma anomalia hiperbólica pequena e que se confunde com o refletor horizontal à mesma profundidade. As anomalias relacionadas ao fundo das caixas de areia e de brita de granito aparecem como refletores horizontais, não havendo qualquer tipo de feição (como aquelas aproximadamente hiperbólicas observadas na caixa de brita em $270 \mathrm{MHz}$ ) que possa sugerir alguma conexão com o refletor à profundidade de $0,50 \mathrm{~m}$, este por sua vez misturando-se à reflexão do topo das caixas. A camada de seixos de quartzo é mais evidente nesta seção, aparecendo logo após uma interrupção no refletor horizontal à profundidade de $0,50 \mathrm{~m}$ em 21,45 m. Não há evidências do muro de tijolos ou da porção de solo revirado nestes dados.

A imagem tomográfica obtida da concatenação das imagens obtidas com a remoção do background através do time-gating em 6 ns (Figura 41c) apresenta mais informações sobre o perfil. Nas posições iniciais deste perfil pode-se definir um contorno para as anomalias associadas às caixas de areia e de brita. A caixa de areia tem sua extensão definida entre $1,0 \mathrm{~m}$ e $3,10 \mathrm{~m}$, sendo que as anomalias localizadas na posição de $1,10 \mathrm{~m}$ podem gerar certa ambiguidade nesta delimitação por estarem separadas do conjunto maior pela interrupção na posição de 1,50 m. Entretanto, elas foram incluídas como parte do alvo por apresentarem disposição em profundidade e amplitude bastante similares às demais anomalias relacionadas ao conjunto. A caixa de brita de granito foi definida entre as posições de 5,10 $\mathrm{m}$ e $6,60 \mathrm{~m}$, sendo portanto menor do que o alvo real. Apesar disto, observa-se como a delimitação das caixas é feita de forma mais precisa nesta imagem do que no radargrama, além de se poder afirmar com alguma conviç̧ão que de fato existem objetos de geometria aproximadamente retangular nos primeiros oito metros da linha de arqueologia. Entre as posições de 9,20 m e 11,50 m observa-se que existe um conjunto de anomalias de baixa amplitude que se 
destaca sutilmente das demais anomalias do seu entorno. Este grupo é bastante difícil de ser delimitado, porém é possível fazê-lo com auxílio de três outras anomalias um pouco mais evidentes, indicadas pelas setas brancas. Estas três anomalias apresentam amplitudes e dimensões semelhantes entre si, além de as duas anomalias na posição de 9,50 $\mathrm{m}$ apresentarem um bom alinhamento vertical e de haver um alinhamento horizontal à profundidade de 1,0 m entre a anomalia em 9,50 m e aquela em 11,50 m. Tomando-se estas características como referência, pode-se traçar um contorno aproximado em que se pode separar anomalias de amplitude da ordem de $|\chi|=0,20$ a $|\chi|=0,30$ no interior do contorno daquelas de amplitude da ordem de $|\chi|=0,10$ a $|\chi|=$ 0,20 fora dele. O contorno delimitado com base nestas considerações fica então apresentando uma geometria aproximadamente retangular, estendendo-se das posições de 9,20 a 11,50 e de $0,50 \mathrm{~m}$ a $1,0 \mathrm{~m}$ de profundidade, o que se aproxima muito das dimensões reais do muro de tijolos. Entre as posições de 12,50 m e 13,50 m é possível observar novamente a variação repentina na profundidade da feição horizontal. A profundidade desta feição varia de $0,40 \mathrm{~m}$ a $1,0 \mathrm{~m}$ na posição de $12,50 \mathrm{~m}$ e de $1,0 \mathrm{~m}$ a 0,50 m na posição de $13,50 \mathrm{~m}$, tal como observado nos dados de $270 \mathrm{MHz}$, evidenciando tratar-se da porção de solo revirado. A feição horizontal mostra-se contínua à profundidade de $0,50 \mathrm{~m}$ até a posição de $16,90 \mathrm{~m}$, onde é interrompida devido ao buraco escavado para instalação do vaso mais raso, reaparecendo na posição de 18,0 m. Na posição de 19,60 m esta feição é interrompida novamente, agora pelo buraco escavado para instalação do vaso mais profundo, reaparecendo em 21,60 m. Note-se que a anomalia causada pelo cano guia à profundidade de $0,50 \mathrm{~m}$ na posição de 15,0 m mistura-se às anomalias desta feição nas posições imediatamente próximas, não possibilitando sua identificação sem ambiguidades. Nesta imagem não é possível também identificar o contorno do interior dos buracos onde estão instalados os vasos cerâmicos de maneira tão clara quanto na imagem obtida a partir dos dados de 270 $\mathrm{MHz}$, embora as anomalias dos vasos em si apareçam de forma mais clara na imagem obtida a partir dos dados de $400 \mathrm{MHz}$. A exceção a esta afirmação é a feição representada pela linha tracejada amarela na posição de $18,0 \mathrm{~m}$, que parece sugerir que esta interrupção também aconteça até a profundidade de 1,0 m. A camada de seixos de quartzo também aparece de maneira bastante clara nesta imagem entre as posições de 21,70 e 22,40 m, sendo mais evidente do que a anomalia associada ao vaso cerâmico instalado na posição de $20,0 \mathrm{~m}$. 
A imagem apresentada na Figura 41d mostra novamente uma seção mais limpa, onde a maior parte das anomalias de baixa amplitude associadas a pequenas variações naturais no meio geológico foi removida restando em sua maioria as anomalias causadas por objetos reais imersos no meio. Aqui as anomalias relacionadas às caixas de areia e de brita aparecem como as anomalias associadas ao topo e à base de cada uma e não mais como um grande conjunto de geometria aproximadamente retangular. Observa-se também que as anomalias presentes entre 9,0 m e 11,50 m permaneceram na imagem, ao contrário das anomalias no seu entorno, que foram removidas. Isto mostra que o contorno aproximadamente retangular pode de fato ser associado a alguma feição envolvendo o muro de tijolos. A ambiguidade na interpretação desta porção da imagem fica por conta da anomalia presente na posição de $12,50 \mathrm{~m}$, indicada pela seta branca e que a princípio poderia ser incluída no conjunto de anomalias associado ao muro. No entanto, esta anomalia foi excluída deste conjunto pois observa-se que existe um certo paralelismo entre as anomalias à profundidade de $0,50 \mathrm{~m}$ e as anomalias à profundidade de 1,0 m no interior do contorno, que não se reproduz para esta anomalia localizada na posição de 12,50 m. As anomalias geradas pelos vasos cerâmicos aparecem ainda bastante evidentes nas posições de 17,50 m e 20,0 m (indicadas pelas setas vermelhas). A camada de seixos de quartzo também aparece de forma clara na porção final da linha, em meio a uma interrupção na continuidade da feição horizontal existente à profundidade de $0,50 \mathrm{~m}$ entre as posições de $21,70 \mathrm{~m}$ e $22,40 \mathrm{~m}$.

A interpretação dos resultados em conjunto fornece uma forma de avaliar melhor as capacidades e limitações da ferramenta de imageamento tomográfico de dados GPR, uma vez que deixa clara as diferenças nas amplitudes das anomalias. Além disso, a análise de um perfil longo é mais comum em uma situação prática do que a análise de trechos isolados, justamente devido ao desconhecimento da localização dos alvos. Desta maneira, uma metodologia proposta para a análise de dados em um levantamento real com esta ferramenta é a de se delimitar o domínio sob investigação $\left(D_{i}\right)$ de forma a fracionar o perfil total e posteriormente fazer a concatenação das imagens resultantes para uma interpretação de todo o conjunto. Esta tarefa pode ser trabalhosa no caso de um grande volume de dados ou de perfis muito longos dada a demanda computacional exigida pelo processo, porém acarreta em melhores resultados no imagemento de alvos com baixo contraste de propriedades elétricas como foi o caso do muro de tijolos. Assim, é necessário fazer um balanço das melhores condições para a obtenção dos 


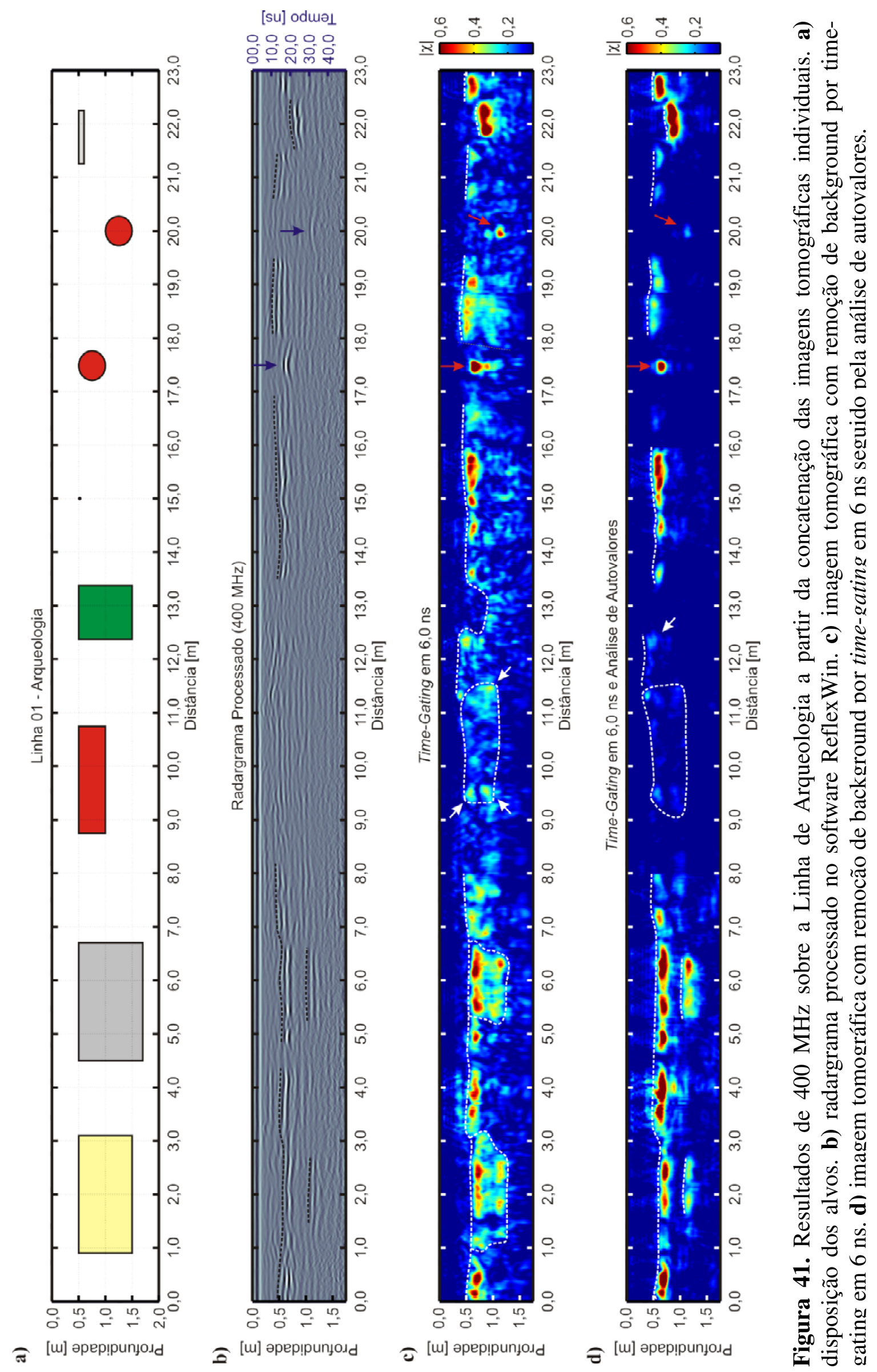


resultados buscando-se o equilíbrio entre a boa qualidade das imagens (e consequentemente dos alvos) e o hardware disponível para executar o trabalho.

A ambiguidade na interpretação dos dados pode ser reduzida dependendo da ferramenta adotada para remoção de background. Algumas feições cuja delimitação possa ser complexa após a remoção com uma ferramenta pode vir a ser mais fácil após a remoção com outra. Anomalias causadas pelo ruído geológico e que podem vir a ser interpretadas como alvos podem ser suprimidas especialmente pela combinação da análise de autovalores combinada com uma das duas outras ferramentas apresentadas.

\subsubsection{Resultados $3 D$}

As imagens obtidas foram analisadas também por meio de visualizações em 3D geradas a partir da interpolação de vários perfis paralelos adquiridos com $0,20 \mathrm{~m}$ de distância entre si. Esta análise foi feita apenas com as imagens obtidas a partir da remoção de background através de time-gating em 7,0 ns para manter as informações acerca das feições causadas tanto pelos alvos como pelo meio geológico. Foram selecionados apenas alguns alvos dentre todos os presentes na linha de arqueologia. Os resultados são apresentados a seguir na forma de colunas onde são mostrados vários cortes em profundidade para que se possa ter uma ideia do comportamento dos alvos em profundidade. As linhas tracejadas vermelhas presentes nestas colunas representam uma projeção de feições associadas à presença dos alvos. Cada figura apresenta ainda três cortes em profundidade vistos em planta para que se possa visualizar melhor a extensão lateral das feições associadas aos alvos. As cruzes vermelhas presentes nestas imagens indicam os pontos onde as linhas tracejadas vermelhas interceptam os planos de corte.

A Figura 42 mostra os resultados obtidos com os dados de $270 \mathrm{MHz}$ sobre a caixa de areia. Na Figura 42a diversos planos de corte são apresentados segundo sua disposição em profundidade. É possível observar nesta figura que as feições associadas ao alvo se concentram entre as profundidades de 0,60 m e 1,30 m. A Figura 42b mostra uma vista em planta do corte à profundidade de $0,63 \mathrm{~m}$. Neste plano observa-se claramente uma feição retangular cujos vértices são indicados pelas cruzes vermelhas nas coordenadas $(0,0,1,0),(0,0,3,0),(2,70,3,0)$ e $(2,70,1,10)$, correspondendo a uma extensão de 2,70 m na direção X e 2,0 m na direção $Y$. No corte à profundidade de 0,88 
$\mathrm{m}$ (Figura 42c), que corresponde a uma profundidade intermediária entre as profundidades das anomalias de topo e base da caixa, esta feição não aparece de forma tão clara. Contudo, ainda é possível observar uma diferença na amplitude da função contraste, que é menor no interior do polígono cujos vértices são representados pelas cruzes vermelhas do que fora dele. Na profundidade de 1,07 m (Figura 42d) observa-se a anomalia relacionada à base da caixa, que se localiza de forma bastante evidente no interior do polígono formado pelas cruzes vermelhas.

Na Figura 43 é apresentada a análise dos dados obtidos com $400 \mathrm{MHz}$ sobre a caixa de brita de granito. Na Figura 43a é possível restringir o alvo entre as profundidades de $0,60 \mathrm{~m}$ e 1,12 $\mathrm{m}$. No corte à profundidade de 0,49 $\mathrm{m}$ (Figura 43b) é possível identificar uma sutil diferença no padrão de anomalias do solo, o que seria um indicativo dos limites do buraco escavado para instalação do alvo. Entretanto, estes limites são determinados com maior clareza no corte à profundidade de $0,66 \mathrm{~m}$ nas coordenadas de $(-0,20,5,0),(-0,25,6,90),(2,20,6,90)$ e $(2,20,5,0)$. À profundidade de 1,12 m (Figura 43d) é possível identificar a anomalia referente ao fundo da caixa, localizada exatamente no centro do polígono representado pelas cruzes vermelhas.

Os resultados obtidos com a antena de $400 \mathrm{MHz}$ sobre o muro de tijolos são mostrados na Figura 44. Conforme já discutido, este alvo mostrou-se de difícil detecção devido ao baixo contraste entre suas propriedades elétricas e as do meio geológico. Observa-se nesta figura que as anomalias presentes na região correspondente ao alvo apresentam amplitude similar à do ruído geológico no meio que o circunda. A Figura 44a mostra os planos de corte em diferentes profundidades para comparação entre estas amplitudes. No plano de corte em 0,38 m (Figura 44b) é possível identificar a feição referente à lateral direita do buraco escavado para instalação do alvo, cujos vértices são indicados pelas cruzes vermelhas nas coordenadas $(2,50,10,80)$ e $(2,50,9,0)$. O recorte no solo fica mais evidente no plano de corte em 0,56 m de profundidade (Figura 44c), onde também é possível observar as feições referentes à lateral esquerda do buraco, cujos vértices são indicados pelas cruzes vermelhas nas coordenadas $(-0,50,9,0)$ e $(-$ $0,50,10,90)$. No interior do polígono formado por estes vértices há um conjunto de anomalias orientado paralelamente à direção $\mathrm{Y}$ (indicadas pelo retângulo branco tracejado). Esta feição se localiza na posição esperada para o muro de tijolos. No entanto, o baixo contraste entre as propriedades elétricas do alvo e do meio faz com que 

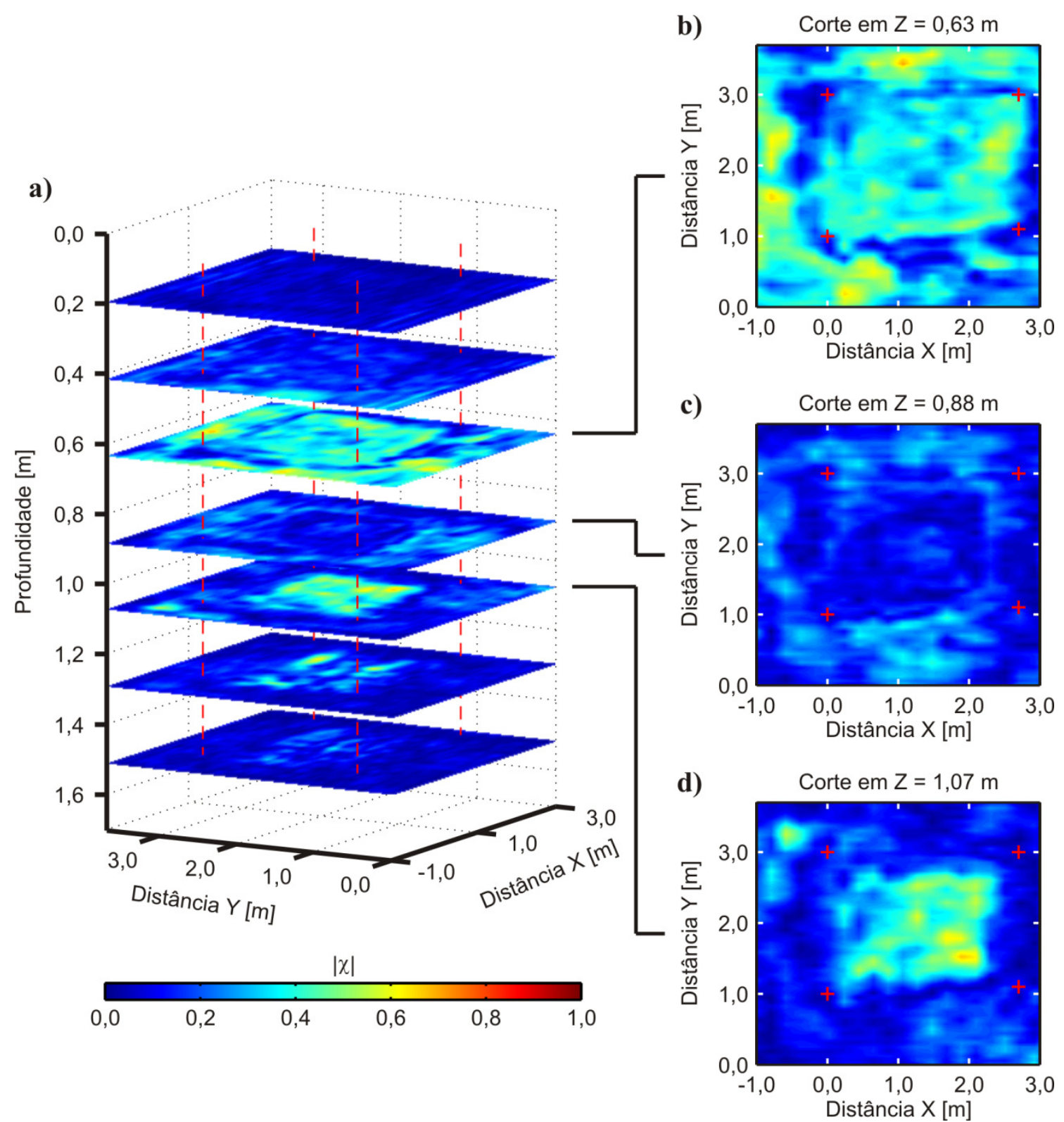

Figura 42. Visualização 3D dos dados de $270 \mathrm{MHz}$ sobre a caixa de areia na forma de cortes em profundidade gerados a partir da interpolação de perfis paralelos. As linhas tracejadas vermelhas representam uma projeção dos vértices do buraco escavado para instalação do alvo. As cruzes vermelhas nas vistas em planta indicam as posições onde estas linhas cruzam os planos de corte em cada profundidade. a) representação de planos de corte em diferentes profundidades. b) plano de corte à profundidade de 0,63 m. c) plano de corte à profundidade de $0,88 \mathrm{~m}$. d) plano de corte à profundidade de 1,07 $\mathrm{m}$.

a amplitude destas anomalias seja similar à amplitude das anomalias causadas pelo ruído geológico. Além disso algumas destas anomalias estão presentes em apenas dois perfis e algumas estão presentes apenas em um dos dois, de modo que a interpolação entre elas é feita de forma precária para caracterizar o alvo de forma conclusiva. A 

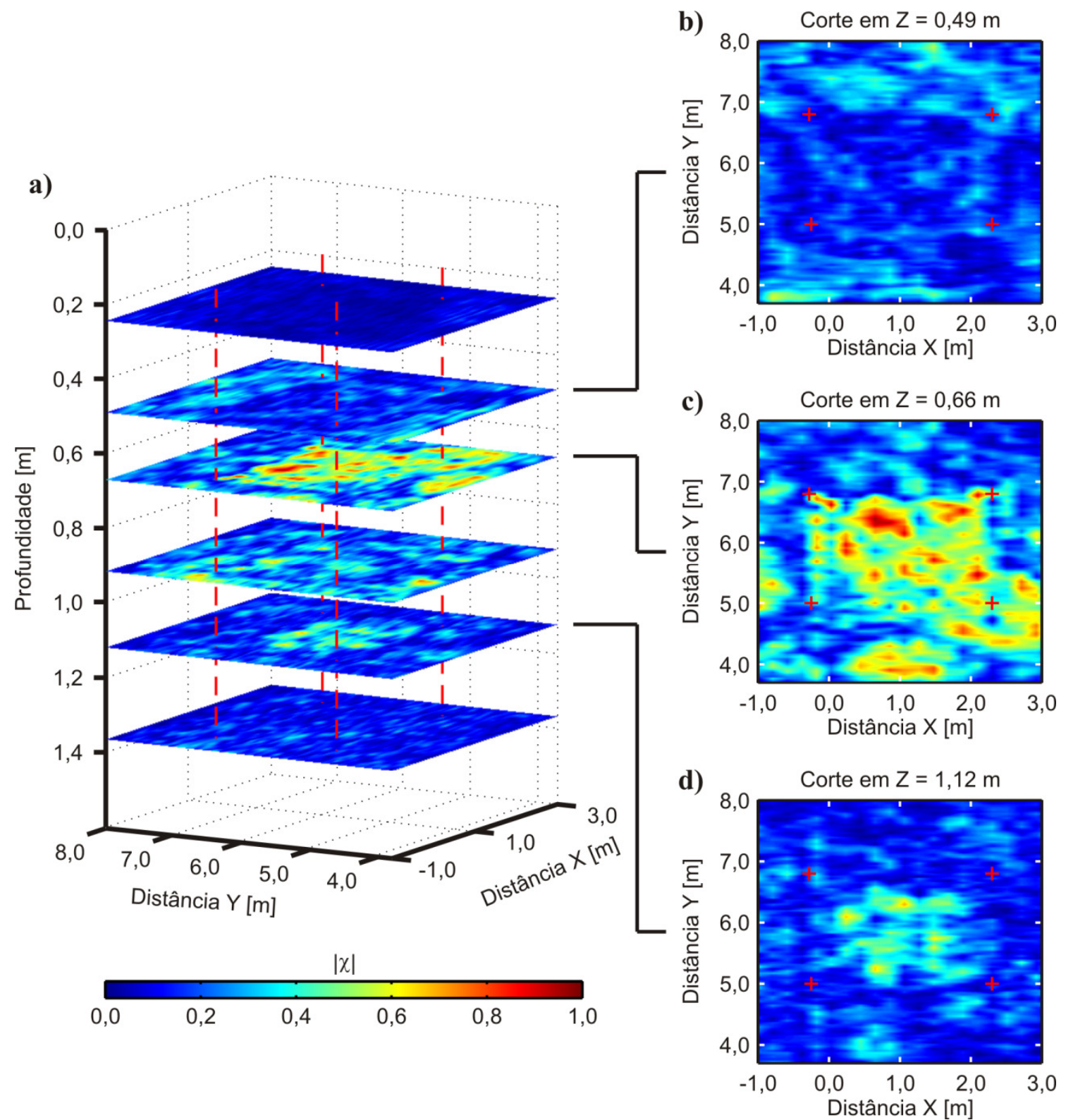

Figura 43. Visualização 3D dos dados de $400 \mathrm{MHz}$ sobre a caixa de brita na forma de cortes em profundidade gerados a partir da interpolação de perfis paralelos. As linhas tracejadas vermelhas representam uma projeção dos vértices do buraco escavado para instalação do alvo. As cruzes vermelhas nas vistas em planta indicam as posições onde estas linhas cruzam os planos de corte em cada profundidade. a) representação de planos de corte em diferentes profundidades. b) plano de corte à profundidade de 0,49 $\mathrm{m}$. c) plano de corte à profundidade de $0,66 \mathrm{~m}$. d) plano de corte à profundidade de $1,12 \mathrm{~m}$.

presença de um alinhamento de anomalias no interior do que aparenta ser um recorte de forma poligonal no solo é um indicativo da presença de um corpo anômalo, porém ainda pode ser interpretada como uma feição natural do solo diante de outras anomalias similares observadas nos cortes em profundidade. No plano de corte em $0,87 \mathrm{~m}$ de 
profundidade (Figura 44d) as anomalias possuem amplitudes bastante semelhantes e apresentam uma distribuição mais uniforme por todo o plano de corte, sugerindo que neste local já não há evidência de perturbação no solo e que portanto esta profundidade já se encontra próxima à do fundo do buraco onde o muro foi instalado.
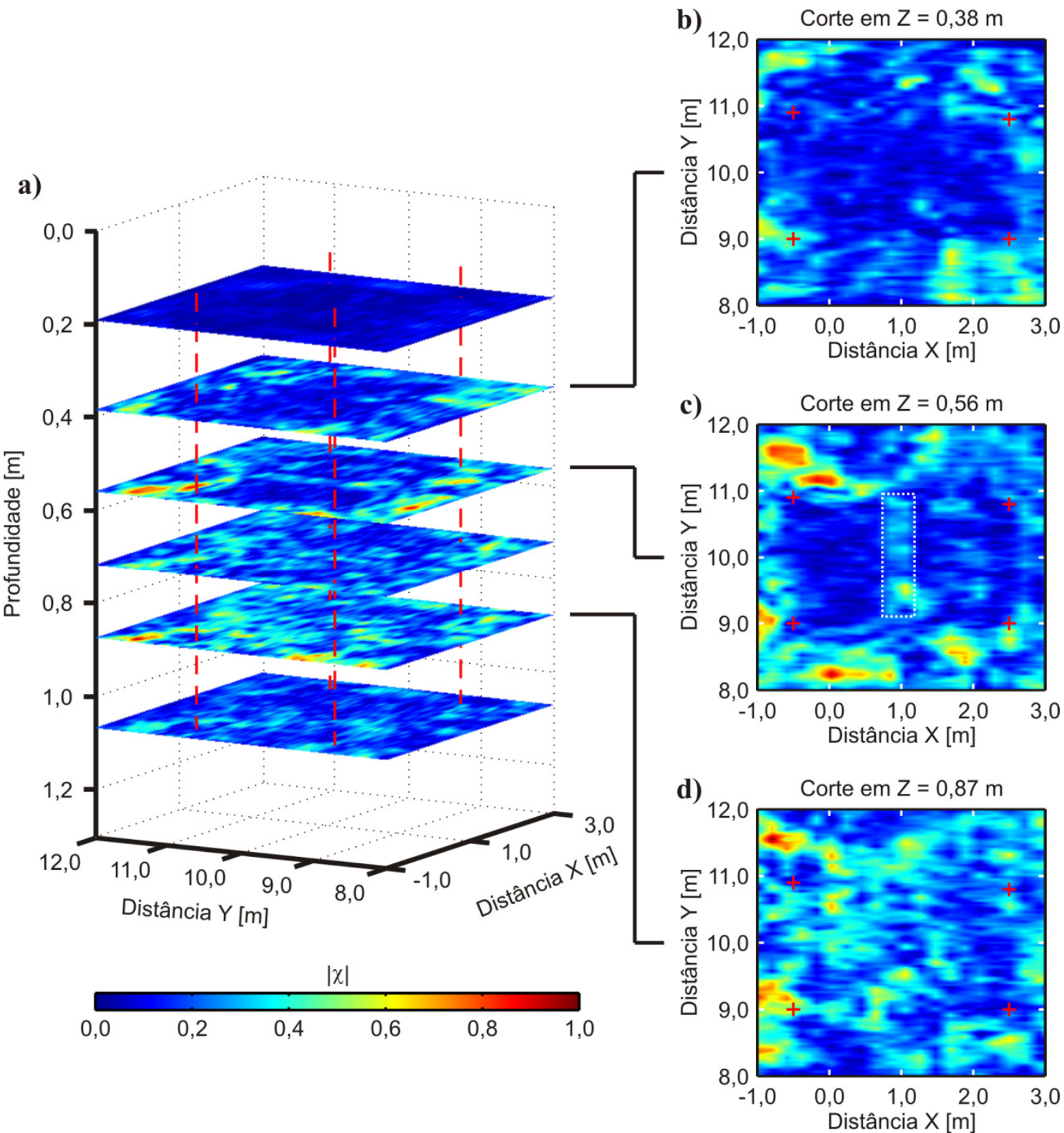

Figura 44. Visualização 3D dos dados de $400 \mathrm{MHz}$ sobre o muro de tijolos na forma de cortes em profundidade gerados a partir da interpolação de perfis paralelos. As linhas tracejadas vermelhas representam uma projeção dos vértices do buraco escavado para instalação do alvo. As cruzes vermelhas nas vistas em planta indicam as posições onde estas linhas cruzam os planos de corte em cada profundidade. a) representação de planos de corte em diferentes profundidades. b) plano de corte à profundidade de 0,38 m. c) plano de corte à profundidade de $0,56 \mathrm{~m}$. d) plano de corte à profundidade de 0,87 $\mathrm{m}$. 
A Figura 45 apresenta a análise referente aos dados de $270 \mathrm{MHz}$ adquiridos sobre o vaso à profundidade de $0,50 \mathrm{~m}$. Na Figura 45 a observa-se que a anomalia referente ao vaso concentra-se em torno dos 0,63 $\mathrm{m}$ de profundidade. No corte em 0,50 $\mathrm{m}$ de profundidade (Figura 45b) nota-se uma diferença sutil no padrão das anomalias associadas ao meio geológico. A partir desta diferença é possível indicar as coordenadas de $(0,24,17,0),(0,34,17,80),(1,8017,90)$ e $(1,80,17,0)$, representadas pelas cruzes vermelhas e que poderiam ser associadas aos vértices do buraco escavado para instalação do vaso. No centro do polígono demarcado por estas coordenadas é possível identificar ainda uma anomalia que seria referente ao topo do vaso cerâmico. No corte em 0,63 m de profundidade (Figura 45c) é possível observar de maneira bastante evidente a localização desta anomalia em relação ao que seriam os vértices do buraco. No terceiro corte, à profundidade de 1,13 m (Figura 45d), as feições que diferenciam o interior do buraco do restante do meio geológico são quase imperceptíveis visto que todas as anomalias presentes neste plano de corte apresentam amplitudes similares, o que sugere que esta profundidade possa ser associada ao fundo do buraco. Há uma anomalia que se localiza num ponto próximo àquele onde foi observada anomalia associada o alvo, nas coordenadas $(1,0,17,70)$, que poderia ser associada à porção inferior da referida anomalia.

Na Figura 46 são apresentados os resultados referentes ao vaso raso a partir dos dados adquiridos em $400 \mathrm{MHz}$. A Figura 46a mostra de uma maneira bastante clara o recorte no solo em torno de $0,50 \mathrm{~m}$ de profundidade, seguido por uma anomalia bem definida à profundidade em torno de $0,65 \mathrm{~m}$ e que estas feições já não são tão bem definidas em torno de $1,0 \mathrm{~m}$ de profundidade. No corte à profundidade de $0,52 \mathrm{~m}$ (Figura 46b) é possível observar o contorno do recorte feito no solo, cujos vértices localizam-se nas coordenadas $(0,30,17,12),(0,42,18,0),(1,95,18,0)$ e $(1,92,17,15)$. À profundidade de 0,63 m (Figura 46c) é possível identificar uma anomalia localizada no centro do polígono delimitado por estas coordenadas. Esta anomalia representa, portanto, o vaso cerâmico no interior do buraco escavado no solo. À profundidade de 0,77 m (Figura 46d) não é possível observar o recorte no solo indicado pelas cruzes vermelhas, mas ainda se observa uma pequena anomalia, ainda relacionada ao alvo. 


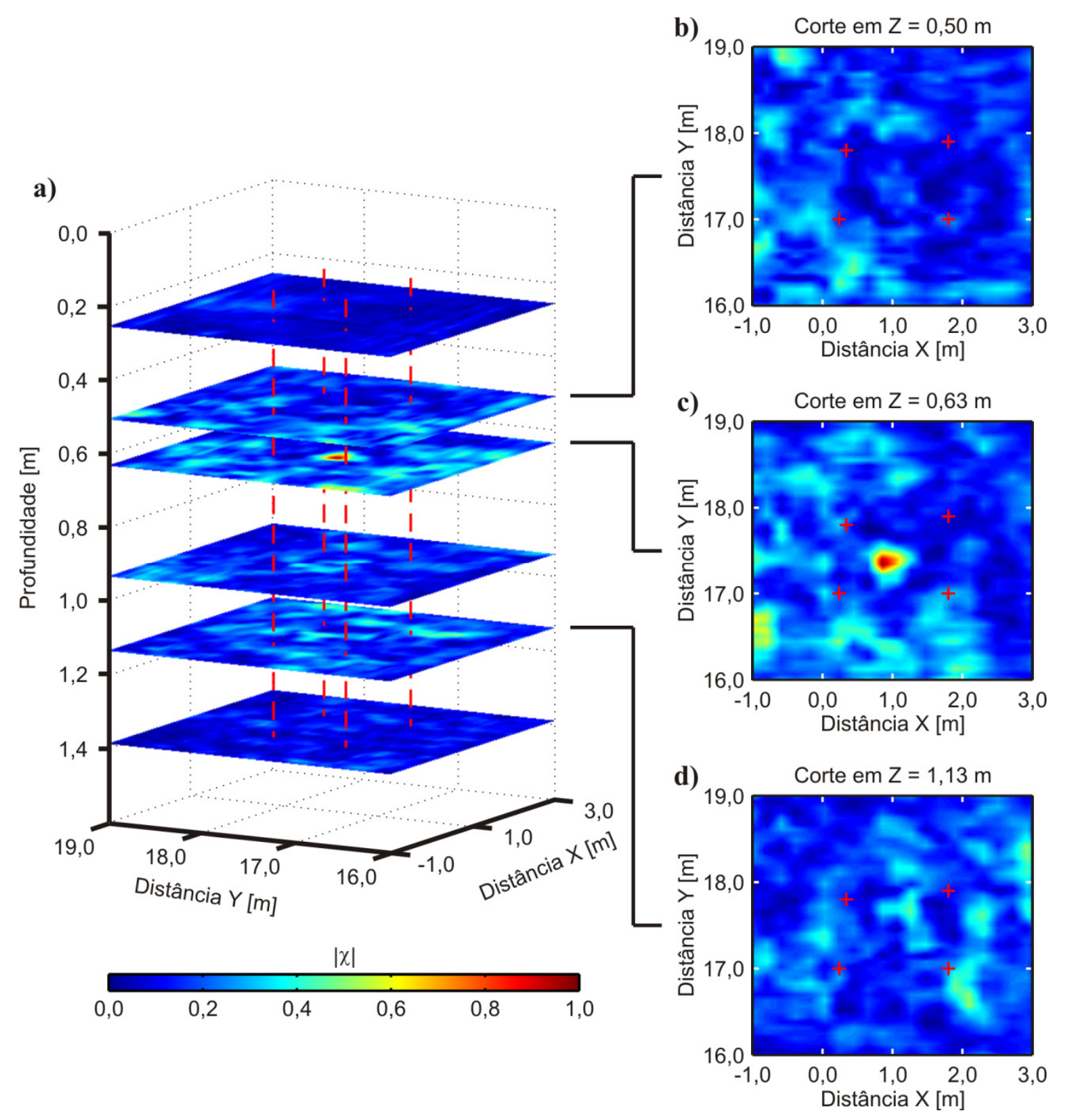

Figura 45. Visualização 3D dos dados de $270 \mathrm{MHz}$ sobre o vaso raso na forma de cortes em profundidade gerados a partir da interpolação de perfis paralelos. As linhas tracejadas vermelhas representam uma projeção dos vértices do buraco escavado para instalação do alvo. As cruzes vermelhas nas vistas em planta indicam as posições onde estas linhas cruzam os planos de corte em cada profundidade. a) representação de planos de corte em diferentes profundidades. b) plano de corte à profundidade de 0,50 m. c) plano de corte à profundidade de $0,63 \mathrm{~m}$. d) plano de corte à profundidade de 1,13 $\mathrm{m}$. 


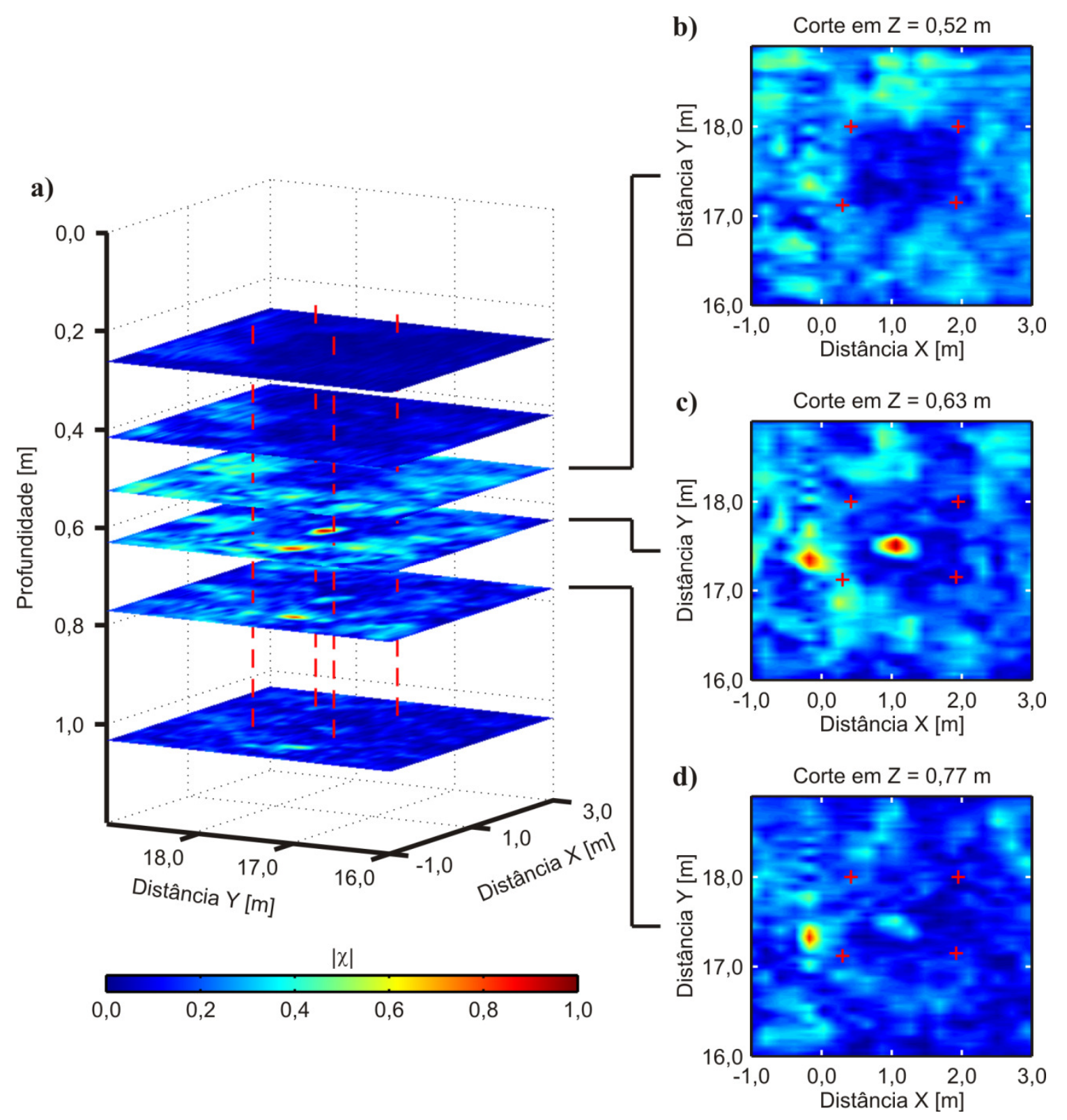

Figura 46. Visualização 3D dos dados de $400 \mathrm{MHz}$ sobre o vaso raso na forma de cortes em profundidade gerados a partir da interpolação de perfis paralelos. As linhas tracejadas vermelhas representam uma projeção dos vértices do buraco escavado para instalação do alvo. As cruzes vermelhas nas vistas em planta indicam as posições onde estas linhas cruzam os planos de corte em cada profundidade. a) representação de planos de corte em diferentes profundidades. b) plano de corte à profundidade de 0,52 m. c) plano de corte à profundidade de $0,63 \mathrm{~m}$. d) plano de corte à profundidade de 0,77 $\mathrm{m}$.

Os resultados obtidos sobre o vaso profundo com a antena de $270 \mathrm{MHz}$ são mostrados na Figura 47. A Figura 47a mostra uma concentração das anomalias relacionadas ao alvo entre as profundidades entre 1,0 $\mathrm{m}$ e 1,50 m, com um recorte no solo visível em torno de $0,50 \mathrm{~m}$. O corte à profundidade de $0,57 \mathrm{~m}$ (Figura $47 \mathrm{~b}$ ) mostra 
este recorte no solo de forma mais clara com um formato que pode ser definido por um polígono cujos vértices são localizados em $(0,34,19,40),(0,34,20,50),(2,0,20,40)$ e $(1,90,19,40)$ (cruzes vermelhas). No corte em 1,13 m de profundidade (Figura 47c) surge a anomalia referente ao alvo, localizada no interior do polígono associado ao buraco. Na profundidade de 1,64 m (Figura 47d) é possível identificar no interior do polígono uma anomalia alongada, disposta paralelamente à direção Y. Esta anomalia corresponde a feições no fundo do buraco onde o vaso está localizado.

A análise correspondente a este alvo obtida a partir de dados de $400 \mathrm{MHz}$ é apresentada na Figura 48. Na Figura 48a fica bastante evidente a relação entre a posição do recorte no solo próximo à profundidade de $0,50 \mathrm{~m}$ e a localização do alvo em torno da profundidade de 1,10 m. Na Figura 48b, onde é apresentado o corte à profundidade de 0,56 m, é possível identificar com clareza os limites do buraco escavado para instalação do alvo segundo as coordenadas $(0,60,19,60),(0,60,20,50),(2,0,20,50)$ e $(1,90,19,70)$, indicadas pelas cruzes vermelhas. À profundidade de $0,91 \mathrm{~m}$ (Figura 48c) esta feição já não é tão evidente, porém ainda pode ser delimitada segundo as mesmas coordenadas. A evidência da existência do alvo ocorre apenas no corte à profundidade de 1,15 m (Figura 48d), localizada no centro do polígono delimitado pelas cruzes vermelhas.

Conforme observado nestas análises, partir das análises em 3D é possível estabelecer com clareza a extensão lateral dos alvos. Os recortes nas feições naturais do solo, decorrentes das escavações durante a construção do SCGR, também podem ser observados com relativa facilidade em alguns planos de corte em profundidade. No caso dos vasos cerâmicos, que são alvos pontuais, é possível fornecer sua localização no interior destes buracos. O muro de tijolos mostrou-se uma situação ainda ambígua para esta metodologia. Foi possível observar algumas anomalias associadas a este alvo na análise 2D, principalmente nos dados de $400 \mathrm{MHz}$, porém não foi possível identificar as interfaces relacionadas ao topo e à base do alvo de maneira tão evidente quanto nos demais alvos. Devido ao baixo contraste das suas propriedades elétricas em relação às do solo as anomalias associadas ao alvo podem facilmente ser mal interpretadas como ruído geológico uma vez que as amplitudes destas feições assumem valores parecidos. A orientação deste alvo, paralela à orientação dos perfis, constitui um fator adicional que dificulta sua visualização nos dados. Por se tratar de um alvo estreito as anomalias 
a)

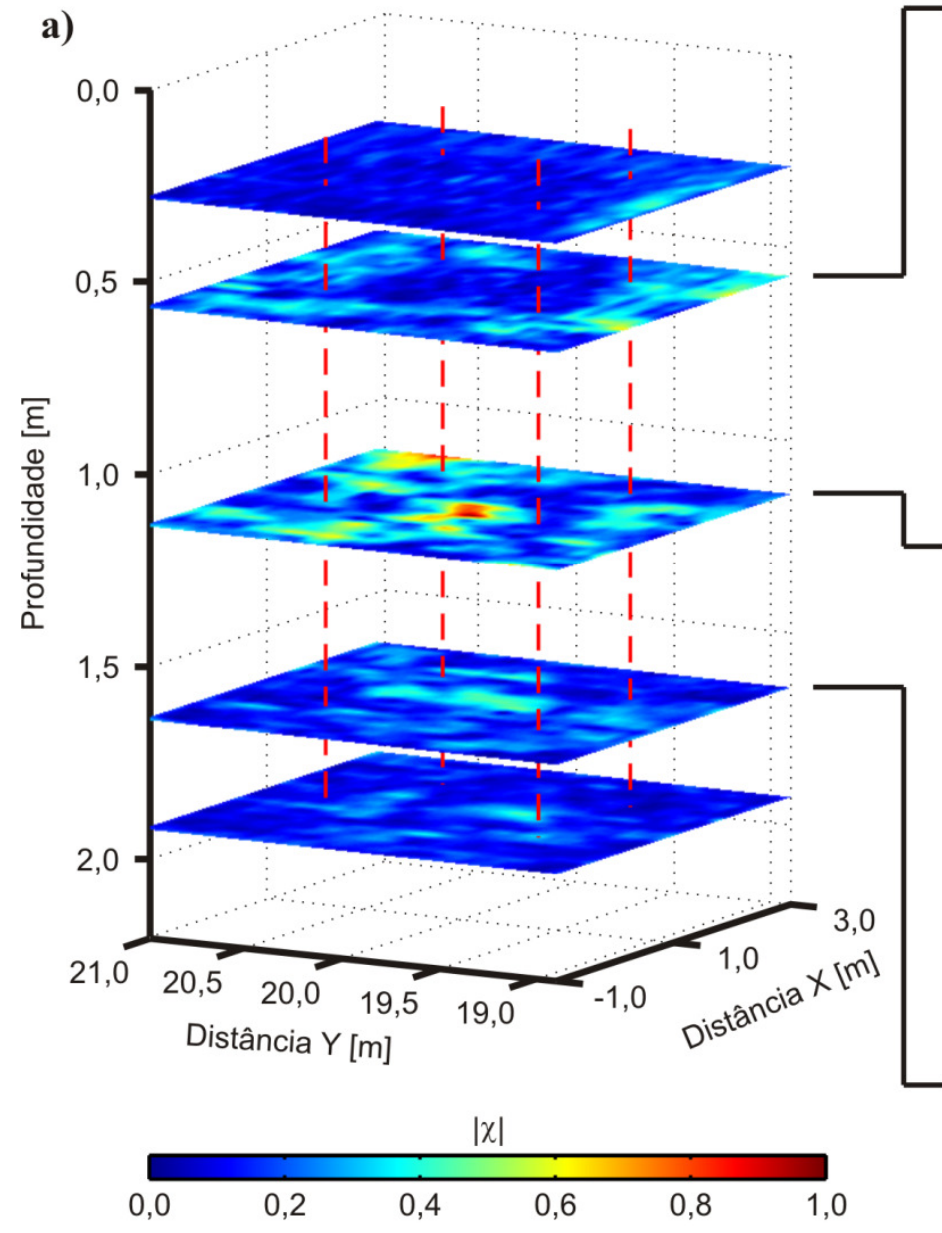

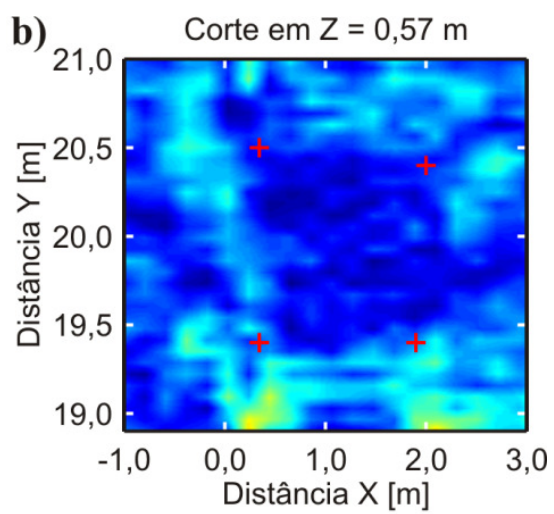

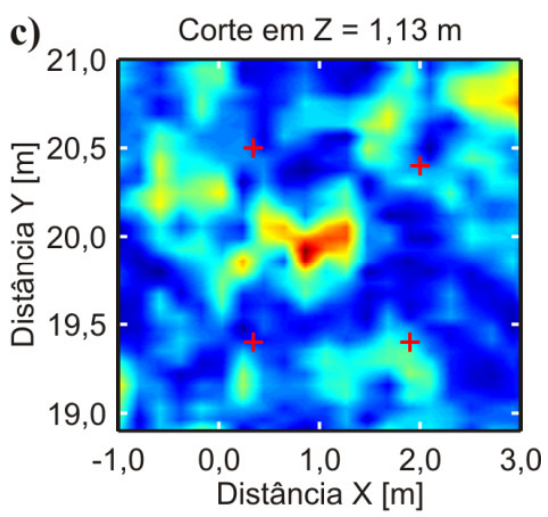

d)

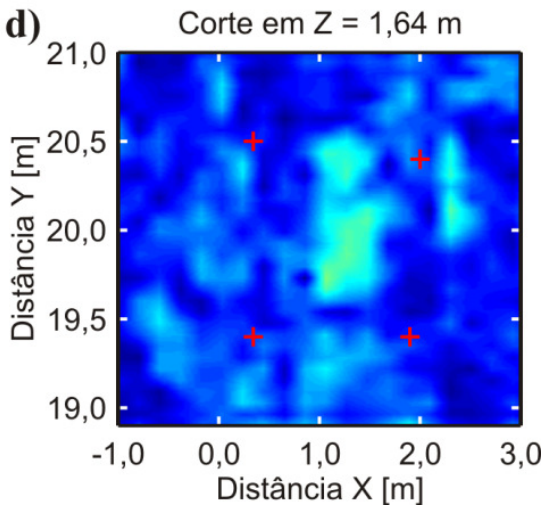

Figura 47. Visualização 3D dos dados de $270 \mathrm{MHz}$ sobre o vaso profundo na forma de cortes em profundidade gerados a partir da interpolação de perfis paralelos. As linhas tracejadas vermelhas representam uma projeção dos vértices do buraco escavado para instalação do alvo. As cruzes vermelhas nas vistas em planta indicam as posições onde estas linhas cruzam os planos de corte em cada profundidade. a) representação de planos de corte em diferentes profundidades. b) plano de corte à profundidade de 0,57 m. c) plano de corte à profundidade de $1,13 \mathrm{~m}$. d) plano de corte à profundidade de 1,64 $\mathrm{m}$.

associadas ao alvo são visíveis em um ou dois perfis apenas e não há informação suficiente para uma interpolação satisfatória na visualização 3D. Em contrapartida, os dados adquiridos sobre os vasos cerâmicos apresentaram resultados muito bons, onde foi possível identificar a borda dos buracos escavados e os alvos no interior dos 


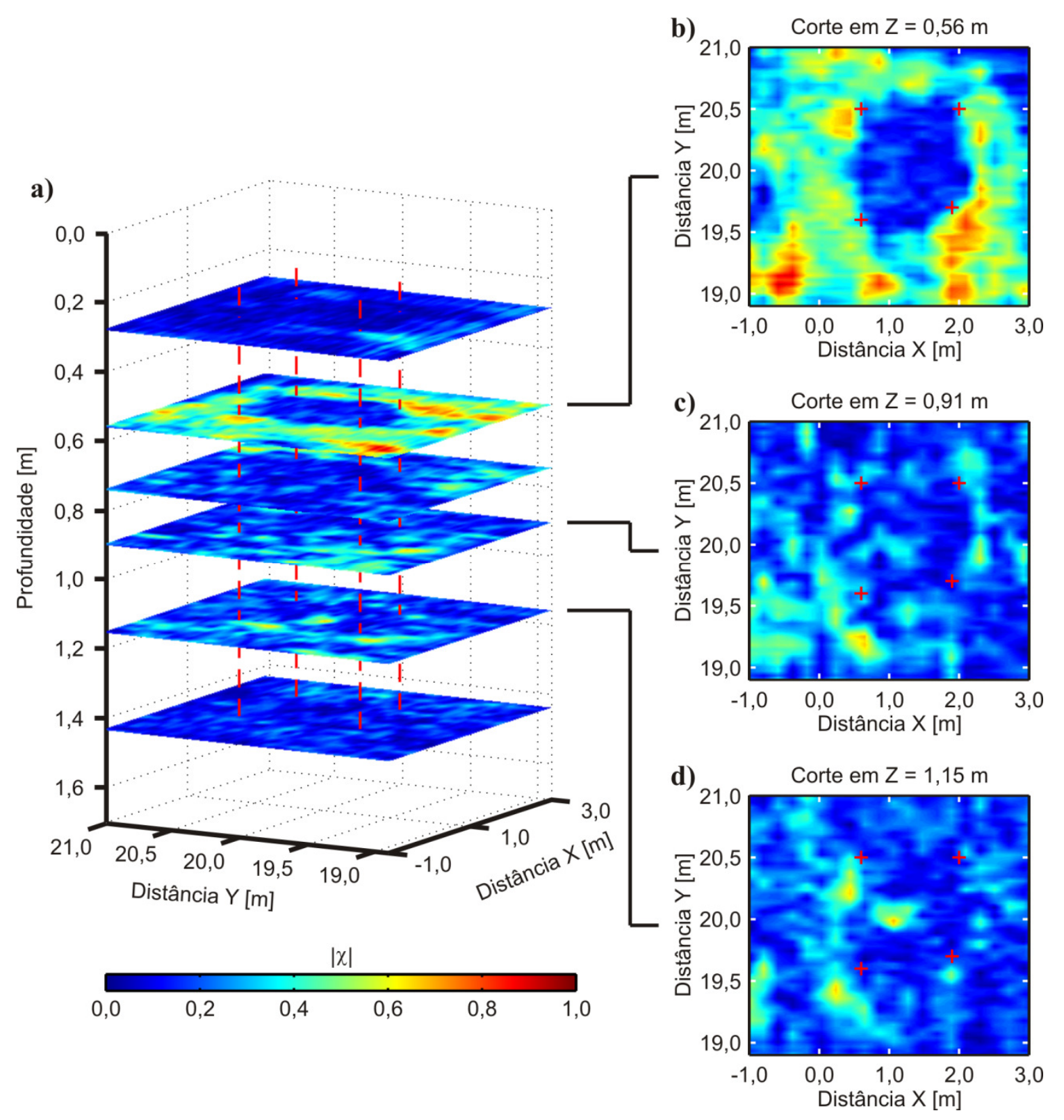

Figura 48. Visualização 3D dos dados de $400 \mathrm{MHz}$ sobre o vaso profundo na forma de cortes em profundidade gerados a partir da interpolação de perfis paralelos. As linhas tracejadas vermelhas representam uma projeção dos vértices do buraco escavado para instalação do alvo. As cruzes vermelhas nas vistas em planta indicam as posições onde estas linhas cruzam os planos de corte em cada profundidade. a) representação de planos de corte em diferentes profundidades. b) plano de corte à profundidade de 0,56 m. c) plano de corte à profundidade de $0,91 \mathrm{~m}$. d) plano de corte à profundidade de 1,15 $\mathrm{m}$.

mesmos. Isto também foi observado para as caixas de areia de brita, em que foi possível identificar as anomalias relacionadas ao topo e à base destes alvos. Nestes casos, entretanto, deve-se atentar ao fato de que as anomalias relacionadas à base dos alvos encontram-se a uma profundidade menor do que a real devido à diferença entre a 
constante dielétrica do material que preenche cada alvo, resultando em um aumento da velocidade de propagação das ondas eletromagnéticas em relação à velocidade destas no meio geológico.

\subsection{Alvo orgânico}

Os resultados sobre este alvo serão apresentados de maneira ligeiramente diferente daquela como os resultados do SCGR foram apresentados. Como este experimento utiliza apenas um alvo com o objetivo de avaliar sua alteração ao longo do tempo, cada perfil relacionado a uma etapa de aquisição de dados específica é apresentado em uma figura contendo os radargramas e suas respectivas imagens tomográficas nas três frequências. As escalas de profundidade têm como referência o ponto mais alto da área onde os dados foram adquiridos, de forma que irá se observar que os perfis não apresentam o ponto mais alto da interface ar-solo coincidindo com a profundidade de $0,0 \mathrm{~m}$. As escalas de amplitude nos perfis $2 \mathrm{D}$ não foram normalizadas, de modo que os radargramas conservam a amplitude do sinal observada ao fim do processamento com o software ReflexWin e as imagens tomográficas conservam a amplitude da função objetivo observada após a inversão e regularização do problema. Optou-se por apresentar os resultados desta maneira devido ao fato deste experimento ter sido conduzido empregando-se antenas de três frequências diferentes, com aquisições de dados em diferentes intervalos de tempo e na forma de vários perfis paralelos, o que torna difícil estabelecer uma referência para a normalização. Ademais, do ponto de vista prático a apresentação dos dados com ou sem normalização é indiferente sob aspecto das informações relevantes à interpretação dos dados uma vez que o imageamento tomográfico fornece uma análise qualitativa em vez de uma análise quantitativa.

Os resultados serão apresentados inicialmente na forma de perfis $2 \mathrm{D}$, onde serão discutidos os perfis com as anomalias mais significativas observadas na posição real do alvo. Em seguida serão apresentados os resultados em uma visualização 3D interpolada, com cortes em profundidade para avaliação da extensão lateral das anomalias observadas. 
Nos resultados que serão apresentados os radargramas são mostrados conforme o que foi obtido ao final do pré-processamento, de forma que o sinal de acoplamento da antena com a superfície é mantido. Para a obtenção das imagens tomográficas foi aplicado o time-gating adequado para suprimir este sinal de acoplamento, o qual via de regra mostra-se predominante nas imagens resultantes do processo de inversão.

\subsubsection{Resultados $2 D$}

Para apresentação concisa dos resultados 2D foram selecionados os perfis com as anomalias mais evidentes à profundidade do alvo em cada conjunto de dados. Estes perfis localizam-se entre as posições de $X=3,40 \mathrm{~m}$ e $\mathrm{X}=3,80 \mathrm{~m}$ dependendo do conjunto de dados considerado. Esta região corresponde à porção traseira do animal enterrado. Em todos os resultados apresentados nesta sub-seção as figuras a, c, e apresentam os radargramas, e as figuras b, d, f apresentam as imagens tomográficas correspondentes. Os radargramas mostrados nas figuras correspondem ao domínio sob investigação adotado para obtenção das imagens tomográficas. As linhas tracejadas brancas presentes nos resultados a partir do conjunto de número [02] representam os limites determinados para a vala onde o animal foi enterrado.

Na Figura 49 são apresentados resultados do perfil na posição $X=3,4 \mathrm{~m}$ das aquisições realizadas com as três antenas dois dias antes do enterro do animal. Este levantamento foi feito para conhecimento das condições prévias do solo e das fontes de anomalia naturais da área onde o experimento seria conduzido. A Figura 49a mostra o perfil adquirido com a antena de $270 \mathrm{MHz}$. Na posição de 1,00 m e em 13,8 ns há uma anomalia hiperbólica bastante evidente. Há também uma anomalia de aspecto horizontal entre as posições de 2,0 m e 3,0 m em 50,0 ns. Embora esta anomalia esteja localizada na posição em que a vala seria escavada para colocação do alvo, sua profundidade é maior do que a profundidade da vala propriamente dita. Na Figura $49 \mathrm{~b}$ a imagem tomográfica mostra que esta anomalia está localizada a profundidades maiores do que 1,5 m. A anomalia mais profunda não é observada no perfil de $400 \mathrm{MHz}$ (Figura 49c) e nem na sua respectiva imagem tomográfica (Figura 48d), devido ao limite de investigação com esta frequência. O mesmo ocorre com os dados de $900 \mathrm{MHz}$ (Figura 49e) e a imagem tomográfica correspondente (Figura 49f). A anomalia hiperbólica mais 
rasa à posição de $1,0 \mathrm{~m}$ é observada tanto na frequência de $400 \mathrm{MHz}$ quanto na de 900 MHz. As imagens tomográficas das três frequências mostram que esta hipérbole corresponde a uma anomalia em $0,5 \mathrm{~m}$ de profundidade. Além das anomalias indicadas são apenas pequenas variações na amplitude do sinal dos radargramas, tipicamente causadas por leves heterogeneidades do solo e observadas comumente em dados GPR. Estas variações aparecem nas imagens tomográficas como anomalias de pequena amplitude espalhadas por todo o domínio sob investigação, sem um padrão definido.
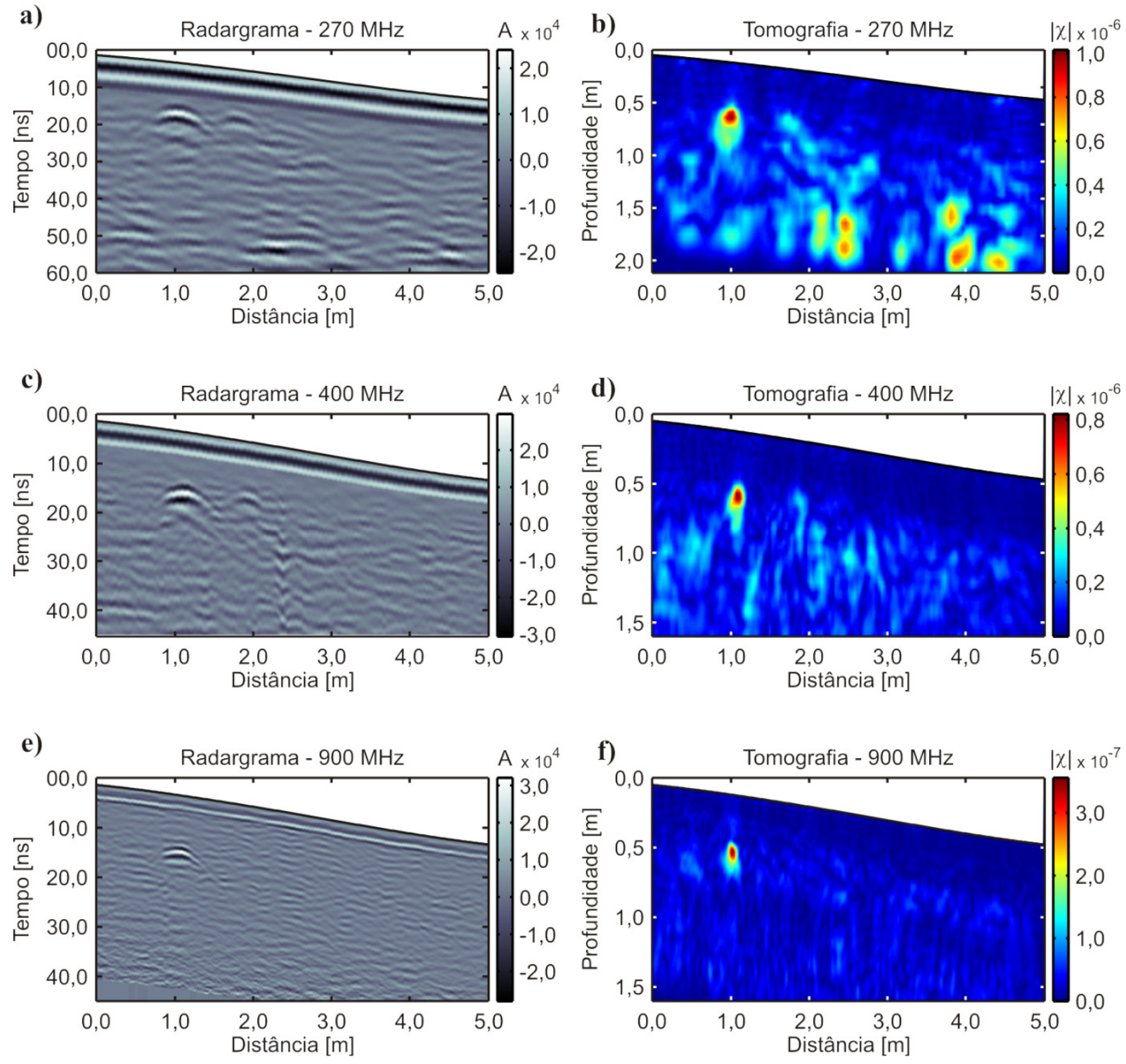

Figura 49. Resultados do conjunto [01] de 17/12/2012 obtidos para o perfil em 3,4 m. a) radargrama adquirido com a antena de $270 \mathrm{MHz}$. b) imagem tomográfica obtida a partir do radargrama de $270 \mathrm{MHz}$. c) radargrama adquirido com a antena de $400 \mathrm{MHz}$. d) imagem tomográfica obtida a partir do radargrama de $400 \mathrm{MHz}$. e) radargrama adquirido com a antena de $900 \mathrm{MHz}$. f) imagem tomográfica obtida a partir do radargrama de $900 \mathrm{MHz}$. 
Durante a escavação realizada ao final do experimento para análise das condições do alvo foi feita uma verificação da causa desta anomalia. A escavação realizada nas coordenadas $(x, y)=(3,4,1,0)$ da área de estudo mostrou que esta anomalia foi causada por uma cavidade preenchida com ar presente no solo (Figura 50).

a)
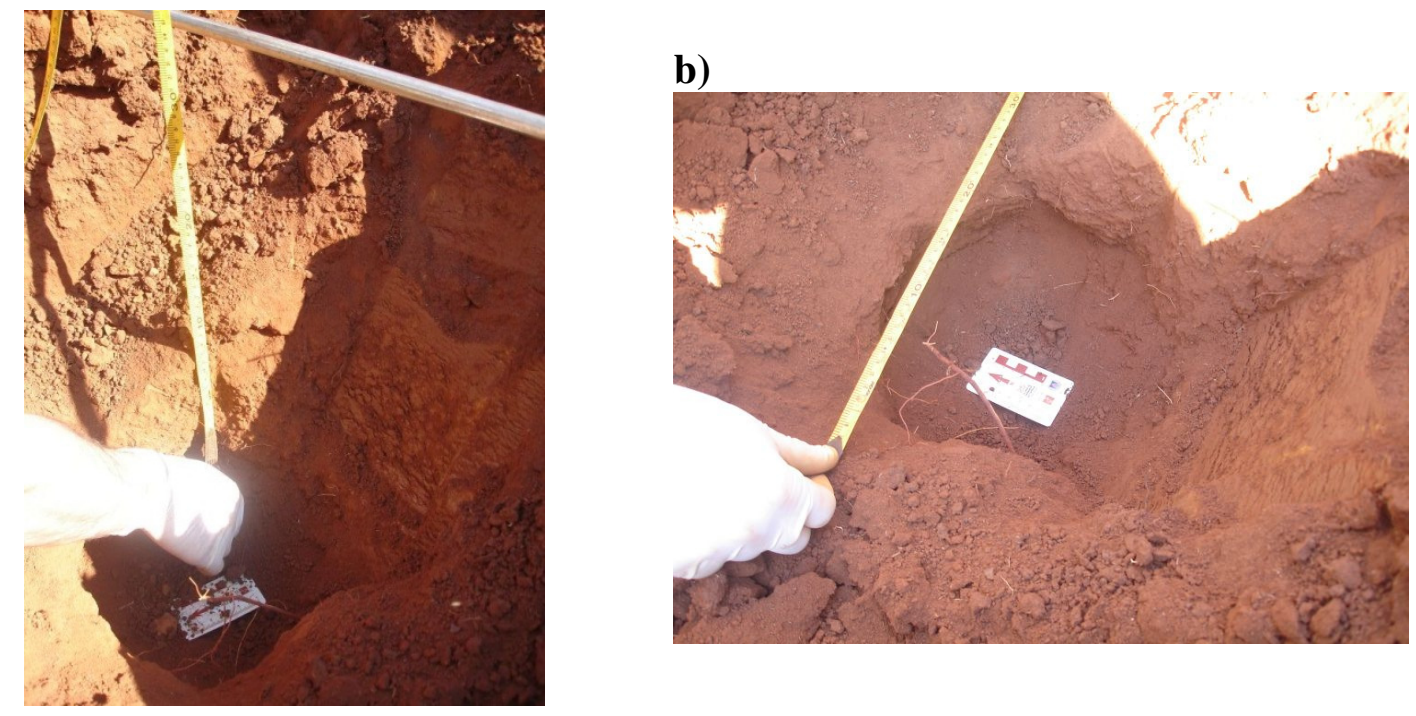

Figura 50. Cavidade presente no solo e causadora da anomalia rasa observada nos perfis adquiridos em $X=3,4 \mathrm{~m}$. a) localização em profundidade. b) vista superior mostrando a extensão lateral.

Na Figura 51 são apresentados resultados de perfis adquiridos na mesma posição $\mathrm{X}=3,4 \mathrm{~m}$ logo após o alvo ter sido enterrado. A anomalia provocada pela cavidade presente no solo à posição de 1,00 m é observada nos três radargramas (Figura 51a, c, e). No radargrama em 270 MHz (Figura 51a) há uma anomalia em 26,6 ns na posição que corresponde ao interior da vala. Como esta anomalia não era observada anteriormente fica claro que ela é causada pelo alvo enterrado, mais especificamente pelo topo do mesmo. Observa-se ainda que acima desta há um padrão perturbado nas reflexões associadas ao background geológico. Este padrão corresponde ao solo que foi removido e recolocado na vala durante o procedimento de enterro do alvo.

A imagem tomográfica correspondente a este perfil (Figura 51b) mostra anomalias bastante claras e com um pouco mais de informação do que o radargrama. A anomalia mais evidente é justamente aquela associada ao alvo no interior da vala. Podese identificar o topo desta anomalia à profundidade de $1,00 \mathrm{~m}$, muito bem localizada no 
interior da vala. Abaixo dela uma pequena anomalia é identificada à profundidade de $1,30 \mathrm{~m}$, correspondendo à localização do fundo da vala. Esta informação não é obtida de forma tão imediata apenas a partir da análise do radargrama. As anomalias relacionadas às perturbações no solo acima do alvo são observadas de maneira bastante sutil devido à aplicação de remoção de background por time-gating em 7,0 ns nos dados. Além disso, o sinal de $270 \mathrm{MHz}$ é pouco suscetível às perturbações deste tipo no solo devido ao comprimento de onda do sinal. A anomalia causada pela cavidade no solo é observada em $0,50 \mathrm{~m}$ de profundidade à posição de $1,00 \mathrm{~m}$. As anomalias previamente identificadas em profundidades maiores do que 1,50 m também podem ser vistas nesta imagem.

Os dados em $400 \mathrm{MHz}$ mostram uma análise bastante similar, com a anomalia gerada pelo alvo e a perturbação no solo na região da vala sendo observados no radargrama (Figura 51c) e com a imagem tomográfica apresentando uma anomalia associada ao alvo com dimensão bastante próxima à da seção cruzada deste (Figura 51d). Nos dados de $900 \mathrm{MHz}$ a anomalia associada ao alvo já não aparece de forma tão clara no radargrama (Figura 51e) nem na imagem tomográfica (Figura 51f) pois se confunde com as anomalias causadas pela perturbação no solo. Entretanto, a imagem tomográfica mostra anomalias de baixa amplitude que se concentram na região interna do contorno da vala, correspondendo à perturbação no solo. No radargrama estas anomalias também são visíveis, mas podem facilmente ser interpretadas como variações naturais do solo.

A Figura 52 apresenta os resultados referentes ao conjunto [03], de 07/01/2013, adquirido três semanas após a instalação do alvo. Novamente são bastante evidentes as anomalias causadas pelo alvo nos radargramas de $270 \mathrm{MHz}$ e $400 \mathrm{MHz}$ (Figura 52a, c). As imagens tomográficas obtidas a partir destes perfis (Figura 52b, d) mostram as anomalias associadas ao alvo no interior da vala. Estas anomalias localizam-se com o topo à profundidade de $1,00 \mathrm{~m}$ e apresentam uma extensão lateral compatível com a seção cruzada do alvo nesta posição.

Nos dados de $900 \mathrm{MHz}$ (Figura 52e) a anomalia associada ao alvo é visível e já não se confunde tanto com a perturbação no solo, por este estar mais compactado do que durante a aquisição do conjunto de dados anterior. A anomalia causada pelo alvo na imagem tomográfica (Figura 52f) localiza-se à profundidade de 1,00 m, porém não se 

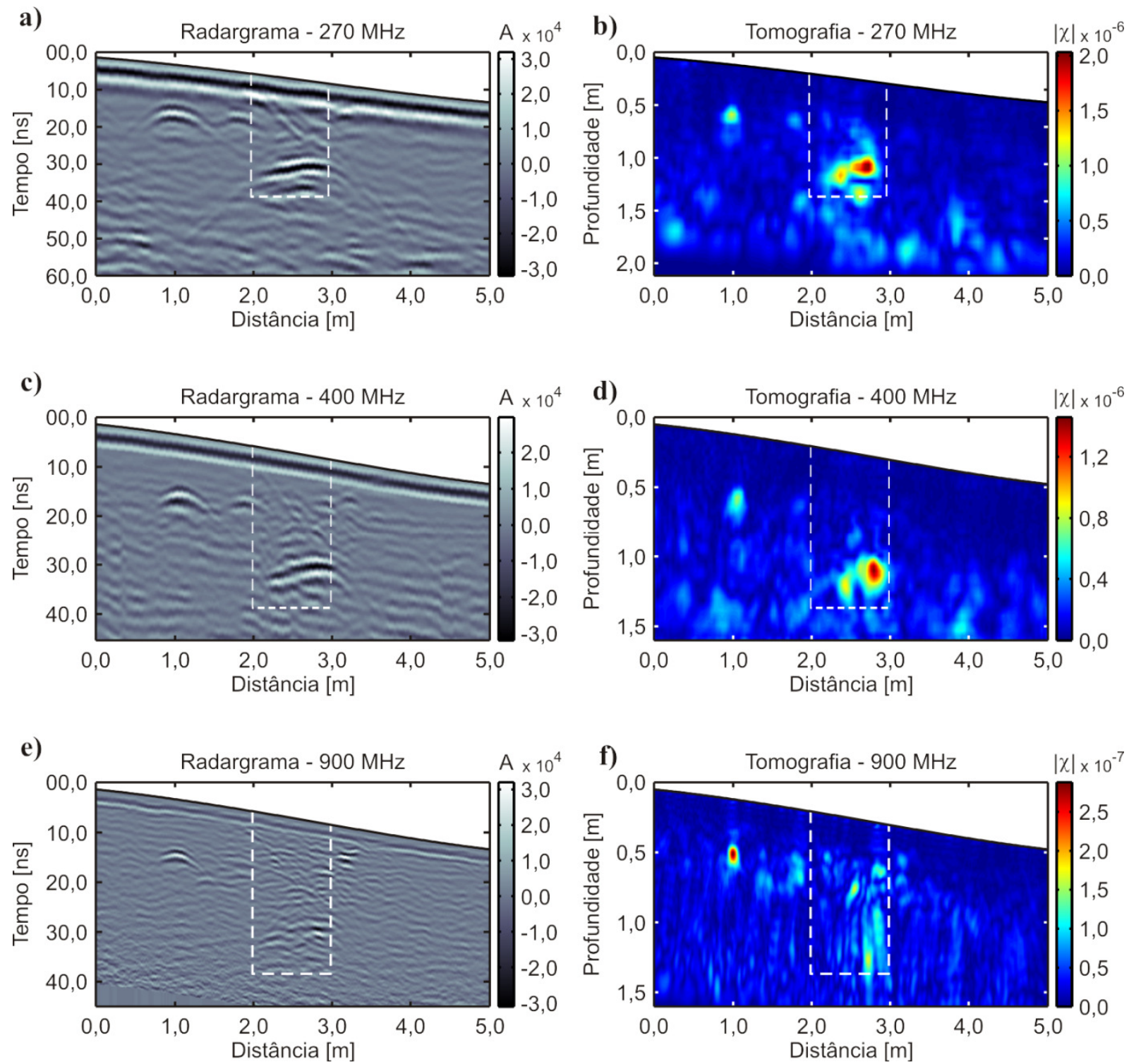

Figura 51. Resultados do conjunto [02] de 19/12/2012 obtidos para o perfil em 3,4 m. As linhas tracejadas brancas indicam os limites do buraco escavado para enterro do animal. a) radargrama adquirido com a antena de $270 \mathrm{MHz}$. b) imagem tomográfica obtida a partir do radargrama de $270 \mathrm{MHz}$. c) radargrama adquirido com a antena de $400 \mathrm{MHz}$. d) imagem tomográfica obtida a partir do radargrama de $400 \mathrm{MHz}$. e) radargrama adquirido com a antena de $900 \mathrm{MHz}$. f) imagem tomográfica obtida a partir do radargrama de $900 \mathrm{MHz}$.

observa a correspondência com a extensão da seção cruzada do alvo como foi observado nos dados de $270 \mathrm{MHz}$ e $400 \mathrm{MHz}$. Isto se deve ao fato de o alvo estar localizado próximo ao limite de profundidade de investigação da antena de $900 \mathrm{MHz}, \mathrm{o}$ que não permite amostrar de forma suficiente a hipérbole gerada pelo alvo. 

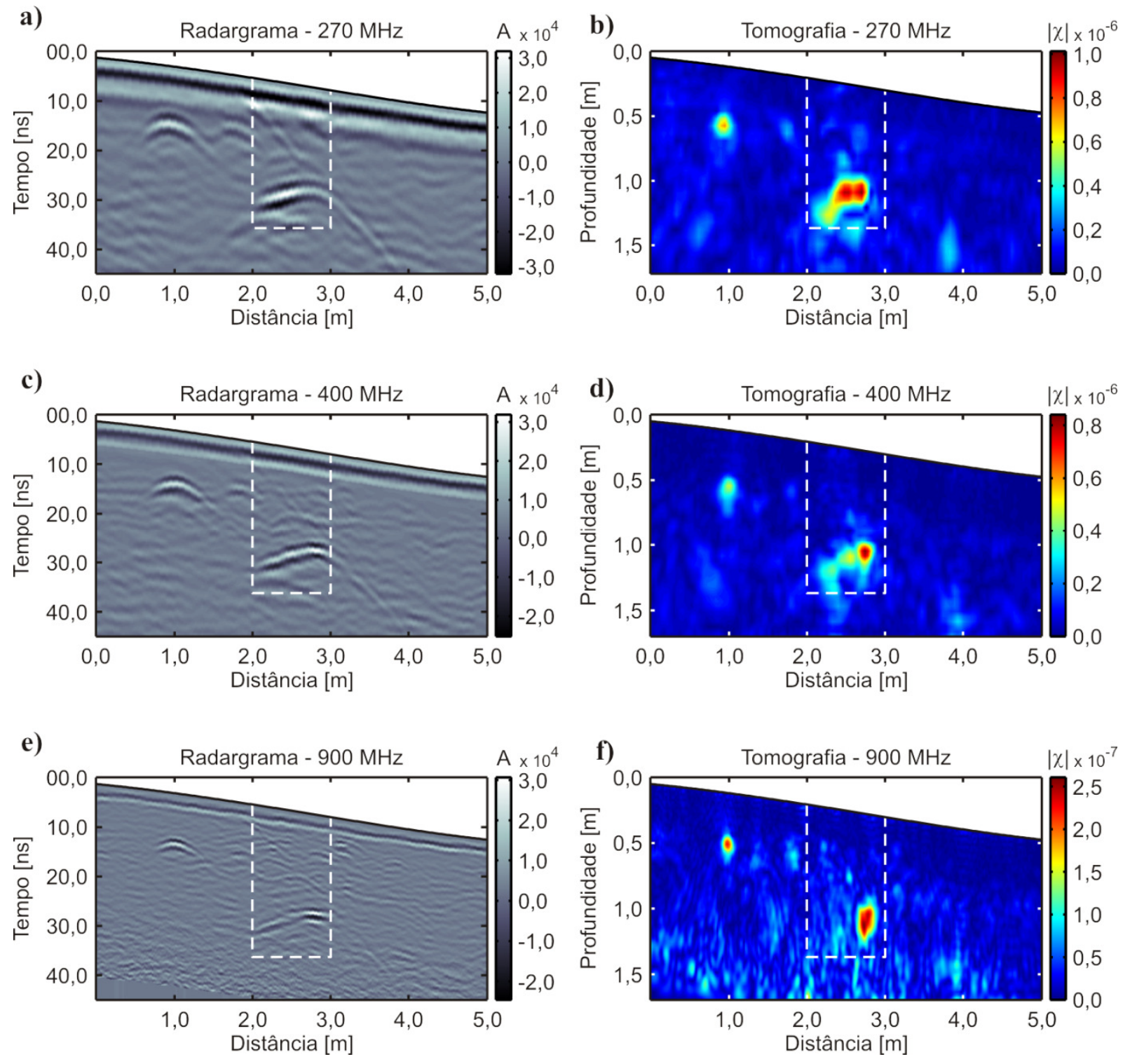

Figura 52. Resultados do conjunto [03] de 07/01/2013 obtidos para o perfil em 3,4 m. As linhas tracejadas brancas indicam os limites do buraco escavado para enterro do animal. a) radargrama adquirido com a antena de $270 \mathrm{MHz}$. b) imagem tomográfica obtida a partir do radargrama de $270 \mathrm{MHz}$. c) radargrama adquirido com a antena de $400 \mathrm{MHz}$. d) imagem tomográfica obtida a partir do radargrama de $400 \mathrm{MHz}$. e) radargrama adquirido com a antena de $900 \mathrm{MHz}$. f) imagem tomográfica obtida a partir do radargrama de $900 \mathrm{MHz}$.

A partir de cinco semanas após o enterro começaram a ser observadas algumas nuances relacionadas ao experimento, como é mostrado na Figura 53. As anomalias os radargramas de $270 \mathrm{MHz}$ e $400 \mathrm{MHz}$ (Figura 53a, c) continuam facilmente identificáveis, embora seja observado uma ligeira redução na amplitude das mesmas. Esta redução na amplitude deve-se a uma variação no contraste entre as propriedades eletromagnéticas do solo e do alvo. Esta variação deve-se principalmente à 
decomposição do alvo após cinco semanas, visto que a variação nas propriedades do solo foi pequena. No entanto, é difícil quantificar esta variação uma vez que a tomografia fornece apenas uma aproximação para o formato do corpo causador da anomalia. Apesar desta redução, as imagens tomográficas ainda mostram as anomalias relacionadas ao alvo de forma clara e mantendo a correspondência entre suas dimensões e a da seção cruzada do alvo (Figura 53b, d).

Nos dados de $900 \mathrm{MHz}$ (Figura 53e) a anomalia hiperbólica causada pelo alvo ainda é visível, porém apresenta-se menor do que a anomalia rasa à posição de 1,00 m. $\mathrm{Na}$ imagem tomográfica obtida a partir destes dados (Figura 53f) a anomalia associada ao alvo apresenta amplitude menor do que observado nas imagens em $270 \mathrm{MHz}$ e 400 $\mathrm{MHz}$, porém aparece com tamanho comparável às anomalias observadas naquelas situações. No interior da vala observa-se o que seriam duas anomalias, uma na posição de 2,30 m e outra na posição de $2,85 \mathrm{~m}$, ambas localizadas próximo ao que seria o fundo da vala. Uma comparação entre as três imagens tomográficas mostra que a anomalia localizada na posição de 2,30 m na imagem em $900 \mathrm{MHz}$ também pode ser associada ao alvo, uma vez que nas frequências mais baixas há a indicação de uma anomalia contínua. Além disso na imagem em $900 \mathrm{MHz}$ pode-se observar uma pequena porção de anomalias de baixa amplitude distribuídas em um padrão aleatório concentradas próximo aos limites da vala, numa indicação de que houve uma perturbação no solo neste local.

Após onze semanas do início do experimento as alterações observadas nos dados passam a ser mais significativas, conforme é apresentado na Figura 54. Esta figura apresenta perfis adquiridos à posição $X=3,70 \mathrm{~m}$, o que representa uma distância de 0,30 m em relação aos perfis apresentados nas figuras anteriores. Contudo este perfil é suficientemente próximo dos demais frente às dimensões do alvo para proporcionar uma análise comparativa satisfatória. A primeira observação que faz é a de que a anomalia associada ao alvo não é identificada nos radargramas de nenhuma das três frequências (Figura 54a, c, e). Estes radargramas mostram um padrão de sinal muito parecido tanto no interior quanto no exterior da região delimitada pelo contorno branco.

Nos radargramas de $400 \mathrm{MHz}$ e $900 \mathrm{MHz}$ (Figura 54c, e) alguma perturbação rasa é observada na região interna da vala, porém não há nada que permita uma associação imediata com o experimento. As imagens tomográficas por sua vez 

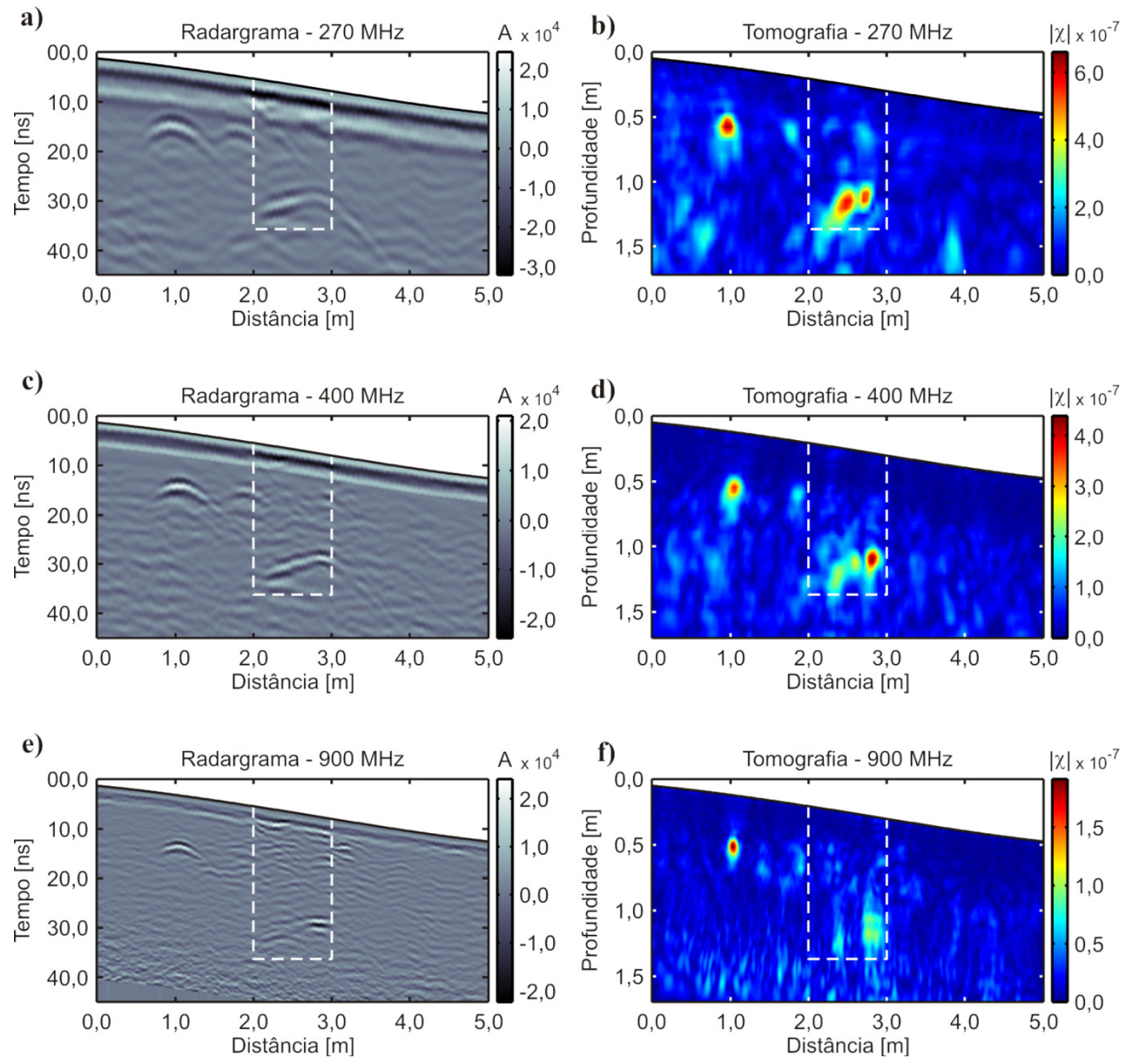

Figura 53. Resultados do conjunto [04] de 22/01/2013 obtidos para o perfil em 3,4 m. As linhas tracejadas brancas indicam os limites do buraco escavado para enterro do animal. a) radargrama adquirido com a antena de $270 \mathrm{MHz}$. b) imagem tomográfica obtida a partir do radargrama de $270 \mathrm{MHz}$. c) radargrama adquirido com a antena de $400 \mathrm{MHz}$. d) imagem tomográfica obtida a partir do radargrama de $400 \mathrm{MHz}$. e) radargrama adquirido com a antena de $900 \mathrm{MHz}$. f) imagem tomográfica obtida a partir do radargrama de $900 \mathrm{MHz}$.

permitem uma interpretação mais detalhada. Em $270 \mathrm{MHz}$ (Figura 54b) há uma anomalia localizada na posição de $2,50 \mathrm{~m}$, no limite inferior da vala. Apesar de ela misturar-se com algumas das anomalias à profundidade de $1,50 \mathrm{~m}$ já presentes nesta região antes do início do experimento, seu topo localiza-se à profundidade de 1,00 m. Isto corresponde à profundidade do topo do alvo, de modo que pode-se fazer uma associação com o mesmo. Na posição de $2,00 \mathrm{~m}$, coincidindo com o contorno da vala, 
há algumas anomalias dispostas verticalmente entre as profundidades de 0,80 m e 1,30 m. Há também uma concentração de anomalias de baixa amplitude no interior da vala, logo acima da anomalia associada ao alvo, dispostas em um padrão que difere daquele do restante do perfil. Todas estas anomalias sugerem a interpretação de que em algum momento o solo foi alterado neste local e que há a presença de uma fonte de contraste localizada numa posição intermediária desta região à profundidade de 1,00 m.

A imagem tomográfica em $400 \mathrm{MHz}$ (Figura 54d) também mostra isto de maneira clara. Aqui há não só uma anomalia no fundo da vala com dimensões similares às observadas nos conjuntos de dados anteriores nesta mesma frequência como há também anomalias de amplitude maior do que no restante do perfil localizadas também no interior da vala, mas em profundidades mais rasas. Por fim, a imagem em $900 \mathrm{MHz}$ (Figura 54f) não mostra anomalias relacionadas ao alvo em si, porém evidencia anomalias à profundidade de $0,65 \mathrm{~m}$ na região interna da vala. Como não são observadas anomalias similares no restante do perfil, pode-se sugerir uma conexão entre elas e a perturbação causada no solo pela escavação da vala. A análise dos resultados desta figura representam um ótimo exemplo de como pode-se extrair informações adicionais de um perfil GPR mediante a inversão por imageamento tomográfico dos dados.

A dificuldade de se definir com clareza a anomalia associada ao alvo deve-se provavelmente à redução do contraste entre as propriedades elétricas do alvo em relação às propriedades do solo, visto que ao final do experimento havia ainda uma quantidade considerável de material orgânico no interior da vala (Figura 55a). Com esta redução a anomalia associada à reflexão do sinal no alvo passou a apresentar amplitude menor do que outras feições observadas nos dados. A hipótese de redução do skin depth devido a alterações na condutividade do solo foi descartada, pois não foram observadas alterações no material geológico no entorno do animal e nem no solo acima deste (Figura 55b). A única alteração observada no solo foi no fundo da vala (Figura 55c), como uma camada de em torno de 7,0 cm de material mais escuro (Figura 55d). 

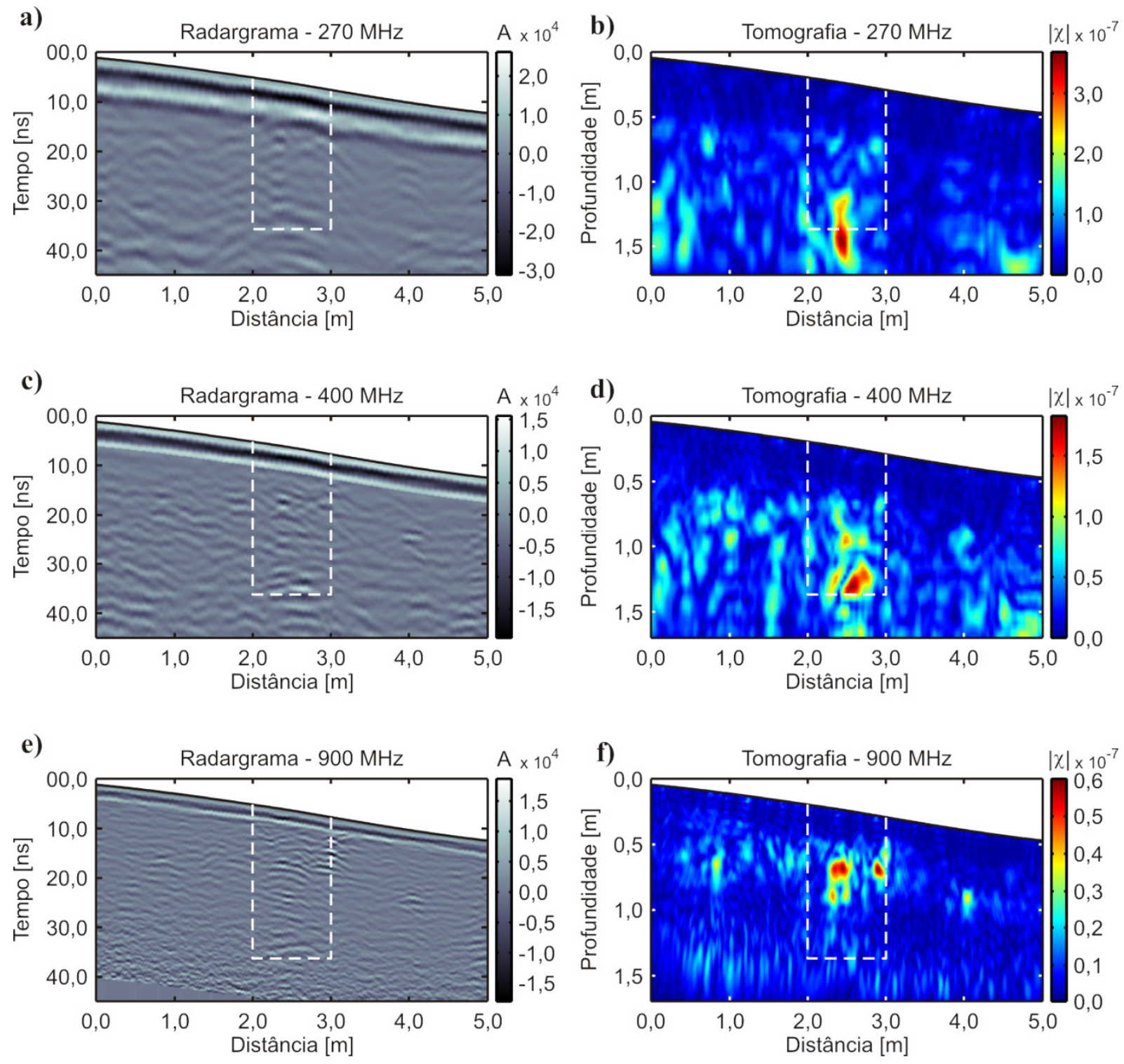

Figura 54. Resultados do conjunto [05] de 04/03/2013 obtidos para o perfil em 3,7 m. As linhas tracejadas brancas indicam os limites do buraco escavado para enterro do animal. a) radargrama adquirido com a antena de $270 \mathrm{MHz}$. b) imagem tomográfica obtida a partir do radargrama de $270 \mathrm{MHz}$. c) radargrama adquirido com a antena de $400 \mathrm{MHz}$. d) imagem tomográfica obtida a partir do radargrama de $400 \mathrm{MHz}$. e) radargrama adquirido com a antena de $900 \mathrm{MHz}$. f) imagem tomográfica obtida a partir do radargrama de $900 \mathrm{MHz}$.

Após 16 semanas do início do experimento foi realizada a etapa para aquisição dos dados do conjunto de número [06], cujos resultados são apresentados na Figura 56. No radargrama em $270 \mathrm{MHz}$ (Figura 56a) observa-se em 30,7,0 ns uma anomalia na região interna da vala que se assemelha bastante àquela observada nos dados adquiridos no início do experimento. A imagem tomográfica correspondente (Figura 56b) mostra esta anomalia à profundidade do alvo juntamente com algumas anomalias de menor 
a)

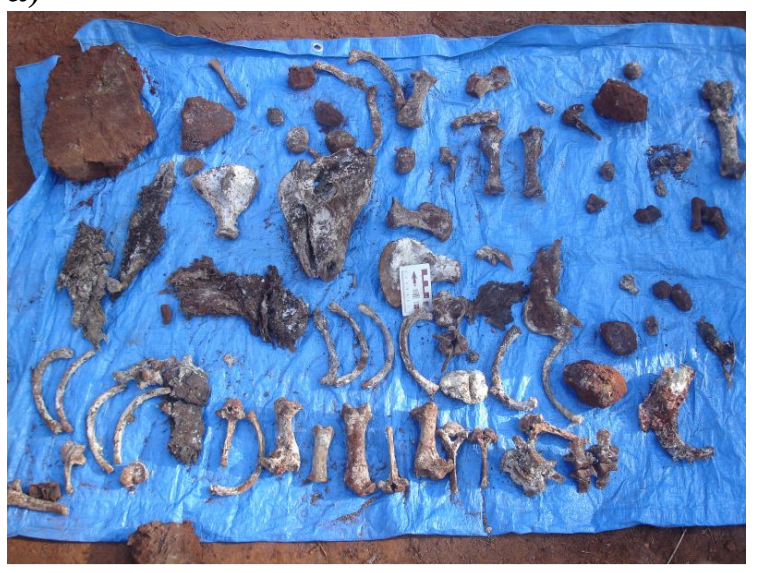

c)

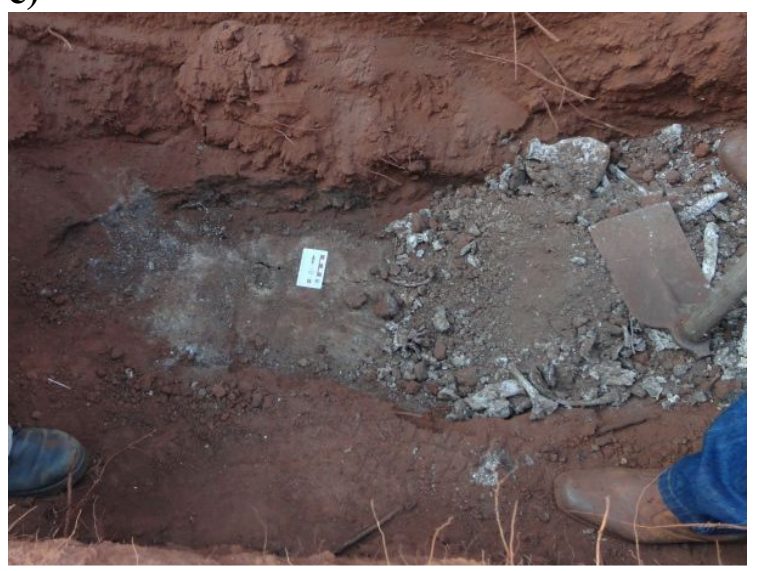

b)

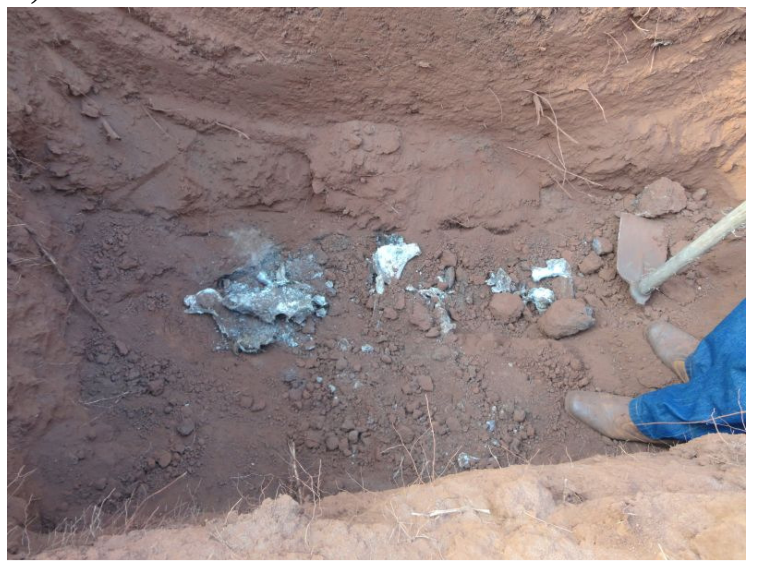

d)

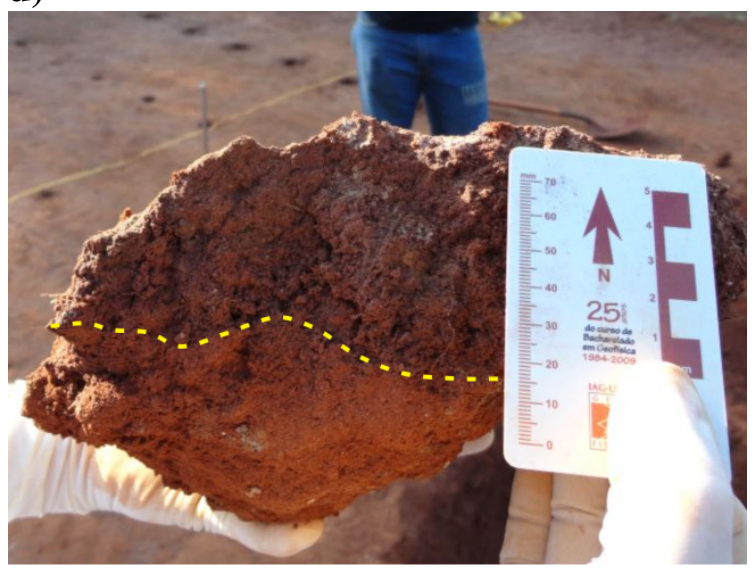

Figura 55. Condições do alvo observadas nas escavações após 18 meses do início do experimento. a) parte do material extraído da vala. A quantidade de material presente não justifica o desaparecimento das hipérboles do radargrama. b) tampouco foram observadas zonas de alteração significativas no solo no entorno do animal. c) a única alteração perceptível foi observada abaixo do alvo. d) a alteração abaixo do alvo resume-se a uma camada de 7,0 cm de espessura em média.

amplitude logo acima dela. Observam-se novamente as anomalias presentes a profundidades maiores do que $1,5 \mathrm{~m}$.

A anomalia associada ao alvo não aparece porém no radargrama em $400 \mathrm{MHz}$ (Figura 56c), o qual mostra o mesmo padrão de variação do sinal para todo o perfil, sem a presença de anomalias que possam sugerir alguma relação com o experimento. A imagem tomográfica obtida a partir destes dados (Figura 56d) mostra um perfil repleto por anomalias de amplitude em torno de $|\chi|=2,0 \times 10^{-7}$. Entretanto, em meio a estas anomalias há um grupo que se destaca por ter uma amplitude maior. Este grupo localiza-se justamente na região da vala, concentrando-se na sua porção mais profunda. Ao longo de todo o perfil, na região mais próxima à superfície, há uma região onde não 
aparecem quaisquer anomalias. A ausência de anomalias na verdade é causada pela remoção do sinal de acoplamento da antena com a interface ar-solo no radargrama através da ferramenta de time-gating em 6,0 ns.

Os dados em $900 \mathrm{MHz}$ (Figura 56e) também não apresentam muitas informações acerca do alvo ou da vala, uma vez que o padrão de oscilação registrado parece se manter o mesmo em todo o perfil. Em contrapartida a imagem tomográfica correspondente (Figura 56f) mostra um conjunto de anomalias em profundidades menores do que $0,75 \mathrm{~m}$, cuja amplitude se intensifica nas posições que correspondem ao interior da vala. Assim como observado na imagem em $400 \mathrm{MHz}$, este comportamento permite observar feições associadas à perturbação no solo que seria precariamente observada apenas através do radargrama.

Os resultados podem ser melhorados ainda mais com a remoção de background utilizando a ferramenta de time-gating combinada com a análise de autovalores, conforme mostrado na Figura 57. Nesta figura os resultados obtidos com a combinação das ferramentas (Figura 57b, d, f) são comparados com os resultados obtidos apenas com o time-gating (Figura 57a, c, e), os quais foram apresentados na figura anterior e são reproduzidos aqui em favor da comparação entre a qualidade das imagens. Na imagem em $270 \mathrm{MHz}$ obtida apenas com o time-gating em 7,0 ns (Figura 57a) observase que a anomalia associada ao alvo apresenta características de dimensão e amplitude semelhantes às anomalias a profundidades maiores do que $1,0 \mathrm{~m}$, nos primeiros $1,00 \mathrm{~m}$ do perfil. Executando a remoção de background através da combinação do time-gating em 7,0 ns com a análise de autovalores (Figura 57b) observa-se que a anomalia relacionada ao alvo permanece bastante evidente e mantém sua dimensão, enquanto que as anomalias no início do perfil são atenuadas. Toda a escala de amplitude do perfil é reduzida em cinco ordens de grandeza, tal como foi observado nos dados da linha de arqueologia do SCGR, porém a anomalia associada ao alvo mantém a maior amplitude dentre as anomalias observadas no perfil. Nesta imagem há ainda uma anomalia acima do alvo, a qual ocorre na porção mais rasa do perfil apenas na região interna da vala, servindo como indicativo da região perturbada no solo.

$\mathrm{Na}$ imagem em $400 \mathrm{MHz}$ apenas com a remoção por time-gating em 6,0 ns (Figura 57c) observa-se que há um grande número de anomalias que dificulta a delimitação da região da vala contendo o animal. Através da combinação das 

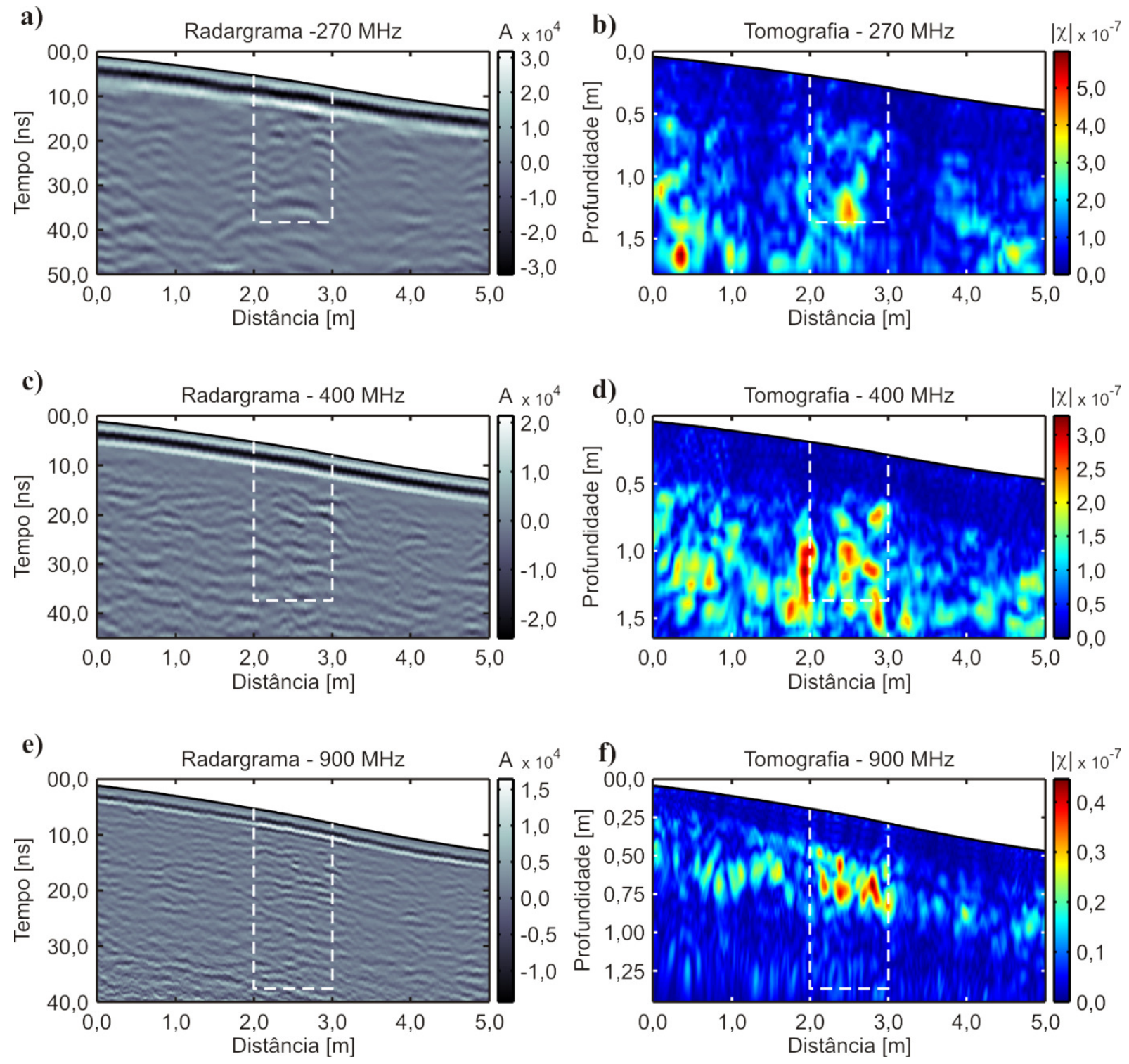

Figura 56. Resultados do conjunto [06] de 12/04/2013 obtidos para o perfil em 3,8 m. As linhas tracejadas brancas indicam os limites do buraco escavado para enterro do animal. a) radargrama adquirido com a antena de $270 \mathrm{MHz}$. b) imagem tomográfica obtida a partir do radargrama de $270 \mathrm{MHz}$. c) radargrama adquirido com a antena de $400 \mathrm{MHz}$. d) imagem tomográfica obtida a partir do radargrama de $400 \mathrm{MHz}$. e) radargrama adquirido com a antena de $900 \mathrm{MHz}$. f) imagem tomográfica obtida a partir do radargrama de $900 \mathrm{MHz}$.

ferramentas de remoção de background (Figura 57d) grande parte das anomalias nas regiões externas da vala são suprimidas e as que permanecem no perfil são atenuadas, permanecendo majoritariamente as anomalias na região interna da vala. Esta imagem mostra que as anomalias correspondem muito bem ao contorno da vala, como é possível observar através da sua distribuição dentro dos limites do contorno tracejado branco. 
Em $900 \mathrm{MHz}$ a imagem cuja remoção de background foi feita apenas com o time-gating em 4,0 ns (Figura 57e) mostra anomalias apenas na porção mais rasa do perfil entre as posições de $0,5 \mathrm{~m}$ e $3,0 \mathrm{~m}$, sendo que aquelas que se localizam na região interna da vala apresentam amplitude ligeiramente maiores. Na imagem obtida através da combinação das ferramentas (Figura 57f) observa-se que as anomalias localizadas na região interna da vala são mantidas enquanto as demais são suprimidas ou fortemente atenuadas.

O sétimo conjunto de dados foi adquirido exatamente um ano após o início do experimento. Os resultados obtidos sobre o perfil na posição $X=3,80 \mathrm{~m}$ são apresentados na Figura 58. Os três radargramas deste conjunto (Figura 58a, c, e) mostram novamente anomalias na região interna da vala com características bastante parecidas com aquelas observadas no início do experimento. A imagem tomográfica obtida a partir dos dados de $270 \mathrm{MHz}$ (Figura 58b) mostram a anomalia relacionada ao alvo à profundidade de $1,00 \mathrm{~m}$ na região interna da vala. Além disso esta imagem mostra anomalias de menor amplitude distribuídas ao redor da anomalia associada ao alvo. A distribuição destas anomalias ocorre de forma a acompanhar o contorno do limite da vala, em torno da posição de 2,00 m e entre as profundidades de 0,50 m e 1,30 $\mathrm{m}$, e também acompanhando o fundo da vala à profundidade de $1,30 \mathrm{~m}$ entre as posições de 2,0 m e 3,0 m. Acima do alvo observam-se algumas anomalias à profundidade de 0,50 m que também estariam relacionadas à região de perturbação no solo nas porções mais rasas. Não é possível observar anomalias a profundidades menores devido ao time-gating aplicado no radargrama em 7,0 ns.

Na imagem em $400 \mathrm{MHz}$ (Figura 58d) observa-se um padrão de distribuição de anomalias bastante similar. Há uma anomalia de maior amplitude localizada próxima ao fundo da vala e diversas anomalias de amplitude menor que se distribuem em torno dela. Embora estas anomalias sejam menores do que as observadas na imagem em $270 \mathrm{MHz}$ observa-se que estas se distribuem em profundidade também acompanhando parte do contorno da vala. Na imagem tomográfica em $900 \mathrm{MHz}$ (Figura 58f) observase um grupo de três anomalias com profundidade iniciando-se em 1,00 e distribuídas da 

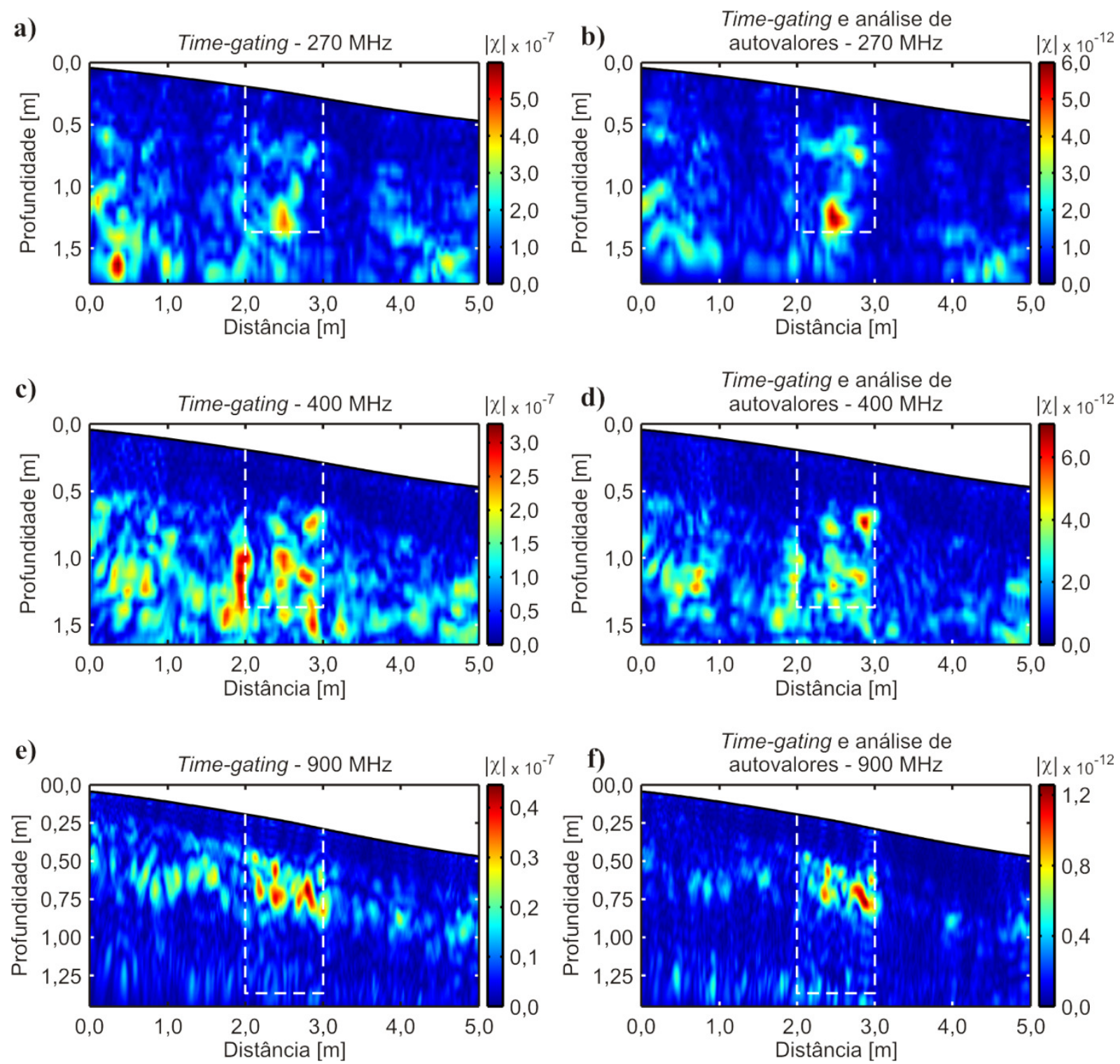

Figura 57. Comparação entre as imagens tomográficas obtidas a partir dos dados sobre o perfil em $\mathrm{X}=3,8 \mathrm{~m}$ do conjunto [06]. a) imagem em $270 \mathrm{MHz}$ com time-gating em 7,0 ns. b) imagem em $270 \mathrm{MHz}$ com time-gating em 7,0 ns seguido por análise de autovalores. c) imagem em $400 \mathrm{MHz}$ com time-gating em 6,0 ns. d) imagem em $400 \mathrm{MHz}$ com time-gating em 6,0 ns seguido por análise de autovalores. e) imagem em $900 \mathrm{MHz}$ com time-gating em 4,0 ns. f) imagem em $900 \mathrm{MHz}$ com time-gating em 4,0 ns seguido por análise de autovalores.

posição de $2,30 \mathrm{~m}$ à posição de $2,90 \mathrm{~m}$. Além de a extensão lateral deste grupo ser compatível com a seção cruzada do alvo a sua distribuição próximo ao fundo da vala é bastante parecida com as anomalias observadas nas imagens tomográficas de $270 \mathrm{MHz}$ e $400 \mathrm{MHz}$ dos conjuntos [02] e [03]. Parte das anomalias observadas ao redor do contorno da vala também pode ser observada aqui, porém já se confundem mais com outras anomalias observadas no restante do perfil. 

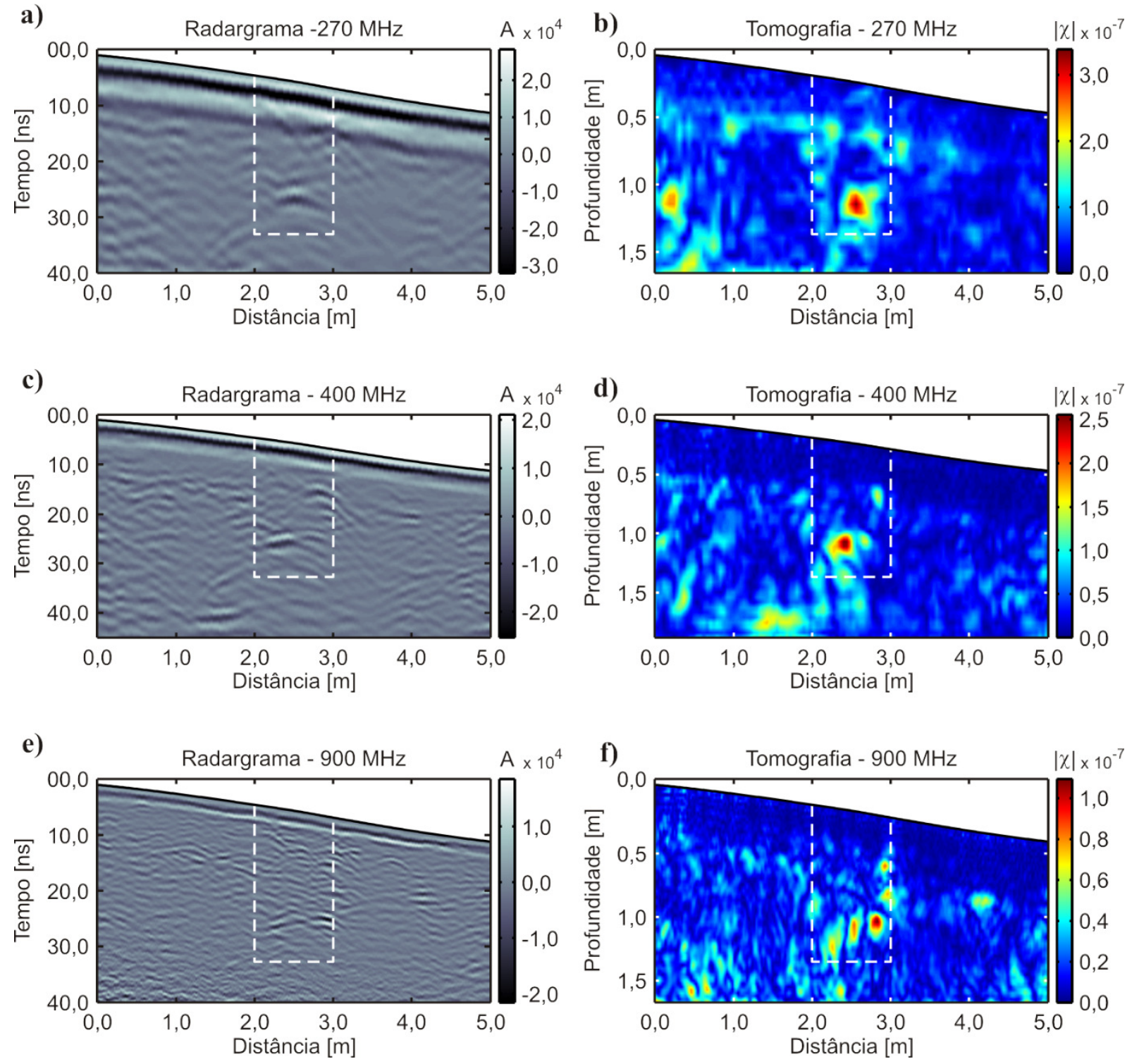

Figura 58. Resultados do conjunto [07] de 17/12/2013 obtidos para o perfil em 3,8 m. As linhas tracejadas brancas indicam os limites do buraco escavado para enterro do animal. a) radargrama adquirido com a antena de $270 \mathrm{MHz}$. b) imagem tomográfica obtida a partir do radargrama de $270 \mathrm{MHz}$. c) radargrama adquirido com a antena de $400 \mathrm{MHz}$. d) imagem tomográfica obtida a partir do radargrama de $400 \mathrm{MHz}$. e) radargrama adquirido com a antena de $900 \mathrm{MHz}$. f) imagem tomográfica obtida a partir do radargrama de $900 \mathrm{MHz}$.

As imagens nas frequências de $400 \mathrm{MHz}$ e $900 \mathrm{MHz}$ apresentam uma sutil melhora quando submetidos à remoção de background por combinação do time-gating e análise de autovalores, conforme apresentado na Figura 59. Na frequência de $270 \mathrm{MHz}$ tanto a remoção de background por time-gating em 7,0 ns (Figura 59a) quanto pela combinação desta ferramenta com a análise de autovalores (Figura 59b) resultam em imagens similares. Na remoção através da combinação das ferramentas a anomalia 
relacionada ao alvo aparece bem definida, porém as anomalias coincidentes com o contorno da vala entre 1,90 e 2,70 m são bastante atenuadas.

O mesmo ocorre com as anomalias observadas no contorno da vala na imagem obtida com o time-gating em 6,0 ns dos dados de $400 \mathrm{MHz}$ (Figura 59c), as quais são suprimidas na imagem obtida com a combinação das ferramentas de remoção de background (Figura 59d). Contudo, a permanência da anomalia na região interna da vala sugere que esta seja causada por alguma feição de interesse e não meramente por pequenas heterogeneidades naturais do solo.

A atenuação das anomalias causadas por pequenas heterogeneidades fica mais evidente nos dados de $900 \mathrm{MHz}$. Na imagem obtida com a remoção de background por time-gating em 4,0 ns (Figura 59e) observa-se uma grande quantidade dessas anomalias em todo o perfil, com o grupo de anomalias associadas ao alvo na região interna da vala. Aplicando-se a remoção por combinação das ferramentas (Figura 59f) o grupo de anomalias referentes ao alvo é praticamente o único que permanece, exceto por algumas anomalias coincidentes com o contorno da vala na posição de 3,0 m e de uma anomalia rasa na posição de 4,0 m. Isto mostra como a combinação de ferramentas pode ser útil para evidenciar alvos de baixo contraste através da supressão de anomalias causadas por pequenas heterogeneidades do solo.

O resultado do último conjunto de dados, adquirido 18 meses após o início do experimento, é apresentado na Figura 60. Os radargramas adquiridos nas três frequências (Figura 60a, c, e) não mostram diferenças significativas nas feições anômalas causadas pelo alvo em relação aos radargramas adquiridos no conjunto [07]. $\mathrm{Na}$ imagem tomográfica obtida a partir dos dados em $270 \mathrm{MHz}$ (Figura 60b) é possível observar a anomalia associada ao alvo na posição central da vala, próximo o fundo desta. Três anomalias de menor amplitude são observadas na porção superior da vala, sendo o último resquício de alguma indicação de perturbação no solo. Na imagem obtida em $400 \mathrm{MHz}$ (Figura 60d) a anomalia associada ao alvo pode ser observada, inclusive com uma anomalia próxima ao fundo da vala que poderia ser causada pela zona de alteração do solo. No entanto, a anomalia associada ao alvo confunde-se com outras anomalias observadas desde o início do perfil até a posição em que o alvo se encontra, num padrão que varia entre as profundidades de 1,0 m e 1,8 m. A imagem em 

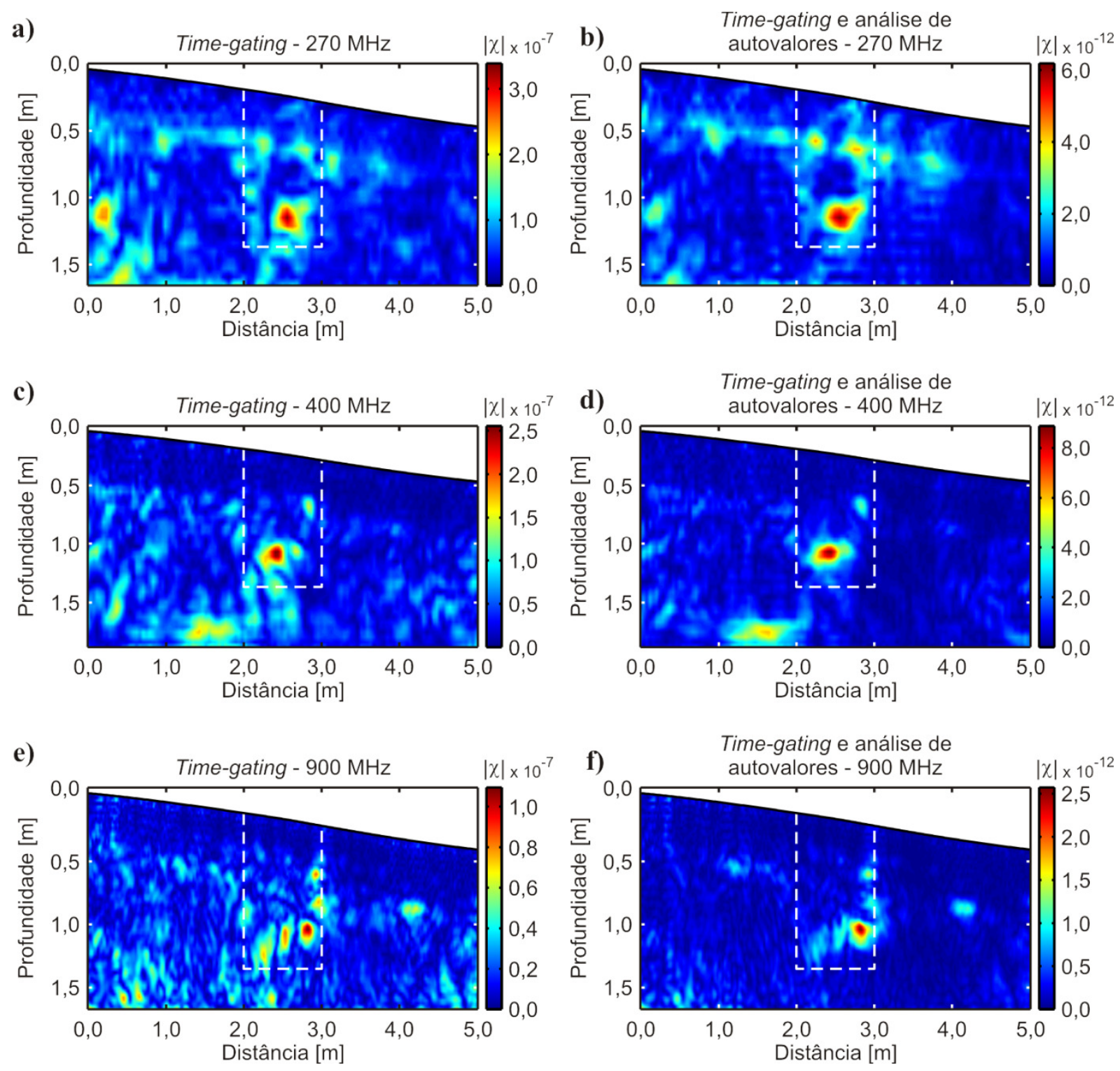

Figura 59. Comparação entre as imagens tomográficas obtidas a partir dos dados sobre o perfil em $\mathrm{X}=3,8 \mathrm{~m}$ do conjunto [07]. a) imagem em $270 \mathrm{MHz}$ com time-gating em 7,0 ns. b) imagem em $270 \mathrm{MHz}$ com time-gating em 7,0 ns seguido por análise de autovalores. c) imagem em $400 \mathrm{MHz}$ com time-gating em 6,0 ns. d) imagem em $400 \mathrm{MHz}$ com time-gating em 6,0 ns seguido por análise de autovalores. e) imagem em $900 \mathrm{MHz}$ com time-gating em 4,0 ns. f) imagem em $900 \mathrm{MHz}$ com time-gating em 4,0 ns seguido por análise de autovalores.

$900 \mathrm{MHz}$ (Figura 60f) mostra de maneira clara as anomalias associadas ao alvo, porém já não permite identificar a perturbação causada no solo devido à escavação.

A Figura 61 mostra uma comparação entre as imagens obtidas com diferentes modos de remoção de background do perfil em $\mathrm{X}=3,8 \mathrm{~m}$ do conjunto [08]. Na frequência de $270 \mathrm{MHz}$ tanto a imagem obtida a partir da aplicação do time-gating em 7,0 ns (Figura 61a) quanto a obtida através da combinação desta com a análise de 

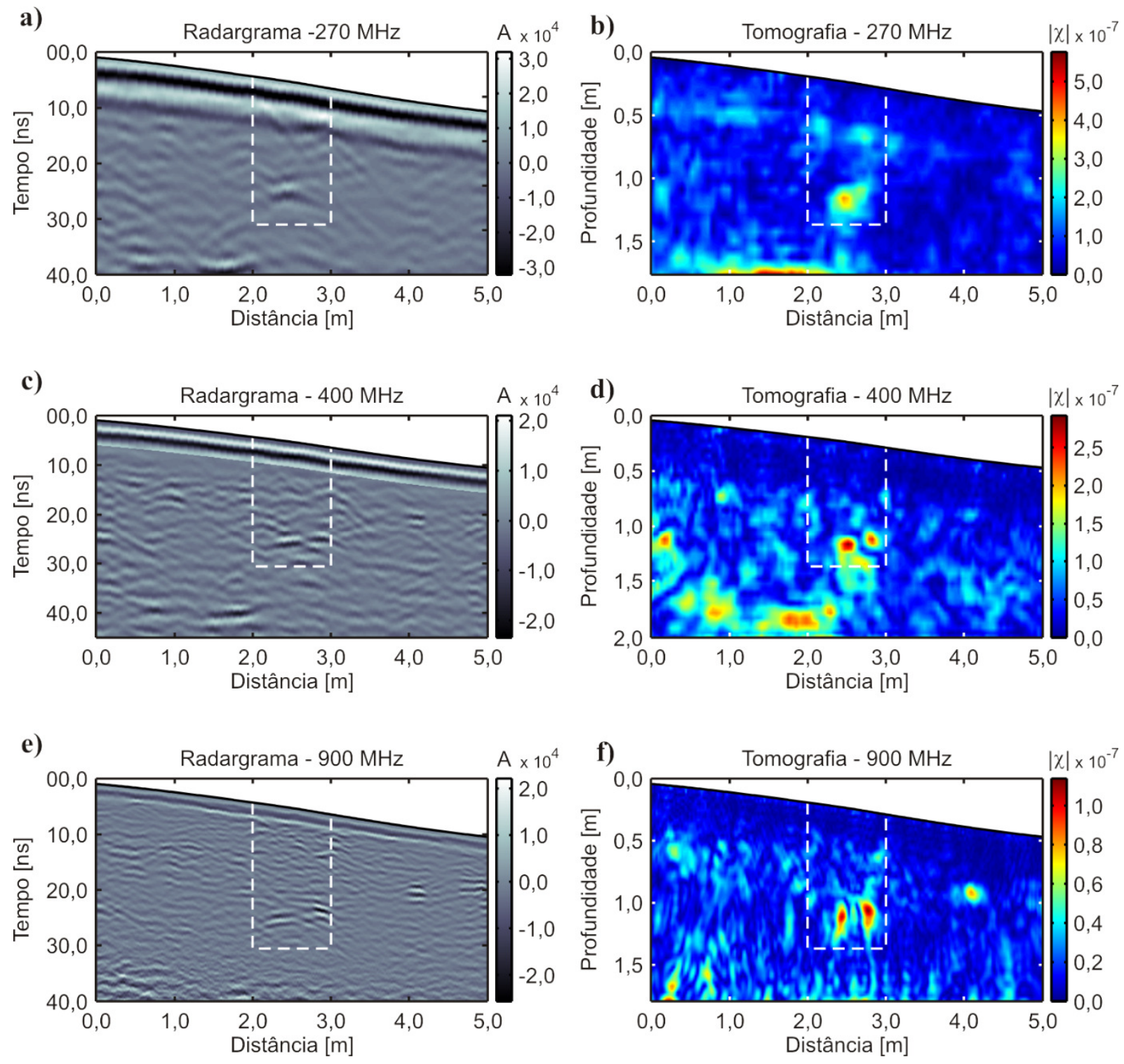

Figura 60. Resultados do conjunto [08] de 13/06/2014 obtidos para o perfil em 3,8 m. As linhas tracejadas brancas indicam os limites do buraco escavado para enterro do animal. a) radargrama adquirido com a antena de $270 \mathrm{MHz}$. b) imagem tomográfica obtida a partir do radargrama de $270 \mathrm{MHz}$. c) radargrama adquirido com a antena de $400 \mathrm{MHz}$. d) imagem tomográfica obtida a partir do radargrama de $400 \mathrm{MHz}$. e) radargrama adquirido com a antena de $900 \mathrm{MHz}$. f) imagem tomográfica obtida a partir do radargrama de $900 \mathrm{MHz}$.

autovalores (Figura 61b) apresentam resultados semelhantes, sobretudo pela predominância da anomalia localizada entre as posições de $1,0 \mathrm{~m}$ e 2,0 $\mathrm{m}$ à profundidade de 1,65 m. Já em $400 \mathrm{MHz}$ observa-se uma melhoria nas imagens. Enquanto a imagem obtida apenas com o time-gating em 6,0 ns (Figura 61c) mostra que as anomalias associadas ao alvo se misturam com uma sequência de anomalias presentes na primeira metade do perfil, a combinação das ferramentas de remoção de 
background fornece uma imagem onde pode-se separar perfeitamente as anomalias relacionadas ao alvo das demais. Estas anomalias presentes no perfil são fortemente atenuadas, destacando-se apenas a anomalia à profundidade de 1,70 m na posição de $1,85 \mathrm{~m}$.

Em $900 \mathrm{MHz}$ a anomalia associada ao alvo é facilmente identificada mesmo na imagem obtida apenas com a aplicação do time-gating em 4,0 ns (Figura 61e), porém há uma grande quantidade de anomalias causadas por pequenas heterogeneidades em todo o perfil. Esta quantidade é fortemente reduzida quando se combina as ferramentas de remoção de background (Figura 61f), permanecendo apenas a anomalia associada ao alvo e uma segunda anomalia na posição de 4,0 m.

O reaparecimento da anomalia associada ao alvo nos conjuntos de dados [07] e [08], ainda que não tão claramente em todos os perfis devido à sua decomposição, é mais um indício de que nos conjuntos de número [05] e [06] o mesmo não era visível por falta de contraste suficiente para que a anomalia gerada por ele se sobressaísse em relação às oscilações típicas do sinal. No conjunto de número [07] a constante dielétrica real do solo foi estimada em 13,0 e no conjunto de número [08] a constante dielétrica real estimada foi de 11,4, enquanto que para os [05] e [06] ela foi estimada em 16,0 e 17,3 respectivamente. Esta variação foi devida a um longo período de estiagem ocorrido entre os anos de 2013 e 2014, o que reduziu a saturação do solo de maneira significativa. Hammon et al. (2012) sugerem que se adote uma constante dielétrica real igual a 52,0 para o material orgânico composto por pele, músculo e cartilagem não decompostos. Através do experimento desenvolvido na presente pesquisa pode-se sugerir que nos primeiros meses de decomposição a constante dielétrica do material sofra uma variação considerável em função da perda do seu conteúdo de água para valores em torno de 17,0. Esta variação não pôde ser estimada de forma precisa devido a particularidades do experimento. 

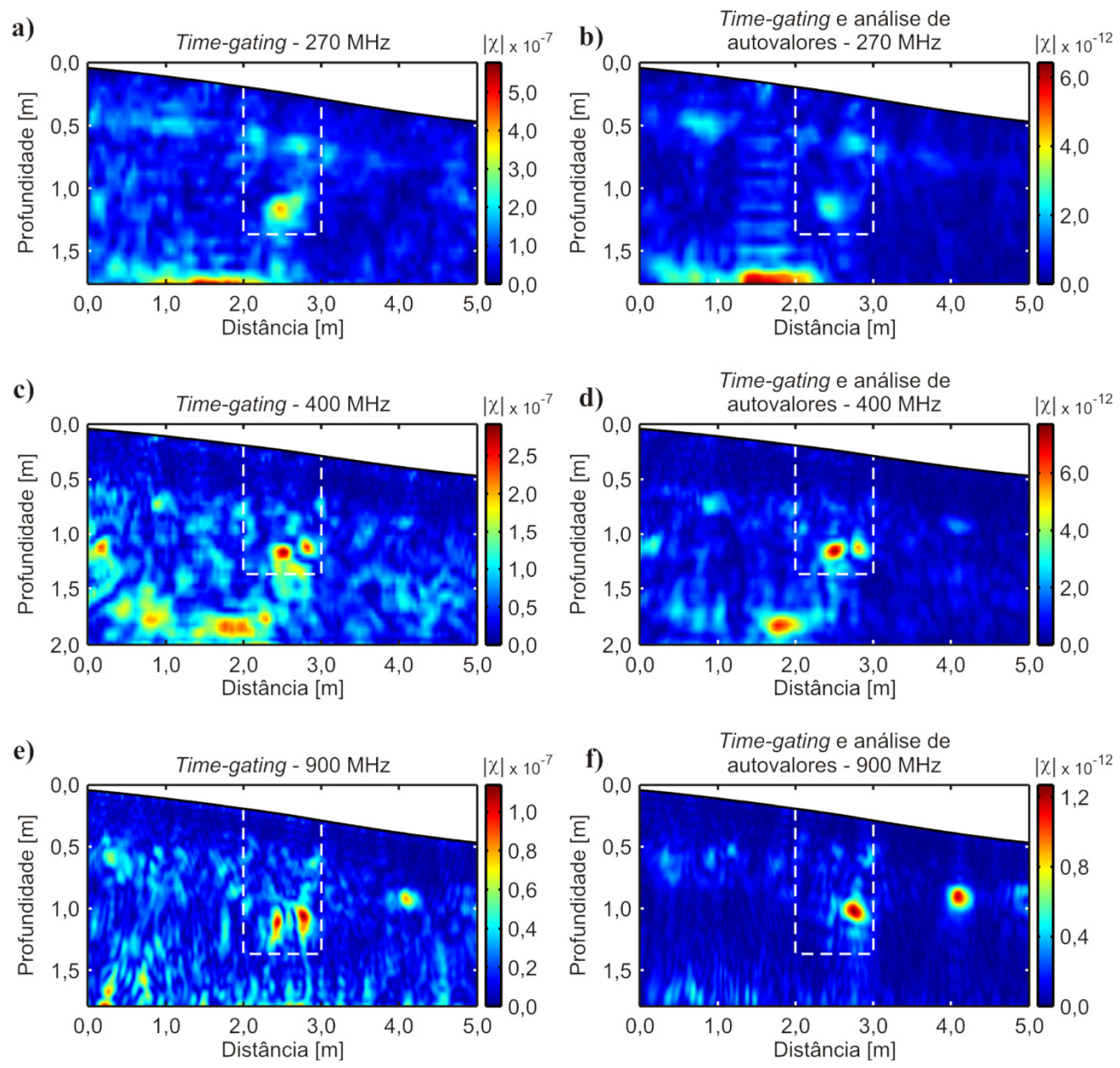

Figura 61. Comparação entre as imagens tomográficas obtidas a partir dos dados sobre o perfil em $\mathrm{X}=3,8 \mathrm{~m}$ do conjunto [08]. a) imagem em $270 \mathrm{MHz}$ com time-gating em 7,0 ns. b) imagem em $270 \mathrm{MHz}$ com time-gating em 7,0 ns seguido por análise de autovalores. c) imagem em $400 \mathrm{MHz}$ com time-gating em 6,0 ns. d) imagem em $400 \mathrm{MHz}$ com time-gating em 6,0 ns seguido por análise de autovalores. e) imagem em $900 \mathrm{MHz}$ com time-gating em 4,0 ns. f) imagem em $900 \mathrm{MHz}$ com time-gating em 4,0 ns seguido por análise de autovalores.

\subsubsection{Resultados 3D}

A seguir serão apresentadas as imagens em 3D interpoladas obtidas a partir de alguns dos dados apresentados. Serão apresentados apenas as imagens referentes aos conjuntos [03] e [07] em $270 \mathrm{MHz}$ e $400 \mathrm{MHz}$. Esta escolha foi feita buscando a 
comparação dos resultados três semanas após o início do experimento, quando o solo já se encontrava mais compactado do que no início e a decomposição ainda estava em seus estágios iniciais, com aqueles obtidos após um ano, quando a decomposição já estava em um estágio mais avançado.

A Figura 62 mostra os resultados obtidos a partir dos dados do conjunto [03] em 270 MHz. A Figura 62a apresenta a disposição das anomalias em profundidade. Há algumas anomalias rasas no corte à profundidade de 0,56 m (Figura 62b), as quais mostraram-se provocadas por cavidades cheias de ar após escavações. Na região interna da vala, delimitada pelo contorno em branco, é possível observar algum indício de perturbação no solo, porém este ainda apresenta amplitude muito baixa. $\mathrm{O}$ alvo orgânico pode ser observado no corte à profundidade de 1,06 m (Figura 62c). Nesta imagem observa-se claramente que a anomalia associada ao alvo predomina em toda a área onde houve aquisição de dados. Há um formato alongado orientado segundo a direção X. As maiores amplitudes da anomalia concentram-se na metade traseira do animal por ser a região com maior quantidade de carne e fluidos, como a barriga e os membros anteriores. A metade dianteira possui partes menores, como a cabeça e os membros posteriores, que possuem menos carne e menor quantidade de fluidos e portanto apresentam um contraste relativamente menor. Um corte à profundidade de 1,29 m (Figura 62d) mostra anomalias mais fracas na região interna da vala. Estas anomalias podem ser associadas ao fundo da vala escavada para alocação do alvo.

A Figura 63 mostra os resultados obtidos a partir dos dados em $400 \mathrm{MHz}$ do conjunto [03]. A sequência de cortes em profundidade apresentada na Figura 63a mostra que as anomalias associadas ao alvo se concentram entre $1,00 \mathrm{~m}$ e 1,40 m. No corte à profundidade de $0,53 \mathrm{~m}$ (Figura 63b) não há qualquer indício de perturbação no solo na região interna da vala. Entretanto, à profundidade de 1,06 m (Figura 63c) a anomalia causada pelo alvo é bastante clara. Assim como na imagem em $270 \mathrm{MHz}$, é possível observar aqui que a anomalia apresenta amplitude maior na região correspondente à parte traseira do animal. Nota-se que o limite da anomalia próximo à distância de 3,0 m na direção Y acompanha quase que perfeitamente o contorno da vala, enquanto que próximo à distância de 2,0 $\mathrm{m}$ na direção $\mathrm{Y}$ apresenta-se mais irregular. A coluna vertebral do animal está posicionada próximo à posição de $3,0 \mathrm{~m}$, de forma que é provável que a irregularidade observada na lateral oposta possa ser causada pelos seus 


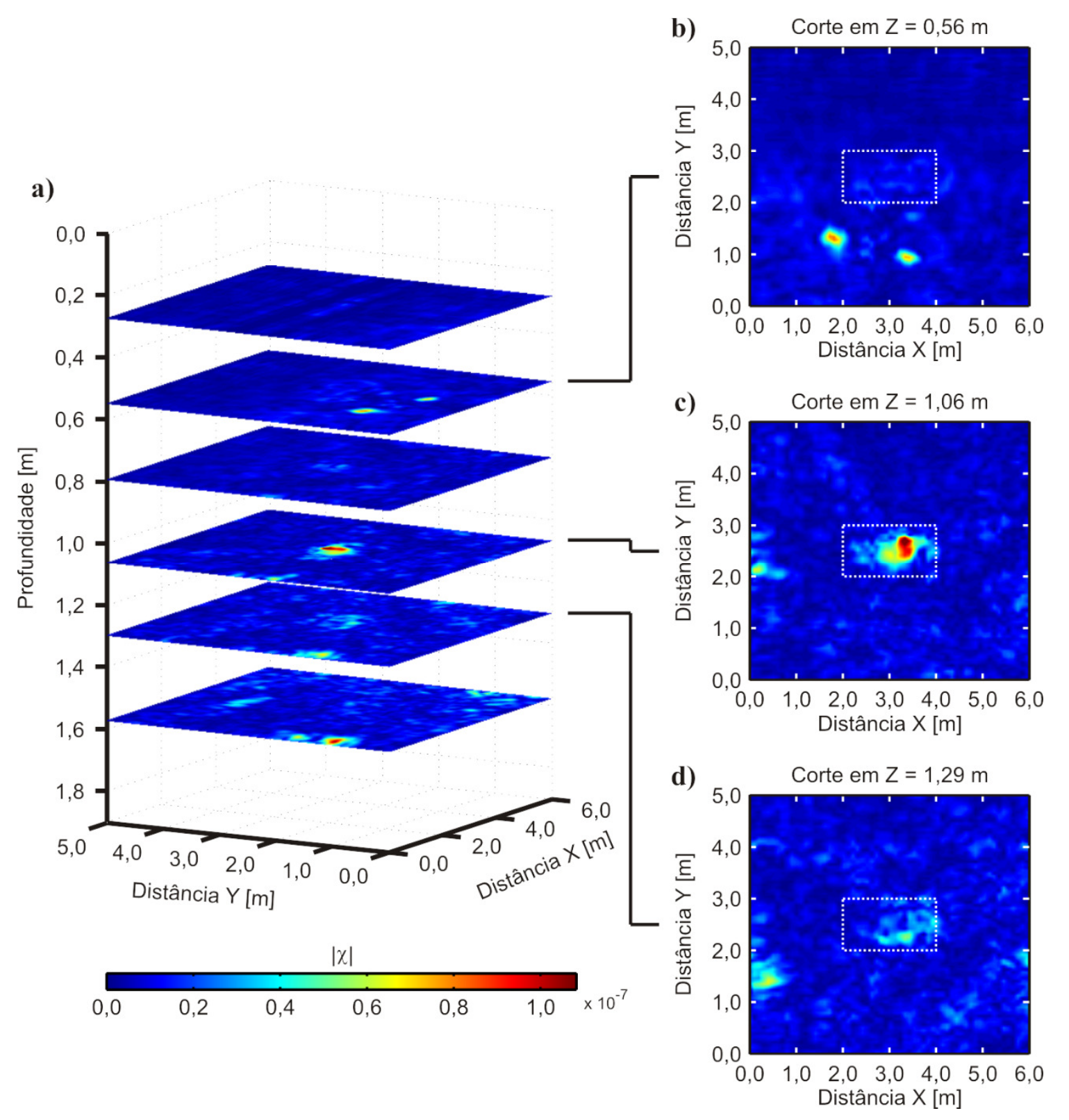

Figura 62. Visualização 3D dos dados do conjunto [03] em $270 \mathrm{MHz}$. O retângulo tracejado representa os limites determinados para a vala que contém o alvo. a) representação de planos de corte em diferentes profundidades. b) plano de corte à profundidade de $0,56 \mathrm{~m}$. c) plano de corte à profundidade de $1,06 \mathrm{~m}$. d) plano de corte à profundidade de $1,29 \mathrm{~m}$.

fluidos corporais em contato com o solo. $\mathrm{O}$ corte à profundidade de 1,29 $\mathrm{m}$ mostra anomalias de amplitude similares preenchendo toda a largura da vala a partir da posição 2,8 m na direção X. Devido a estas características, estas anomalias possivelmente estão associadas ao fundo da vala. 


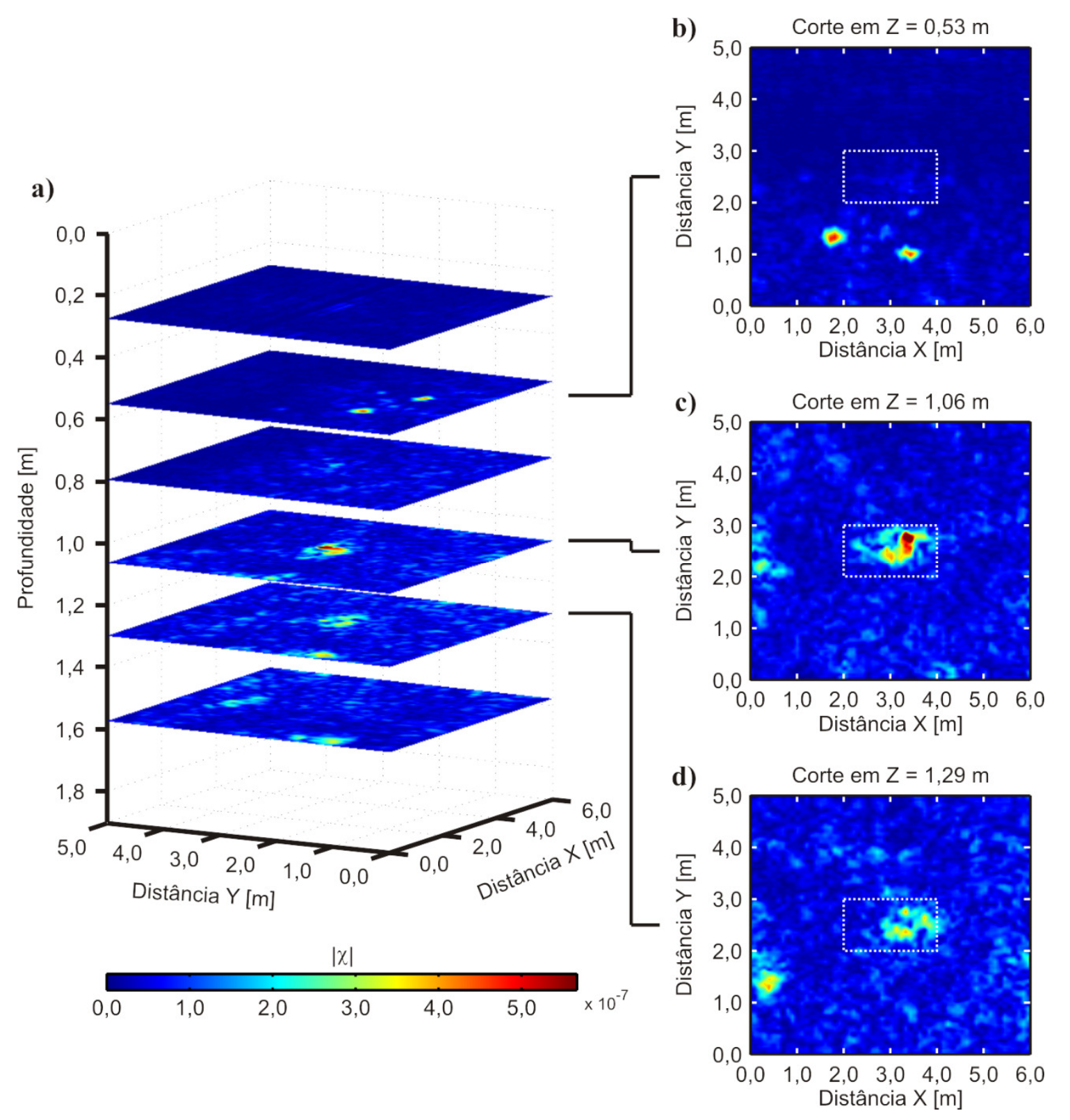

Figura 63. Visualização 3D dos dados do conjunto [03] em $400 \mathrm{MHz}$. O retângulo tracejado representa os limites determinados para a vala que contém o alvo. a) representação de planos de corte em diferentes profundidades. b) plano de corte à profundidade de $0,53 \mathrm{~m}$. c) plano de corte à profundidade de $1,06 \mathrm{~m}$. d) plano de corte à profundidade de $1,29 \mathrm{~m}$.

A Figura 64 mostra os cortes em profundidade para os resultados obtidos a partir dos dados do conjunto [07] em $270 \mathrm{MHz}$. A Figura 64a apresenta a distribuição de alguns cortes em profundidade, onde é possível observar que nenhum corte apresenta uma anomalia tão clara quanto aquela observada nos resultados do conjunto [03]. Entretanto, é possível ainda extrair informações acerca dos alvos ao se analisar alguns cortes separadamente. $\mathrm{O}$ corte à profundidade de 0,62 m (Figura 64b) mostra uma 
região de concentração de anomalias na região interna da vala e na região externa próximo ao contorno da mesma. Estas anomalias podem ser associadas às perturbações do solo, que ainda podem ser observadas nestes dados mesmo após um ano possivelmente devido a alterações a profundidades mais rasas. À profundidade de 1,05 m (Figura 64c) ainda é possível detectar uma anomalia associada ao alvo na região interna da vala. Entretanto, nota-se que a amplitude desta anomalia é comparável à amplitude de outras anomalias observadas na região externa da vala e que não têm relação com o alvo, destacando-se unicamente pelo seu aspecto ligeiramente alongado. $\mathrm{O}$ corte à profundidade de 1,30 m (Figura 64d) mostra apenas uma anomalia de baixa amplitude localizada paralelamente ao contorno da vala na posição de 4,0 $\mathrm{m}$ na direção $\mathrm{X}$, na região interna desta. Esta anomalia dificilmente seria associada ao experimento caso apenas este corte fosse analisado, uma vez que ela apresenta amplitude muito mais baixa do que aquela observada nas coordenadas $(0,0 \mathrm{~m}, 1,5 \mathrm{~m})$. Entretanto, uma associação positiva com o experimento pode ser feita comparando-se o posicionamento das anomalias nos três cortes apresentados.

A Figura 65 apresenta as imagens obtidas em profundidade a partir dos dados do conjunto [07] com a antena de $400 \mathrm{MHz}$. Devido ao menor comprimento de onda do sinal as anomalias relacionadas ao alvo se confundem fortemente com as anomalias nas regiões externas da vala, conforme pode-se observar pela relação de cortes mostrada na Figura 65a. $\mathrm{O}$ corte à profundidade de $0,71 \mathrm{~m}$ (Figura 65b) mostra algumas anomalias causadas pela perturbação do solo na região interna da vala, porém a amplitude destas anomalias são comparáveis a várias outras observadas nesta profundidade. Na Figura 65c o corte à profundidade de 1,05 m mostra uma anomalia de maior amplitude à posição de 3,80 m na direção X e na posição de 2,5 m na direção Y. Esta anomalia pode ser associada a alguma porção da matéria orgânica que ainda apresenta contraste suficiente para ser detectada a esta profundidade. $\mathrm{O}$ corte seguinte, à profundidade de 1,30 m (Figura 65d), mostra algumas anomalias de baixa amplitude no interior da vala. Embora estas também se assemelhem bastante às anomalias observadas na área externa da vala, é possível afirmar que elas estão relacionadas ao experimento devido sua posição em relação às anomalias observadas nos demais perfis, que ocorrem sempre na mesma região da vala em um intervalo de profundidade de quase $0,50 \mathrm{~m}$. 


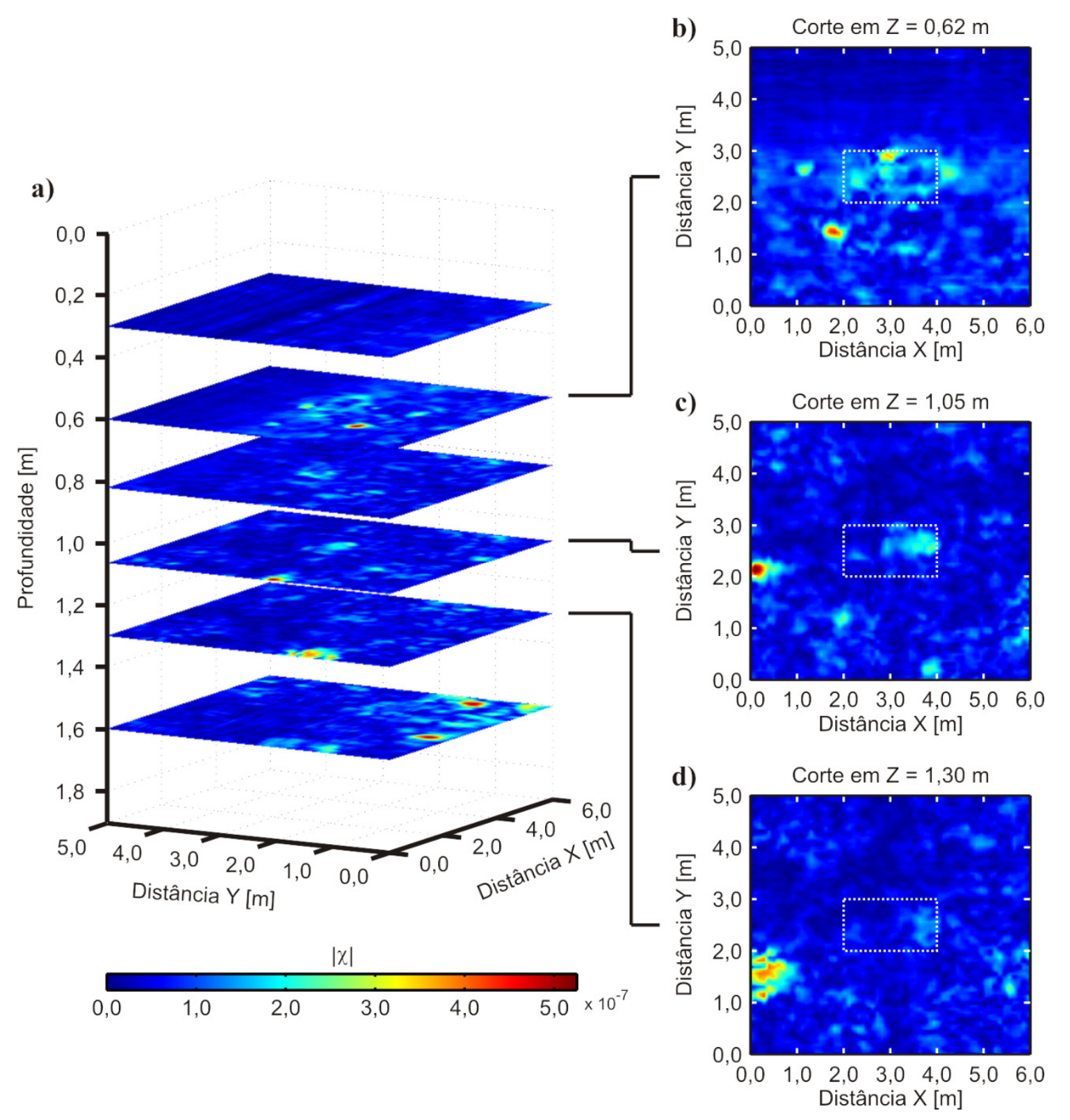

Figura 64. Visualização 3D dos dados do conjunto [07] em $270 \mathrm{MHz}$. O retângulo tracejado representa os limites determinados para a vala que contém o alvo. a) representação de planos de corte em diferentes profundidades. b) plano de corte à profundidade de $0,56 \mathrm{~m}$. c) plano de corte à profundidade de $1,05 \mathrm{~m}$. d) plano de corte à profundidade de $1,30 \mathrm{~m}$.

As anomalias observadas em todos os conjuntos de dados nas coordenadas $(x, y, z)=(0,0,2,0,1,05) \mathrm{m}$ e $(x, y, z)=(0,0,1,5,1,30) \mathrm{m}$ são causadas por cavidades cheias de ar, conforme observado após as escavações (ver Figura 9).

Pela análise individual dos perfis nas três frequências é possível observar tanto as feições associadas ao alvo quanto feições associadas à vala onde o mesmo foi enterrado. Na análise em 3D dos dados é possível fazer uma avaliação da extensão 


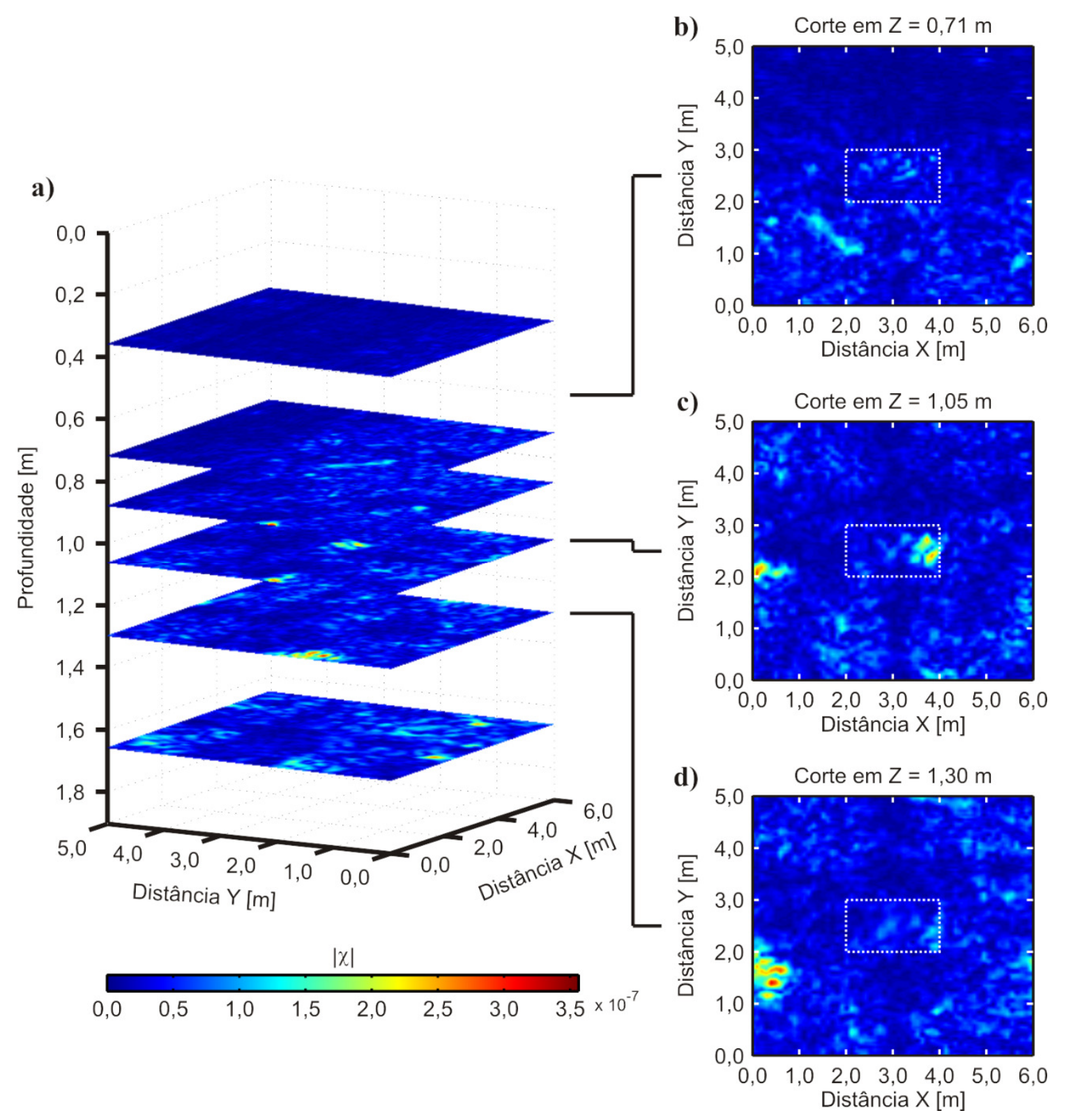

Figura 65. Visualização 3D dos dados do conjunto [07] em $400 \mathrm{MHz}$. O retângulo tracejado representa os limites determinados para a vala que contém o alvo. a) representação de planos de corte em diferentes profundidades. b) plano de corte à profundidade de $0,71 \mathrm{~m}$. c) plano de corte à profundidade de $1,05 \mathrm{~m}$. d) plano de corte à profundidade de $1,30 \mathrm{~m}$.

lateral das principais anomalias associadas ao alvo. Embora a tomografia de microondas não permita uma análise quantitativa das anomalias observadas, é possível estimar a extensão das mesmas com maior precisão do que apenas observando-se os radargramas. Almeida et al. (2016) usaram de maneira sintetizada parte dos dados adquiridos neste experimento para demonstrar que esta estimativa pode ser feita de maneira mais eficiente através da tomografia de micro-ondas do que através da análise 
dos radargramas migrados. Neste trabalho os autores apresentam uma comparação entre imagens 2D e 3D interpoladas obtidas com a migração Kirchhoff e com a tomografia de micro-ondas. Foi mostrado que as imagens 2D obtidas a partir do imageamento tomográfico com as antenas de $270 \mathrm{MHz}$ fornecem uma estimativa mais precisa do tamanho do alvo do que a migração. De maneira similar, os autores mostraram que os dados de $900 \mathrm{MHz}$ fornecem informações mais precisas acerca da delimitação da região escavada para o enterro do que os dados migrados. O trabalho completo está anexado ao final desta tese.

Os dados adquiridos neste experimento foram úteis para estudar a resposta de um alvo orgânico em decomposição quando submetido a um levantamento com o método GPR. Do mesmo modo, os resultados obtidos com a tomografia de micro-ondas mostram que esta ferramenta é útil para extrair informações acerca dos dados mesmo quando as anomalias observadas nos radargramas são provocadas por um contraste reduzido entre as propriedades elétricas do alvo e do solo. Este estudo demonstra como esta ferramenta pode ser bem aplicada na localização de corpos humanos enterrados clandestinamente, uma vez que o uso do porco no experimento foi motivado pelas suas similaridades com um corpo humano. 


\section{CAPÍTULO 6}

\section{CONCLUSÕES E RECOMENDAÇÕES}

Esta pesquisa de doutorado permitiu uma avaliação das vantagens e limitações da inversão de dados GPR através do emprego da tomografia de micro-ondas, formulado a partir de uma aproximação que permite a análise de dados adquiridos em perfis de afastamento constante. Esta técnica mostrou-se bastante útil para a interpretação dos dados GPR com ênfase no mapeamento de alvos de interesse arqueológico instalados no Sítio Controlado de Geofísica Rasa do IAG/USP e no mapeamento de um porco em decomposição que foi enterrado no campus da USP em Pirassununga (SP), visando uma simulação de estudos em arqueologia forense.

\section{Desenvolvimento e implementação do programa:}

Nesta pesquisa foi implementado o programa de inversão de dados GPR, escrito em linguagem Matlab, visando o imageamento da subsuperfície por meio da tomografia de micro-ondas. O programa foi validado através de dados sintéticos gerados no software GprMax a partir de modelos equivalentes aos alvos da linha de Arqueologia do SCGR e foi testado em dados reais através de aquisições realizadas no SCGR. Os resultados foram bastante satisfatórios, apresentando maior nitidez e permitindo uma interpretação mais acurada em comparação com a análise de dados GPR processados de maneira convencional utilizando o software ReflexWin.

O programa contempla três ferramentas de remoção de background: time-gating, remoção do traço médio e análise de autovalores. A remoção por time-gating e por subtração do traço médio apresentaram resultados similares, sendo mais indicadas para extrair as reflexões indesejadas nos perfis GPR provenientes de feições presentes no meio geológico onde o alvo se encontra. A combinação do time-gating com a análise de autovalores mostrou-se capaz de eliminar boa parte das anomalias de reflexões GPR associadas ao ruído geológico, sendo mais interessante para destacar as anomalias de interesse relacionadas com os alvos reais. 
A implementação do programa de inversão de dados GPR das ferramentas de remoção do background foram feitas de modo a permitir as suas aplicações em análises de dados GPR em futuras pesquisas geofísicas.

\section{Estudo sobre alvos arqueológicos no SCGR do IAG/USP:}

As imagens tomográficas GPR obtidas com as antenas de $270 \mathrm{MHz}$ e $400 \mathrm{MHz}$ sobre as caixas de areia e de brita de granito permitiram estimar com clareza a geometria destes alvos ao longo do perfil. Também foi possível estabelecer uma conexão entre as anomalias observadas no topo e na base dos alvos de maneira mais nítida do que através da análise dessas anomalias observadas nos radargramas após o processamento convencional.

Os vasos cerâmicos, representando urnas funerárias, foram bem determinados. Entretanto, as anomalias associadas a estes alvos referem-se apenas ao topo dos mesmos, como pôde ser verificado através da comparação com os dados sintéticos. Na região onde os vasos se encontram foi possível observar feições relacionadas às escavações feitas no solo para instalação dos mesmos, constituindo assim uma evidência complementar para a interpretação dos dados.

Em contrapartida, o muro de tijolos não pôde ser identificado de forma conclusiva apesar de a distribuição das anomalias observadas no local sugerirem a presença de um corpo anômalo. As anomalias localizadas na região onde o alvo deveria estar localizado ainda não permitiram delimitar o mesmo de maneira tão clara quanto nos demais alvos mesmo após a remoção do background. Este fato deve-se ao baixo contraste nas propriedades físicas do alvo (muro de tijolos) e do background (solo).

De maneira geral os resultados obtidos a partir dos dados adquiridos no SCGR do IAG/USP mostram que a tomografia de micro-ondas tem grande potencial para ser empregada com sucesso nos sítios arqueológicos brasileiros.

Estudo sobre o alvo orgânico no campus da USP em Pirassununga:

As imagens tomográficas GPR obtidas com as antenas de $270 \mathrm{MHz}, 400 \mathrm{MHz}$ e $900 \mathrm{MHz}$ sobre o porco enterrado no campus da USP em Pirassununga mostraram com clareza os diferentes estágios de decomposição.

A geometria do alvo mostrou-se mais evidente nas aquisições feitas no início do experimento. Após os primeiros meses houve redução no contraste entre as 
propriedades elétricas do solo e do material do porco, acarretando na redução da amplitude do sinal eletromagnético refletido e prejudicando a sua localização nos radargramas após o processamento convencional. No entanto, a tomografia de microondas apresentou bons resultados na localização do porco mesmo nestas situações de baixo contraste, sendo possível extrair informações mais acuradas a partir das imagens tomográficas do que dos radargramas. Isto foi observado principalmente nos dados de $270 \mathrm{MHz}$ e $400 \mathrm{MHz}$. A tomografia de micro-ondas possibilitou também identificar com maior clareza algumas feições mais rasas associadas à escavação para enterro do alvo, sobretudo nos dados adquiridos com as antenas de $900 \mathrm{MHz}$.A partir dos resultados sobre o experimento com o porco enterrado foi observado que esta metodologia apresenta grande potencial para ser empregada em estudos forenses para mapeamento de covas clandestinas.

Com base nos resultados obtidos recomenda-se:

i) Desenvolver metodologias para estimar matematicamente as propriedades elétricas do meio geológico, pois a qualidade final da imagem tomográfica GPR está condicionada à acurácia destes valores inseridos no programa no início do processo de inversão dos dados;

ii) Realizar novos estudos simulando outros tipos de alvos controlados de interesse arqueológico, visando avaliar o desempenho da metodologia proposta como, por exemplo, caixas contendo material carbonático (conchas). Estes estudos podem ser feitos sobre alvos como vasos cerâmicos preenchidos com diferentes materiais (solo, ossos ou ambos) simulando outros tipos de urnas funerárias, ossadas de bois no subsolo de forma a simular antigos cemitérios, pavimentos simulando calçamentos antigos e muros construídos com diferentes tipos de materiais a fim de simular fundações observadas em construções de diferentes épocas.

Em futuros estudos forenses novos experimentos podem ser conduzidos com mais de um porco, variando o tamanho dos mesmos. Estes animais podem ser enterrados em diferentes profundidades e em situações que considerem, por exemplo, o animal envolto por roupas, lençóis ou lona plástica, podendo fornecer informações acerca da decomposição do alvo sob diferentes condições. 


\section{REFERÊNCIAS}

ALMEIDA, E. R., PORSANI, J. L., CATAPANO, I., GENNARELLI, G., SOLDOVIERI, F., 2016. Microwave Tomography-Enhanced GPR in Forensic Surveys: The Case Study of a Tropical Environment. IEEE Journal of Selected Topics in Applied Earth Observations and Remote Sensing (JSTARS), v. 9, n. 1, p. 115-123.

ANNAN, A. P., 1973. Radio interferometry depth sounding: Part I - Theoretical discussion. Geophysics, v. 38, n. 3, p. 557-580.

ANNAN, A. P., DAVIS, J. L., 1976. Impulse radar sounding in permafrost. Radio Science, v. 11, n. 4, p. 383-394.

ANNAN, A. P., DAVIS, J. L., GENDZWILL, D., 1988. Radar sounding in potash mines, Saskatchewan, Canada. Geophysics, v. 53, n. 12, p. 1556-1564.

ANNAN, A. P. (2003). Ground penetrating radar - Principles, procedures \& applications. Technical Paper, Sensors \& Software, Inc.

BALANIS, C. A., 1989. Advanced engineering electromagnetics. New York: Wiley. $981 \mathrm{p}$.

BERTOLLA, L., PORSANI, J. L., SOLDOVIERI, F., CATAPANO, I., 2014. GPR-4D monitoring a controlled LNAPL spill in a masonry tank at USP, Brazil. Journal of Applied Geophysics, v. 103, p. 237-244.

BEVAN, B. W., 1977. Ground-penetrating radar at Valley Forge. Geophysical Survey System, North Salem, New Hampshire.

BEVAN, B. W., 1991. The search for graves. Geophysics, v. 56, n. 9, p. 1310-1319.

BEVAN, B. W., KENYON, J. L., 1975. Ground-penetrating radar for historical archaeology. MASCA Newsletter, v. 11, v. 2, p. 2-7.

BORGES, W., 2007. Caracterização geofísica de alvos rasos com aplicações no planejamento urbano e meio ambiente: estudo sobre o sítio controlado do IAG/USP. Tese de Doutorado. Instituto de Astronomia, Geofísica e Ciências Atmosféricas, Universidade de São Paulo, São Paulo. 
BORGES, W. R. et al., 2010. Aplicação de geofísica forense na busca de vestígios de pessoas desaparecidas na guerrilha do Araguaia. IV Simpósio Brasileiro de Geofísica. Brasília, p. 1-7.

BRADFORD, J. H., 2007. Frequency-dependent attenuation analysis of groundpenetrating radar data. Geophysics, v. 72, n. 3, p. J7-J16.

BUSCH, S., van der KRUK, J., BIKOWSKI, J., VEREECKEN, H., 2011. Combined effective wavelet estimation and full-waveform inversion of GPR data. 6th International Workshop on Advanced Ground Penetrating Radar (IWAGPR 2011), p. 1-5. Aachen, Alemanha.

CARTER, D. O., YELLOWLEES, D., TIBBETT, M., 2007. Cadaver decomposition in terrestrial ecosystems. Naturwissenschaften, v. 94, p. 1, p. 12-24.

CAGNOLI, B., ULRYCH, T. J., 2001. Singular value decomposition and wavy reflections in ground-penetrating radar images of base surge deposits. Journal of Applied Geophysics, v. 48, p. 175-182.

CATAPANO, I., CROCCO, L., KRELLMANN, Y., TRILTZSCH, G., SOLDOVIERI, F., 2012. A Tomographic Approach for Helicopter-Borne Ground Penetrating Radar Imaging. IEEE Geoscience and Remote Sensing Letters, v. 9, n. 3, p. 378-382.

CATAPANO, I., AFFINITO, A., BERTOLLA, L., PORSANI, J. L., SOLDOVIERI, F., 2014. Oil spill monitoring via microwave tomography enhanced GPR surveys. Journal of Applied Geophysics, v. 108, p. 95-103.

CHEW, W. C., 1995. Waves and fields in inhomogeneous media. New York: IEEE Press, 608 p.

CHOMMELOUX, L., PICHOT, C., BOLOMEY, J., 1986. Electromagnetic modeling for microwave imaging of cylindrical buried inhomogeneities. IEEE Transactions on Microwave Theory and Techniques, v. 34, n. 10, p. 1064-1076.

COOK, J. C., 1975. Radar transparencies of mine and tunnel rocks. Geophysics, v. 40, n. 5 , p. $865-885$.

COON, J. B., FOWLER, J. C., SCHAFERS, C. J., 1981. Experimental uses of short pulse radar in coal seams. Geophysics, v. 46, n. 8, p. 1163-1168. 
CROCCO, L., PRISCO, G., SOLDOVIERI, F., CASSIDY, N., 2009. Early-stage leaking pipes GPR monitoring via microwave tomographic inversion. Journal of Applied Geophysics, v. 67, n. 4, p. 270-277.

DANIELS, D. J., 2004. Ground Penetrating Radar (2nd ed.). London: The Institution of Electrical Engineers. 726 p.

DEBYE, P.J., 1945. Polar Molecules. Dover Publishing Inc.

DEMING, R. W., DEVANEY, A. J., 1997. Diffraction tomography for multimonostatic ground penetrating radar imaging. Inverse Problems, v. 13, p. 29-45.

DENT, B. B., FORBES, S. L., STUART, B. H. (2004). Review of human decomposition processes in soil. Environmental Geology, v. 45, n. 4, p. 576-585.

DEVANEY, A. J., 1984. Geophysical Diffraction Tomography. IEEE Transactions on Geoscience and Remote Sensing, v. GE-22, n. 1, p. 3-13.

EL SAID, M. A. H., 1956. Geophysical Prospection of Underground Water in the Desert by Means of Electromagnetic Interference Fringes. Proceedings of the IRE, v. 44, n. 1 , p. 24-30.

ERNST, J. R., MAURER, H., GREEN, A. G., HOLLIGER, K., 2007. Full-waveform inversion of crosshole radar data based on 2-D finite-difference time-domain solutions of Maxwell's equations. IEEE Transactions on Geoscience and Remote Sensing, v. 45, n. 9, p. 2807-2828.

EVANS, S., 1967. Progress report on radio echo sounding. The Polar Record, v. 13, n. 85, p. 413-420.

FRANCE, D., GRIFFIN, T., SWANBURG, J., LINDEMANN, J., DAVENPORT, G. C., TRAMmell, V., ARMBRUSt, C., KONDRATIEFF, B., NELSON, A., CASTEllanO, K., HOPKINS, D., 1992. A Multidisciplinary Approach to the Detection of Clandestine Graves. Journal of Forensic Sciences, v. 37, n. 6, p. 14451458.

GENNARELli, G., CATAPANO, I., PERSICO, R., SOLDOVIERI, F., 2014. A comparison between two measurement configurations for full 3D GPR imaging. The 8th European Conference on Antennas and Propagation (EuCAP 2014), p. 33743377. The Hague, Netherlands. 
GIANNOPOULOS, A., 2005. Modelling ground penetrating radar by GprMax. Construction and Building Materials, v. 19, n. 10, p. 755-762.

GIBSON, W. C., 2008. The method of moments in electromagnetics. NW: Chapman and Hall/CRC, 272 p.

GOODMAN, D., NISHIMURA, Y., ROGERS, J. D., 1995. GPR time slices in archaeological prospection. Archaeological Prospection, v. 2, p. 85-89.

GRIFFITHS, D. J., 1999. Introduction to electrodynamics (3rd ed.). Upper Saddle River, N.J.: Prentice Hall, 576 p.

HADAMARD, J., 1923. Lectures on Cauchy's Problem in Linear Partial Differential Equations. New Haven: Yale University Press.

HARRINGTON, R. F., 1968. Field computation by moment methods. New York: Macmillan, 229 p.

HOLSER, W. T., BROWN, R. J. S., ROBERTS, F. A., FREDRIKSSON, O. A., UNTERBERGER, R. R., 1972. Radar logging of a salt dome. Geophysics, v. 37, n. 5, p. 889-906

JERVIS, J. R., PRINGLE, J. K., TUCKWELL, G. W., 2009. Time-lapse resistivity surveys over simulated clandestine graves. Forensic Science International, v. 192, n. 1-3, p. 7-13.

JOL, H. M., 2009. Ground Penetrating Radar - Theory and Applications (1st ed.). Amsterdam: Elsevier, 524 p.

KALOGEROPOULOS, A., van der KRUK, J., BIKOWSKI, J., 2012. GPR fullwaveform inversion of chloride gradients in concrete. 14th International Conference on Ground Penetrating Radar (GPR 2012), p. 320-323. Shanghai, China.

KEAREY, P., BROOKS, M., HILL, I., 2009. Geofísica de exploração. São Paulo: Oficina de Textos, $438 \mathrm{p}$.

KENYON, J. L., 1977. Ground-Penetrating Radar and Its Application to a Historical Archaeological Site. Historical Archaeology, v. 11, pp. 48-55. 
KHAN, U. S., AL-NUAIMY, W., 2010. Background removal from GPR data using eigenvalues. 13th International Conference on Ground Penetrating Radar (GPR 2010), p. 1-5.

LAMBOT, S., SLOB, E. C., van den BOSCH, I., STOCKBROECKX, B., VANCLOOSTER, M., 2004. Modeling of ground-penetrating radar for accurate characterization of subsurface electric properties. IEEE Transactions on Geoscience and Remote Sensing, v. 42, n. 11, p. 2555-2568.

LAMBOT, S., SLOB, E., CHAVARRO, D., LUBCZYNSKI, M., VEREECKEN, H., 2008. Measuring soil surface water content in irrigated areas of southern Tunisia using full-waveform inversion of proximal GPR data. Near Surface Geophysics, v. 6, n. 6, p. 403-410.

LEUCCI, G., MASINI, N., PERSICO, R., SOLDOVIERI, F., 2011. GPR and sonic tomography for structural restoration: the case of the cathedral of Tricarico. Journal of Geophysics and Engineering, v. 8, n. 3, p. S76-S92.

LIU, F., LING, Y., XIA, X., SHI, X., 2004. Wavelet methods for Ground Penetrating Radar imaging. Journal of Computational and Applied Mathematics, v. 169, p. 459474 .

MILLER, M. L.; FREELAND, R. S.; KOPPENJAN, S. K., 2002. Searching for concealed human remains using GPR imaging of decomposition. 9th SPIE International Conference on Ground Penetrating Radar, p. 539-544, Santa Barbara, USA.

MOLYNEUX, J. E., WITTEN, A., 1993. Diffraction tomographic imaging in a monostatic measurement geometry. IEEE Transactions on Geoscience and Remote Sensing, v. 31, n. 2, p. 507-511.

NASCIMENTO, W. G., 2009. Investigação geofísica ambiental e forense nos cemitérios do Bengui e do Tapanã (Belém - PA). Dissertação de Mestrado. Instituto de Geociências, Universidade Federal do Pará, Belém, 153p.

NOTTER, S. J., STUART, B. H., ROWE, R., LANGLOIS, N., 2009. The initial changes of fat deposits during the decomposition of human and pig remains. Journal of Forensic Sciences, v. 54, n. 1, p. 195-201. 
PAREN, J. G., ROBIN, G. DE Q., 1975. Internal reflections in polar ice sheets. Journal of Glaciology, v. 14, n. 71, p. 251-259.

PASTORINO, M., 2010. Microwave Imaging. New Jersey: John Wiley \& Sons, Inc., $285 \mathrm{p}$.

PERSICO, R., SOLDOVIERI, F., LEONE, G., 2006. A Microwave Tomographic Imaging Approach for Multibistatic Configuration: The Choice of the Frequency Step. IEEE Transactions on Instrumentation and Measurement, v. 55, n. 6, p. 19261934.

PERSICO, R., SOLDOVIERI, F., 2008. Effects of Background Removal in Linear Inverse Scattering. IEEE Transactions on Geoscience and Remote Sensing, v. 46, n. 4, p. 1104-1114.

PETTINElli, E., di MATTEO, A., MATTEI, E., CROCCO, L., SOLDOVIERI, F., REDMAN, J. D., ANNAN, A. P., 2009. GPR Response From Buried Pipes: Measurement on Field Site and Tomographic Reconstructions. IEEE Transactions on Geoscience and Remote Sensing, v. 47, n. 8, p. 2639-2645.

PHILlIPS, R. J., ADAMS, G. F., BROWN, W. E., JR., EGGLETON, R. E., JACKSON, P., JORDAN, R., 1973. The Apollo 17 Lunar Sounder. Proceedings of the Lunar Science Conference, v. 4, p. 2821-2831.

POLAT, B., MEINCKE, P., 2004. A Forward Model for Ground Penetrating Radar Imaging of Buried Perfect Electric Conductors within the Physical Optics Approximation. AEU - International Journal of Electronics and Communications, v. 58, n. 5 , p. 362-366.

PORCELLO, L. J., JORDAN, R. L., ZELENKA, J. S., ADAMS, G. F., PHILLIPS, R. J., BROWN, W. E., WARD, S. H., JACKSON, P. L., 1974. The Apollo lunar sounder radar system. Proceedings of the IEEE, v. 62 , n. 6, p. 769-783.

PORSANI, J. L., 1999. Ground Penetrating Radar (GPR): Proposta metodológica de emprego em estudos geológico-geotécnicos nas regiões de Rio Claro e Descalvado SP. Tese de Doutorado. Instituto de Geociências e Ciências Exatas, Universidade Estadual Paulista, Rio Claro. 
PORSANI, J. L., BORGES, W. R., ELIS, V. R., DIOGO, L. A., HIODO, F. Y., MARRANO, A., BIRELLI, C. A., 2004a. Investigações geofísicas de superfície e de poço no Sítio Controlado de Geofísica Rasa do IAG-USP. Revista Brasileira de Geofísica, v. 22, n. 3, p. 245-258.

PORSANI, J. L., MALAGUTTI FILHO, W., ELIS, V. R., DOURADO, J. C., MOURA, H. P., 2004b. The Use of GPR and VES in Delineating a Contamination Plume in a Landfill site: a Case Study in SE Brazil. Journal of Applied Geophysics, v. 55, p. 199-209.

PORSANI, J. L., BORGES, W., RODRIGUES, S. I., HIODO, F. Y., 2006. O sítio controlado de geofísica rasa do IAG/USP: Instalação e resultados GPR 2D-3D. Revista Brasileira de Geofísica, v. 24, p. 49-61.

PORSANI, J., SAUCK, W., 2007. Ground-penetrating radar profiles over multiple steel tanks: Artifact removal through effective data processing. Geophysics, v. 72, p. J77$\mathrm{J} 83$.

PORSANI, J. L., JANGELME, G. M., KIPNIS, R., 2010. GPR survey at Lapa do Santo archaeological site, Lagoa Santa karstic region, Minas Gerais state, Brazil. Journal of Archaeological Science, v. 37, p. 1141-1148.

PORSANI, J. L., RUY, Y. B., RAMOS, F. P., YAMANOUTH, G. R. B., 2012. GPR applied to mapping utilities along the route of the Line 4 (yellow) subway tunnel construction in São Paulo City, Brazil. Journal of Applied Geophysics, v. 80, p. 2531.

POWELL, K., 2004. Detecting buried human remains using near-surface geophysical instruments. Exploration Geophysics, v. 35, n. 1, 88-92.

PRINGLE, J. K., CASSELlA, J. P., JERVIS, J. R., 2010. Preliminary soilwater conductivity analysis to date clandestine burials of homicide victims. Forensic Science International, v. 198, n. 1-3, p. 126-133.

REYNOLDS, J. M., 1997. An introduction to applied and environmental geophysics. Chichester: John Wiley, 796 p.

RICKER, N., 1943. Further developments in the wavelet theory of seismogram structure. Bulletin of the Seismological Society of America, v. 33, n. 3, p. 197-228. 
RICKER, N., 1944. Wavelet functions and their polynomials. Geophysics, v. 9, n. 3, p. 314-323.

RODRIGUES, S. I.; PORSANI, J. L.; SANTOS, V. R. N.; DE BLASIS, P. A. D.; GIANNINI, P. C. F., 2009. GPR and Inductive Electromagnetic Surveys Applied in Three Coastal Sambaqui (Shell Mounds) Archaeological Sites in Santa Catarina State, South Brazil. Journal of Archaeological Science, v. 36, p. 2081-2088.

ROSA, A. L. R., 2010. Análise do sinal sísmico. Rio de Janeiro: SBGf, 668 p.

ROSSITER, J .R., LATORRACA, G. A., ANNAN, A. P. STRANGWAY, D. W., SIMMONS, G., 1973. Radio interferometry depth sounding: Part II - Experimental results. Geophysics, v. 38, n. 3, p. 581-599.

RUBIN, L. A., FOWLER, J. C., 1978. Ground-probing radar for delineation of rock features. Engineering Geology, v. 12, p. 163-170.

SANDMEIER, K. J. (2012). ReflexWin 7.0 - Windows ${ }^{\mathrm{TM}}$ 9x/NT/2000/XP/7- program for Processing of Seismic, Acoustic or Electromagnetic Reflection, Refraction, and Transmission Data. Karlsruhe, Germany.

SANTOS, V. R. N., 2014. Detecção e classificação automática de interferências no subsolo com GPR utilizando Redes Neurais Artificiais (RNAs): estudo no SCGR do IAG/USP. Tese de Doutorado. Instituto de Astronomia, Geofísica e Ciências Atmosféricas, Universidade de São Paulo, São Paulo.

SANTOS, V., AL-NUAIMY, W., PORSANI, J., HIRATA, N., ALZUBI, H. S., 2014. Spectral analysis of ground penetrating radar signals in concrete, metallic and plastic targets. Journal of Applied Geophysics, v. 100, p. 32-43.

SARAIVA, F. A., 2010. Avaliação de métodos geofísicos no comportamento espacial de plumas de necrochorume. Tese de Doutorado. Instituto de Geociências, Universidade de São Paulo, São Paulo.

SCHULTZ, J. J., COLLINS, M. E., FALSETTI, A. B., 2006. Sequential monitoring of burials containing large pig cadavers using ground-penetrating radar. Journal of forensic sciences, v. 51, n. 3, p. 607-616.

SCHULTZ, J. J., 2008. Sequential monitoring of burials containing small pig cadavers using ground penetrating radar. Journal of forensic sciences, v. 53, n. 2, p. 279-287. 
SOLDOVIERI, F., LEONE, G., LISENO, A., TARTAGLIONE, F., PIERRI, R., 2005. Linear tomographic inversion of stepped-frequency GPR data: experimental results on two test-sites. AEU - International Journal of Electronics and Communications, v. 59, n. 6, p. 329-336.

SOLDOVIERI, F., ORLANDO, L., 2009. Novel tomographic based approach and processing strategies for GPR measurements using multifrequency antennas. Journal of Cultural Heritage, v. 10, p. e83-e92.

SOLDOVIERI, F., PRISCO, G., PERSICO, R., 2009. A strategy for the determination of the dielectric permittivity of a lossy soil exploiting GPR surface measurements and a cooperative target. Journal of Applied Geophysics, v. 67, n. 4, p. 288-295.

SOLDOVIERI, F., SOLIMENE, R., 2010. Ground Penetrating Radar Subsurface Imaging of Buried Objects. In: G. Kouemou (Ed.), Radar Technology. InTech, 410 p.

STOVE, G. C., ADDYMAN, P. V., 1989. Ground probing impulse radar: an experiment in archaeological remote sensing at York. Antiquity, v. 63, p. 337-342.

STRATTON, J. A., 1941. Electromagnetic Theory. New York: McGraw Hill, 615 p.

STRONGMAN, K. B., 1992. Forensic applications of ground penetrating radar. In: PILON, J. Ground penetrating radar (Paper 90-4). Ottawa: Geological Survey of Canada. p. 203-211.

TAI, C. T., 1994. Dyadic Green Functions in Electromagnetic Theory (2nd ed.). New Jersey: IEEE Press.

TELFORD, W. M., GELDART, L. P., SHERIFF, R. E., 1990. Applied Geophysics (2nd ed.). New York: Cambridge University Press, 770p.

TURK, A. S., HOCAOĞLU, K. A., \& VERTIY, A. A., 2011. Subsurface sensing. New Jersey: Wiley, $920 \mathrm{p}$.

VAUGHAN, C. J., 1986. Ground-penetrating radar surveys used in archaeological investigations. Geophysics, v. 51, n.3, p. 595-604.

WARD, S. H., HOHMANN, G. W., 1988. Electromagnetic theory for geophysical applications. In: Nabighian, M. N. (Ed.), Electromagnetic methods in applied geophysics (Volume 1). Tulsa: Society of Exploration Geophysicists. 
WARREN, C., GIANNOPOULOS, A., 2011. Creating finite-difference time-domain models of commercial ground-penetrating radar antennas using Taguchi's optimization method. Geophysics, v. 76, n. 2, p. G37-G47.

WEBER, J. R., ANDRIEUX, P., 1970. Radar soundings on the Penny Ice Cap, Baffin Island. Journal of Glaciology, v. 9, n. 55, p. 49-54.

WITTEN, A. E., MOLYNEUX, J. E., NYQUIST, J. E., 1994. Ground penetrating radar tomography: algorithms and case studies. IEEE Transactions on Geoscience and Remote Sensing, v. 32, n. 2, p. 461-467.

YEE, K. S., 1966. Numerical Solution of Initial Boundary Value Problems Involving Maxwell's Equations in Isotropic Media. IEEE Transactions on Antennas and Propagation, v. 14, p. 302-307.

YILMAZ, O., 2001. Seismic Data Analysis: Processing, Inversion, and Interpretation of Seismic Data. Investigations in Geophysics, n. 10, v. 1/2. Tulsa: Society of Exploration Geophysicists. 


\section{PRODUÇõES BIBLIOGRÁFICAS}

\section{Artigo completo}

ALMEIDA, E. R., PORSANI, J. L., CATAPANO, I., GENNARALLI, G., SOLDOVIERI, F., 2016. Microwave Tomography-Enhanced GPR in Forensic Surveys: The Case Study of a Tropical Environment. IEEE Journal of Selected Topics in Applied Earth Observations and Remote Sensing (JSTARS), v. 9, p. 115124.

\section{Resumos expandidos}

ALMEIDA, E. R., PORSANI, J. L., SOLDOVIERI, F., 2016. Effects of background removal in GPR microwave tomography for archaeological and forensic studies. 29th Annual Symposium on the Application of Geophysics to Engineering and Environmental Problems (SAGEEP 2016). Denver, EUA.

ALMEIDA, E. R., PORSANI, J. L., CATAPANO, I., GENNARELLI, G., SOLDOVIERI, F., 2014. GPR data analysis enhanced by microwave tomography for forensic archaeology. 15th International Conference on Ground Penetrating Radar (GPR 2014), Bruxelas, Bélgica, p. 493-497.

ALMEIDA, E. R., PORSANI, J. L, 2013. GPR Monitoring on an OrganicTarget Decomposition. Near Surface Geoscience 2013 - 19th EAGE European Meeting of Environmental and Engineering Geophysics, Bochum, Alemanha, p.1-4. 